DESENVOL VIMENTO DE INSTRUMENTACÃO E METODOLOGIA RELATIVAS À ATIVIDADE DE AQUISIÇÃO, PROCESSAMENTO E INTERPRETAÇÃO DE SINAIS ELETROMIOGRÁFICOS DE SUPERFÍCIE

GUSTAVO SOUTO DE SÁ E SOUZA HENRIQUE BUENO DE SOUSA LOUZADA

ORIENTADOR: ADSON FERREIRA DA ROCHA CO-ORIENTADOR: WILSON HENRIQUE VENEZIANO

PROJETO FINAL DE GRADUAÇÃO

BRASÍLIA / DF: AGOSTO/2006 


\begin{tabular}{|l|l|}
\hline & $\begin{array}{l}\text { UNIVERSIDADE DE BRASÍLIA } \\
\text { FACULDADE DE TECNOLOGIA } \\
\text { DEPARTAMENTO DE ENGENHARIA ELÉTRICA }\end{array}$ \\
\hline
\end{tabular}

\title{
DESENVOLVIMENTO DE INSTRUMENTACÃO E METODOLOGIA RELATIVAS À ATIVIDADE DE AQUISIÇÃO, PROCESSAMENTO E INTERPRETAÇÃO DE SINAIS ELETROMIOGRÁFICOS DE SUPERFÍCIE
}

\author{
GUSTAVO SOUTO DE SÁ E SOUZA \\ HENRIQUE BUENO DE SOUSA LOUZADA
}

PROJETO FINAL DE GRADUAÇÃO SUBMETIDA AO DEPARTAMENTO DE ENGENHARIA ELÉTRICA DA FACULDADE DE TECNOLOGIA DA UNIVERSIDADE DE BRASÍLIA, COMO PARTE DOS REQUISITOS NECESSÁRIOS PARA A OBTENÇÃO DO GRAU DE ENGENHEIRO.

APROVADA POR:

ADSON FERREIRA DA ROCHA, PhD, ENE/UnB (ORIENTADOR)

RICARDO ZELENOVSKY, Doutor, ENE/UnB (EXAMINADOR)

MARCELINO MONTEIRO DE ANDRADE, Mestre, UnB (EXAMINADOR) 


\section{SOUZA, GUSTAVO SOUTO DE SÁ}

Desenvolvimento de instrumentação e metodologia relativas à atividade de aquisição, processamento e interpretação de sinais eletromiográficos de superfície [Distrito Federal] 2006.

(ENE/FT/UnB, Bacharel, Engenharia Elétrica, 2006).

Projeto Final de Graduação - Universidade de Brasília, Faculdade de Tecnologia. Departamento de Engenharia Elétrica.

\section{LOUZADA, HENRIQUE BUENO DE SOUSA}

Desenvolvimento de instrumentação e metodologia relativas à atividade de aquisição, processamento e interpretação de sinais eletromiográficos de superfície [Distrito Federal] 2006.

(ENE/FT/UnB, Bacharel, Engenharia Elétrica, 2006).

Projeto Final de Graduação - Universidade de Brasília, Faculdade de Tecnologia. Departamento de Engenharia Elétrica.

\section{- REFERÊNCIA BIBLIOGRÁFICA}

- SOUZA, GUSTAVO SOUTO DE SÁ (2006). Desenvolvimento de instrumentação e metodologia relativas à atividade de aquisição, processamento e interpretação de sinais eletromiográficos de superfície. (Projeto Final de Graduação), Departamento de Engenharia Elétrica, Universidade de Brasília, Brasília, DF.

- LOUZADA, HENRIQUE BUENO DE SOUSA (2006). Desenvolvimento de instrumentação e metodologia relativas à atividade de aquisição, processamento e interpretação de sinais eletromiográficos de superfície. (Projeto Final de Graduação), Departamento de Engenharia Elétrica, Universidade de Brasília, Brasília, DF. 


\section{- CESSÃO DE DIREITOS}

- $\quad$ NOME DO AUTOR: Gustavo Souto de Sá e Souza; Henrique Bueno de Sousa Louzada.

- $\quad$ TÍTULO DA DISSERTAÇÃO: Desenvolvimento de instrumentação e metodologia relativas à atividade de aquisição, processamento e interpretação de sinais eletromiográficos de superfície.

- $\quad$ GRAU/ANO: Bacharel/2006.

$\bullet$

- $\quad$ É concedida à Universidade de Brasília permissão para reproduzir cópias deste Projeto Final de Graduação e para emprestar ou vender tais cópias somente para propósitos acadêmicos e científicos. Os autores reservam outros direitos de publicação e nenhuma parte desta dissertação de graduação pode ser reproduzida sem a autorização por escrito dos autores.

- $\quad$ Gustavo Souto de Sá e Souza

- $\quad$ SCLN 407 Bloco C Apt. 25

- $\quad$ CEP 70855-530 - Brasília - DF - Brasil

- Henrique Bueno de Sousa Louzada

- $\quad$ SCLN 407 Bloco B Apt. 07

- $\quad$ CEP 70855-520 - Brasília - DF - Brasil 


\section{AGRADECIMENTOS}

Gustavo e Henrique agradecem a todos aqueles que, de alguma forma, contribuíram para a conclusão deste projeto e para a graduação de ambos no curso de Engenharia Elétrica.

A nossos pais, avós, tios, primos, demais familiares e amigos. Estes que mesmo à distância não deixaram, em momento algum, de nos apoiar. Saibam que a saudade nos momentos de maiores dificuldades durante o curso, somente valorizou ainda mais essa nossa conquista.

Ao professor Doutor Adson Ferreira da Rocha que nos deu a oportunidade e acreditou em nossa capacidade de realizar tal projeto. Agradecemos toda a atenção, incentivo e tempo dispensado a este projeto. Tempo este em que sempre se mostrou prestativo e bastante cordial com relação a dúvidas e demais dificuldades que surgiram durante esta caminhada. Foi um prazer enorme trabalhar com esta pessoa excelente.

Ao nosso co-orientador Doutor Wilson Henrique Veneziano pela imprescindível participação durante todas as etapas do projeto. Agradecemos ao apoio e vasto conhecimento a nós passado, através de várias reuniões, artigos, livros, e resumos; que nos foram transmitidos com enorme paciência e notável didática. Seu apoio, incentivo e amizade foram essenciais para o resultado final do trabalho e para o nosso desenvolvimento como pesquisadores.

Ao professor Doutor Jake Carvalho do Carmo que nos possibilitou o acesso ao Laboratório de Biomecânica e nos ajudou prontamente com toda a estrutura e enorme boa vontade na elaboração do protocolo executado durante os experimentos.

Aos pesquisadores do Grupo de Processamento Digital de Sinais, GPDS, que sempre se mostraram prontos a ajudar na resolução de dúvidas. Aos técnicos Célio e Reiber, responsáveis pelo Laboratório de Confecção de Placas de Circuitos Impressos e pelo Laboratório de Eletrônica respectivamente; obrigado pela atenção e infra-estrutura disponibilizada durante a montagem e posterior fase de teste do hardware desenvolvido. 


\section{DEDICATÓRIA}

O autor Gustavo dedica este trabalho a seu pai, Walter, que sempre o deu suporte afetivo e financeiro, o apoiando sempre em suas decisões; à sua mãe, Acioni, que sempre se fez presente nos momentos mais felizes e também nos mais difíceis; a seu irmão Rodrigo, que sempre fez tudo para tornar sua vida mais colorida; a todos seus amigos, que tornaram suportável a distância de seu verdadeiro lar, e, por fim, à sua namorada Débora, que sempre esteve presente em seu coração, e o ensinou a nunca desistir de seus sonhos. Este trabalho é dedicado também àqueles que futuramente utilizarão este conhecimento para fazer a vida de outras pessoas mais fácil.

O autor Henrique dedica este trabalho a seus pais Carlos e Tâmara, os verdadeiros merecedores deste diploma; por tornarem possível esta conquista, nunca deixando que faltasse condições ou apoio nos momentos de dificuldades e de desânimo durante o curso. Aos seus irmãos Virgilio e Lygia sempre responsáveis por momentos de alegria e descontração nos finais de semanas em que havia a possibilidade de ficarmos juntos. Aos avós, tios e primos que sempre foram uma família maravilhosa e carinhosa. À sua namorada, Raquel, que sempre esteve ao seu lado dando apoio e forças para conquistar este tão suado diploma. E finalmente aos amigos; os que ficaram em Goiânia, mas nem por isso se tornaram esquecidos e aos muitos conquistados durante o curso e que vão continuar para sempre como amigos incondicionais. 


\section{DESENVOLVIMENTO DE INSTRUMENTACÃO E METODOLOGIA RELATIVAS À ATIVIDAdE DE AQUISIÇÃO, PROCESSAMENTO E INTERPRETAÇÃO DE SINAIS ELETROMIOGRÁFICOS DE SUPERFÍCIE}

\section{RESUMO}

A tese proposta apresenta a realização de estudos relacionados com a eletromiografia de superfície em basicamente duas frentes de estudo. Uma parte do projeto consiste na elaboração e desenvolvimento de uma metodologia para a aquisição, o processamento e a interpretação de sinais eletromiográficos em ambientes subaquáticos. Na outra frente de trabalho tivemos o projeto, implementação e posterior validação de um eletromiógrafo composto por 7 canais de aquisição capaz de captar sinais elétricos dos músculos com precisão bastante satisfatória.

A parte experimental do projeto consiste na estimativa de amplitude e de frequiência mediana no eletromiograma de superfície do bíceps braquial e no tríceps braquial em contração isométrica em ambiente aéreo e subaquático. Foi criado todo um protocolo para a coleta desses dados, levando em consideração os padrões recomendados pelo projeto SENIAM; referência européia no estabelecimento de pesquisa envolvendo eletromiografia de superfície. De posse desses dados, desenvolveu-se um software em ambiente MatLab para se realizar todo o processamento dos mesmos. Foi realizado posteriormente um tratamento estatístico dos resultados alcançados com o objetivo de concluir o projeto desenvolvido, comprovando semelhanças e diferenças entre sinais de EMG-S no ambiente aéreo e subaquático. A segunda parte do projeto foi focada no projeto e construção de um eletromiógrafo de superfície capaz de captar 7 canais de EMG simultaneamente. Este hardware consiste de uma sonda seca composta de 8 eletrodos ativos de prata e de um condicionador de sinais que, ligado diretamente à primeira, realiza todo o tratamento do sinal obtido. Este tratamento consiste na filtragem, amplificação e adequação do sinal, minimizando ruídos e isolando o paciente da rede elétrica. Após a implementação deste hardware, foi realizada toda uma extensa gama de testes de funcionamento, assim como aplicações práticas da utilização de um eletromiógrafo de múltiplos canais. 


\title{
DEVELOPMENT OF INSTRUMENTATION AND METHODS USED TO ACQUIRE, PROCESS AND INTERPRET SURFACE ELETROMIOGRAPHIC SIGNS
}

\begin{abstract}
The proposed thesis presents a research related to surface electromyography basically in two ways. First, the project is about the elaboration and development of methods to acquire, processing and interpretation of electromyographic signs on sub aquatic environments. And second, we had the project, implementation and later, the validation of a electromyograph composed by 7 acquisition channels, capable of catching electric signs from muscles with quite good results.
\end{abstract}

The project's experimental part consists in amplitude and median frequency estimatives on surface electromyogram from brach biceps and triceps, in isometric contraction in air and sub aquatic environments. A protocol was created for data gathering, considering all the recommended SENIAM project standards - European reference when dealing with surface electromyography researches. With those data, a software was developed in MatLab environment, so all the signal processing could be done. Later, the data was analyzed in a statistical way, so we could prove the similarities and differences in signals, concluding the experiment on EMG-S in air and sub aquatic environments.

On this project's second part we focused on projecting and building a surface electromyograph able to catch 7 channels of EMG signs at once. This hardware consists on a dry array composed of 8 active electrodes in pure silver, and a signal conditioner connected to the array, that is responsible for further treating of the signals. This treatment consists on filtering and amplification of the signal, minimizing the noise and isolating the patient from the electricity distribution. After this hardware implementation, we made a lot of tests to prove that it works as it should, as well as practical applications of a multiple channel electromyograph. 


\section{ÍNDICE}

\section{CAPÍTULO}

\section{INTRODUÇÃO}

1.1. OBJETIVOS DO PROJETO

1.2. MOTIVAÇÕES QUE LEVARAM A ESSA LINHA DE PESQUISA 2

\section{REVISÃO BIBLIOGRÁFICA}

2.1. HISTÓRICO 4

2.2. PRINCÍPIOS DOS SINAIS ELETROMIOGRÁFICOS 5

2.3. TIPOS DE ELETROMIOGRAMA 6

2.4. AQUISIÇÃ̃O DO EMG SUBAQUÁTICO

3. PROJETO DE HARDWARE

3.1. CARACTERÍSTICAS GERAIS 9

3.1.1. DESING 10

3.1.2. FILTROS

3.1.3. AMPLIFICADORES

3.1.4. REGULADORES DE TENSÃO, TERRA E ALIMENTAÇÃO 21

3.2. MONTAGEM DO CIRCUITO 23

3.2.1. PCI 23

3.2.2. LAYOUT 26

3.2.3. COMPATIBILIDADE ELETROMAGNÉTICA 29

3.3. VALIDAÇÃO DO PROJETO ANALÓGICO 32

3.3.1. TESTES REALIZADOS 32

3.3.2. ANÁLISE DOS RESULTADOS OBTIDOS

\section{PROJETO EXPERIMENTAL}

4.1. PROTOCOLO EXPERIMENTAL 51

4.1.1. EQUIPAMENTOS E SOFTWARES UTILIZADOS

4.1.2. SUJEITOS

4.1.3. OBTENÇÃO DA CVM 
4.1.4. COLOCAÇÃO DOS ELETRODOS

4.1.5. COLETA DOS DADOS 57

4.2. ANÁLISE E PROCESSAMENTO DOS DADOS 63

4.2.1. SOFTWARE DESENVOLVIDO PARA ANÁLISE EM MATLAB 63

4.2.2. STATISTICA 6.0 69

4.3. VALIDAÇÃO DA PARTE EXPERIMENTAL

4.3.1. TRATAMENTO ESTATÍSTICO DOS DADOS COLETADOS $\quad 70$

4.3.2. AVALIAÇÃO DOS RESULTADOS 78

5. CONCLUSÕES

5.1. CONCLUSÕES DOS OBJETIVOS PROPOSTOS 81

5.2. DIFICULDADES ENCONTRADAS NO PROJETO 82

5.3. SUGESTÕES PARA APRIMORAMENTO DO PROJETO 84

REFERÊNCIAS BIBLIOGRÁFICAS

ANEXO A - FERRAMENTAS COMPUTACIONAIS DESENVOLVIDAS $\quad 88$

ANEXO B - ESQUEMÁTICO DOS CIRCUITOS IMPLEMENTADOS 108

ANEXO C - PROTOCOLO EXPERIMENTAL 109

ANEXO D - PUBLICAÇÕES RESULTANTES DESTE PROJETO 114 


\section{LISTA DE ABREVIAÇÕES}

ANOVA Analysis of variance (Análise de variância)

CVM Contração voluntária máxima

EMG Eletromiografia

EMG-S Eletromiografia de superfície

UM Unidade motora

FFT Fast Fourier Transform (transformada rápida de Fourier)

MDF Median frequency (freqüência mediana)

ARV Average rectified value (valor retificado médio)

MUAP Motor unit action potential (potencial de ação de unidade motora)

MUAPT Motor unit action potential train (trem de potenciais de ação de UM)

RMS Root mean square (raiz quadrática média)

SENIAM Surface electromyography for the non-invasive assessment of muscles

PCI Placa de circuito impresso

PCB Printed circuit board (placa de circuito impresso)

SMD Surface mounted device (dispositivos de soldagem superficial)

RF Radio frequency (radio freqüência)

DIP Dual in-line package (encapsulamento com duplos pinos em série)

CMRR Commom Mode Rejection Ratio (relação de rejeição em modo comum)

DC Direct current (corrente contínua)

CI Circuito integrado 


\section{LISTA DE FIGURAS}

Figura 3.1 - Conceitos básicos da interface pele-eletrodo.

Figura 3.2 - Esquemático da configuração amplificador diferencial.

Figura 3.3 - Último estágio do circuito detector de sinais eletrofisiológicos.

Figura 3.4 - Esquemático com os valores do último estágio do circuito de EMG.

Figura 3.5 - Configuração inversora de um amplificador operacional.

Figura 3.6 - Circuito de alimentação de +5V. Especificações do datasheet do L7805C-V.

Figura 3.7 - Circuito de alimentação de -5V. Especificações do datasheet do LM7905CT.

Figura 3.8 - Circuito de alimentação completo.

Figura 3.9 - Representação do furo de uma placa para ilha convencional e ilha de superfície.

Figura 3.10 - Leiaute da placa de circuito impresso para o arranjo linear de 8 eletrodos.

Figura 3.11 - Leiaute da placa de circuito impresso para o condicionador de sinais.

Figura 3.12 - Leiaute detalhado da placa de circuito impresso para o condicionador de sinais.

Figura 3.13 - Característica dos componentes passivos a emissões em radiofreqüência.

Figura 3.14 - Onda senoidal injetada nos canais do arranjo linear de 8 eletrodos.

Figura 3.15 - Onda senoidal observada na saída do $1^{\circ}$ canal do arranjo linear de 8 eletrodos.

Figura 3.16 - Onda senoidal observada na saída do $2^{\circ}$ canal do arranjo linear de 8 eletrodos.

Figura 3.17 - Onda senoidal observada na saída do $3^{\circ}$ canal do arranjo linear de 8 eletrodos.

Figura 3.18 - Onda senoidal observada na saída do $4^{\circ}$ canal do arranjo linear de 8 eletrodos.

Figura 3.19 - Onda senoidal observada na saída do $5^{\circ}$ canal do arranjo linear de 8 eletrodos.

Figura 3.20 - Onda senoidal observada na saída do $6^{\circ}$ canal do arranjo linear de 8 eletrodos.

Figura 3.21 - Onda senoidal observada na saída do $7^{\circ}$ canal do arranjo linear de 8 eletrodos.

Figura 3.22 - Onda senoidal observada na saída do $1^{\mathrm{o}}$ canal do condicionador de sinais.

Figura 3.23 - Onda senoidal observada na saída do $2^{\circ}$ canal do condicionador de sinais.

Figura 3.24 - Onda senoidal observada na saída do $3^{\circ}$ canal do condicionador de sinais.

Figura 3.25 - Onda senoidal observada na saída do $4^{\circ}$ canal do condicionador de sinais.

Figura 3.26 - Onda senoidal observada na saída do $5^{\circ}$ canal do condicionador de sinais.

Figura 3.27 - Onda senoidal observada na saída do $6^{\circ}$ canal do condicionador de sinais.

Figura 3.28 - Onda senoidal observada na saída do $7^{\circ}$ canal do condicionador de sinais.

Figura 3.29 - Sinal de EMG-S captado no bíceps braquial cabeça curta do sujeito 1.

Figura 3.30 - Espectro do sinal captado no bíceps braquial cabeça curta do sujeito 1.

Figura 3.31 - Sinal de EMG-S captado no bíceps braquial cabeça curta do sujeito 2. 
Figura 3.32 - Espectro do sinal captado no bíceps braquial cabeça curta do sujeito 2.

Figura 3.33 - Sinal de EMG-S captado em dois canais durante uma contração isométrica.

Figura 3.34 - Sinal de EMG-S captado em dois canais durante uma contração isométrica.

Figura 3.35 - Trecho de EMG-S bruto de uma contração isométrica no bíceps braquial.

Figura 3.36 - Trecho de EMG-S bruto de uma contração isométrica no bíceps braquial.

Figura 3.37 - Gráficos da densidade espectral de potência referente aos 7 canais.

Figura 4.1 - Eletrodos de captação e de referência e amplificador de EMG.

Figura 4.2 - Medição da contração voluntária máxima.

Figura 4.3 - Tela da captura de força máxima do software Aquisição Subaquático.

Figura 4.4 - Fitas Adesivas para proteção dos eletrodos contra água e trena para as medições.

Figura 4.5 - Arranjo físico do posto de trabalho em ambiente aéreo.

Figura 4.6 - Arranjo físico geral do posto de trabalho tanque pequeno.

Figura 4.7 - Detalhe do posto de trabalho tanque pequeno.

Figura 4.8 - Arranjo físico do posto de trabalho tanque grande.

Figura 4.9 - Tela do software AquisiçãoSubaquático adquirindo sinais de EMG e de força.

Figura 4.10 - Forças peso e empuxo aplicadas na mão e antebraço.

Figura 4.11 - Janela de Diálogo do modo de funcionamento do programa.

Figura 4.12 - Janela de escolha do arquivo no Filtrar06.

Figura 4.13 - Gráficos gerados pelo Filtrar06.

Figura 4.14 - Caixa de diálogo de normalização de dados do Filtrar06.

Figura 4.15 - Caixa de diálogo de processamento de outros arquivos do Filtrar06.

Figura 4.16 - Caixa de seleção de dados a serem exportados através do Filtrar06.

Figura 4.17 - Arquivos gerados pelo Filtrar06.

Figura 4.18 - Delineamento estatístico (5x19x15).

Figura 4.19 - Sinal bruto de EMG. Contração isométrica de 5 segundos.

Figura 4.20 - Densidade espectral de potência do sinal de EMG.

Figura 4.21 - Valores médios, erros padrão e desvios-padrão dos valores RMS obtidos.

Figura 4.22 - ANOVA para medidas repetidas entre os postos: Ar, BCP e TCP.

Figura 4.23 - ANOVA para medidas repetidas entre os postos: BSP e BCP.

Figura 4.24 - ANOVA para medidas repetidas entre os postos: TSP e TCP.

Figura 4.25 - ANOVA para medidas repetidas entre os postos: BSP e TSP.

Figura 4.26 - ANOVA para medidas repetidas de RMS nos cinco postos de trabalho.

Figura 5.1 - Fonte da interferência de linha captada nos sinais de EMG.

Figura 5.2 - Circuito integrado tipo SMD. 
Figura B.1 - Esquemático do arranjo linear de oito eletrodos.

Figura B.2 - Esquemático de três dos sete canais do condicionador de sinais. 


\section{LISTA DE TABELAS}

Tabela 4.1 - Estatística descritiva dos valores de RMS para de cada contração de cada posto de trabalho, estratificada por sujeito.

Tabela 4.2 - Estatística descritiva dos valores de RMS de cada contração de cada posto de trabalho, estratificada por sujeito.

Tabela 4.3 - Tendências da amplitude do EMG de cada um dos cinco postos de trabalho. 



\section{1 - INTRODUÇÃO}

\section{1 - OBJETIVOS}

O objetivo deste projeto é desenvolver uma instrumentação e uma metodologia relativa à atividade de aquisição, processamento e interpretação de sinais eletromiográficos de superfície.

O projeto apresentado pretende aprofundar-se nas questões metodológicas do uso de sinais eletromiográficos para a caracterização de atividades físicas em ambientes subaquáticos. Vários fatores serão abordados objetivando esclarecer se existem diferenças na amplitude e na assinatura espectral do sinal eletromiográfico de superfície quando o mesmo é captado em ambiente aéreo e subaquático, mantendo-se as condições de contorno. Pretende-se validar a necessidade de utilização de proteção dos eletrodos contra a água, observando as conseqüências deste tipo de proteção na obtenção do sinal. Outro aspecto a ser abordado é com relação do comportamento do eletromiograma quando da variação de profundidade de imersão do sujeito na água e da contribuição do empuxo no sinal captado.

Para que se possam avaliar as diferenças do eletromiograma nos dois ambientes de trabalho, aéreo e subaquático, juntamente com as variações questionadas anteriormente; serão estudadas e aplicadas técnicas de processamento de sinais. Processamento este realizado através de programas que serão desenvolvidos ao longo do trabalho.

Complementando o projeto, será concebido e implementado um hardware para a captação de sinais eletromiográficos de superfície. Este deverá constituído de um arranjo linear composto por 8 eletrodos ativos em conjunto com um condicionador de sinais; definido pela parte de aquisição dos dados captados pelos eletrodos, filtros, amplificadores e placa de circuito impresso projetada para montagem do circuito. Posteriormente serão verificadas aplicações práticas do eletromiógrafo de múltiplos canais desenvolvido; determinando-se com o mesmo, a localização de zonas de enervações e calculo de velocidade de propagação do potencial de ação das fibras musculares. Para tal, será desenvolvido um software responsável pelo processamento e análise gráfica dos dados obtidos. 


\section{2 - MOTIVAÇÕES QUE LEVARAM A ESSA LINHA DE PESQUISA}

A eletromiografia é uma área sedutora, pois proporciona fácil acesso a processos fisiológicos que levam os músculos a gerarem força, produzirem movimentos e realizarem incontáveis atividades que nos permitem interagir com o mundo ao nosso redor. O estágio atual da eletromiografia de superfície, porém, pode ser considerado enigmático. A eletromiografia de superfície propicia muitas aplicações úteis e importantes, mas com algumas limitações que devem ser compreendidas, consideradas e eventualmente removidas para que esta área seja cada vez mais baseada em fatos científicos e menos confiante na simples arte de seu uso.

Dentro deste objetivo, a necessidade de se realizar novos experimentos e desenvolver novas metodologias com relação à captação do sinal de EMG-S nos levou a procurar-mos questões ainda pouco estudadas neste universo de pesquisa. Uma ampla e ainda pouco explorada área neste universo da EMG-S é o estudo da eletromiografia de superfície em ambientes subaquáticos.

Tratamentos de reabilitação em ambiente aquático são frequentemente recomendados principalmente durante as fases iniciais de recuperação. Terapia física subaquática vem sendo sugerida como um método para se melhorar movimentos em um ambiente em que os tecidos danificados ou cirurgicamente reparados não são excessivamente exigidos. Este tipo de terapia geralmente vem sendo acompanhada com a EMG-S para se determinar a ativação muscular durantes os movimentos e monitorar o progresso do tratamento. Apesar de seu uso crescente, existem poucos registros na literatura científica com o objetivo de validar e padronizar os aspectos da metodologia destas atividades.

Através de uma revisão bibliográfica, verificamos que não existe um consenso a respeito do comportamento da amplitude do sinal eletromiográfico no ambiente subaquático. Não se sabe se tal fato está relacionado à falta de padronização nos métodos de aquisição e de processamento computacional e estatístico dos dados obtidos, ou se está relacionado a outros fatores intrínsecos com as características do meio aquoso.

Seguindo este pensamento, tentou-se desenvolver uma metodologia que verificasse a existência de variação na amplitude do sinal EMG-S coletado no ambiente subaquático 
mantendo-se as condições de contorno. Desta forma, tenta-se esclarecer dúvidas que ainda não foram cuidadosamente trabalhadas por outros pesquisadores; tais como a influência do empuxo na variação da atividade eletromiográfica em ambiente subaquático e a variação deste sinal com relação à profundidade de imersão.

Outra área ainda pouco explorada da eletromiografia de superfície, iniciado há alguns anos atrás, é a do arranjo linear de eletrodos. Essa tecnologia vem sendo desenvolvida principalmente por dois grupos de pesquisas: um localizado no Laboratorio di Ingegneria del Sistema Neuromuscolare e della Riabilitazione Motoria do Politecnico di Torino, em Turim, na Itália e outro no Industrial Products Research Institute, em Tsukuba, no Japão. Os resultados de pesquisa com arranjos lineares de eletrodos vêm abrindo novas possibilidades no estudo de sinais eletromiográficos. Dentre estas possibilidades podemos citar a decomposição destes sinais, estimativa de velocidade de condução das MUAPT's e localização de zonas de enervação.

No Brasil, ainda não há notícias da presença desse tipo de equipamento. Visando suprir, em parte, essa deficiência, partiu-se para o desenvolvimento de um arranjo linear de oito eletrodos para eletromiografia de superfície neste projeto de graduação. 


\section{2 - REVISÃO BIBLIOGRÁFICA}

\section{1 - HISTÓRICO}

Data já de 280 antes de Cristo estudos feitos sobre a musculatura humana, onde Erasistratis afirmava ser o músculo um órgão de contração. Especificamente a eletromiografia é o estudo do comportamento muscular através da investigação dos sinais elétricos proveniente dos músculos, e a sua história remonta à metade do século XVII.[13]

O italiano Francesco Redi pesquisou a fonte de energia de certo peixe e reportou que era um músculo. Walsh demonstrou em 1773 que o tecido muscular da enguia podia produzir picos de eletricidade. Na década de 1790, o italiano Luiggi Galvani provou que descargas elétricas causavam contrações musculares, mostrando que a eletricidade e a musculatura interagiam intimamente. Entretanto, somente no século XIX que o uso de eletricidade para estímulo muscular ganhou maior notoriedade. O francês Du Bois-Reymond comprovou a existência de eletricidade durante a atividade muscular. Mas o primeiro estudo sistemático por meio de eletroestimulação das funções de músculos intactos foi efetuado pelo francês Duchenne somente por volta de 1860. Com a invenção dos osciloscópios de tubos de raios catódicos, os sinais dos músculos puderam ser visualizados a partir da década de 1920. Então até a década de 1950, o desenvolvimento da instrumentação para eletromiografia de superfície propiciou estudos variados envolvendo a musculatura humana. Entre eles temos técnicas de relaxamento, pesquisas de patologias neuromusculares e análise de movimentos dinâmicos. [13]

O emprego da eletromiografia intensificou-se para os estudos clínicos de biofeedback a partir da década de 1960, de patologias em pacientes hemiplégicos e de dores na coluna vertebral. Nas décadas mais recentes houve avanços significativos na análise espectral e em outras técnicas de processamento de sinais eletromiográficos, possibilitando o melhor entendimento da fisiologia muscular, dos parâmetros da fadiga, das disfunções e das mialgias. [13]

Recentemente tem sido progressiva a utilização da eletromiografia em técnicas de treinamento desportivo, biomecânica, fisioterapia e reabilitação. 


\section{2 - PRINCÍPIOS DOS SINAIS ELETROMIOGRÁFICOS}

Como é impossível especificar todas as características de controle dos vários sistemas motores, vamos focalizar nosso estudo nos princípios do controle motor, com especial atenção para o sistema esqueleto-motor, que desempenha o papel principal no controle da força e dos movimentos nos humanos.

O sinal de eletromiografia, ou mais comumente chamado de EMG, consiste em um sinal cuja base é a unidade motora. A unidade motora (UM) consiste de um moto-neurônio localizado na coluna espinhal em conjuntos com as fibras musculares que ele enerva. A contração do músculo se dá com a chegada de impulsos a suas fibras que se contraem para que o movimento seja executado.

O número de fibras em uma unidade motora (número de fibras musculares servidas por um axônio) varia dependendo do tipo de atividade desempenhada por ela. Músculos responsáveis por movimentos finos e pequenos ajustes tem menor quantidade de fibras por músculo, e músculos de maior porte possuem maior quantidade de fibras controladas pelo mesmo axônio.

Apesar de alguns músculos possuírem um tamanho avantajado os feixes musculares são pequenos e por isso uma contração forte requer participação de muitas unidades motoras. Além disso, há uma completa assincronia na contração das unidades motoras que ocorre justamente por haver uma assincronia dos grupos de impulso que descem pelos axônios que comandam um músculo. A contração e o relaxamento muscular em tempos diferentes geram uma distribuição homogênea de tensão no músculo como um todo.

Durante o abalo de uma fibra muscular gera-se um potencial elétrico extracelular, este dissipado ao longo de do tecido adjacente de forma a provocar o movimento. A duração deste potencial associado ao abalo pode chegar a $4 \mathrm{~ms}$. Devido ao fato de que todas as fibras musculares de uma mesma unidade motora não se contraem exatamente ao mesmo tempo, algumas defasadas de vários milissegundos, o potencial desenvolvido por um único abalo é prolongado, possui amplitude por volta de $0,5 \mathrm{mV}$ e uma duração em torno de 5 a $8 \mathrm{~ms}$ (podendo chegar a 12ms). 


\section{3 - TIPOS DE ELETROMIOGRAMA}

A eletromiografia pode ser dividida em dois tipos, dependendo do tipo de eletrodo utilizado:

1. Eletromiografia de profundidade: os eletrodos são colocados no interior do músculo, em contato direto com as fibras musculares. Este tipo de registro não é representativo quando o objetivo é estudar a atividade global de um músculo é pouco utilizado por ser um método invasivo. Este método tem uma leitura do sinal bem menos problemática, já que o eletrodo está em contato direto com a fibra muscular, mas tem a grande desvantagem de causar dor e desconforto ao paciente.

2. Eletromiografia de superfície: os eletrodos são colocados sobre a pele, captando a soma da atividade elétrica de todas as fibras musculares ativas naquela região. Caracteriza-se por ser um método não invasivo e de fácil execução, este método é largamente utilizado em áreas como o estudo cinesiológico e neurofisiológico dos músculos superficiais.

A eletromiografia de superfície, como foi dito acima, é um método de coleta de sinais seguro, não-invasivo e simples, propiciando a quantificação da energia do músculo. É possível observar a energia do músculo em repouso e, posteriormente, suas alterações à medida que um movimento ocorre. Mais recentemente, por meio de arranjos (cadeias) de sensores, puderam-se diferenciar aspectos de como certos músculos realizam tarefas diferentes. Por exemplo, é possível determinar se um determinado exercício está ativando um determinado músculo alvo ou se está havendo substituição dele por outro músculo. Em outra aplicação, a informação obtida do sinal eletromiográfico pode ser fornecida ao paciente, como uma realimentação, a fim de ensiná-lo a relaxar ou a contrair melhor um músculo sob tratamento fisioterápico.[13]

Uma dificuldade reside na ocorrência de crosstalk, que se apresenta quando a energia de um músculo interfere no campo de gravação de outro músculo. Assim, pode haver problemas de especificidade nos sinais coletados. Finalmente, outra limitação é a existência de poucas publicações com atlas de posicionamento de eletrodos e o respectivo sinal eletromiográfico. Ainda pior, inexiste uma padronização quanto a captação, processamento e interpretação do eletromiograma de superfície.[13] 
A configuração dos eletrodos de superfície pode ser dividida de acordo com a quantidade de eletrodos utilizados na região em estudo:

- Monopolar: onde um eletrodo é colocado sobre o feixe muscular de interesse e o outro eletrodo (chamado de referência) é colocado num ponto não afetado pela atividade do feixe muscular de interesse, mede-se então a diferença de potencial entre estes dois pontos.

- Bipolar: consiste em colocar dois eletrodos sobre a região que se deseja estudar e um terceiro eletrodo, chamado terra, é colocado num local não afetado pela atividade da região de interesse. Mede-se então a diferença de potencial elétrico entre os dois eletrodos que estão sobre a região de interesse, tomando-se como referência o eletrodo terra. Desta forma é possível a utilização de amplificadores diferenciais de alto ganho, o que em última análise melhoram significativamente a relação sinal-ruído, uma vez que os ruídos presentes nos cabos que levam o sinal dos eletrodos ao condicionador são subtraídos pelo amplificador diferencial.

\section{4 - AQUISIÇÃO DO EMG SUBAQUÁTICO}

Atividades físicas em ambiente subaquático têm recebido uma atenção especial de profissionais da área de fisiologia e terapia. Isso se deve ao fato da atividade física ser essencial para a manutenção da saúde do ser humano, além de propiciar formas mais eficiente de tratamento em certas patologias.

É bastante reconhecida a utilidade de atividades físicas realizadas em ambiente subaquático, pois são muito afetadas as diversas funções do organismo humano, como as dos sistemas cardiorespiratório e metabólico.

Além disso, as propriedades físicas da água e sua capacidade térmica desencadeiam efeitos terapêuticos, psicológicos e sensório-motores. Entre eles, figuram a facilitação da coordenação motora, a redução dos estímulos proprioceptivos e o alívio da tensão e do estresse. As propriedades físicas da água mais importantes para estudos com EMG-S em atividades subaquáticas são: densidade (músculos: $1158 \mathrm{~kg} / \mathrm{m}^{3}$, costela: $1383 \mathrm{~kg} / \mathrm{m}^{3}$ ) e gravidade específica, empuxo - Princípio de Arquimedes - (90\% de redução do peso-suporte 
quando a imersão é até a sétima vértebra cervical), pressão hidrostática (Lei de Pascal), turbulência (Princípio de Bernoulli), viscosidade, tensão superficial e refração.

Vários estudos foram feitos abordando a eficácia da hidrocinesioterapia (aplicação externa da água para fins terapêuticos) em pacientes com afecções variadas. Tem-se observado que os exercícios nesse tipo de ambiente apresentam, em muitos casos, resultados melhores que exercícios em ambiente aéreo. Muitas têm sido as justificativas para essa constatação, indo desde o fato de que o impacto de exercícios nos músculos, tendões e ossos ser menor, até o fato de o metabolismo humano se comportar de forma diferente em ambiente subaquático.

Temos dois fatores de fundamental importância para a análise das atividades hidrocinesioterápicas: a temperatura da água $\left(31^{\circ}\right.$ a $\left.35^{\circ} \mathrm{C}\right)$ e a profundidade da imersão do indivíduo, pois elas afetam o sistema musculoesquelético, conseqüentemente, o eletromiograma. Por este motivo, esses dois fatores foram considerados quando da elaboração dos experimentos aqui feitos, já que podem afetar a amplitude da eletromiograma de superfície. 


\section{3 - PROJETO DE HARDWARE}

\section{1 - CARACTERÍSTICAS GERAIS}

O sinal de EMG de superfície apresenta uma menor "definição" quando comparado ao sinal de EMG intramuscular. Isso ocorre devido ao fato dos tecidos que separam as fibras musculares e os eletrodos de captação atuarem como filtros passa-baixos. Esforços vêm sendo aplicados a pesquisas voltadas ao desenvolvimento de técnicas de processamento (no domínio do tempo e da freqüência) que possam nos fornecer bons indicativos da atividade eletromiográfica global, sem que seja focada analises a níveis de unidades motoras individuais; ou seja, sem a necessidade de utilização de eletrodos invasivos. Recentemente a possibilidade de se extrair a contribuição de uma única unidade motora (UM) do sinal de EMG tornou-se viável a partir do uso de sistemas de detecção avançados, junto com algoritmos especificamente desenvolvidos para processar informações adquiridas de múltiplos canais de aquisição.

A estratégia principal adotada para separar as atividades de uma única UM e estimar suas propriedades a partir do EMG de superfície, é baseada na amostragem espacial dos potenciais de superfície. Neste caso a detecção é realizada por um número maior de eletrodos, o que requer sistemas mais complexos e com métodos de extração de informações mais sofisticados.[4]

A disponibilidade de sistemas detecção de múltiplos canais pode ser utilizada para a obtenção de mais informações no processo de geração e extinção dos potenciais de ação das unidades motoras. Os primeiros sistemas deste tipo, foram propostos por De Luca, Merletti e Masuda[6,7,8], que aplicaram arranjos lineares de eletrodos para estimar a velocidade de propagação do potencial de ação ou para identificar zonas de inervação.

A possibilidade de acompanhar a propagação dos potencias de ação ao longo das

fibras musculares é particularmente importante. Pode-se, por exemplo, investigar as propriedades de condução das UM. A velocidade de propagação dos potenciais de ação é um indicativo das propriedades de contração das UM, podendo, portanto, ser utilizada para se definir a fadiga muscular. 
Uma área promissora nesse sentido é a que enfocamos em nosso projeto. Os arranjos lineares de eletrodos possibilitam extrair propriedades de uma única UM através de medições obtidas a partir da eletromiografia de superfície de vários canais. Recentemente foi apresentado um método para se estimar automaticamente a distribuição dos potenciais propagantes das unidades motoras a partir de sinais detectados de arranjos lineares.[9] Estes arranjos também vem sendo aplicados para estudos metodológicos a respeito da influência da localização do eletrodo ao longo das fibras musculares e suas consequiências nas variáveis extraídas do sinal de EMG.

\subsection{1 - Design}

Apesar do grande número de artigos clínicos, a questão da detecção dos sinais de EMG (tamanho, distância, localização e ganho dos eletrodos) ainda é pouco compreendida. Confusão generalizada sobre essa questão dentre os pesquisadores vem causando contradições e gerando resultados sem repetibilidade. Durante todo nosso projeto, seguimos as recomendações estabelecidas pelo projeto SENIAM (Surface Electromyography for the NonInvasive Assessment of Muscles). Projeto este que resultou nas recomendações européias para tipos de sensores, procedimentos para posicionamento de sensores e métodos para processamento de sinais para a eletromiografia de superfície.

O projeto do eletrodo de superfície é o aspecto mais crítico da aparelhagem eletrônica que será usada para a obtenção do sinal de EMG. A fidelidade deste sinal detectado pelo eletrodo influencia todo o subseqüente tratamento do sinal. É, portanto, bastante difícil melhorar a qualidade do sinal e a relação sinal-ruído do sinal de EMG-S além deste ponto. Antes de iniciarmos a descrição dos fatores considerados no projeto do eletromiógrafo de superfície, vamos ressaltar algumas características do meio no qual o sinal é "capturado".

A condição ideal para se medir a distribuição de potencial sobre a pele, é considerarmos um eletrodo pontual conectado a um voltímetro cuja impedância de entrada seria infinita e que estaria medindo a tensão com relação a um referencial remoto cujo potencial é zero. Apesar de essa configuração estar sendo comumente utilizada na literatura, ela é pouco realística, pois o eletrodo possui dimensões físicas, o contato pele-eletrodo tem uma impedância complexa, e o voltímetro utilizado (amplificador) possui uma impedância de entrada finita como pode ser observado através da figura seguinte. Adicionam-se ainda outras 
fontes de potenciais que estão contribuindo com o sinal a ser medido. Dentre essas fontes, podemos citar tensão DC e ruídos gerados na interface pele-eletrodo, ruído de linha e outros fenômenos elétricos não relacionados com EMG.[4]

a)

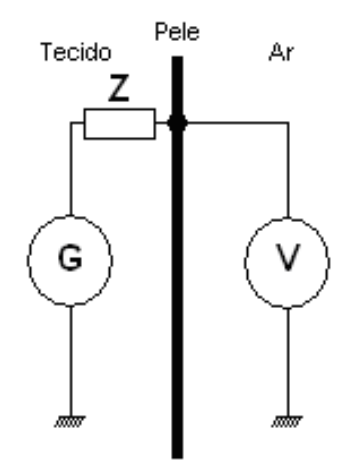

$\mathrm{G}=$ gerador de tensẫo equivalente

$\checkmark=$ voltímetro ideal

$Z=$ impedância equivalente

$\frac{1}{m}=$ referência de tensẫo b)

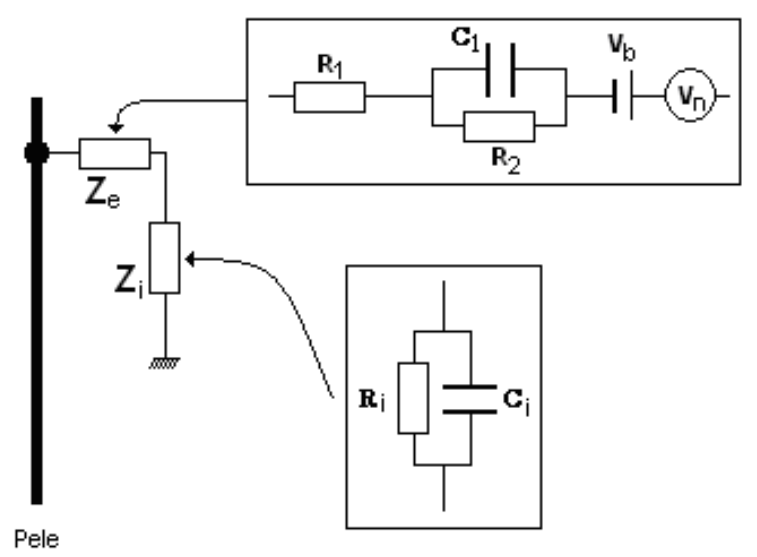

Figura 3.1 - Conceitos básicos da interface pele-eletrodo. (a) Situação ideal onde um voltímetro de impedância infinita monitora a tensão proveniente de um gerador equivalente. (b) Modelo de uma situação real com o circuito equivalente pele-eletrodo e a impedância de entrada do amplificador, onde $V_{b}=$ tensão DC e $V_{n}=$ tensão de ruído.

O eletrodo consiste de uma superfície de metal aplicada sobre a pele. Quatro considerações devem ser observadas sobre este ponto:

- A pele é um tecido moderadamente condutor, feito de células cujo material intracelular e extracelular consiste em sua maioria de soluções eletrolíticas nas quais a corrente é carregada por íons; como o metal é um material altamente condutor, a corrente no mesmo é carregada por elétrons. O resultado desta diferença na interface é ruído.[4]

- A interface pele-eletrodo é bastante complexa, com uma impedância capacitiva cujos componentes $\mathbf{R}$ e $\mathbf{C}$ são dependentes da corrente e da freqüência; além de ser incorporado um gerador DC devido ao potencial de bateria resultante da interface metal-eletrolítica.[4]

- A superfície de metal em contato com a pele irá forçar a área de contato a se tornar equipotencial, portanto, modificando a distribuição dos potenciais da pele nas regiões vizinhas.[4] 
- A impedância de entrada de um bom amplificador de EMG é modelada como um resistor $\left(10^{9}-10^{12} \Omega\right)$ em paralelo com um capacitor $(2-10 \mathrm{pF})$, sendo, portanto dependente da freqüiência.[4]

Deve ser levado em consideração que na faixa de freqüência ocupada pelo sinal de EMG, o componente capacitivo é dominante e não pode ser negligenciado. Em outras palavras, o potencial debaixo do eletrodo será modificado pela própria aplicação do eletrodo e pelo instrumento responsável por medir a tensão; além de ser somado a uma tensão de ofsete e ruído.

É desejável que se obtenha um sinal de EMG que contenha a quantidade máxima de informação do EMG e uma quantidade mínima de contaminação por parte de ruídos elétricos. Porém, a maximização da relação sinal-ruído deve ser feita com mínima distorção do sinal de EMG. As seguintes características devem ser observadas para se alcançar o objetivo citado:

- Amplificação Diferencial - Com o objetivo de se eliminar o sinal de interferência de linha proveniente de fontes de energia, a amplificação diferencial é empregada. A técnica de amplificação diferencial é mostrada esquematicamente na figura abaixo. $\mathrm{O}$ seu princípio de funcionamento é simples. O sinal é detectado em dois locais diferentes, um circuito eletrônico então subtrai os dois sinais e amplifica a diferença. Como resultado, qualquer sinal comum a ambos os locais de detecção será removido e os sinais que são diferentes nestes dois locais terão um "diferencial" que será amplificado. Quaisquer sinais que se originem a uma grande distância dos locais de detecção irão aparecer como sinais comuns, enquanto sinais nas imediações próximas aos eletrodos apresentarão diferenças e consequentemente serão amplificados. Portanto, sinais de ruído originários de fontes relativamente distantes serão removidos. A partir desta explicação, podemos ver a necessidade de utilizarmos um diferenciador altamente preciso. Na prática, mesmo com o nível de avanço da eletrônica atual, é muito difícil subtrair sinais perfeitamente. A precisão com que o amplificador diferencial consegue subtrair dois sinais é medida pelo CMRR (Common Mode Rejection Ratio). Um CMRR da ordem de 32,000 ou 90dB geralmente é suficiente para suprimir com eficiência ruídos elétricos. A tecnologia atual permite um CMRR em torno de $120 \mathrm{~dB}$, porém existem pelo menos 3 motivos para não se forçar este 
parâmetro ao limite: 1) Tais dispositivos são caros. 2) São componentes difíceis de serem mantidos eletricamente estáveis. 3) Os sinais de ruído externo podem não chegar aos lugares de detecção numa mesma fase, não sendo, portanto sinais de modo comum em um sentido absoluto.

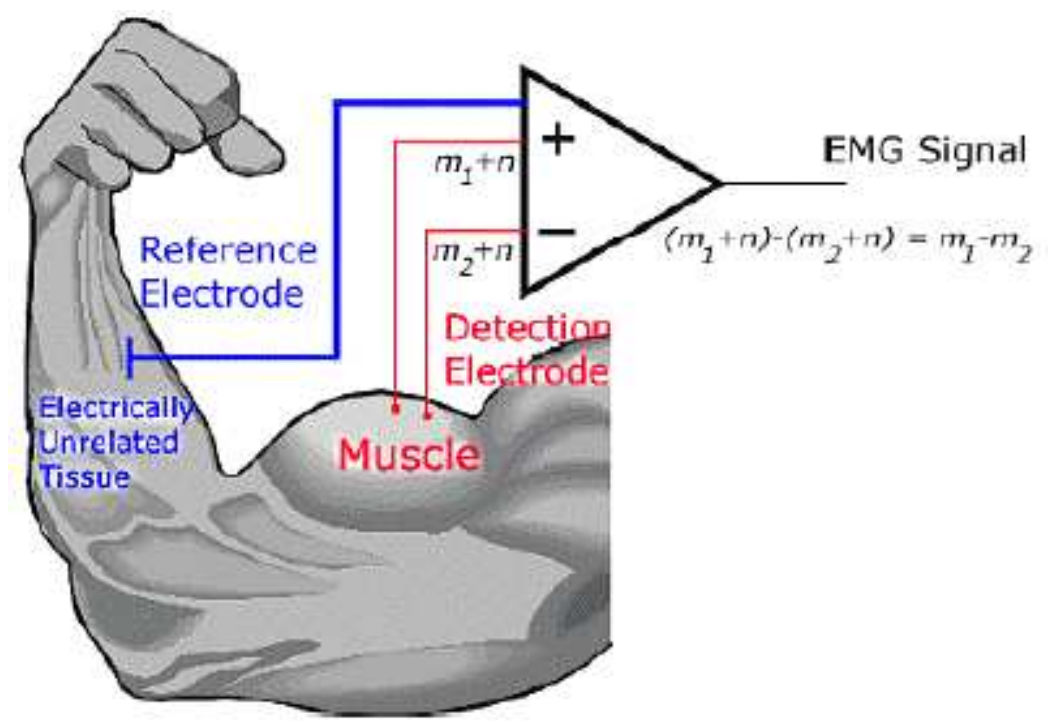

Figura 3.2 - Esquemático da configuração amplificador diferencial. O sinal de EMG é representado pela letra "m" enquanto o sinal de ruído é representado pela letra "n”.[3]

- Impedância de Entrada - A fonte de impedância na junção entre a pele e a superfície de detecção pode variar de vários milhares de ohms até vários megaohms para a pele seca. Para se prevenir atenuação e distorção do sinal capturado devido a efeito desta carga de entrada, a impedância de entrada do amplificador diferencial deve ser mais alta possível, porém sem causar complicações no funcionamento do amplificador.

- Projeto de eletrodo ativo - A necessidade de uma alta impedância de entrada induz a um problema conhecido como capacitância de acoplamento na entrada do amplificador diferencial. Uma pequena capacitância entre os fios que conectam a entrada do amplificador e a linha de alimentação, irá induzir um sinal de ruído de linha ao amplificador. Como solução, devemos posicionar o amplificador diferencial o mais próximo possível das superfícies de detecção dos eletrodos. A esta abordagem damos o nome de "eletrodo ativo". Uma outra vantagem desta configuração é que a impedância de saída do amplificador diferencial pode ser bastante reduzida; da ordem de 10 ohms. Dessa forma qualquer movimento de cabos a partir da saída deste amplificador diferencial não irá gerar sinais de ruídos significantes para o amplificador subseqüente. 
- Filtragem - Mesmo com as considerações acima citadas, o sinal de EMG capturado será contaminado com algum ruído. A relação sinal-ruído pode ser, portanto melhorada com através de uma filtragem passa-banda entre $20 \mathrm{~Hz}$ e $500 \mathrm{~Hz}$. Essa etapa de filtragem geralmente é realizada no estágio de amplificação localizado fora do eletrodo ativo. Deve-se observar que no processo de condicionamento do sinal, o sinal de EMG não deve ser ceifado, ou seja, os picos não devem ser distorcidos e, além disso, nenhum tipo de filtragem desnecessária deve ser realizado. Devido ao fato da interferência de linha $(60 \mathrm{~Hz})$ ser uma fonte dominante de ruído elétrico, é tentador a possibilidade de se projetar eletrodos que contenham filtros notch nessa freqüência. Teoricamente, este tipo de filtro removeria somente a freqüência do ruído de linha não desejada, porém, na prática, a implementação deste dispositivo remove também porções de componentes de freqüência adjacentes. Como a energia dominante de um sinal de EMG está localizada na faixa de freqüência entre $50 \mathrm{~Hz}$ e $100 \mathrm{~Hz}$, o uso de filtros notch não é recomendado; pois existem outros métodos para se lidar com este tipo de interferência.

Ao longo da história da eletromiografia, o formato e o leiaute do eletrodo de eletromiografia de superfície não receberam muita atenção. Isso porque o uso anterior da eletromiografia de superfície era focado basicamente nos aspectos qualitativos do sinal de EMG. Com o desenvolvimento de novas técnicas de processamento para se extrair informações quantitativas do sinal de EMG, um foco maior foi direcionado à configuração do eletrodo. Dentro dessa visão consideramos em nosso projeto vários pontos.

A relação sinal-ruído é uma função de complicadas interações entre a pele e a superfície de detecção de metal do eletrodo. O tamanho da superfície de detecção tem um comprometimento direto com essa relação, onde uma maior superfície do eletrodo leva a uma redução do ruído no sinal capturado. Porém, deve se levar em consideração a susceptibilidade do eletrodo ao efeito de cross-talk. Quanto maior o comprimento e a largura da superfície de detecção, mais próximo o eletrodo vai se encontrar a músculos adjacentes. Portanto, grandes eletrodos são mais susceptíveis a detectar sinal de músculos adjacentes; além de introduzirem uma excessiva filtragem passa-baixos.

Além disso, a área amostrada do músculo não necessita ser muito grande uma vez que as unidades motoras das fibras musculares estão distribuídas através da maior parte da secção 
transversal do músculo. Não é necessário, portanto, cobrir uma grande porção do músculo com a superfície de detecção do eletrodo para se obter uma amostra representativa do sinal de EMG para um particular conjunto de unidades motoras. É recomendado que o tamanho dos eletrodos na direção das fibras musculares não exceda 10.0mm.[5] Através de analise da literatura atual, chegamos a conclusão que a implementação de uma superfície de detecção feita de prata pura (grau de pureza superior a 99,5\%) na forma de uma barra de $1 \mathrm{~cm}$ de comprimento por $1 \mathrm{~mm}$ de largura nos garantiria um meio suficientemente bom para aquisição de sinais de EMG-S.

À distância intereletrodos é definida como a distância centro a centro entre as superfícies condutoras de dois eletrodos na configuração bipolar. A amplitude do sinal de EMG é diretamente proporcional a esta distância intereletrodos. Essa distância, portanto deveria ser maximizada, porém, o aumento dessa distância introduz características indesejáveis no projeto do eletrodo.

À medida que o eletrodo se torna maior, ele fica impossibilitado de capturar sinais de músculos relativamente pequenos. Quando aplicados a esse tipo de músculos, a distância intereletrodos não deve exceder $1 / 4$ do comprimento da fibra muscular, dessa forma efeitos tais como a influencia de zonas com tendões e zonas de inervação são reduzidos. Adicionalmente, a configuração amplificação diferencial possui uma característica de filtragem espacial que pode ser expressa como um filtro passa banda na região espectral de freqüência do sinal de EMG. A largura de banda do sinal de EMG é afetada, portanto pelo espaçamento entre as superfícies de detecção e pela velocidade de condução dos potenciais de ação ao longo das fibras musculares. Para uma velocidade média de condição de $4.0 \mathrm{~m} / \mathrm{s}$ e uma distância intereletrodos de $1.0 \mathrm{~cm}$ obtemos uma freqüência central de $200 \mathrm{~Hz}$ com atenuação a partir de $400 \mathrm{~Hz}$; tendo portanto uma largura de banda que captura todo o espectro de frequiência do sinal de EMG e elimina ruídos em altas freqüências.

\subsection{2 - Filtros}

Em cada circuito são utilizados dois filtros. Um passa alta, logo após o primeiro estágio de amplificação de forma a atenuar fortemente o potencial de meia célula. $\mathrm{O}$ outro filtro utilizado é um filtro passa - baixa usado logo após o último estágio de amplificação. Sua finalidade é atenuar fortemente o ruído que possa estar contaminando o sinal. Esse ruído pode 
ter uma alta intensidade, podendo distorcer o sinal de forma significante, levando a algum erro de interpretação. Assim, os filtros têm papel fundamental nos circuitos de detecção de sinais, especialmente em se tratando de sinais biomédicos.

Sabe-se que a freqüência de corte de um filtro passa-alta representa a freqüência a partir da qual a potencia do sinal cai de $3 \mathrm{~dB}$ (ou ainda cai a potencia pela metade) e é calculada por sua constante de tempo. A constante de tempo, por sua vez, depende dos valores de resistência e de capacitância existentes no filtro. Sendo assim, define-se a freqüência de corte de um circuito como sendo inversamente proporcional ao produto destas grandezas. $\mathrm{Ou}$ ainda, como mostrada pela equação 3.1:

$$
f_{c}=\frac{1}{2 \pi R C}
$$

No filtro passa-alta de primeira ordem, desejamos obter uma freqüência de corte próxima de zero. Fixando o valor do capacitor em $33 \mathrm{nF}$, devido a restrições de mercado, e a freqüência de corte em $20 \mathrm{~Hz}$, usamos a equação 3.1 para encontrar o valor da resistência:

$$
f_{c}=\frac{1}{2 \pi R C}=20 \quad \therefore \quad R=\frac{1}{40 \pi \cdot 33 \cdot 10^{-9}}=241 \mathrm{~K} \Omega
$$

O resistor mais próximo deste disponível no mercado foi o de $220 \mathrm{~K} \Omega$, que nos deu uma freqüência de corte bem próxima da desejada: $21,9 \mathrm{~Hz}$, como mostra a equação seguinte.

$$
f_{C}=\frac{1}{2 \pi \cdot R \cdot C}=\frac{1}{2 \pi \cdot 220 \cdot 10^{3} \cdot 33 \cdot 10^{-6}}=21,9 \mathrm{~Hz}
$$

O filtro passa-baixa que utilizamos foi um Sallen-Keys, composto pela realimentação negativa de um capacitor em um amplificador com ganho unitário. Neste projeto é encontrado no último estágio sendo apenas responsável pela filtragem do sinal e seus componentes foram calculados a partir da análise de seu circuito mostrada pela figura 3.3: 


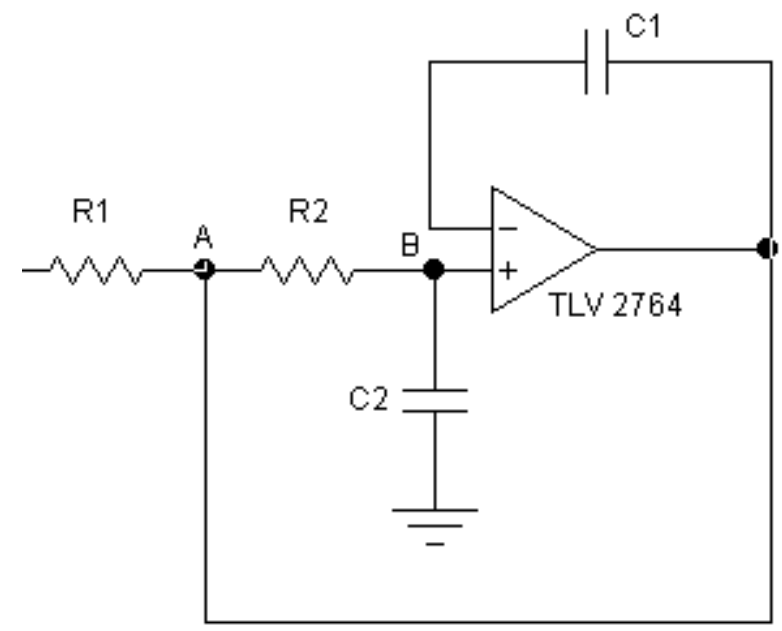

Figura 3.3 - Último estágio do circuito detector de sinais eletrofisiológicos composto por filtro passa-baixa de segunda ordem em um amplificador operacional de ganho unitário.

Escrevendo as equações da lei de Kirchoff das correntes nos nós indicados na figura 3.3, obtêm-se as equações 3.4:

$$
\begin{aligned}
& \text { KCL em } A: \frac{V-V_{i}}{R_{1}}+\frac{V-V_{o}}{\frac{1}{j \omega C_{1}}}+\frac{V-V_{o}}{R_{2}}=0 \\
& K C L \operatorname{em~} B: \frac{V_{o}-V}{R_{2}}+\frac{V_{o}}{\frac{1}{j \omega C_{2}}}=0
\end{aligned}
$$

A tensão na saída $\mathrm{V}_{\mathrm{o}}$ é mostrada pela equação 3.5:

$$
V_{o}=\frac{\frac{1}{R_{1} \times R_{2} \times C_{1} \times C_{2}}}{s^{2}+s\left(\frac{1}{R_{1} \times C_{1}}+\frac{1}{R_{2} \times C_{1}}\right)+\frac{1}{R_{1} \times R_{2} \times C_{1} \times C_{2}}}
$$

Pode-se normalizar a equação acima de forma a facilitar os cálculos, desta forma, temos os valores mostrados pelo conjunto de equações 3.6: 


$$
\begin{aligned}
& R_{1}=R_{2}=1 \\
& C_{1}=\sqrt{2} \\
& C_{2}=\frac{1}{\sqrt{2}}
\end{aligned}
$$

Divide-se o valor de cada capacitor por um fator da freqüência do sistema, este valor, C é dado pela equação 3.7 :

$$
C=\frac{1}{2 \pi f}
$$

onde f é a freqüência de corte. No caso do EMG a freqüência de corte é de $500 \mathrm{~Hz}$.

Multiplica-se o valor dos resistores por uma constante $\mathrm{K}$ para determinar seu valor final. Divide-se o valor do capacitor pela mesma constante. Sendo assim, escolheu-se o valor da constante como sendo mil, ou seja, os resistores são de mil ohms.

Para o circuito do EMG temos os valores calculados pelo conjunto de equações 3.8:

$$
\begin{aligned}
& c_{1}=\frac{\sqrt{2}}{2 \times \pi \times f}=\frac{\sqrt{2}}{2 \times \pi \times 500}=0,00045 \\
& c_{2}=\frac{1 / \sqrt{2}}{2 \times \pi \times f}=\frac{1 / \sqrt{2}}{2 \times \pi \times 500}=0.000225 \\
& K=1000 \quad \therefore \quad R_{1}=R_{2}=1000 \Omega \\
& C_{1}=\frac{c_{1}}{K}=0,45 \mu F \quad e \quad C_{2}=\frac{c_{2}}{K}=0,225 \mu F
\end{aligned}
$$

O último estágio fica então representado pela figura 3.4: 


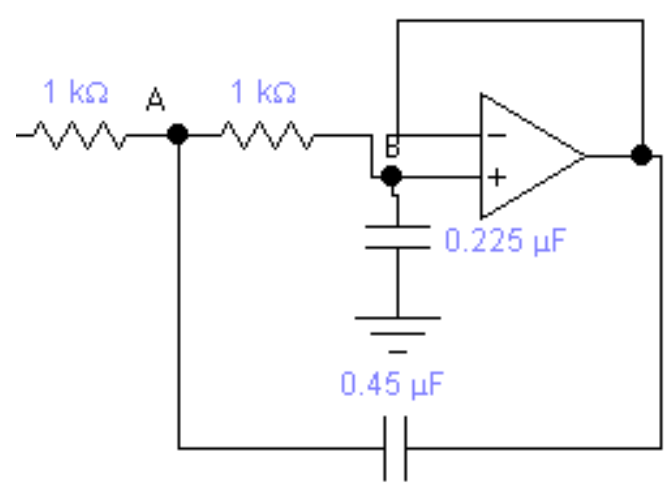

Figura 3.4 - Esquemático com os valores do último estágio do circuito de EMG com os valores para o filtro SallenKeys.

Com os filtros determinados, basta determinar os valores dos componentes para ajuste do ganho dos amplificadores.

\subsection{3 - Amplificadores}

Partiu-se da prerrogativa que os circuitos possuiriam dois estágios de amplificação, sendo que o ganho final deveria ser em primeira idéia de 2200 vezes. Sendo assim, dividiu-se o ganho em duas partes, uma com o valor de 10 e a outra com valor de 220. Para obtenção de melhor optou-se pela utilização de dois tipos de amplificadores operacionais: um direcionado para obtenção de sinais biomédicos (primeiro estágio) e um amplificador diferencial comum (para o segundo estágio).

Após analise de diversas data sheets, optou-se pela utilização do amplificador de instrumentação INA118 da Texas Instruments. Justifica-se a sua escolha por ser um dispositivo que possui uma alta sensibilidade a sinais biomédicos, pois possui uma alta precisão na obtenção destes sinais além de requerir uma baixa potência para seu funcionamento.

Segundo a folha de dados fornecida pela Texas Instruments, o ganho deste circuito pode ser facilmente ajustado apenas pela variação de uma resistência de entrada, conectada entre os pinos 1 e 8 do referido circuito integrado, como mencionado anteriormente. Pode-se calcular este ganho como mostra a equação 3.9: 


$$
G=1+\frac{50 k \Omega}{R_{G}}
$$

O ganho neste primeiro intervalo é projetado para ser de 10. Para isto, calcula-se o valor da resistência pelo valor desejado para o ganho. A equação 3.10 demonstra isso.

$$
10=1+\frac{50 * 10^{3}}{R_{G}} \quad \therefore \quad \frac{50 * 10^{3}}{R_{G}}=9 \quad \therefore \quad R_{G}=\frac{50 * 10^{3}}{9}=5,55 \mathrm{k} \Omega
$$

Para amplificar o sinal obtido pelo primeiro estágio buscou-se por um amplificador que possuísse baixo consumo, sempre com esta preocupação para que a bateria possuísse uma vida útil maior; alto slew rate, ou seja, uma alta taxa de variação da tensão da saída (medida dada em volts por unidade de tempo), o que garante que a saída será um espelho real do que está acontecendo naquele estágio de amplificação.

Após longa análise chegou-se a conclusão que o melhor dispositivo para atender as estas exigências seria o TL064 também da Texas Instruments. Sua taxa de amplificação é calculada como em qualquer amplificador operacional: através de realimentação com resistores de acordo com a configuração de montagem desejada (inversora ou não-inversora).

O maior atrativo do TL064 é realmente seu preço. Além disso, possui já 4 amplificadores por encapsulamento, o que nos permitiu reduzir o número de chips amplificadores na placa condicionadora de sinais para apenas 4. É um chip de baixíssimo custo, e ainda assim nos proporcionou um funcionamento excelente para a nossa aplicação.

O cálculo do ganho é feito como para qualquer amplificador operacional. Neste caso, têm-se a configuração inversora feita duas vezes seguidas (uma com o ganho de 220 a outra com o ganho unitário juntamente com o filtro Salen-Keys). O arranjo da configuração inversora é mostrado pela figura 3.5 . 


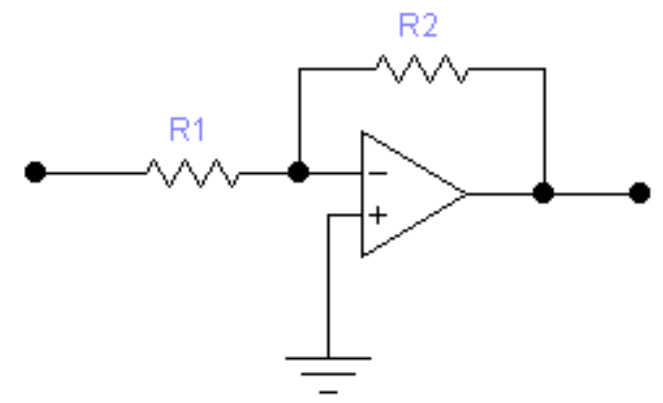

Figura 3.5 - Configuração inversora de um amplificador operacional.

Para um amplificador com esta configuração sabe-se que o ganho é calculado como mostra a equação 3.11 :

$$
G=-\frac{R_{2}}{R_{1}}
$$

De forma a simplificar os cálculos podemos considerar $\mathrm{R}_{1}$ com o valor de mil ohms e assim calcular o valor de $\mathrm{R}_{2}$ para obtermos um ganho de 220 como mostra a equação 3.12 :

$$
\begin{aligned}
& |G|=\left|\frac{R_{2}}{R_{1}}\right| \quad \therefore \quad R_{2}=G \times R_{1} \\
& R_{2}=220 \times 10^{3} \rightarrow R_{2}=220 \mathrm{k} \Omega
\end{aligned}
$$

O valor de duzentos e vinte mil ohms calculado para o ganho justifica a escolha feita do resistor para o filtro de primeira ordem acoplado ao amplificador, justamente para determinar o ganho de duzentos e vinte neste amplificador operacional.

\subsection{4 - Reguladores de Tensão, Terra e Alimentação}

Uma preocupação que tivemos com a alimentação foi de eliminar a necessidade de uma fonte ligada à rede elétrica, de modo a evitar ruídos no sinal coletado. Assim optamos por alimentar o condicionador de sinais com baterias, e esta mesma alimentação seria usada para a sonda ativa. 
Levamos em consideração a excursão do sinal de saída, as especificações de alimentação dos chips utilizados e principalmente o custo do circuito de alimentação, que deveria ser o mínimo possível.

A solução que supriu muito bem todas estas necessidades foi de utilizar 2 baterias comuns de 9V, alimentando reguladores de tensão comuns: o L7805C-V para alimentando o circuito com $+5 \mathrm{~V}$ e um LM7905CT suprindo $-5 \mathrm{~V}$. Assim podemos obter um sinal já amplificado na saída de até $10 \mathrm{~V}$. Utilizamos capacitores de $3,3 \mu \mathrm{F}$ e $0.47 \mu \mathrm{F}$ conforme requisitado no datasheet dos reguladores de tensão. $\mathrm{O}$ circuito da alimentação de $+5 \mathrm{~V}$ é mostrado na figura 3.6 e o da alimentação de $-5 \mathrm{~V}$ na figura 3.7 :

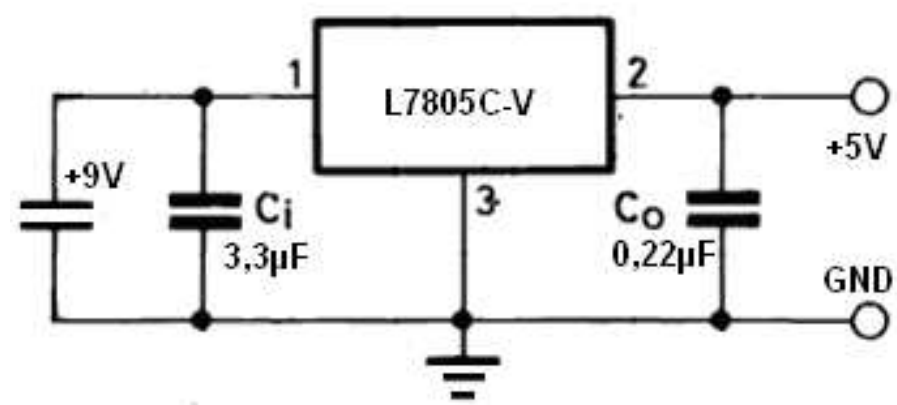

Figura 3.6 - Circuito de alimentação de $+5 \mathrm{~V}$, conforme especificações do datasheet do L7805C-V.

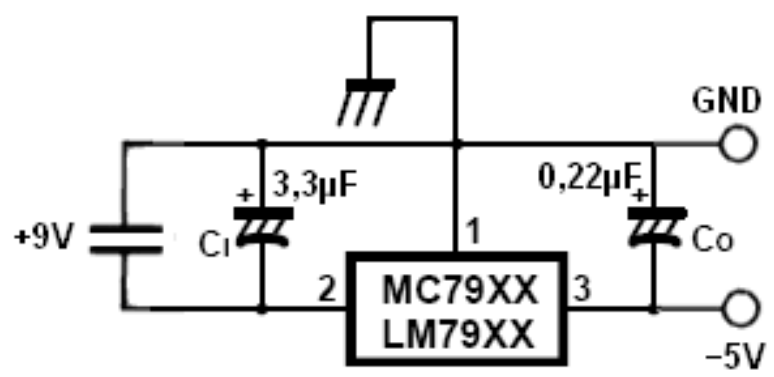

Figura 3.7 - Circuito de alimentação de -5V, conforme especificações do datasheet do LM7905CT.

Deste modo, o circuito completo de alimentação fica conforme é mostrado na figura 3.8 , onde temos as 2 baterias conectadas na entrada e como saída 3 terminais: $+5 \mathrm{~V},-5 \mathrm{~V}$ e o referência do condicionador e sonda. 


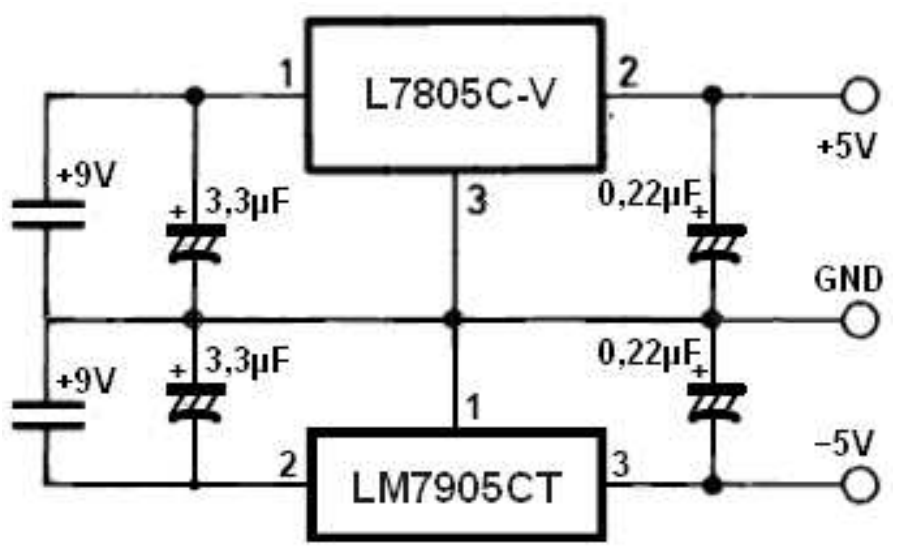

Figura 3.8 - Circuito de alimentação completo.

O aterramento do sistema todo foi feito conectado nos reguladores conforme especificação do datasheet de cada um. Note que o aterramento dos reguladores é o mesmo dos chips utilizados, tanto na sonda quanto no condicionador de sinais, e também é o mesmo usado no eletrodo de referência. Deste modo obtivemos um sinal mais livre de ruídos externos.

Implementamos o circuito de alimentação na mesma placa do condicionador de sinais. O conector entre sonda e condicionador de sinais inclui, alem dos fios que levam o sinal de EMG, os fios de alimentação. Assim poupamos espaço na placa da sonda, que deve ser mais compacta para não atrapalhar o manuseio durante a coleta de dados.

As baterias utilizadas nos testes do projeto foram baterias alcalinas de $9 \mathrm{~V}$, facilmente encontrada no mercado. A carga da bateria deve ser monitorada, pois a diminuição da tensão nos terminais pode chegar a valores que podem influenciar a funcionamento do equipamento e comprometer a análise dos sinais adquiridos.

\section{2 - MONTAGEM DO CIRCUITO}

\subsection{1 - Placa de Circuito Impresso}

As Placas de Circuito Impresso (PCI) são placas que servem de suporte mecânico para os componentes eletrônicos, além de interligá-los eletronicamente através das comumente chamadas trilhas. Tais placas também são conhecidas como PCB (Printed Circuit Board) e possuem basicamente as mesmas características ou propriedades, podendo diferir uma das 
outras através de detalhes de fabricação ou acabamento. As placas são, portanto constituídas de material isolante, podendo ser de baquelite, fenolite ou fibra de vidro. Já as trilhas são de material condutor, geralmente este material sendo o cobre.

Atualmente, a complexidade dos sistemas eletrônicos vem crescendo de forma cada vez mais rápida, exigindo uma conseqüente evolução nos processos de projeto e fabricação de placas de circuito impresso. Mais componentes em um menor espaço, mais pinos por componentes, distâncias e furos cada vez menores e um numero de camadas nunca antes imaginados vem se tornando práticas comuns no desenvolvimento dessas placas, exigindo dos projetistas novas técnicas, ferramentas e procedimentos.

O projeto de uma placa consiste em se planejar tanto a disposição dos componentes como a disposição das trilhas que interligam os mesmos, resultando no circuito eletrônico desejado. O fato das trilhas serem impressas, ou seja, só havendo possibilidade de ocupar um único plano na placa de circuito impresso, traz algumas dificuldades aos projetistas. As trilhas não podem se cruzar, levando a tentarmos percursos ou disposições alternativas. Os cruzamentos de trilhas que não tenham solução por um trajeto maior ou no caso que se deseja evitar esse procedimento, podem ser resolvidos com a colocação de "jumpers" (como foi utilizado em nosso hardware) ou a utilização de placas com múltiplas camadas condutoras.

Outro ponto a ser observado diz respeito a circuitos de elevada potência como amplificadores e transmissores. Em tais circuitos existem pontos em que a intensidade da corrente pode ser elevada acima de 1A. As trilhas de cobre depositado na superfície de uma placa são extremamente finas, de modo que sua capacidade de conduzir corrente depende basicamente de sua largura. Dessa forma, uma trilha estreita de alguns poucos milímetros não suporta correntes intensas, podendo aquecer e até romper-se, com efeitos desastrosos para o circuito.[1]

Estes circuitos eletrônicos que apresentam componentes com elevada dissipação de potência, podem acarretar sérios problemas ao desenvolvimento do projeto, pois ocasionam uma elevação na temperatura da placa de circuito impresso. Os componentes eletrônicos apresentam certos limites em relação às temperaturas a que são submetidos. Caso esses limites não forem respeitados, o componente pode apresentar um comportamento inadequado ou até mesmo ser danificado. 
Dessa forma, a análise térmica da PCI se torna uma necessidade. Analise esta realizada antes da finalização do projeto, possibilitando uma prévia detecção de problemas e o estudo de possíveis soluções. Além disso, a análise térmica aumenta a confiabilidade do sistema já que evita que os componentes operem fora de sua faixa especificada de temperatura.[1]

O local onde o terminal do componente é soldado na placa de circuito impresso denomina-se ilha de soldagem, ou simplesmente ilha. É também conhecido pela sua denominação em inglês: pad. As ilhas podem ser de dois tipos: convencionais e de superfície. As ilhas convencionais são utilizadas para soldagem de componentes com terminais (chamados também de componentes convencionais). As ilhas de superfície são utilizadas em componentes SMD e em contatos de bordas (também conhecidos como conectores de borda).

As ilhas convencionais possuem dois parâmetros a serem considerados no seu dimensionamento: o diâmetro do furo e a largura do anel metálico. A escolha do diâmetro do furo leva em consideração o diâmetro do terminal a ser inserido (no caso de terminais de secção retangular deve-se considerar a dimensão da diagonal) e se o furo será metalizado ou não (a metalização só é possível em placas do tipo dupla-face).
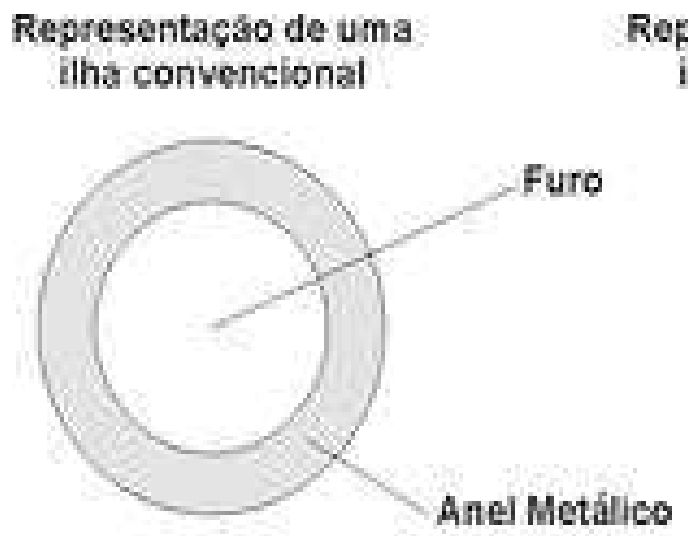

Figura 3.9 - Representação do furo de uma placa para ilha convencional e ilha de superfície.
Representaço de una ithat desuperficie

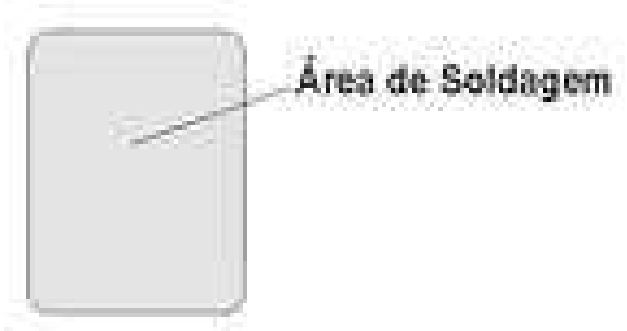

O dimensionamento do anel metálico leva em consideração a sustentação mecânica do componente, o tipo de material base utilizado e até a corrente elétrica e/ou uma possível dissipação térmica. Placas de circuito impresso fabricadas utilizando materiais como o fenolite requer um anel metálico mais reforçado se comparadas às mesmas placas utilizando 
fibra de vidro, por exemplo. Isto se deve principalmente à aderência do cobre ao material utilizado como base (o fenolite possui menor aderência ao cobre do que a fibra de vidro).

\subsection{2 - Layout}

Nesta seção, faremos um breve comentário a respeito do layout desenvolvido para a fabricação das placas de circuito impresso da sonda e do condicionador de sinais de nosso eletromiógrafo.

Em forma de barras de prata com $10 \mathrm{~mm}$ de comprimento e $1 \mathrm{~mm}$ de diâmetro, os 8 eletrodos são espaçados entre si de $10 \mathrm{~mm}$. Cada par de eletrodos está conectado diretamente a um INA118 e o circuito responsável pela amplificação do sinal. Como o circuito é praticamente uma repetição a cada par de eletrodos, fica fácil sua visualização completa na figura 3.10. A saída do sinal dos CI's vai direto para o conector à direita, de onde parte um cabo que é conectado no condicionador de sinais. Note que este conector supre a alimentação e a tensão de referência dos CI's.

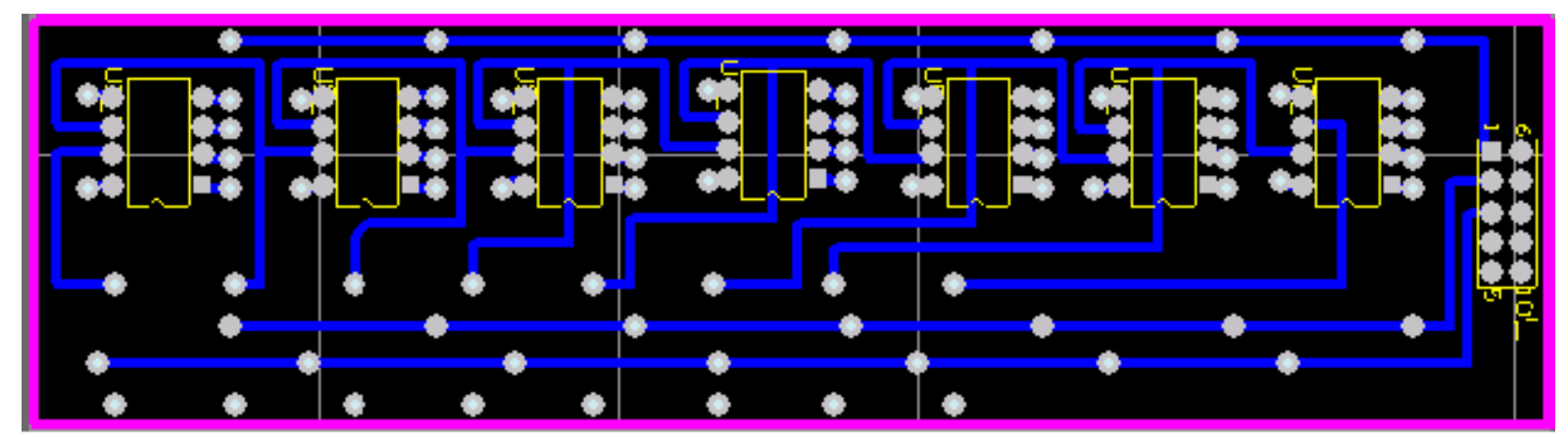

Figura 3.10 - Leiaute da placa de circuito impresso para o arranjo linear de 8 eletrodos.

No condicionador de sinais temos 4 partes bem destacadas, onde ficam os 4 CI's responsáveis pela amplificação do sinal em 220 vezes. Note que temos 2 canais a cada CI amplificador, o que nos dá ao todo 8 canais nesta placa. A sonda usa apenas 7 destes, e ainda assim decidimos incluir o layout do oitavo na placa, já que não ocuparia mais espaço, teríamos 2 amplificadores sobrando e não causaria nenhum problema. O leiaute é mostrado na figura 3.11 . 


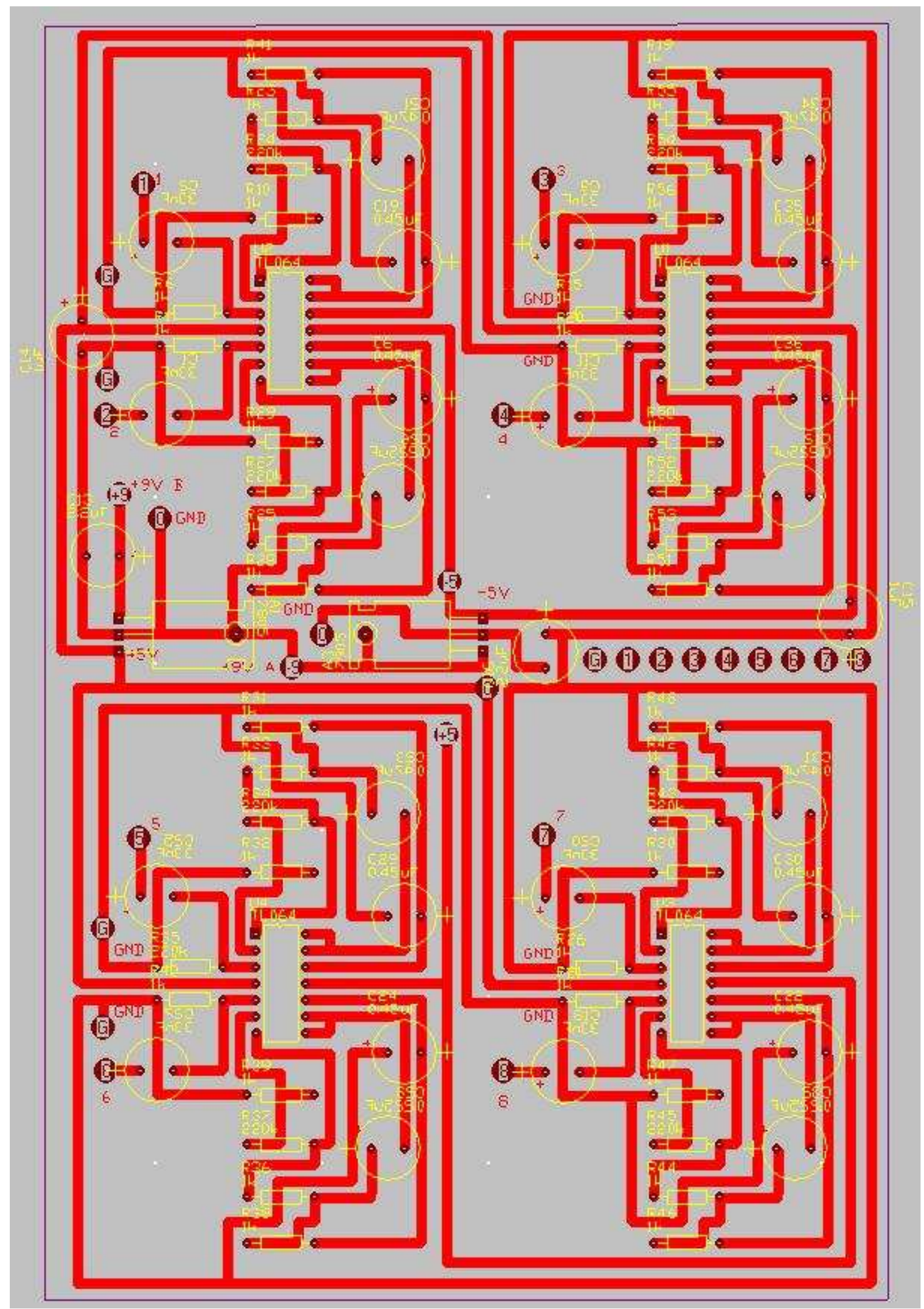

Figura 3.11 - Leiaute da placa de circuito impresso para o condicionador de sinais. 
O bloco de alimentação foi colocado no centro da placa. Esta disposição é a ideal, pois desta forma a alimentação será disponível para todos os componentes com uma maior proximidade.

Na figura 3.12 abaixo temos em destaque a área da placa destinada a cada canal de amplificação (azul), ao circuito de alimentação (preto) e ao conector que parte da placa do condicionador para a sonda (verde).

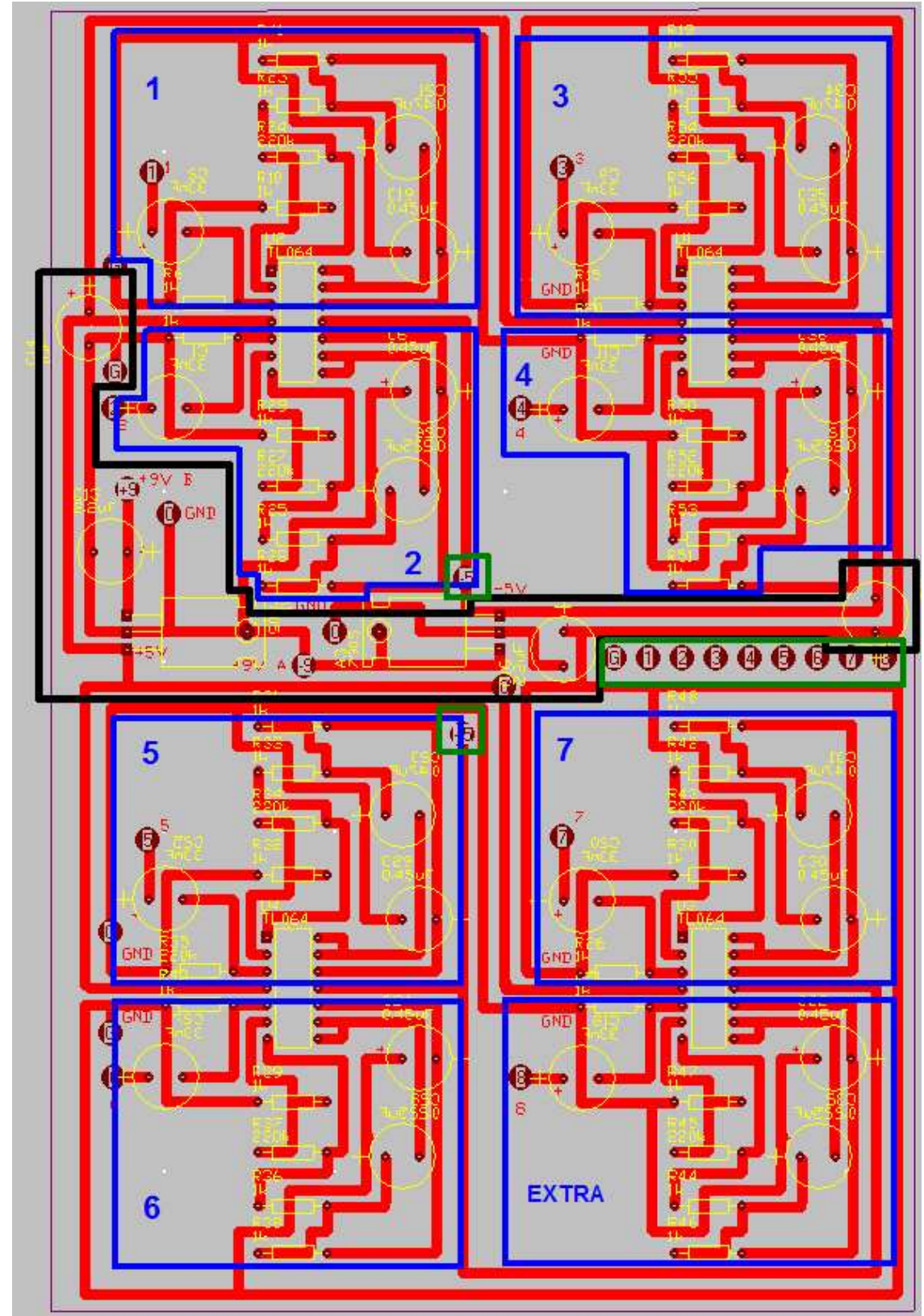

Figura 3.12 - Leiaute da placa de circuito impresso para o condicionador de sinais, com destaque em azul dos canais enumerados, em verde os fios que partem para o cabo que é conectado à sonda e em preto o circuito de alimentação. 


\subsection{3 - Compatibilidade Eletromagnética}

Iniciamos este tópico definindo alguns conceitos básicos para um melhor entendimento a respeito de nosso próximo assunto. Entende-se por Compatibilidade Eletromagnética a capacidade de sistemas, equipamentos e dispositivos eletro-eletrônicos de operar em seu ambiente eletromagnético dentro de margem de segurança definida (em níveis de performance projetados), sem que sofram ou causem degradação inesperada como resultado de interferência eletromagnética.[2]

Como a essência de uma interferência é a falta de compatibilidade, definimos Interferência Eletromagnética como sendo a falta de Compatibilidade Eletromagnética. É, portanto o processo pelo qual energia eletromagnética "perturbadora" é transmitida de um dispositivo eletrônico para outro através de radiação ou caminhos condutores.[2]

Dentro do campo da Compatibilidade Eletromagnética, existem múltiplas questões a respeito da elaboração de projetos. O conhecimento de cinco áreas chaves é imprescindível para se compreender o porquê da compatibilidade eletromagnética. A partir do domínio dessas áreas, podemos reduzir drasticamente dificuldades uma vez que aproximadamente 95\% dos problemas estão associados com os assuntos que se seguem:

- Regulação: A necessidade da regulação se faz necessário devido a constante interferência que dispositivos eletrônicos oferecem em outros produtos eletrônicos, além de ser necessário proteger sistemas de comunicações vitais. Sem essa regulação, o ambiente eletromagnético em que vivemos hoje estaria abarrotado de interferências, e somente alguns dispositivos eletrônicos sobreviveriam e operariam normalmente. A regulação controla não somente a emissão, mas também a susceptibilidade, ou seja, a imunidade que o dispositivo deve ter a certa interferência.[2]

- Interferência por Radio Freqüência: Esse tipo de interferência se apresenta como grande ameaça a sistemas eletrônicos devido à grande disseminação de radio transmissores. E não é necessária uma grande quantidade de potência radiada para se causar interferência danosa. Tipicamente, falhas de equipamentos eletrônicos ocorrem dentro de uma faixa do campo elétrico de 1 a 10 volts/metro.[2] 
- Descarga Eletrostática: A sensibilidade de microprocessadores de alta velocidade faz com estes dispositivos sejam facilmente danificados por eventos externos de descargas eletrostáticas. Esses eventos podem ser causados por meios diretos ou radiados. Eventos de descargas eletrostáticas causadas por contato direto geralmente provocam danos permanentes no dispositivo, ou criam falhas que podem vir a danificar os aparelhos permanentemente no futuro.[2]

- Distúrbios de Energia: Com um número cada vez maior de equipamentos eletrônicos conectados em linhas de energia, temos um maior numero de problemas relacionados potência entregue a esses equipamentos. Dentre os problemas mais preocupantes podemos citar os distúrbios na linha, EFT (Eletrical Fast Transient), variações bruscas de tensão, e harmônicos nas linhas de energia. Dispositivos analógicos e digitais respondem diferentemente a esses distúrbios. Os dispositivos analógicos geralmente operam de acordo com níveis de tensão, que podem ser degradados por variações que alteram o nível de tensão referencia da fonte de energia do sistema. Já os dispositivos digitais são afetados por picos no sistema de energia (EFT), assim como falhas devido a níveis de tensões excessivamente altas ou baixas.[2]

- Compatibilidade Interna: Um assunto geralmente pouco lembrado é a compatibilidade própria do dispositivo. Um parte ou circuito digital pode interferir em dispositivos analógicos, criar "crosstalk" entre trilhas ou fios, ou, por exemplo, um motor interno pode causar falha em circuitos digitais. $\mathrm{O}$ reconhecimento destes problemas, junto com implementações que previnem falhas internas do sistema, ira resultar em um produto final mais barato e mais robusto.[2]

Muitas variáveis são responsáveis pela existência de interferência eletromagnética. Isso porque essa interferência geralmente é resultado de exceções no comportamento normal de componentes passivos de circuitos. Por exemplo, um indutor em altas freqüências atua como um indutor com um capacitor em paralelo com seus dois terminais. Estes comportamentos de componentes passivos em alta e baixa frequiência estão ilustrados na figura seguinte: 


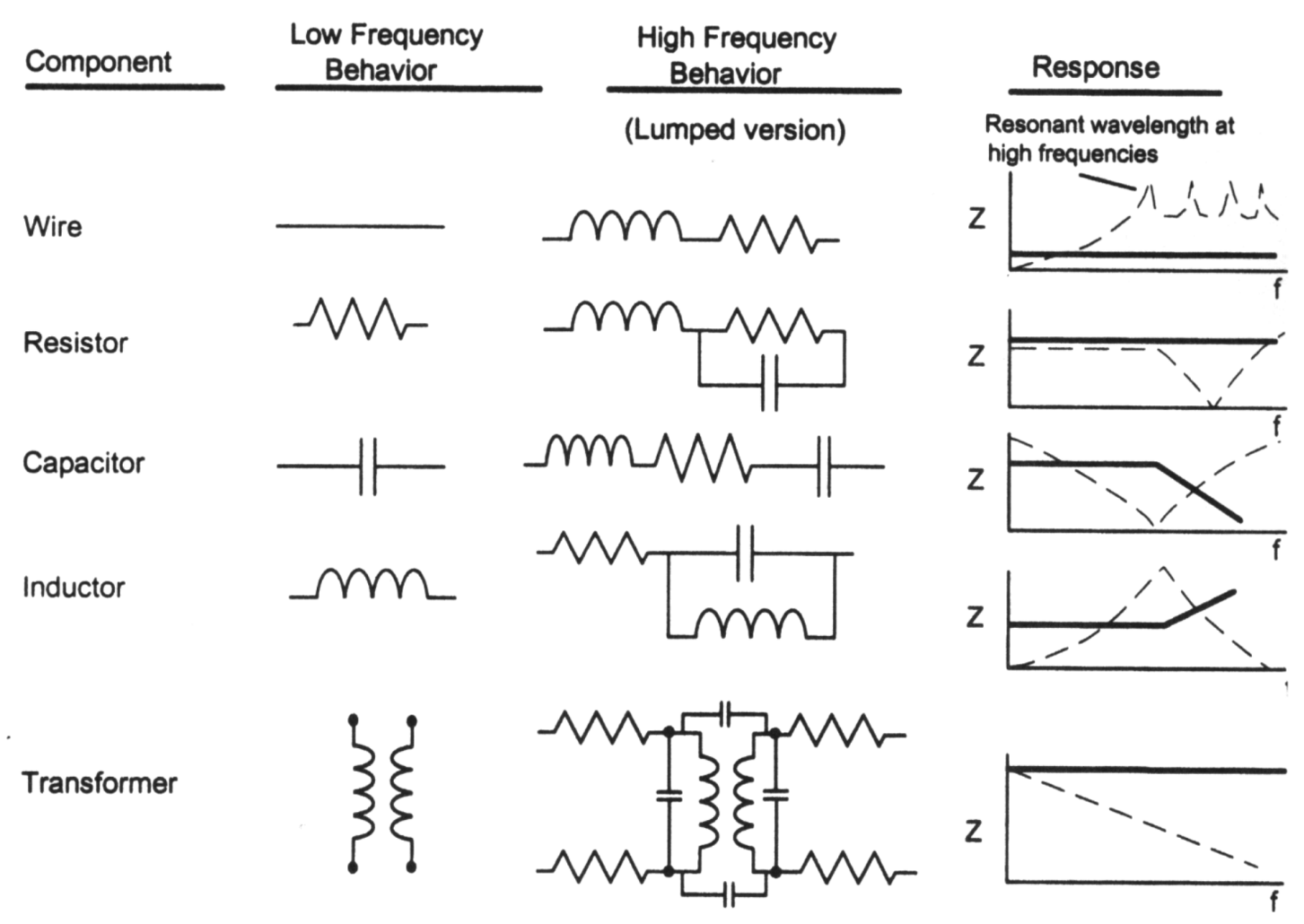

Figura 3.13 - Característica dos componentes passivos a freqüências de emissões em radiofreqüência.[2]

Para se tornar um projetista bem sucedido, devemos, portanto reconhecer as limitações destes elementos passivos de circuitos. O uso de técnicas apropriadas para a anulação destas características "obscuras" se torna imprescindível para que o produto alcance especificações funcionais estabelecidas pelo mercado. Engenheiros especializados na área digital, geralmente assumem que componentes possuem resposta em uma única freqüência. Como resultado, a seleção de componentes passivos é baseada na performance funcional no domínio do tempo, sem que sejam levadas em consideração as características exibidas no domínio da freqüência. [2]

Uma vez que o comportamento completo desses componentes seja compreendido, torna-se simples o processo de elaboração de produtos que atendam requisitos de compatibilidade eletromagnética. Quando temos um problema de interferência eletromagnética, devemos abordar a situação de maneira lógica identificando 3 elementos básicos: uma fonte de energia, um receptor afetado por essa energia e um meio de acoplamento entre fonte e receptor para que ocorra a transferência de energia. 
Para que a interferência ocorra, todos os 3 elementos acima citados devem estar presentes. Cabe, portanto ao engenheiro determinar qual o elemento mais fácil de ser eliminado. No caso de nosso hardware implementado, a solução encontrada foi projetar as placas de circuito impresso que eliminassem a maior parte das fontes de interferência por RF (Radio Frequency). Essa abordagem foi adotada por apresentar uma melhor relação custobenefício.

Dentre os cuidados para se anular ou amenizar as fontes de energia que causam interferência, nosso projeto teve especial cuidado com radiações de componentes que não possuem blindagens plástica e eletromagnética. Foi observado também o roteamento correto das trilhas, evitando trilhas eletricamente longas. O controle de impedância dos componentes e correta conexão interna de cabos também foram levados em consideração.

\section{3 - VALIDAÇÃO DO PROJETO ANALÓGICO}

\subsection{1 - Testes Realizados}

Com o objetivo de validar o hardware implementado, foi realizada uma série de testes para se observar o comportamento do circuito em termos de seus componentes discretos bem como seu funcionamento global e suas aplicações práticas. Os testes com os componentes individuais do circuito foram realizados no laboratório de eletrônica do departamento de Engenharia Elétrica da Faculdade de Tecnologia localizada na Universidade de Brasília. Tais testes foram realizados pelos próprios autores utilizando inicialmente um gerador de funções e um osciloscópio para se analisar de forma bem clara o comportamento de cada parte do circuito com relação ao ganho e a freqüência.

Inicialmente foi testada a parte do circuito relativo aos eletrodos de captação, parte esta responsável pelo primeiro estágio de amplificação do circuito. Foi injetada uma onda senoidal de amplitude $100 \mathrm{mV}$ pico a pico, em diferentes freqüências ao longo do espectro do sinal de EMG. Tal processo foi realizado em todos os canais da sonda. Foram utilizadas, portanto, ondas senoidais com freqüências $20 \mathrm{~Hz}, 50 \mathrm{~Hz}, 100 \mathrm{~Hz}, 150 \mathrm{~Hz}, 300 \mathrm{~Hz}$ e $500 \mathrm{~Hz}$ respectivamente com o objetivo de se verificar o ganho projetado de 10 vezes e o comportamento nessas diversas freqüências. As seguintes figuras exemplificam os testes realizados para a freqüência de $100 \mathrm{~Hz}$. Neste teste, podemos confirmar o esperado 
comportamento do circuito com um ganho bastante próximo do calculado, apresentando ainda mínimas distorções na componente freqüêncial utilizada.

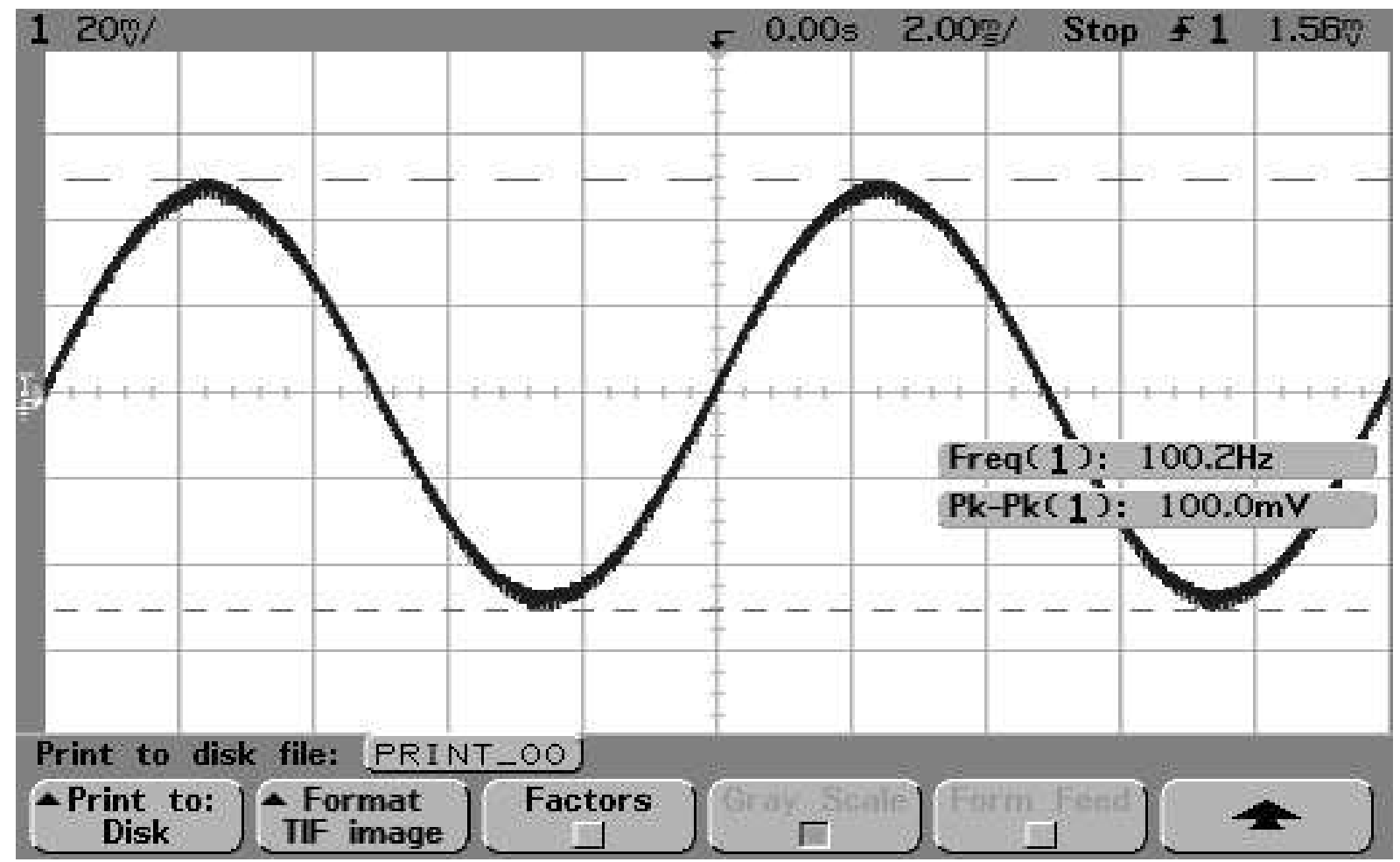

Figura 3.14 - Onda senoidal injetada nos canais do arranjo linear de 8 eletrodos.

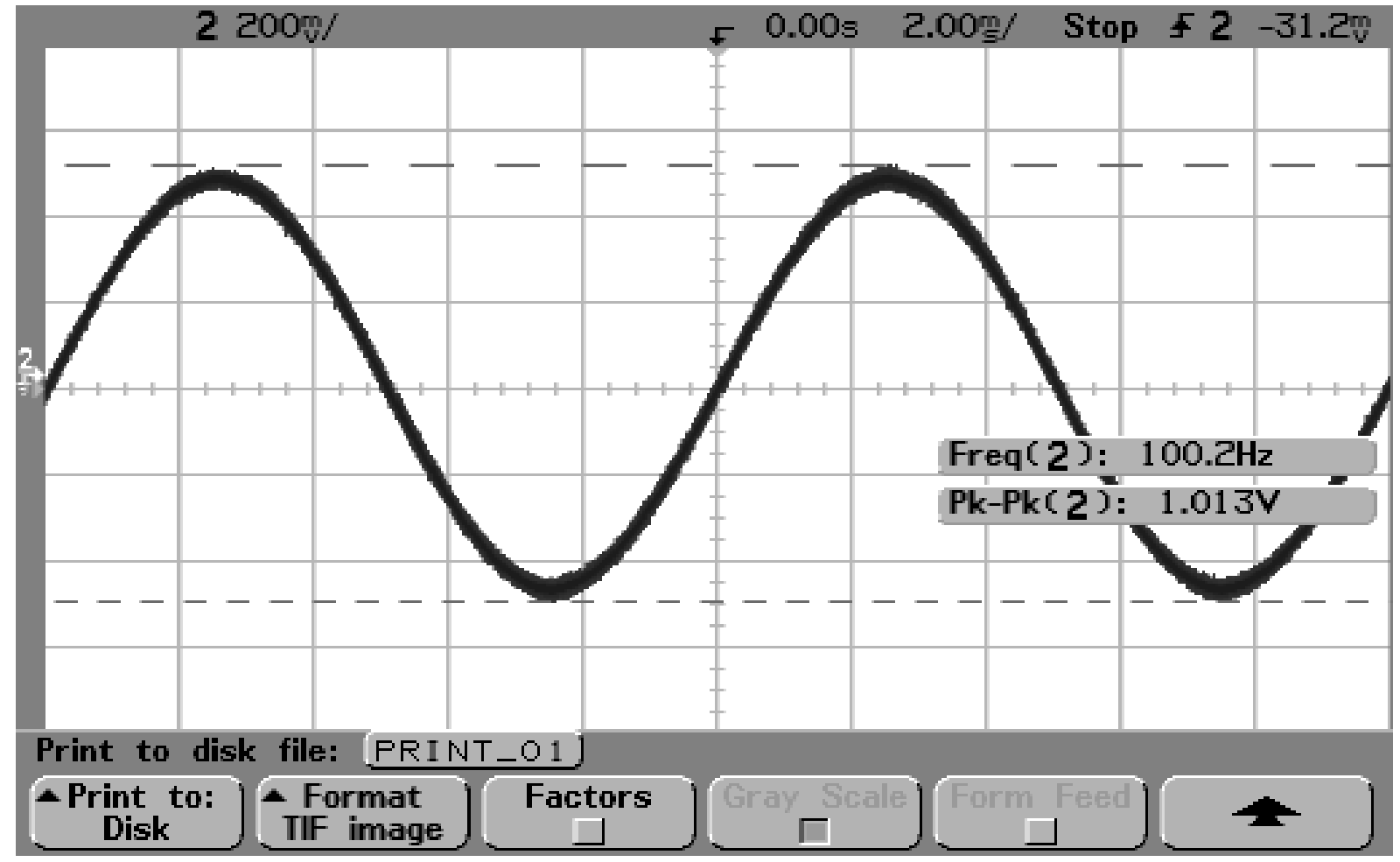

Figura 3.15 - Onda senoidal observada na saída do $1^{\circ}$ canal do arranjo linear de 8 eletrodos. 


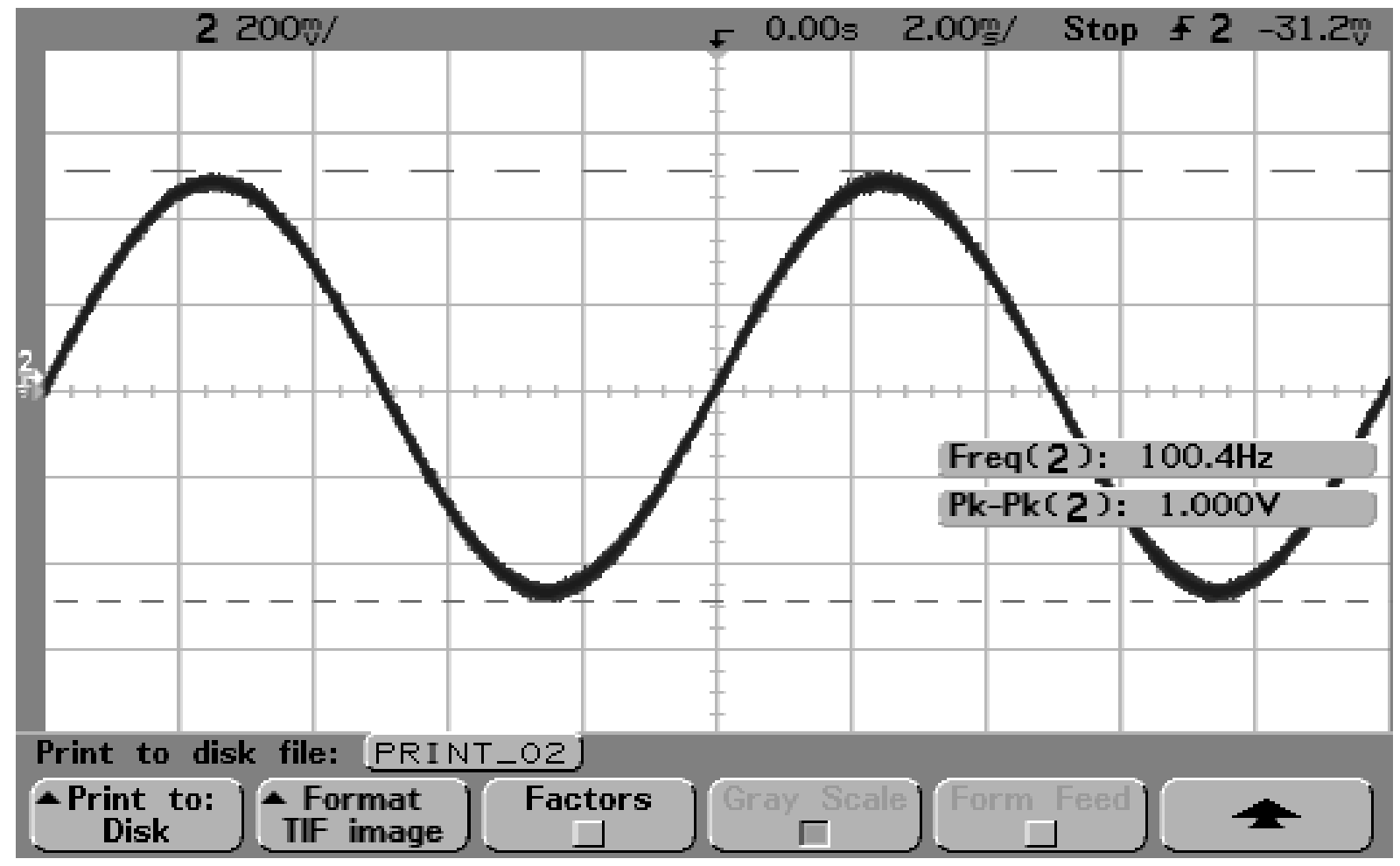

Figura 3.16 - Onda senoidal observada na saída do $2^{\circ}$ canal do arranjo linear de 8 eletrodos.

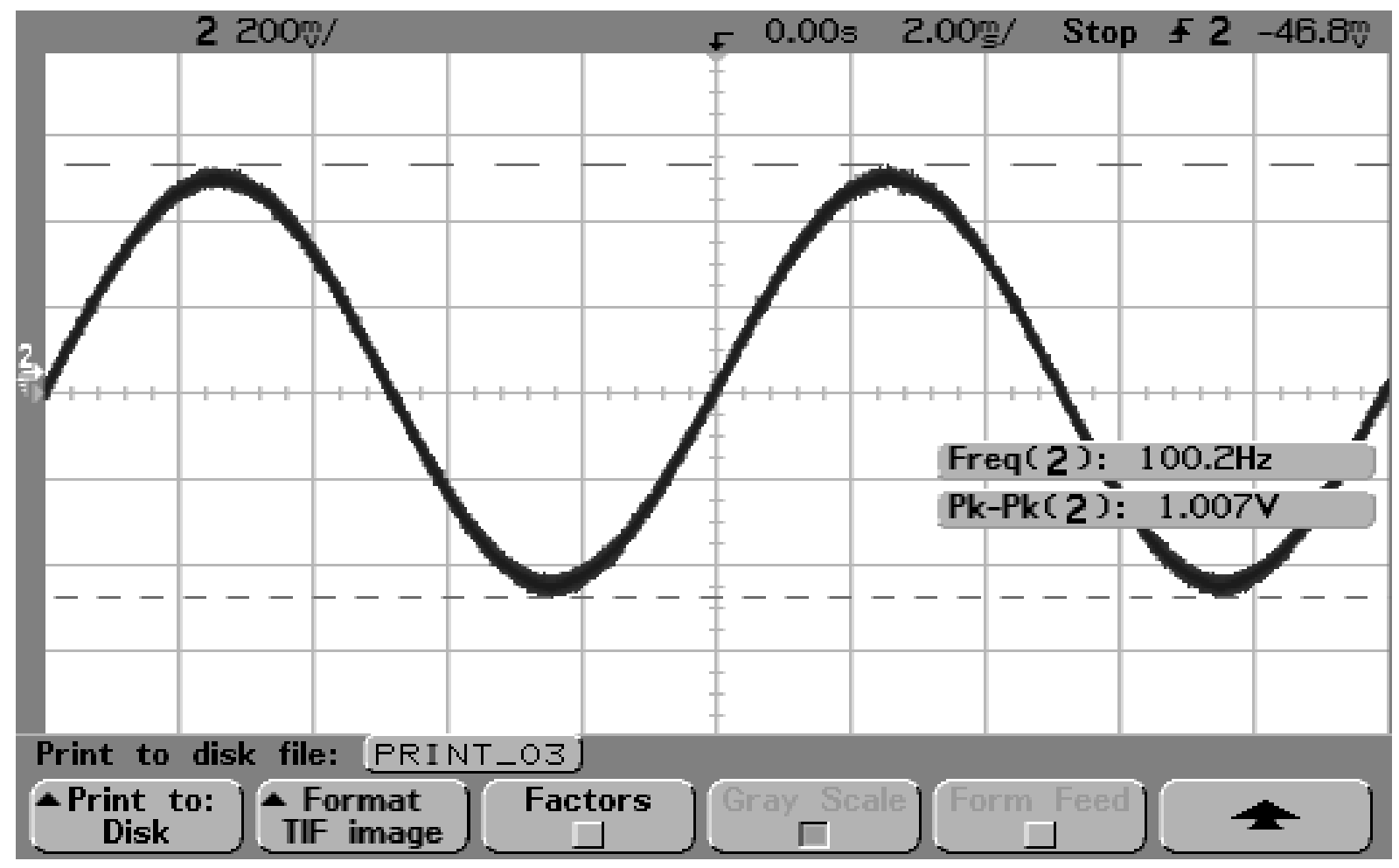

Figura 3.17 - Onda senoidal observada na saída do $3^{\circ}$ canal do arranjo linear de 8 eletrodos. 


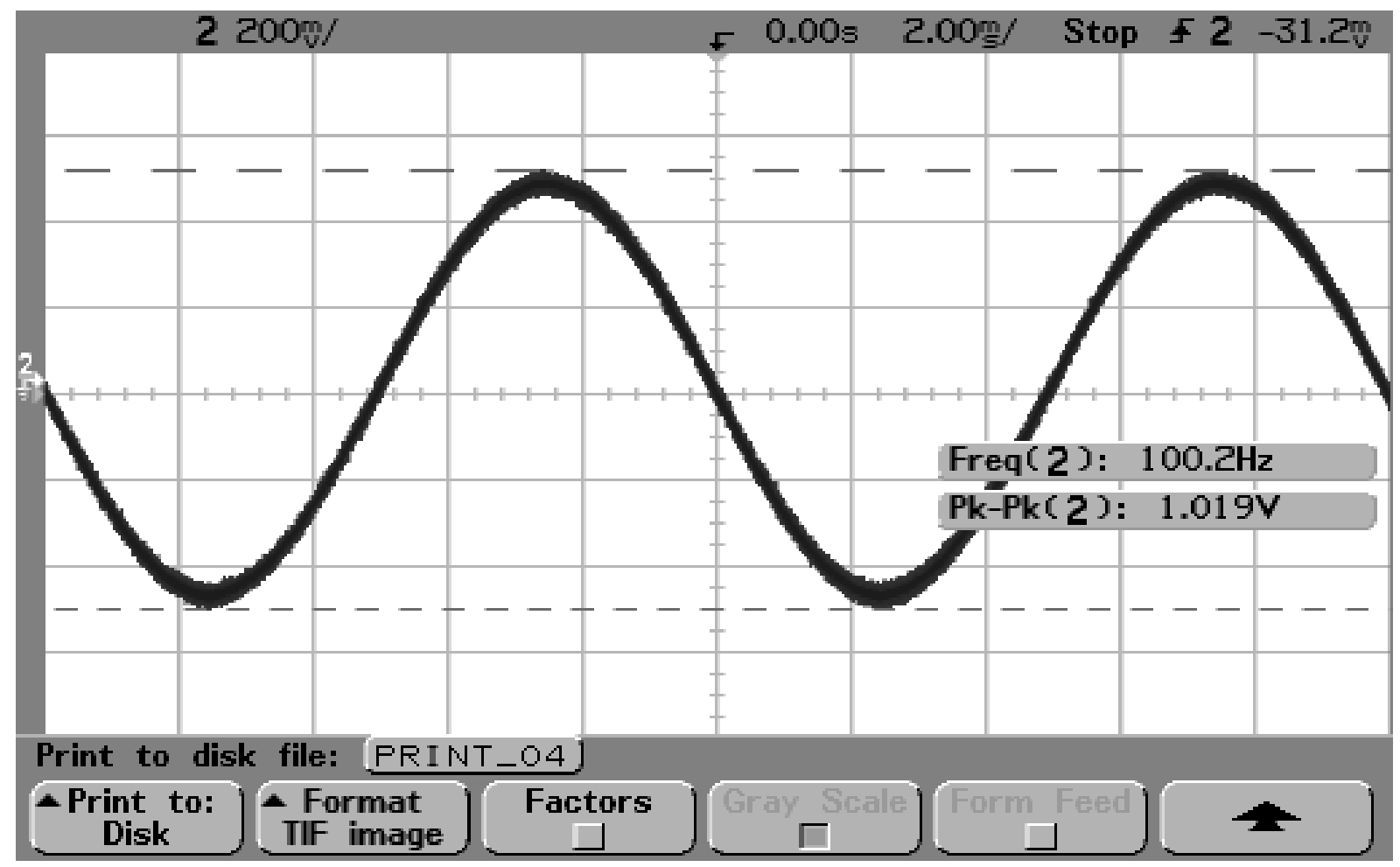

Figura 3.18 - Onda senoidal observada na saída do $4^{\circ}$ canal do arranjo linear de 8 eletrodos.

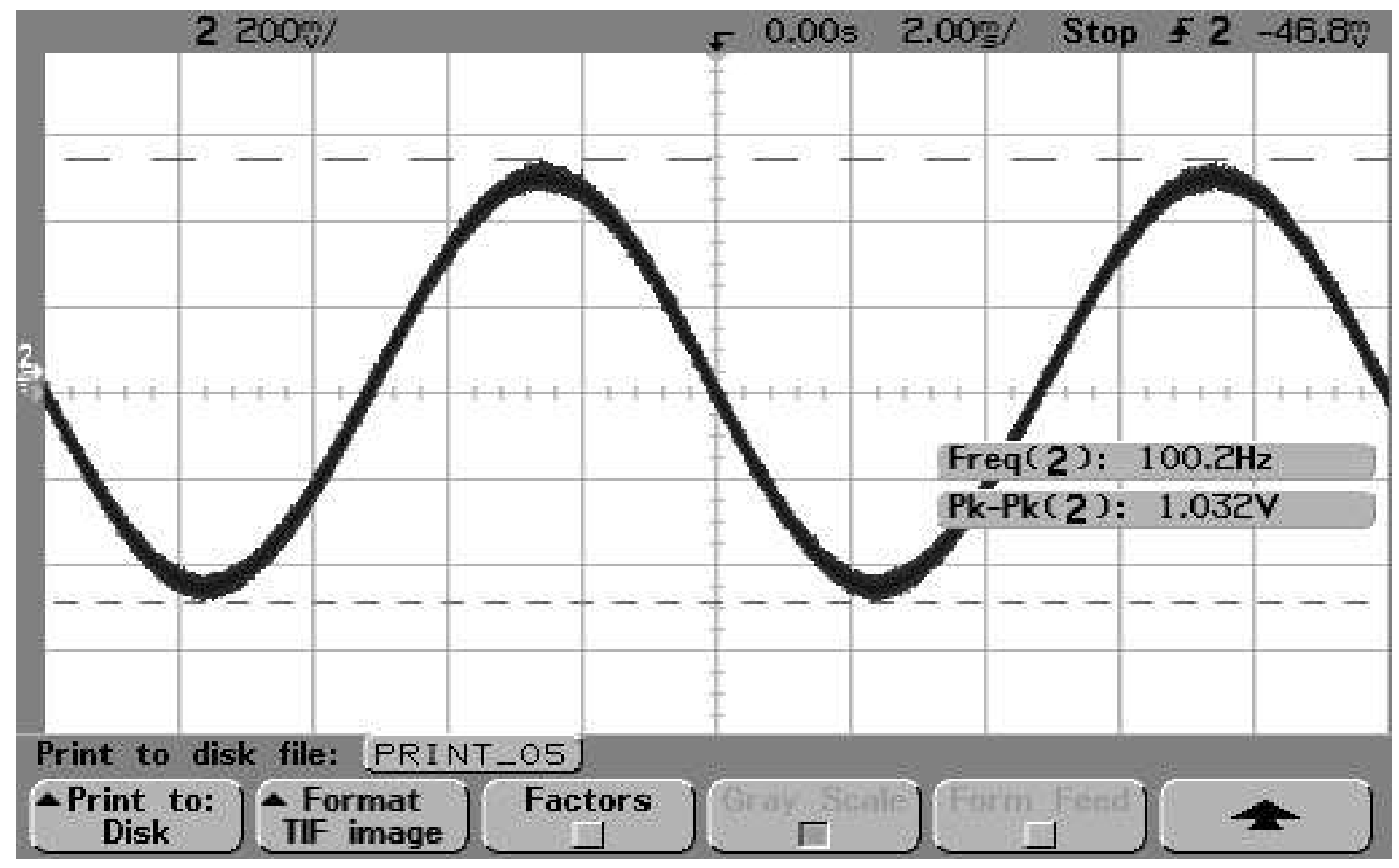

Figura 3.19 - Onda senoidal observada na saída do $5^{\circ}$ canal do arranjo linear de 8 eletrodos. 


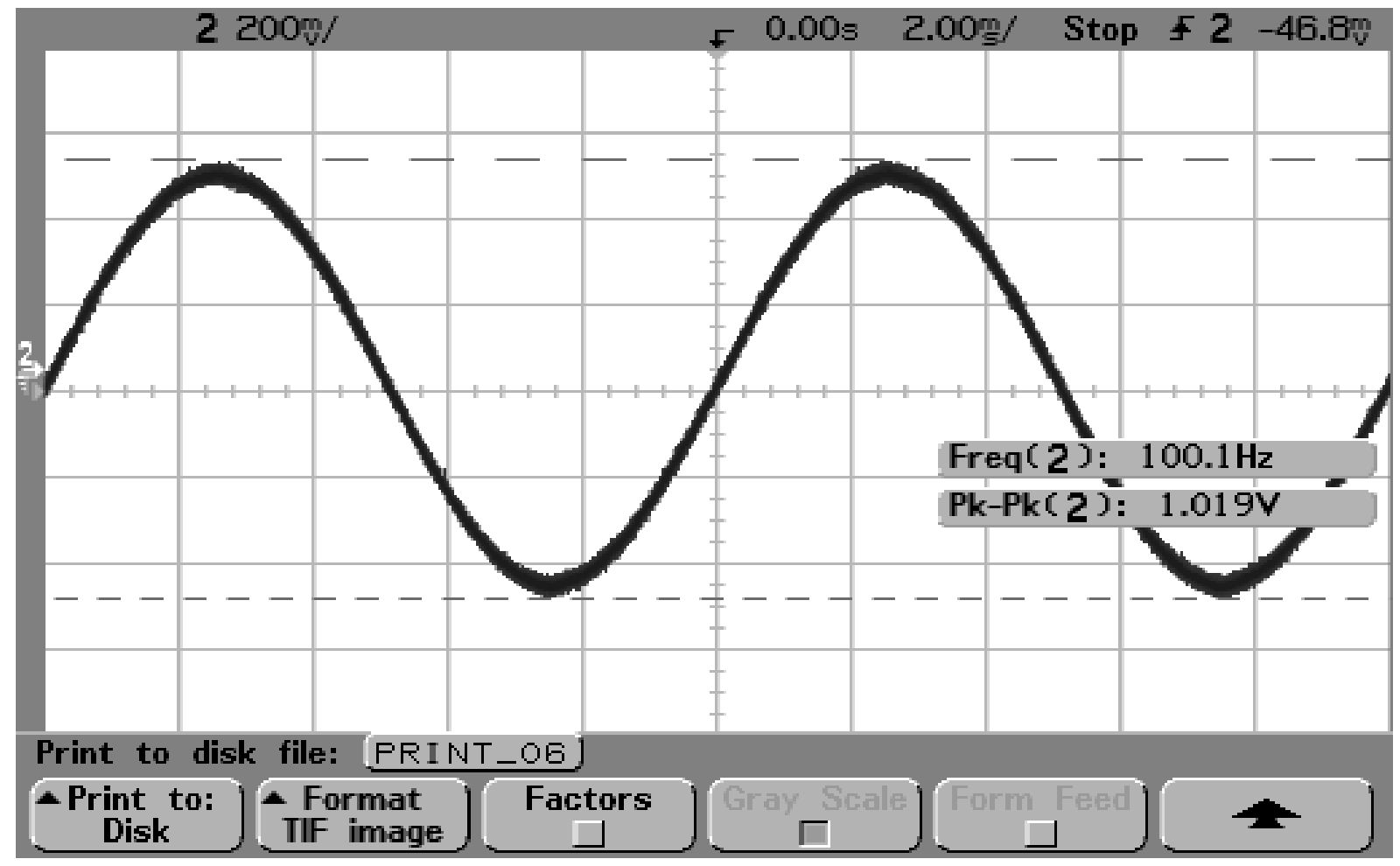

Figura 3.20 - Onda senoidal observada na saída do $6^{\circ}$ canal do arranjo linear de 8 eletrodos.

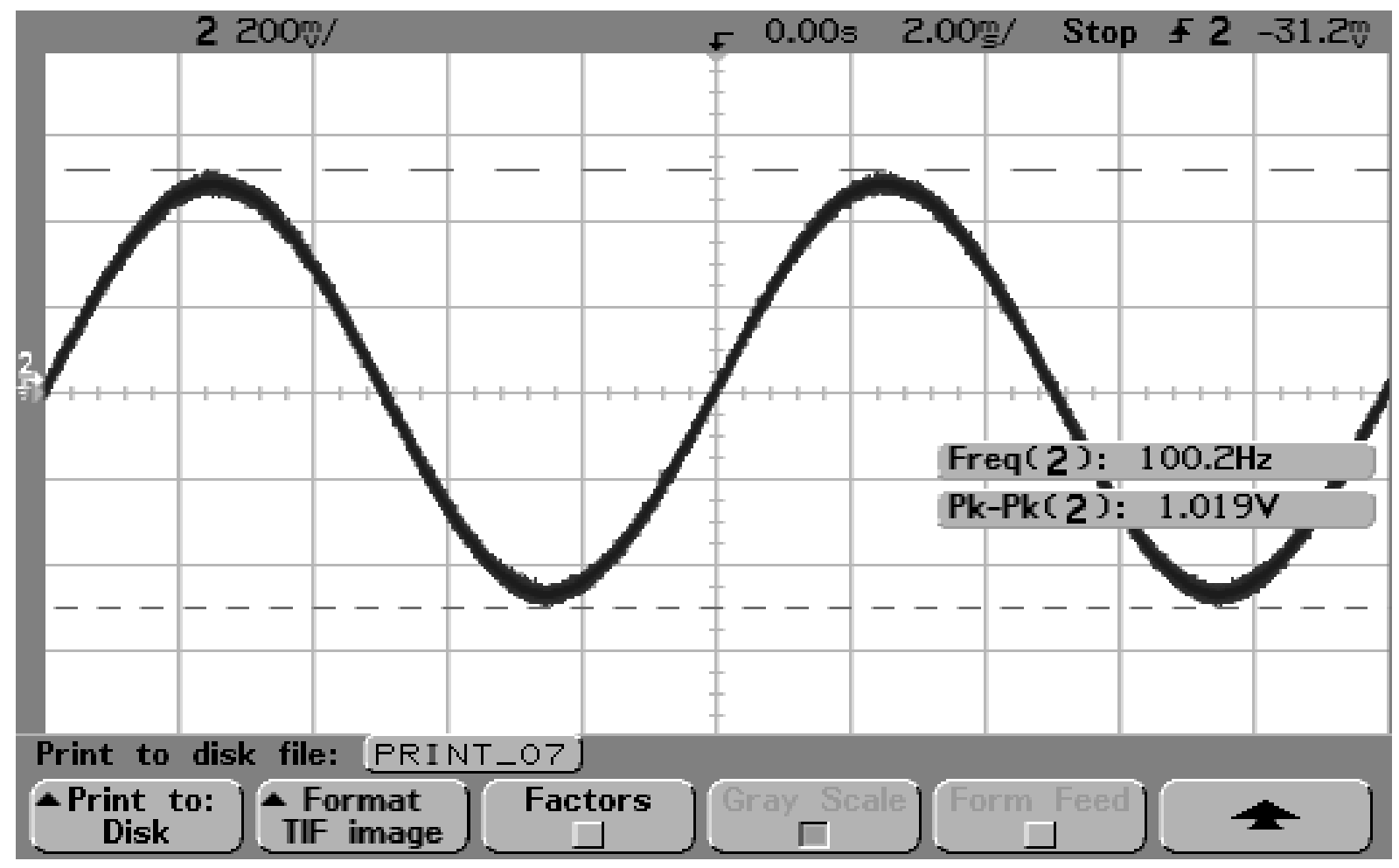

Figura 3.21 - Onda senoidal observada na saída do $7^{\circ}$ canal do arranjo linear de 8 eletrodos. 
Numa segunda parte de testes com os componentes discretos do eletromiógrafo desenvolvido, foi testado o funcionamento do condicionador de sinais, circuito responsável pelo segundo estágio de amplificação, bem como a filtragem do sinal de EMG-S capturado. Nessa bateria de testes, foi injetada uma onda senoidal de amplitude $20 \mathrm{mV}$ nas frequiências $20 \mathrm{~Hz}, 50 \mathrm{~Hz}, 100 \mathrm{~Hz}, 150 \mathrm{~Hz}, 300 \mathrm{~Hz}$ e $500 \mathrm{~Hz}$ em cada um dos canais do condicionador de sinais e foi capturado o valor apresentado nas respectivas saídas de cada canal. As figuras abaixo são relativas aos testes realizados utilizando a frequiência de $100 \mathrm{~Hz}$. No canal 1 pode ser observada a onda senoidal de freqüência $100 \mathrm{~Hz}$ com amplitude de $2.0 \mathrm{~V}$ pico a pico; essa onda, porém passa por um circuito divisor de tensão, sendo injetada na entrada dos canais do condicionador de sinais em um nível de tensão pequeno desejado, no caso $20 \mathrm{mV}$. Já canal 2, pode ser observado de fato a saída do sinal após o processo de filtragem e estágio de ganho de 220 vezes em cada um dos canais.

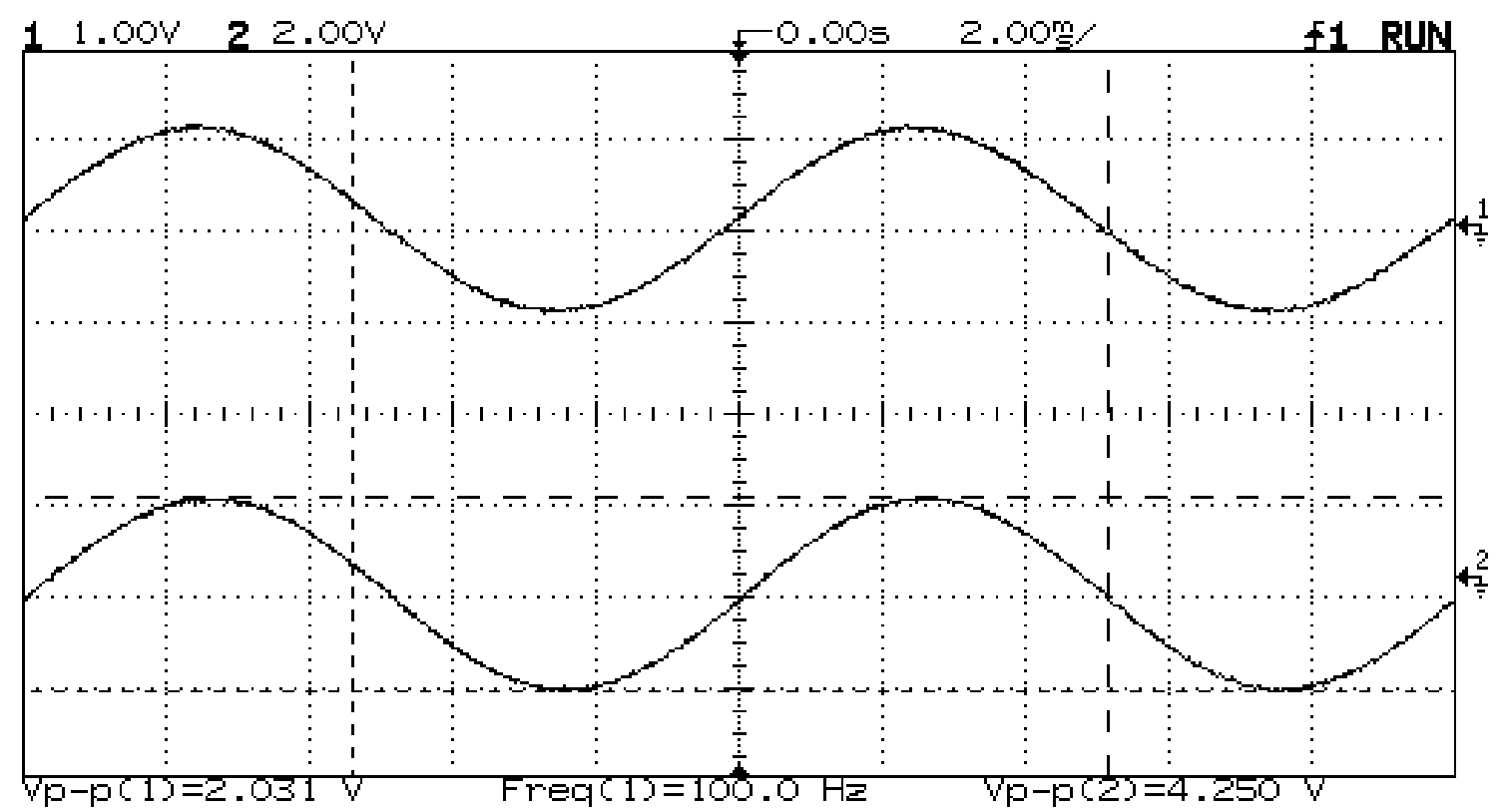

Figura 3.22 - Onda senoidal observada na saída do $1^{\circ}$ canal do condicionador de sinais. 


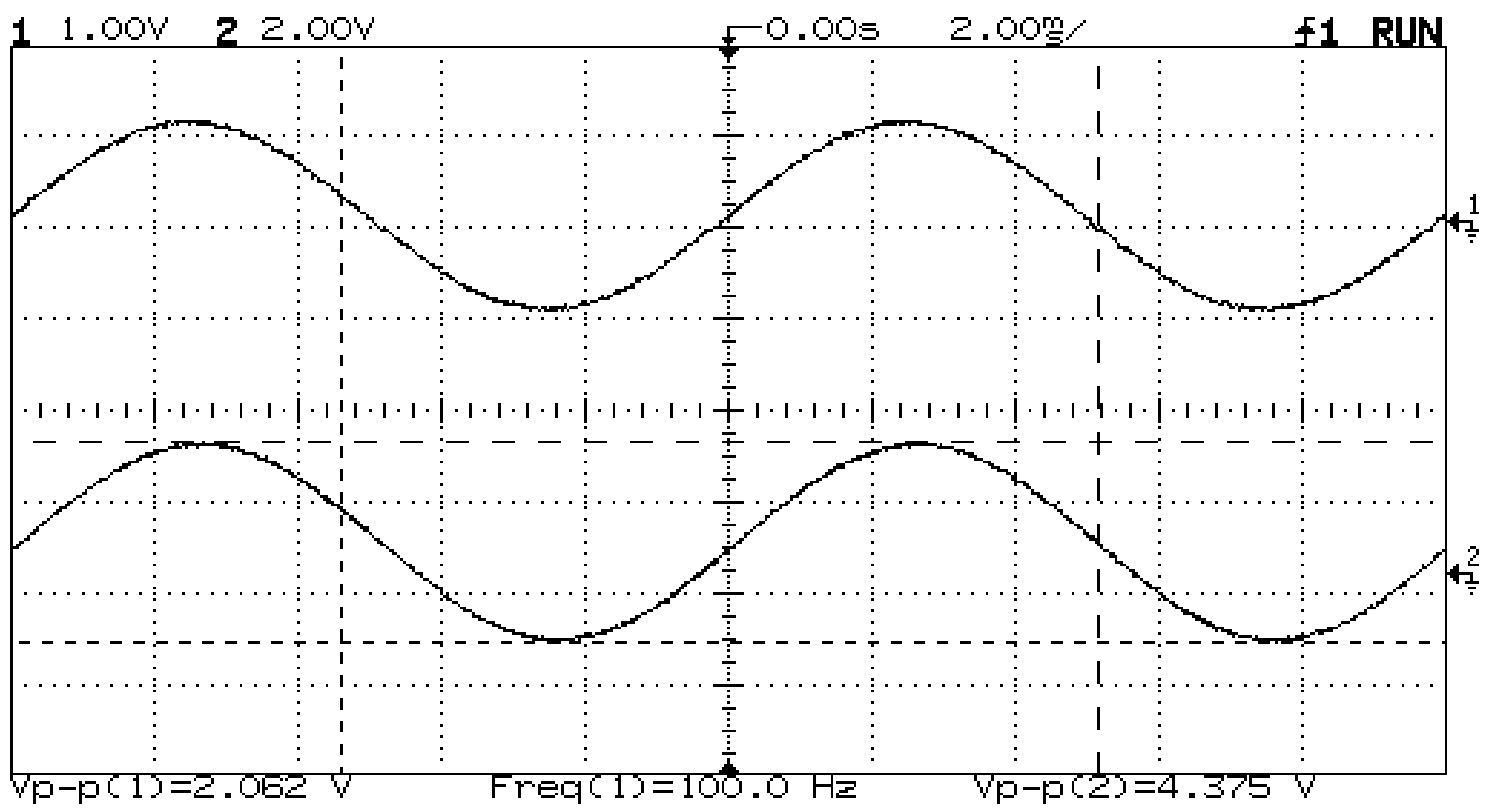

Figura 3.23 - Onda senoidal observada na saída do $2^{\circ}$ canal do condicionador de sinais.

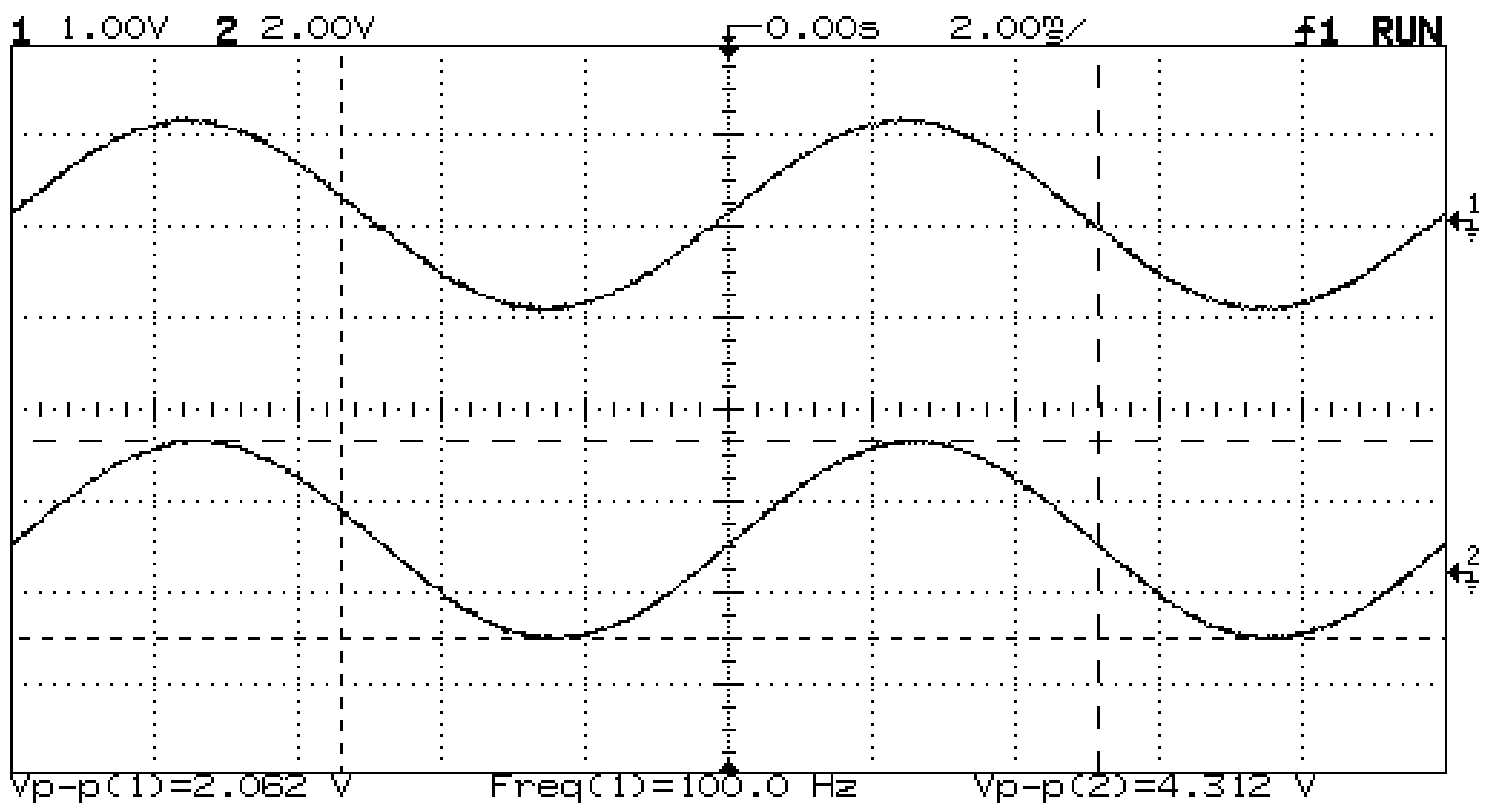

Figura 3.24 - Onda senoidal observada na saída do $3^{\circ}$ canal do condicionador de sinais. 


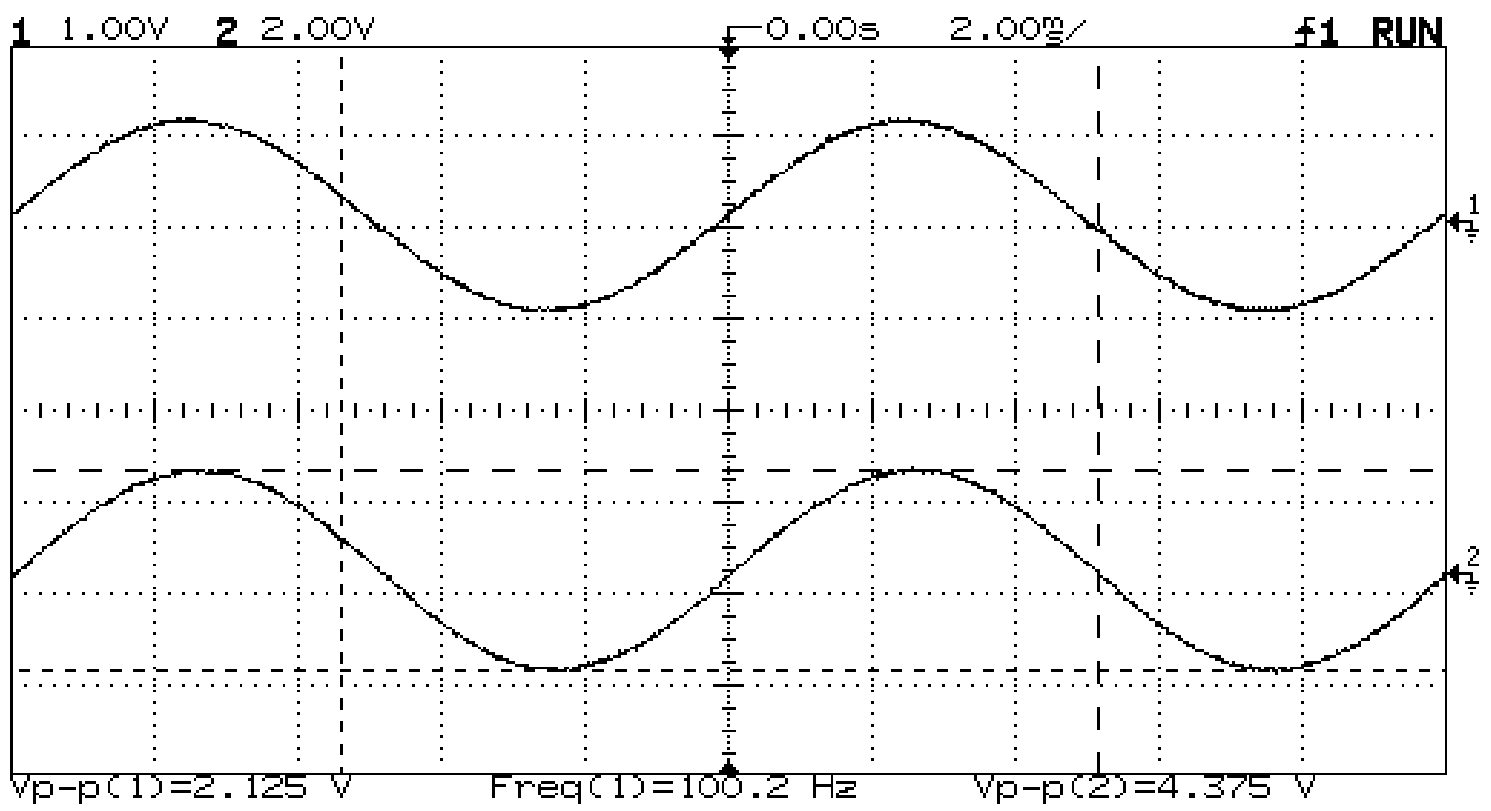

Figura 3.25 - Onda senoidal observada na saída do $4^{\circ}$ canal do condicionador de sinais.

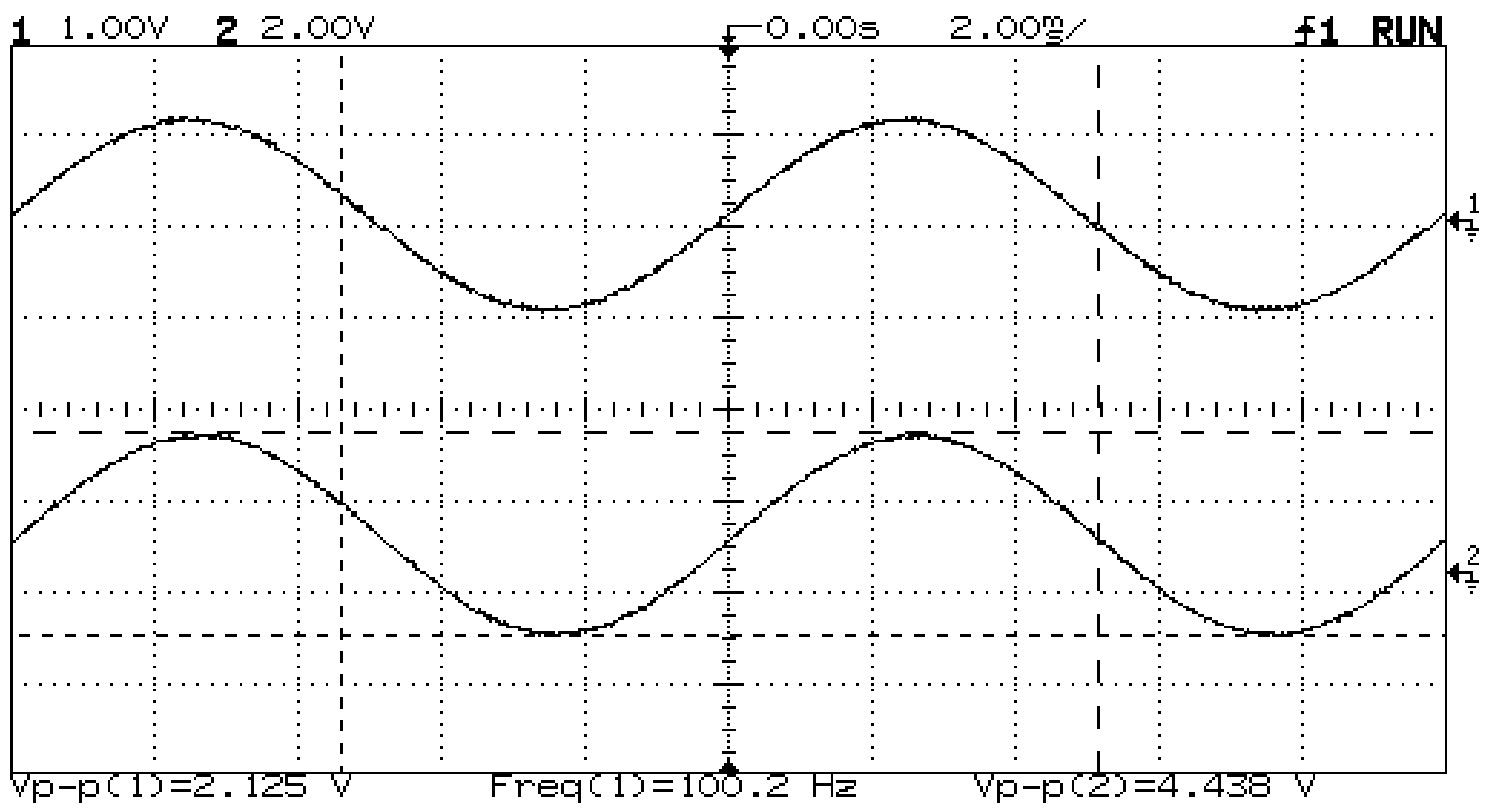

Figura 3.26 - Onda senoidal observada na saída do $5^{\circ}$ canal do condicionador de sinais. 


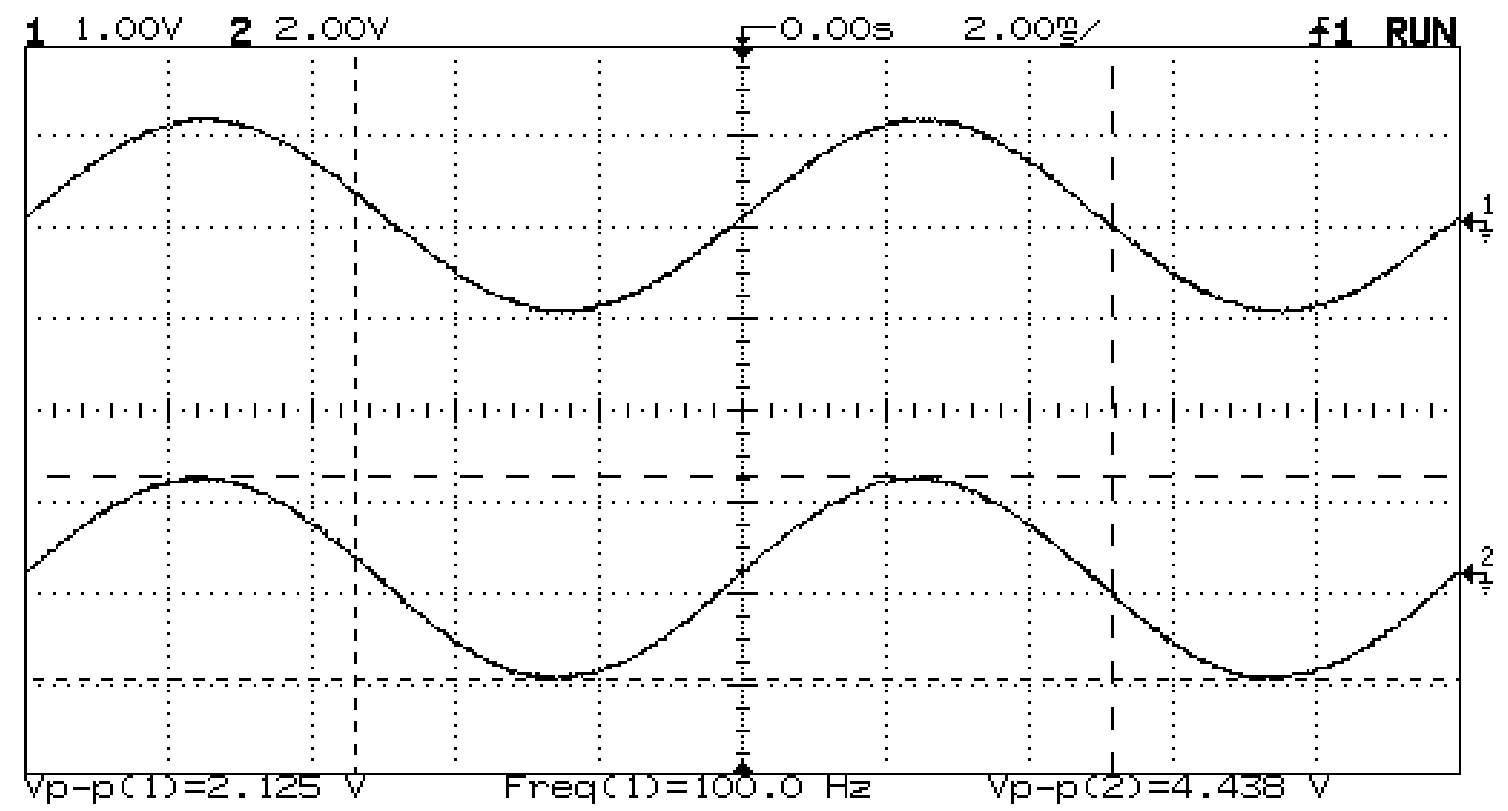

Figura 3.27 - Onda senoidal observada na saída do $6^{\circ}$ canal do condicionador de sinais.

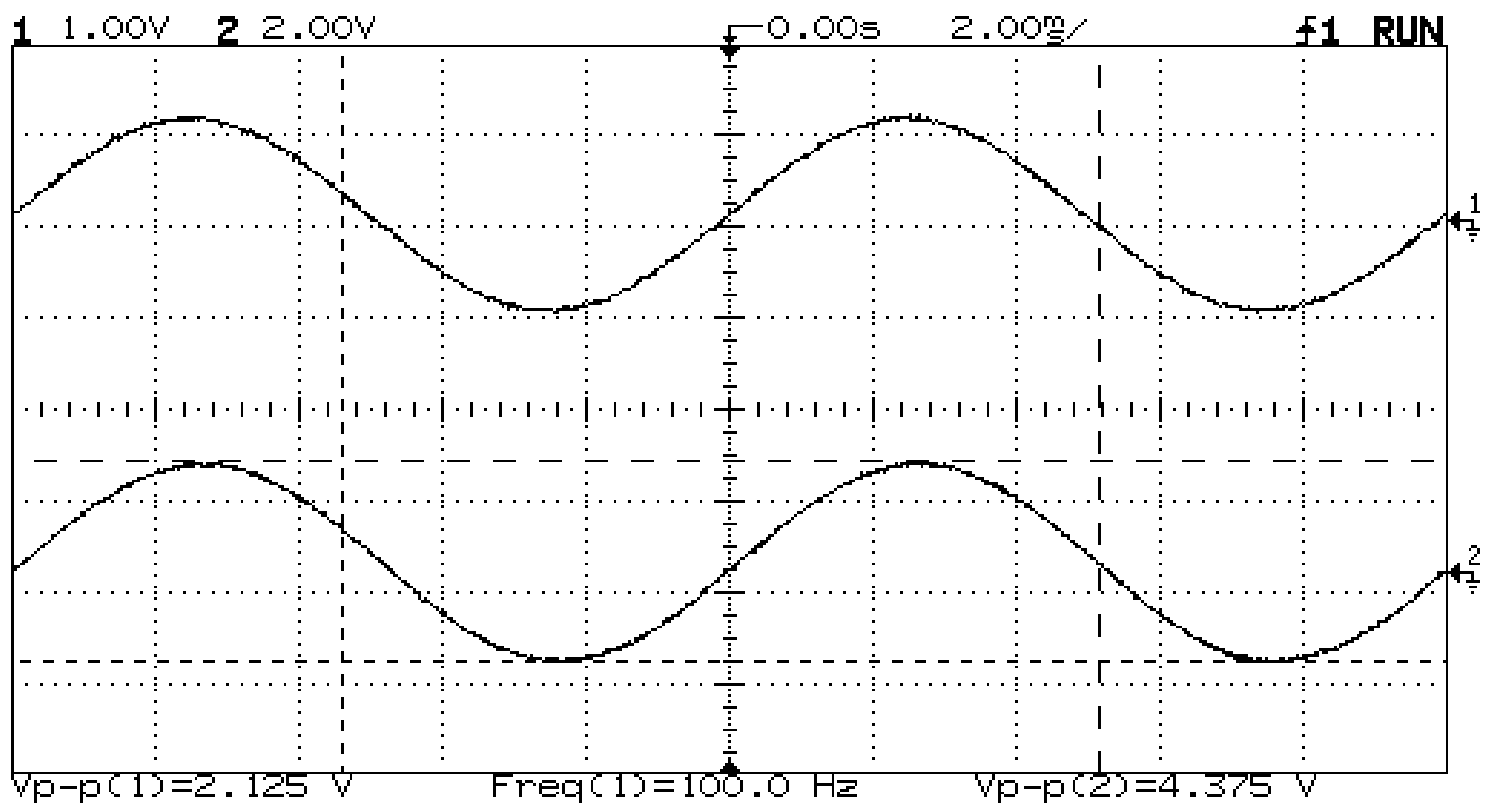

Figura 3.28 - Onda senoidal observada na saída do $7^{\circ}$ canal do condicionador de sinais.

Após os resultados satisfatórios obtidos nos testes realizados em partes distintas do eletromiógrafo, passamos para uma segunda fase de testes em que comprovamos agora o funcionamento do circuito por completo; ou seja, com ambos os estágios de tratamento do sinal de EMG-S detectado.

Com o objetivo de comprovar o funcionamento global do circuito projetado, realizamos testes diretamente no bíceps de voluntários, levando em consideração somente a presença de atividade eletromiográfica no sujeito em estudo, não havendo um rígido controle 
de vários parâmetros para a aquisição do sinal de EMG, tais como força aplicada na contração isométrica, preparo cuidadoso da região a ser estudada e posicionamento do eletrodo no músculo estudado. Estes testes foram também realizados no laboratório de eletrônica do departamento de Engenharia Elétrica da Faculdade de tecnologia na Universidade de Brasília, utilizando-se unicamente de um osciloscópio e de eletrodo para referência (Kendall, Meditrace, diâmetro de 10mm, EUA). 
As contrações isométricas a seguir foram realizadas ao longo de 3 segundos no bíceps braquial cabeça curta direito dos sujeitos e posteriormente passaram por uma análise espectral feita no próprio osciloscópio utilizado para a obtenção do sinal.

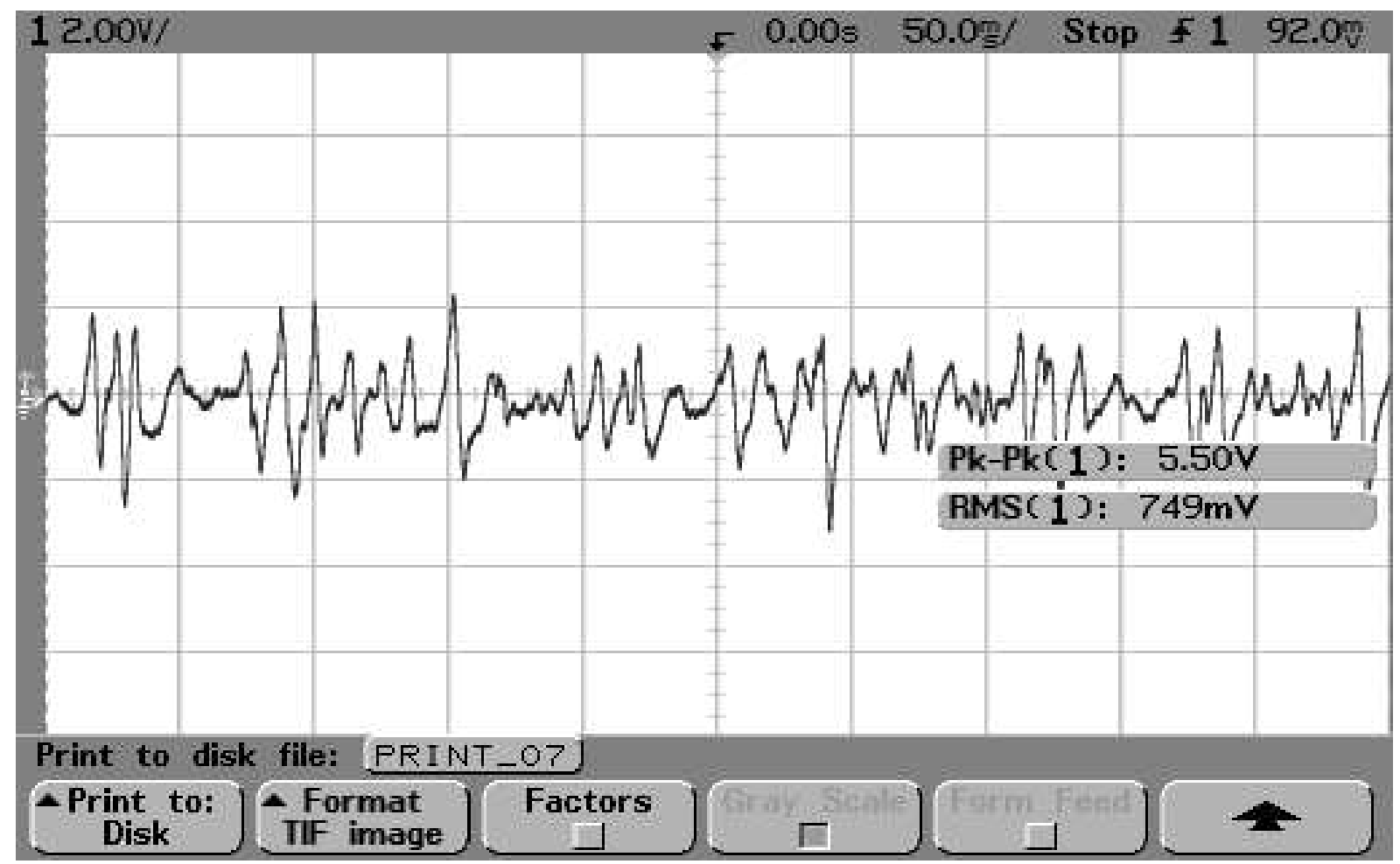

Figura 3.29 - Sinal de EMG-S captado no bíceps braquial cabeça curta do sujeito 1.

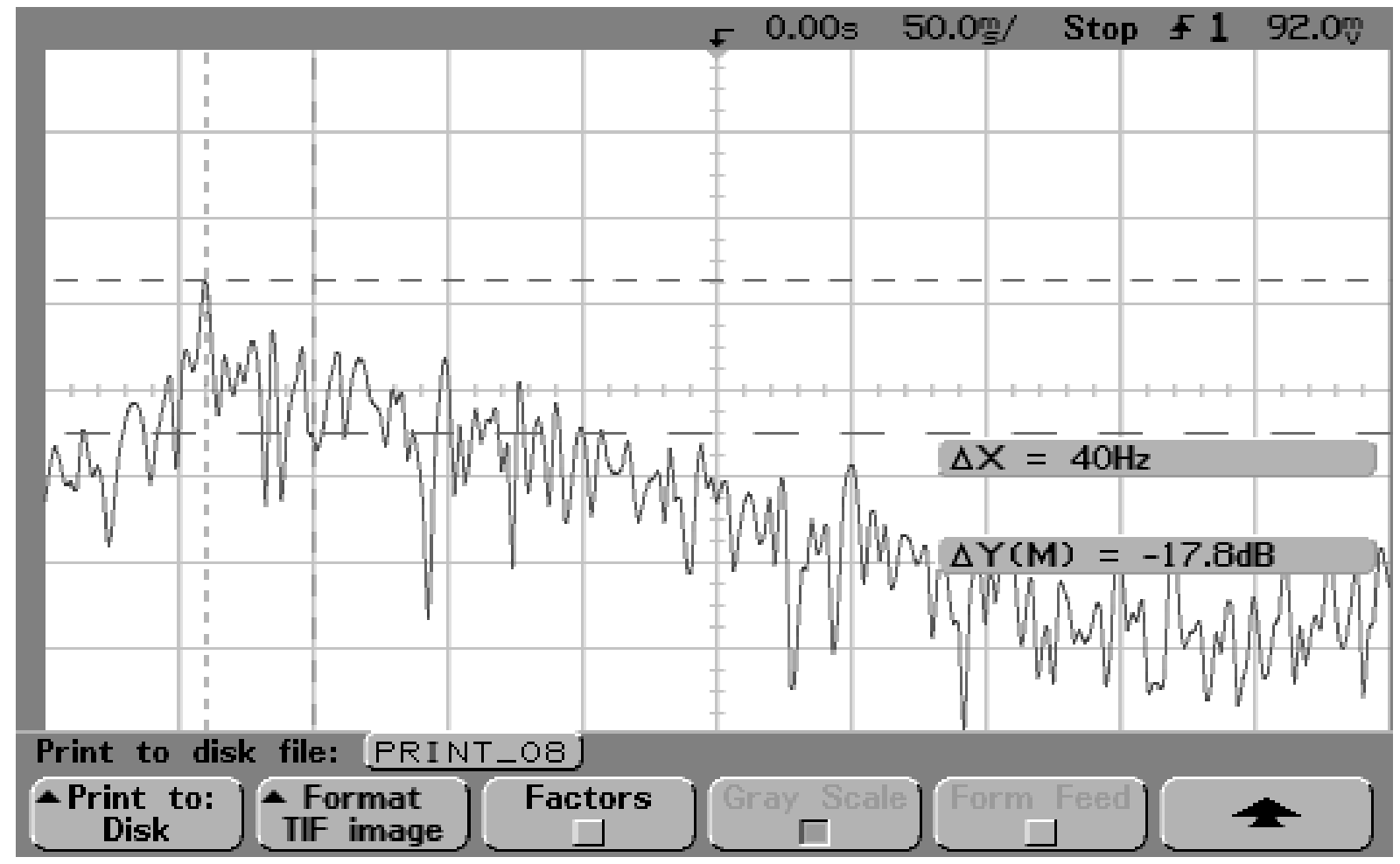

Figura 3.30 - Espectro do sinal de EMG-S captado no bíceps braquial cabeça curta do sujeito 1. 


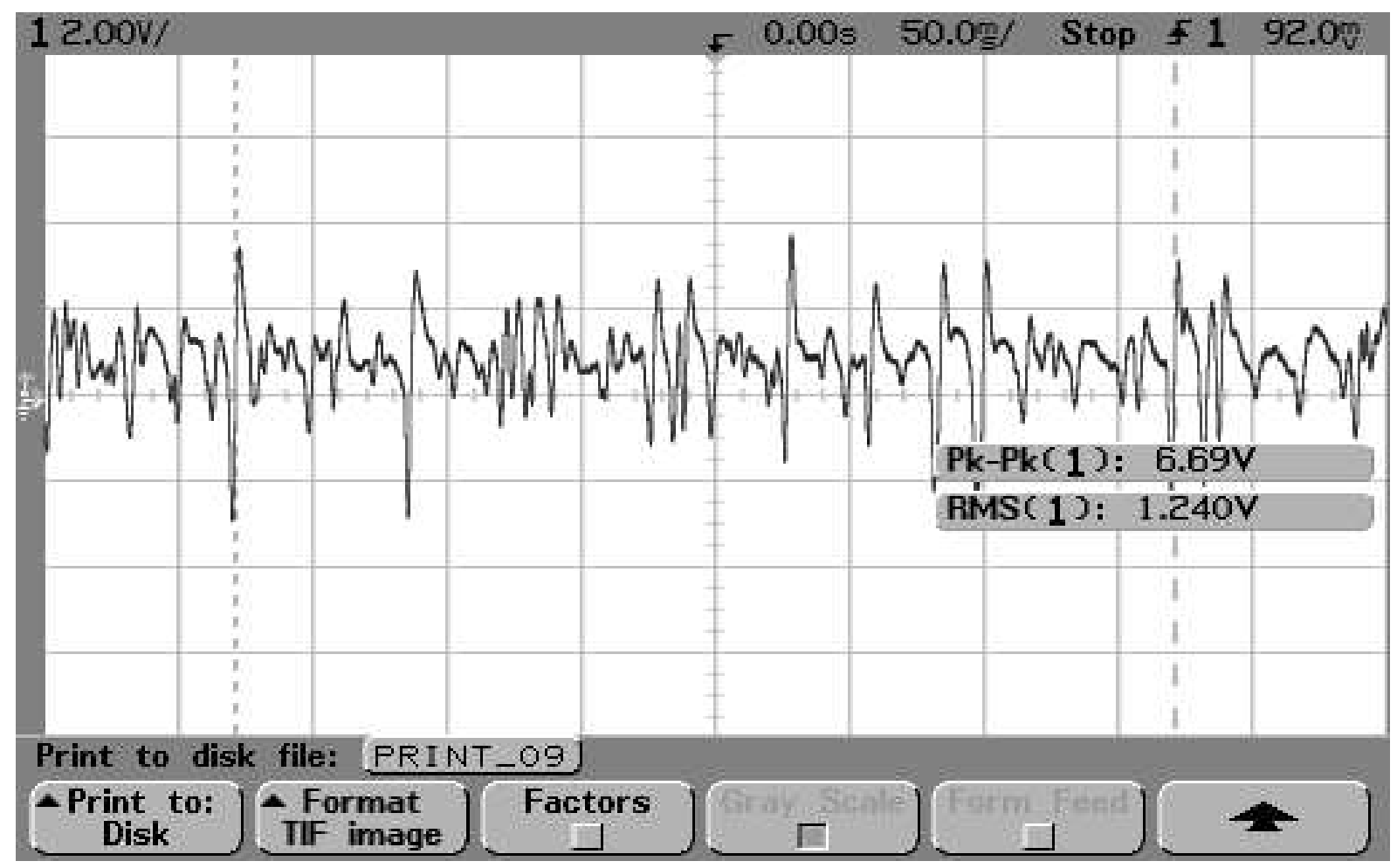

Figura 3.31 - Sinal de EMG-S captado no bíceps braquial cabeça curta do sujeito 2.

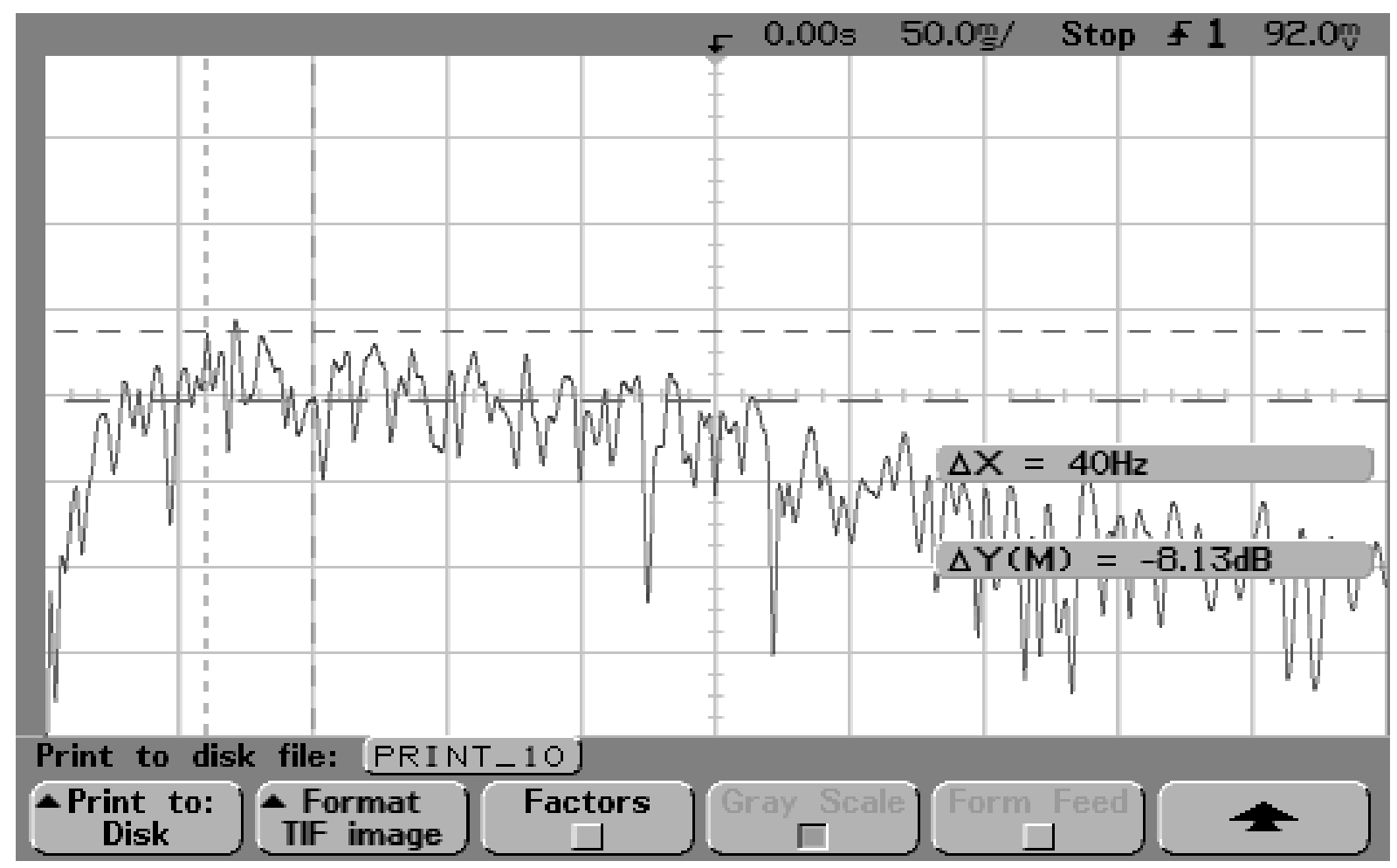

Figura 3.32 - Espectro do sinal de EMG-S captado no bíceps braquial cabeça curta do sujeito 2.

Através da análise dos dados obtidos, podemos confirmar que o circuito funciona exatamente dentro de suas especificações de projeto. Pelo sinal de EMG-S bruto captado, podemos verificar o bom nível de amplitude alcançado pelo sinal, o que valida o valor de 
ganho do sistema que foi previamente projetado. Mas é através da análise espectral deste sinal que podemos perceber exatamente o comportamento correto do eletromiógrafo. A energia significante do sinal está limitada à faixa de freqüência de 0 a $500 \mathrm{~Hz}$, com a energia dominante do sinal estando na faixa de frequiência de $50 \mathrm{~Hz}$ a $150 \mathrm{~Hz}$.

Podemos verificar também uma boa imunidade do sistema implementado ao indesejável ruído de linha; fato este que pode ser verificado através das informações presentes nos gráficos dos espectros. Foram utilizados cursores de marcação para indicar a frequiência de $60 \mathrm{~Hz}$ e compará-la a uma componente espectral dominante, no caso $100 \mathrm{~Hz}(\Delta \mathrm{X}=40 \mathrm{~Hz})$. Nesta comparação, vemos que a componente de $100 \mathrm{~Hz}$ possui uma atenuação de apenas $8.13 \mathrm{~dB}$ com relação à componente de $60 \mathrm{~Hz}$, o que pode ser considerado aceitável se for levado em consideração o ambiente extremamente sujeito a influência de ruídos de linha em que foram realizados tais testes, além da própria susceptibilidade do osciloscópio utilizado a este fenômeno.

Finalmente, foi realizada uma última bateria de testes, com o objetivo de verificar a aplicabilidade do arranjo de eletrodos desenvolvido. Está última seção de testes teve, portanto o objetivo de comprovar a viabilidade utilização do eletromiógrafo nas análises de sinais obtidos de múltiplos canais de aquisição. Análise estas previamente discutidas. Infelizmente, como o osciloscópio disponível no laboratório apresenta somente duas entradas, ficamos limitados à verificação de somente dois canais do eletromiógrafo funcionando simultaneamente. Desta vez, o sinal foi captado no bíceps braquial cabeça curta do braço direito do próprio pesquisador durante uma contração isométrica de 3 segundos de duração. 


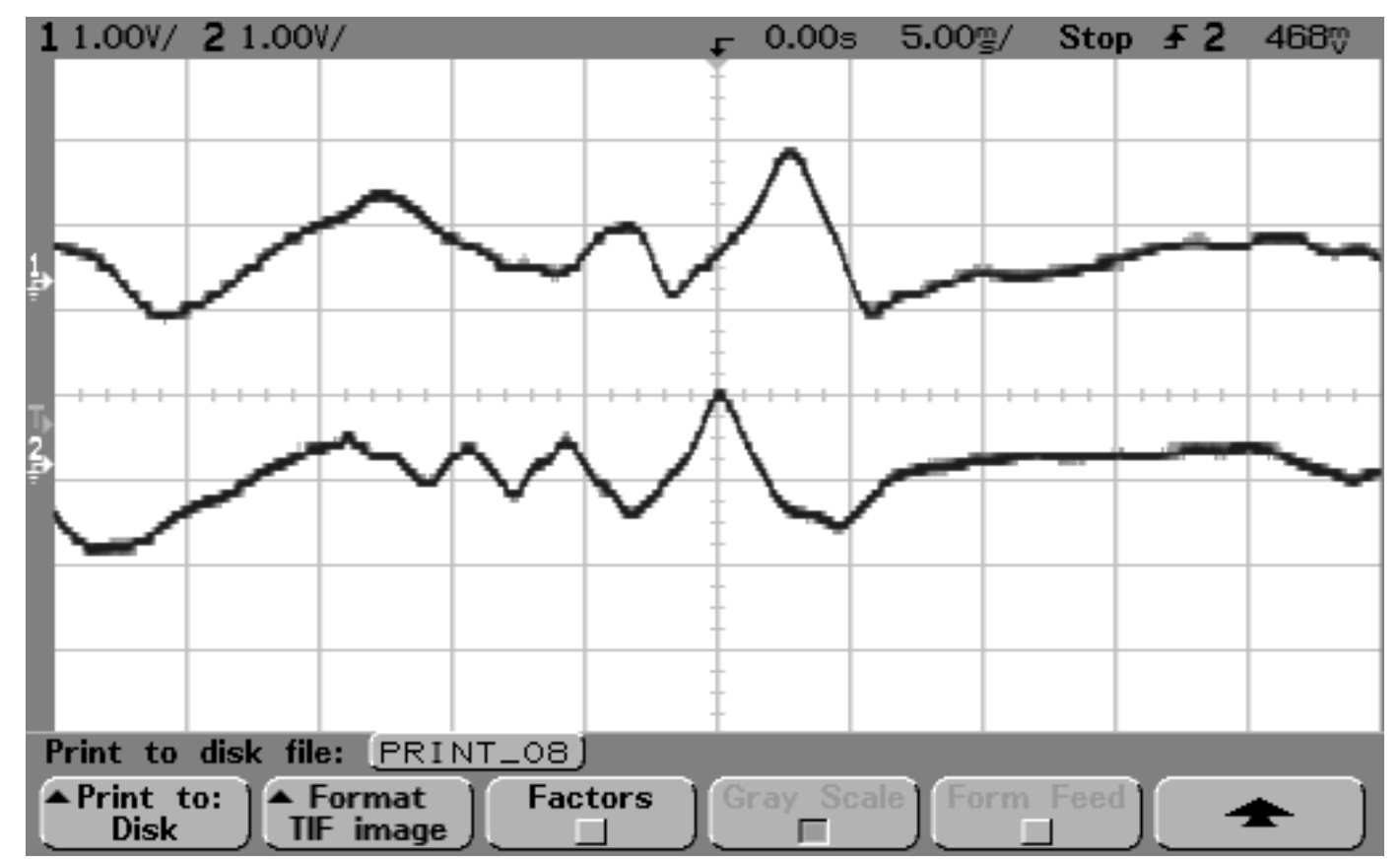

Figura 3.33 - Sinal de EMG-S captado em dois canais consecutivos durante uma contração isométrica do bíceps braquial cabeça curta.

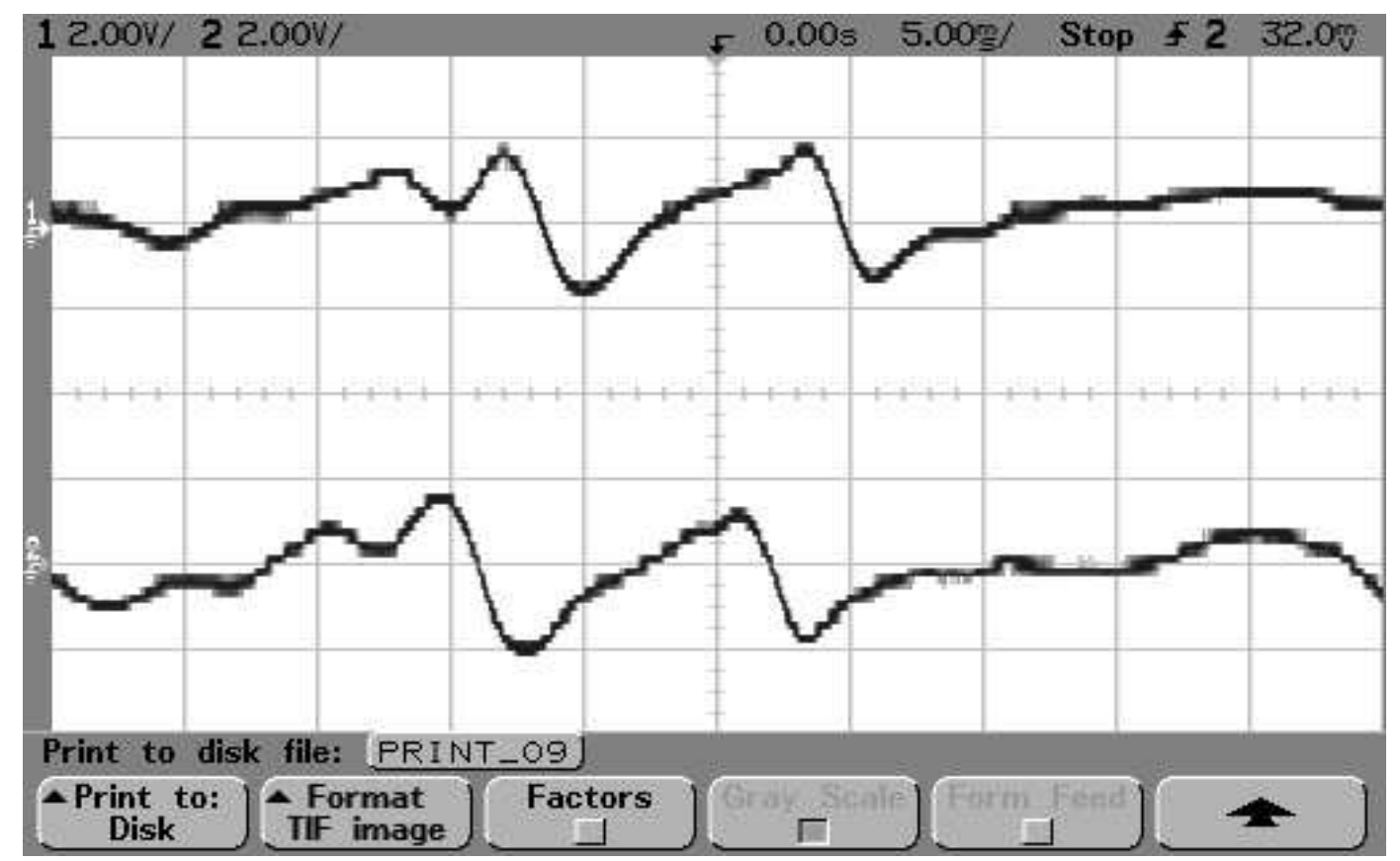

Figura 3.34 - Sinal de EMG-S captado em dois canais consecutivos durante uma contração isométrica do bíceps braquial cabeça curta.

\subsection{2 - Análise dos Resultados Obtidos}

Após uma minuciosa análise dos componentes discretos do circuito em laboratório, partiu-se para a verificação do funcionamento do eletromiografo em suas condições reais de utilização. Através de testes realizados no Laboratório de Biomecânica da Faculdade de 
Educação Física na Universidade de Brasília, tentou-se comprovar a aplicabilidade de um arranjo linear de eletrodos. Ou seja, tentou-se verificar a qualidade e a capacidade de nosso hardware de atuar na decomposição de sinais eletromiográficos, na determinação da velocidade de condução de MUAPT's e na localização de zonas de enervação.

Essa etapa de teste consistiu na captação do sinal eletromiográfico no bíceps braquial cabeça curta de um voluntário através do arranjo linear de sete canais. Foram realizadas contrações isométricas de flexão com duração de 1s, com o cotovelo do sujeito a um ângulo articular de $90^{\circ}$. Os dados foram amostrados a uma taxa de $1.024 \mathrm{~Hz}$ e convertidos em sinal digital por uma placa de aquisição de sete canais e 12 bits (PCI-6024E, National Instruments, Austin, EUA). Os sinais foram adquiridos por meio de um software desenvolvido em ambiente Labview 7 (National Instruments, EUA) e executado em sistema operacional Windows XP (Microsoft, EUA). O processamento dos dados capturados foi realizado no software MatLab 7 (The MathWorks Inc., USA) através de códigos especialmente desenvolvidos para análise do arranjo linear em estudo. 


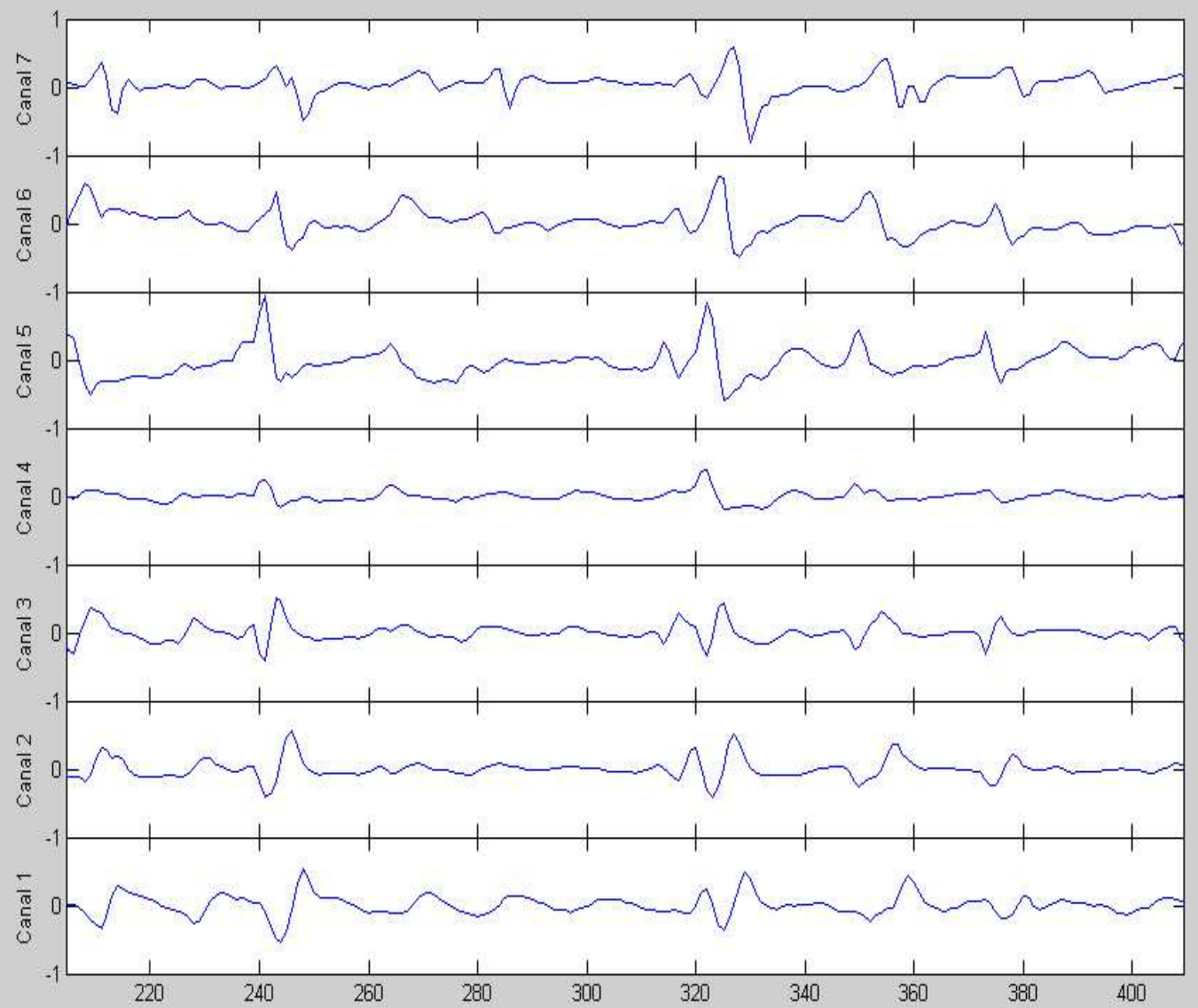

Figura 3.35 - Trecho de EMG-S bruto de uma contração isométrica no bíceps braquial. 


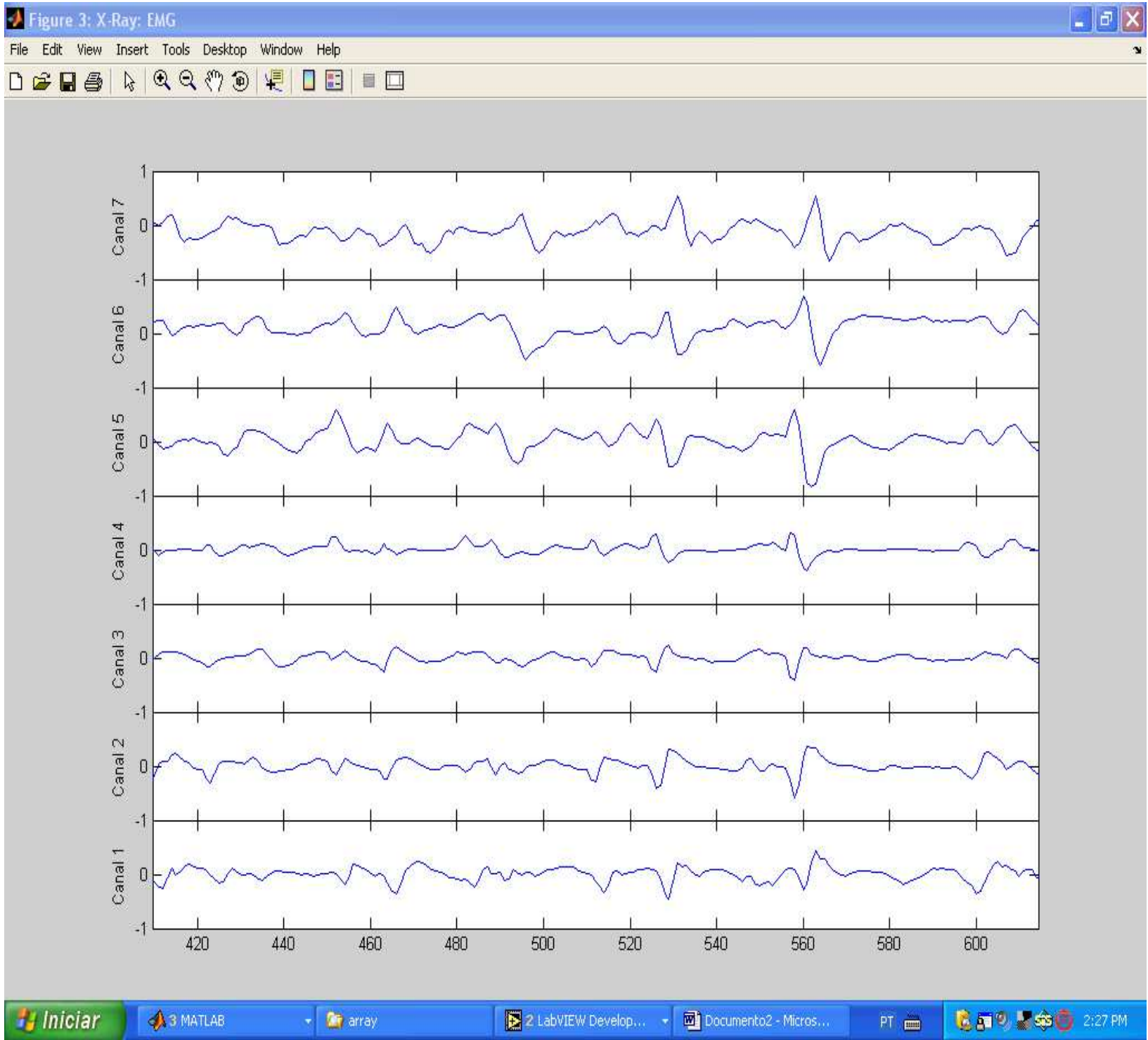

Figura 3.36 - Trecho de EMG-S bruto de uma contração isométrica no bíceps braquial.

As duas figuras anteriores apresentam a evolução no tempo dos sinais de EMG-S bruto captados nos oito eletrodos durante um período de aproximadamente de $200 \mathrm{~ms}$. Através da análise visual das figuras acima, podemos perceber claramente a propagação dos sinais de EMG-S ao longo do tempo. A possibilidade de se identificar essa propagação nos garante algumas aplicações práticas, como por exemplo, acompanhar o deslocamento do potencial de ação desde a geração nas junções neuromusculares até sua extinção em um tendão.

Uma outra aplicação do arranjo linear de eletrodos em validação é a possibilidade de localização de zonas de enervação no músculo examinado. Podemos perceber claramente a presença de zonas de enervação entre os canais 3 e 4 no caso de ambas as figuras 3.35 e 3.36. 
A possibilidade de acompanhar os potenciais de ação durante sua propagação ao longo das fibras musculares é particularmente importante para se investigar as propriedades de condução das unidades motoras. A velocidade de condução das fibras musculares é um parâmetro fisiológico básico. Ela está relacionada com o tipo e o diâmetro da fibra muscular, a concentração de íons, o pH, a temperatura muscular e a taxa de disparo (firing-rate) das UM's. A velocidade de propagação dos potenciais de ação é, portanto, um indicativo das propriedades de contração das UM's e pode ser utilizada para se determinar a fadiga muscular.

Para os dados obtidos com o arranjo linear de sete canais, foi calculada a velocidade de condução das fibras musculares, por meio do algoritmo de McGill. Através deste algoritmo, obtivemos um valor de 2,98 $\pm 1,06 \mathrm{~m} / \mathrm{s}$ (média \pm desvio padrão); valor este que se encontra conforme a faixa fisiológica encontrada na literatura.

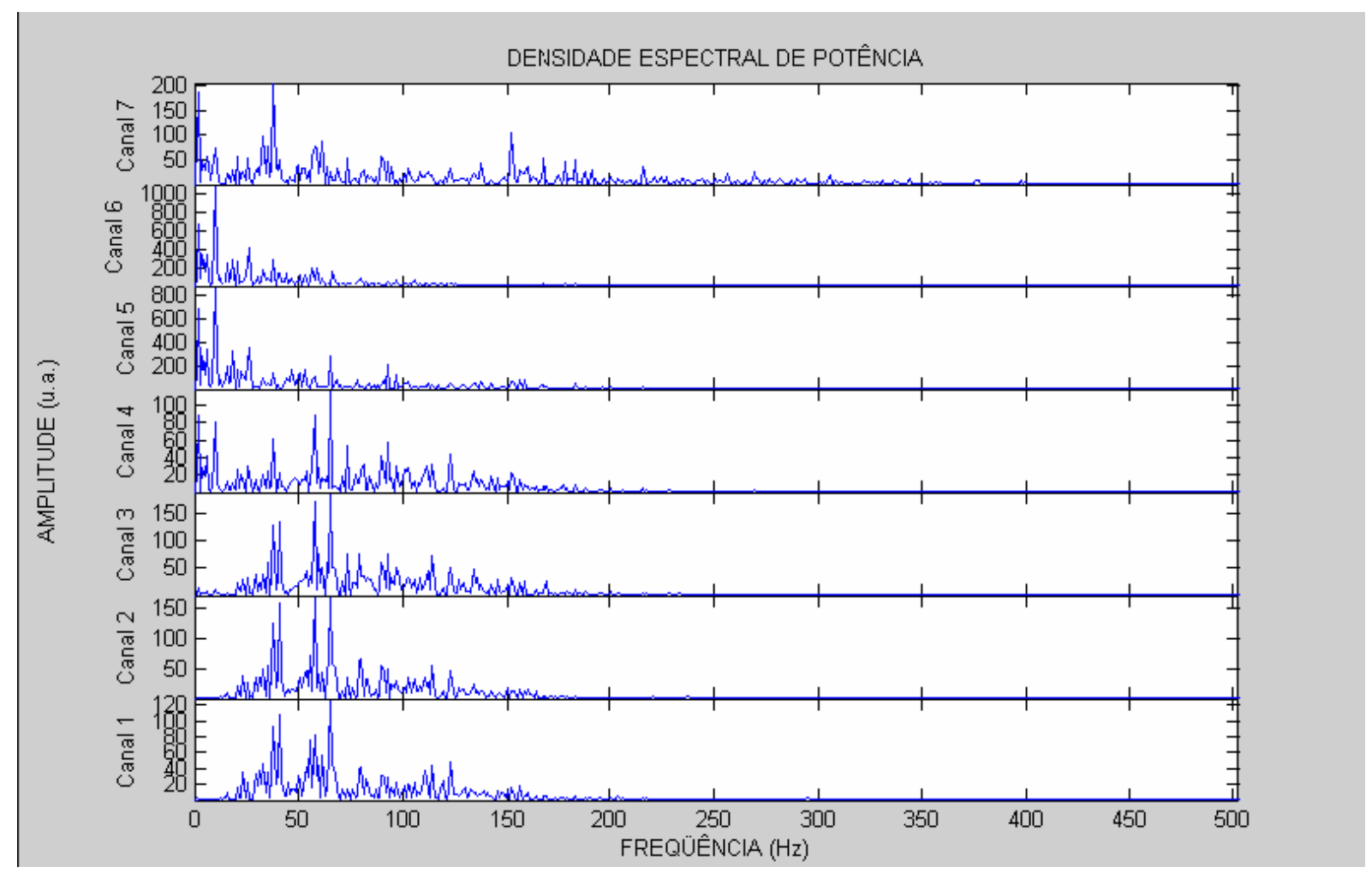

Figura 3.37 - Gráficos da densidade espectral de potência referente aos 7 canais.

$\mathrm{Na}$ figura acima estão apresentados os gráficos da densidade espectral de freqüência para os sinais de EMG-S captados nos sete canais. Podemos perceber que a energia dominante do sinal se encontra na faixa de freqüência entre $50 \mathrm{~Hz}$ e $150 \mathrm{~Hz}$, com um certo destaque para a componente de ruído de linha $(60 \mathrm{~Hz})$. 
Concluímos através destes testes, que o hardware implementado atende as especificações sobre as quais foi concebido o projeto. $\mathrm{O}$ arranjo de eletrodos linear desenvolvido durante este projeto final de graduação se comporta muito bem dentro dos parâmetros verificados na literatura existente. Pôde ser verificada a satisfatória margem de amplificação no sinal de EMG-S captado; assim como a eficiência no processo de filtragem, obtendo assim sinais exatamente dentro da faixa de frequiência útil para um sinal de EMG. Pôde também ser confirmada a aplicabilidade de tal dispositivo, sendo realizado várias análises com os sinais obtidos em laboratório. Análises estas que somente se tornaram viáveis através da aquisição dos sinais eletromiográficos por meio de múltiplos canais. 


\section{4 - PROJETO EXPERIMENTAL}

\section{1 - PROTOCOLO EXPERIMENTAL}

Uma análise da literatura científica mostra que alguns pesquisadores realizaram experimentos subaquáticos com captação de sinais eletromiográficos de superfície (EMG-S) em humanos, tais como Poyhonen[14,16], Fujisawa[15], Kelly[17], Rainoldi[11] e Veneziano[13]. Verificou-se que houve diferenças metodológicas significativas entre os experimentos. Alguns realizaram medições somente com imersão de membro (Rainoldi[11] e Veneziano[13]), enquanto que outros as fizeram com imersão do corpo humano até a altura do pescoço (Poyhonen[14,16] e Fujisawa[15]). Talvez isto explique o fato de alguns pesquisadores terem concluído que, em comparação com ambiente aéreo, o ambiente subaquático (por si só) não interfere na amplitude do sinal de EMG de superfície (Rainoldi[11] e Veneziano[13]), enquanto que outros encontraram redução da amplitude. Esses trabalhos não apresentaram justificativas convincentes para essa diminuição. É fato que o organismo humano quando imerso em água sofre efeito de forças de empuxo que podem ser biomecanicamente significativas em membros de grande volume (por exemplo, antebraço e pernas), a ponto de alterarem o esforço muscular efetuado pelo membro.

Por outro lado, inúmeros estudos de fisiologistas relatam que a imersão em água do organismo humano até o crânio altera a distribuição e a circulação sangüíneas, o ritmo dos batimentos cardíacos e a pressão sangüínea, assim como o tônus muscular, entre outros parâmetros fisiológicos. Decidiu-se, então, investigar se a imersão do corpo até o pescoço afeta o sinal eletromiográfico de superfície de forma diversa da situação de imersão somente do membro sob estudo (por exemplo, braço ou perna). Como oscilações na temperatura ambiente podem acarretar variações na temperatura intramuscular (Merletti[18]), para que não houvesse alteração na amplitude do EMG-S optou-se por padronizar a temperatura da água usada para a imersão dos sujeitos em $33^{\circ} \mathrm{C}$. Este valor, similar ao da pele humana, pouco influencia a temperatura intramuscular $\left(36^{\circ} \mathrm{C}\right)$ quando a imersão não é prolongada.

Foram formuladas duas hipóteses para serem investigadas. A primeira é a de que, quanto à amplitude do sinal de EMG-S, devem pertencer a um mesmo grupo estatístico as contrações isométricas (flexão de cotovelo) do bíceps braquial cabeça curta realizadas em 
ambiente aéreo, em um tanque com imersão somente desse membro e em um outro tanque com imersão dos sujeitos até a altura do pescoço, sempre mantido o mesmo nível de esforço muscular, por meio do uso de uma pulseira compensadora do empuxo na água. A segunda hipótese é a de que a compensação do empuxo na água faz diferença, ou seja, pertencem a grupos estatisticamente distintos as amplitudes do EMG-S de contrações isométricas realizadas sem a compensação de empuxo (grupo 1) e com a compensação dele (grupo 2), apesar da força externa aplicada ao membro ser de mesma amplitude. Buscando atingir esse objetivo, foi realizado entre os meses de agosto e dezembro de 2005 um experimento no Laboratório de Biomecânica da Universidade de Brasília, descrito a seguir.[13]

\subsection{1 - Equipamentos e Softwares Utilizados}

Os sinais de EMG foram captados por meio de dois eletrodos ativos de superfície (DE2.1, Delsys, Boston, EUA) na configuração diferencial simples (Figura 4.1). Encapsulados em um bloco único de plástico e blindados eletromagneticamente, eles são formados por duas barras de 99,9\% de prata com 10mm de comprimento e $1 \mathrm{~mm}$ de diâmetro, distanciadas entre si de $10 \mathrm{~mm}$. A impedância de entrada é maior do que $1015 \mathrm{ohms} / / 0,2 \mathrm{pF}$, a razão de rejeição de modo comum é maior do que $84 \mathrm{~dB}$ a $60 \mathrm{~Hz}$, o ruído (RMS) é de $1,2 \mathrm{mV}$, referido à entrada, não há filtragem e o ganho de tensão elétrica (pré-amplificação) é de 10V/V ( $\pm 2 \%)$.Um eletrodo adesivo de gel foi utilizado para referência (Kendall, Meditrace, diâmetro de 10mm, EUA); tendo sido colocado na parte posterior do pescoço, na altura da vértebra $\mathrm{C} 3$.

Os sinais passaram por um amplificador de sinais eletromiográficos (Bagnoli2, Delsys, Boston, EUA), com ganho de tensão ajustado para 1000V/V ( $\pm 1 \%)$, saída analógica de \pm 5 volts, resposta em freqüência entre $20 \pm 5 \mathrm{~Hz}$ e $450 \pm 50 \mathrm{~Hz}$ (12dB por oitava) e ruído de sistema menor que $1,2 \mathrm{mV}$ sobre a largura de banda especificada. Não foi efetuada retificação dos sinais analógicos. Eles foram amostrados a uma taxa de $1.024 \mathrm{~Hz}$ e convertidos em sinal digital por uma placa de aquisição de dados de sete canais, 12 bits (PCI-6024E, National Instruments, Austin, EUA). 


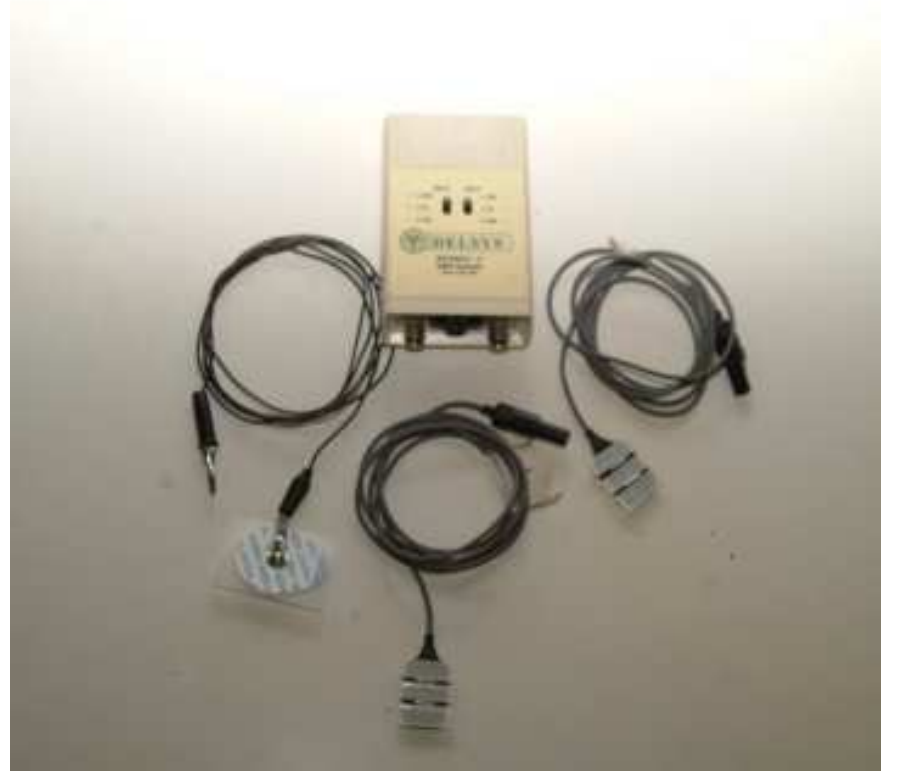

Figura 4.1 - Eletrodos de captação e de referência e amplificador de EMG.

Os sinais foram adquiridos por meio de um software desenvolvido na Universidade de Brasília (BARROSO; OLIVEIRA, 2004), em ambiente Labview 7 (National Instruments, EUA), e executado em sistema operacional Windows XP (Microsoft, EUA). Esse software permite a aquisição simultânea de dois canais de EMG e um de força.

\subsection{2 - Sujeitos}

Participaram desse estudo quinze voluntários do sexo masculino, com idade de 25,2 \pm 5,37 anos (média \pm desvio padrão), altura de 1,77 $\pm 0,05 \mathrm{~m}$ e massa corporal de 77,7 \pm 9,34 kg. Nenhum sujeito reportou sintomas de patologias neuromusculares. Descreveram-se para os voluntários os equipamentos e o protocolo experimental antes da realização dos experimentos. Em seguida, os voluntários subscreveram um termo de consentimento livre e esclarecido.

Esse estudo foi aprovado pelo Comitê de Ética em Pesquisa com Seres Humanos da Faculdade de Ciências da Saúde da Universidade de Brasília (projeto número 081/2005). 


\subsection{3 - Obtenção da CVM}

A primeira fase do experimento consistiu na medição da contração voluntária máxima (CVM) de cada sujeito posicionado na mesma situação utilizada para a captação posterior dos sinais de EMG.

Os sujeitos sentaram-se em uma cadeira padrão, construída para o experimento, com o tronco ereto e encostado no encosto da cadeira, as pernas relaxadas e os joelhos flexionados a um ângulo interno de $90^{\circ}$. A mão esquerda permaneceu relaxada sobre a coxa esquerda. $\mathrm{O}$ cotovelo direito foi apoiado em um suporte construído especificamente para isso, tendo sido mantido um ângulo interno articular de $90^{\circ}$ entre o antebraço e o braço. $\mathrm{O}$ antebraço permaneceu paralelo ao plano sagital do corpo.

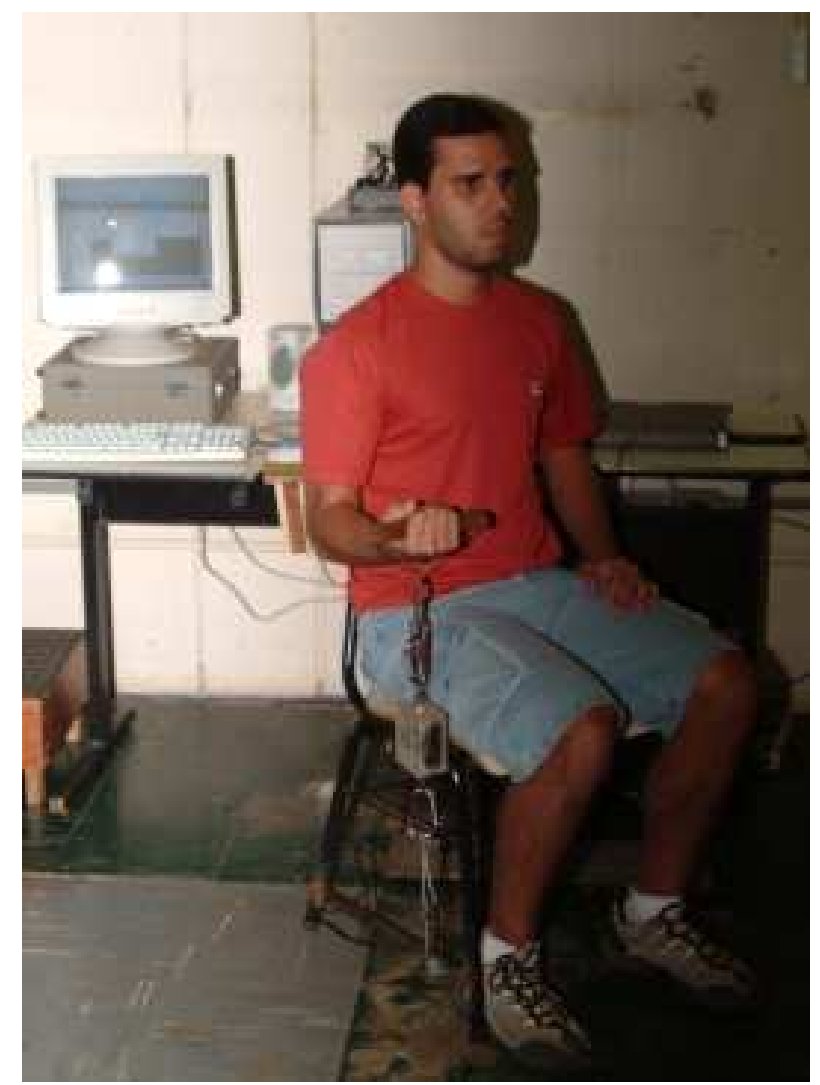

Figura 4.2 - Medição da contração voluntária máxima.

A mão direita segurou uma empunhadura presa a uma célula de carga de 50kg (tipo S, Kratos, Brasil), que possui um erro combinado de $0,03 \%$ sobre o fundo de escala. Por sua vez, a célula de carga foi fixada à base da cadeira. Em contrações isométricas de flexão de cotovelo, a força exercida pelo membro foi medida pela célula de carga, cujo sinal foi 
amplificado por um amplificador (MCS1000, Lynx, São Paulo, Brasil) e digitalizado pela mesma placa de aquisição de dados usada para os sinais eletromiográficos.

Os valores de força foram medidos automaticamente pela função Força Máxima do software Aquisição Subaquático (BARROSO; OLIVEIRA, 2004), desenvolvido no Departamento de Engenharia Elétrica da Universidade de Brasília.

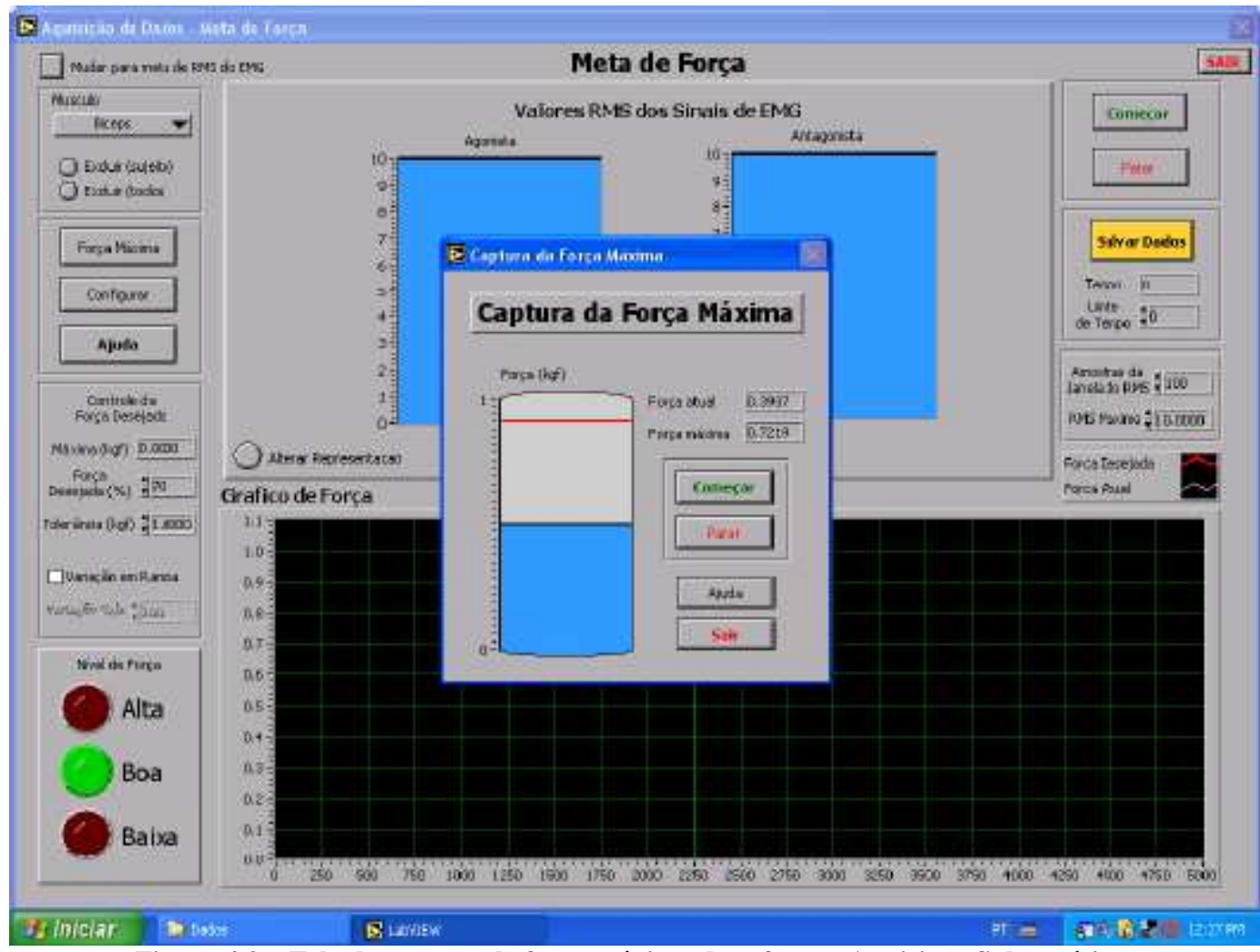

Figura 4.3 - Tela da captura de força máxima do software Aquisição Subaquático.

Solicitou-se aos voluntários que fizessem três contrações máximas de três segundos de duração cada uma, intercaladas por um repouso de dois minutos. O maior valor das três tentativas foi tomado para ser a CVM. Durante a medição da CVM, os sujeitos não tiveram acesso ao valor da força medida. Eles realizaram, previamente, um pequeno treinamento desse procedimento e foram incentivados pelo experimentador a aplicarem a sua capacidade máxima de esforço muscular durante a captação definitiva.

\subsection{4 - Colocação dos Eletrodos}

A região para colocação dos eletrodos de captação sobre o músculo bíceps braquial cabeça curta foi determinada seguindo-se as recomendações do relatório SENIAM[5]. Os 
eletrodos foram fixados distantes das zonas de inervação e dos tendões, pois eles seriam fatores de confusão para a análise do sinal eletromiográfico[4]. Outra preocupação foi reduzir a interferência indesejável do EMG de músculos próximos, efeito conhecido como crosstalk.

Assim, foi medida a distância entre o acrômio direito (lado dominante de todos os sujeitos) e a fossa cubital, desenhando-se uma linha sobre a pele. A um terço dessa distância, a partir da fossa cubital, foi depositado o eletrodo da captação, após palpação para a determinação do ventre muscular e dos tendões. A região da pele onde foram depositados os eletrodos foi previamente depilada e higienizada com água, detergente e bucha, em processo abrasivo. Não foram empregados álcool, gel ou pasta abrasiva. A orientação dos eletrodos (barras) com respeito à direção das fibras musculares foi a perpendicular. Os eletrodos de captação foram fixados à pele por meio de fita adesiva do tipo dupla face (Highland 19mm, 3M, Brasil). Sobre eles foi aplicada uma porção de fita adesiva (Silver Tape, 3M, Brasil) nas dimensões de $5 \mathrm{~cm}$ por $8 \mathrm{~cm}$. Um eletrodo adesivo de gel foi utilizado para referência (Kendall, Meditrace, diâmetro de 10mm, EUA); tendo sido colocado na parte posterior do pescoço, na altura da vértebra $\mathrm{C} 3$.

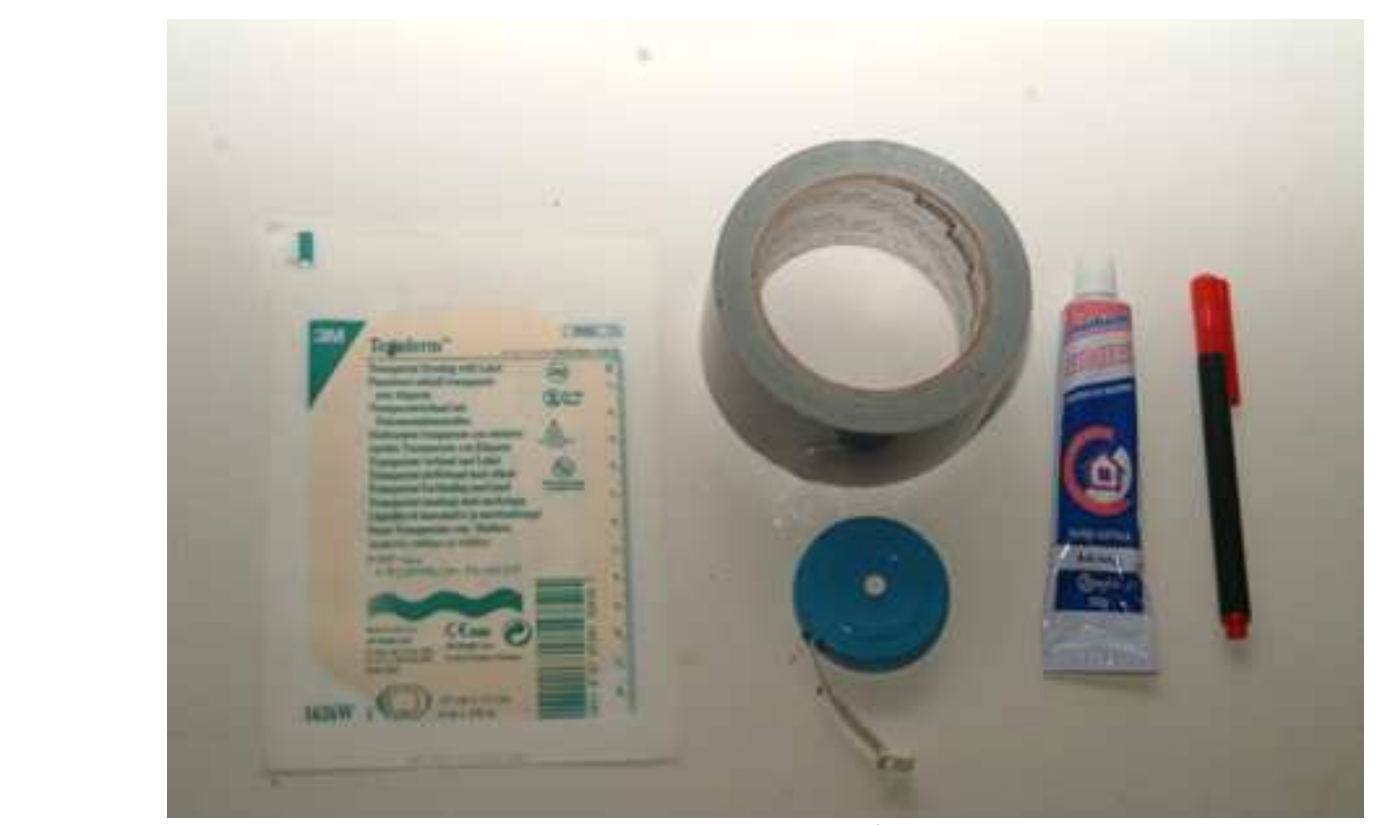

Figura 4.4 - Fitas Adesivas para proteção dos eletrodos contra água e trena para as medições antropométricas.

Finalizando a proteção contra a entrada de água, foi depositada mais uma fita adesiva, um curativo cirúrgico (Tegaderm, 3M, St. Paul, EUA), com dimensões de $10 \mathrm{~cm}$ por $12 \mathrm{~cm} . \mathrm{O}$ eletrodo de referência ficou em uma região que não foi submergida, não tendo, portanto, recebido proteção contra água. 


\subsection{5 - Coleta dos Dados}

As coletas de sinais eletromiográficos de superfície foram realizadas em cinco situações experimentais (aqui chamadas de postos de trabalho): ambiente aéreo (Figura 4.5); tanque pequeno com imersão somente de membro (mão, antebraço e braço), com e sem colocação de pulseira de 1,6kg (cálculo apresentado posteriormente neste texto) para a compensação de efeito de empuxo (Figuras 4.6 e 4.7); e tanque grande, com imersão do corpo até a vértebra C7 do pescoço, com e sem a utilização de pulseira (Figura 4.8). A ordem dos postos de trabalho foi definida aleatoriamente para cada sujeito. A postura dos sujeitos (tronco e ângulos de cotovelos e pernas) foi a mesma de quando foi adquirida a contração voluntária máxima.

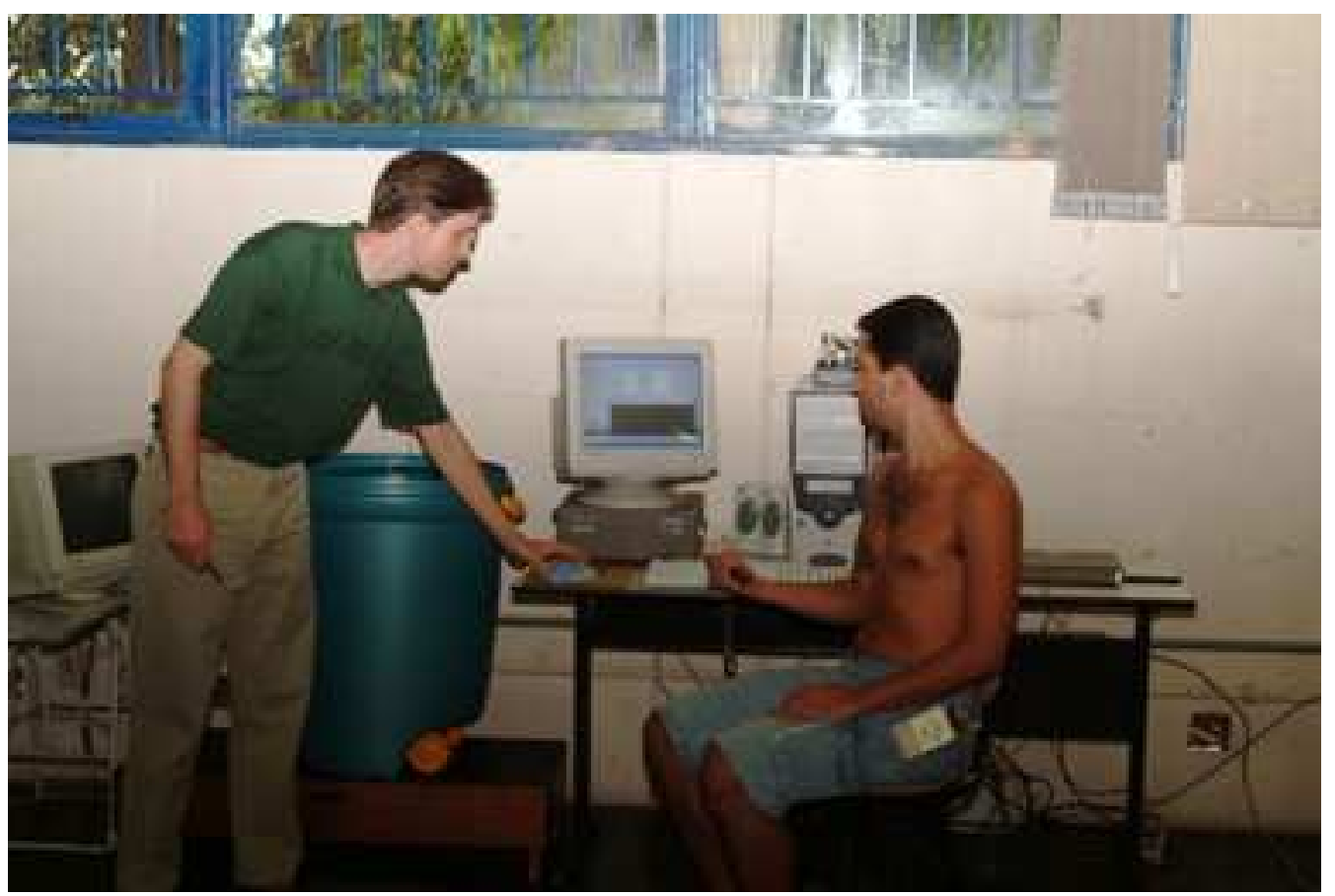

Figura 4.5 - Arranjo físico do posto de trabalho em ambiente aéreo. O sujeito flexiona o cotovelo direito, puxando verticalmente a empunhadura, e vê o valor instantâneo de sua força no monitor de vídeo (retroalimentação visual).

Em cada um dos cinco postos de trabalho os sujeitos efetuaram uma contração isométrica (flexão de cotovelo) com duração de cinco segundos. Entre os postos de trabalho, houve um repouso de vinte minutos, minimizando, assim, a fadiga muscular. Os sujeitos e o experimentador acompanharam o valor instantâneo da força exercida por meio de dois monitores de vídeo, apresentando a tela Meta de Força do software AquisiçãoSubaquático (Figura 4.9). Esse sistema propiciou uma retroalimentação visual adequada aos sujeitos e ao experimentador. A meta de força para os sujeitos foi padronizada em 50\% da CVM, sendo a 
variação máxima admitida de $\pm 4 \%$ da meta de força. Essa padronização da meta de força acarreta em uma normalização dos sinais de EMG, não requerendo, assim, a coleta do EMG relativo à CVM para posterior normalização por ele, procedimento adotado por alguns pesquisadores. Os sujeitos iniciaram e concluíram cada contração após um comando de voz do experimentador. É importante notar que a aquisição dos sinais foi iniciada somente após os sujeitos atingirem a meta de força, e que a finalização foi feita automaticamente pelo software, após $5 \mathrm{~s}$ de registro. Não houve, portanto, a necessidade de realização de recortes nos sinais digitalizados de EMG-S.

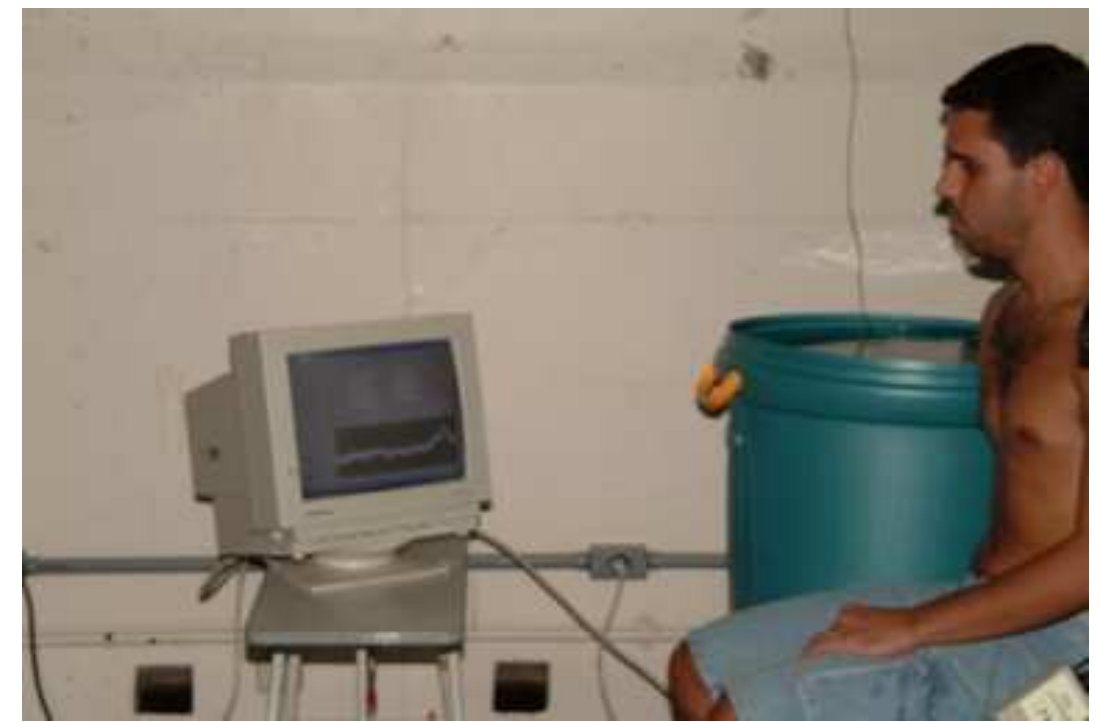

Figura 4.6 - Arranjo físico geral do posto de trabalho tanque pequeno. O sujeito submerge em água somente a mão, o antebraço e o braço até a altura da axila.

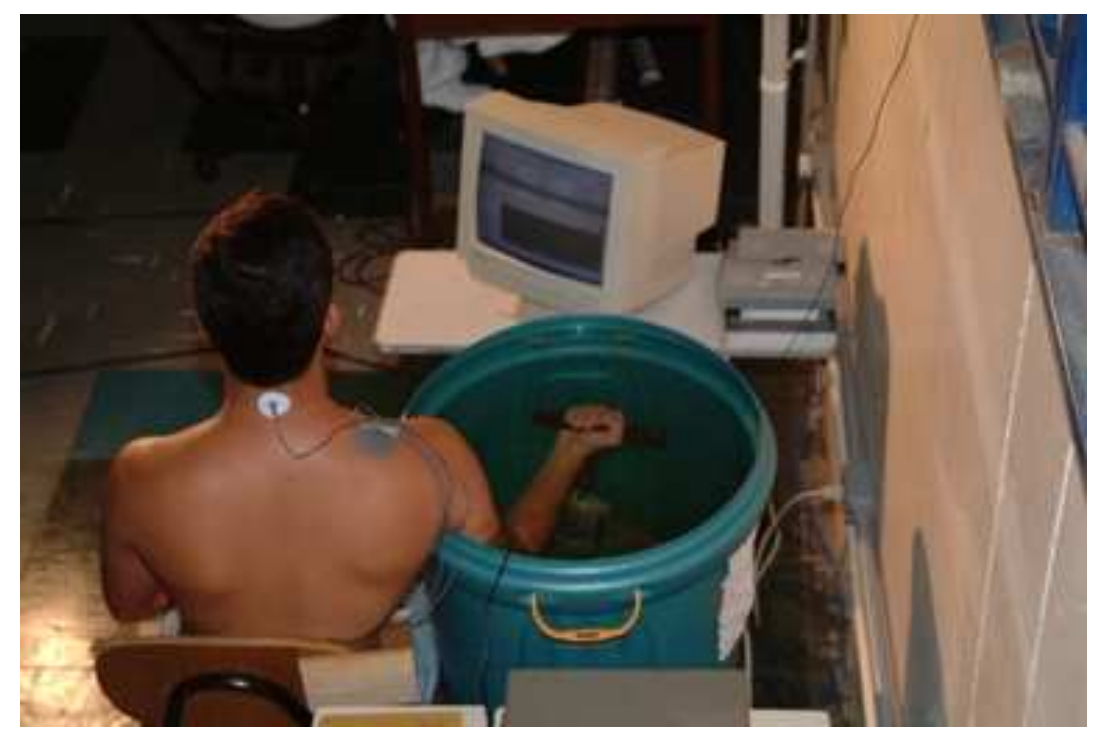

Figura 4.7 - Detalhe do posto de trabalho tanque pequeno. A célula de carga foi fixada no fundo do tanque. 


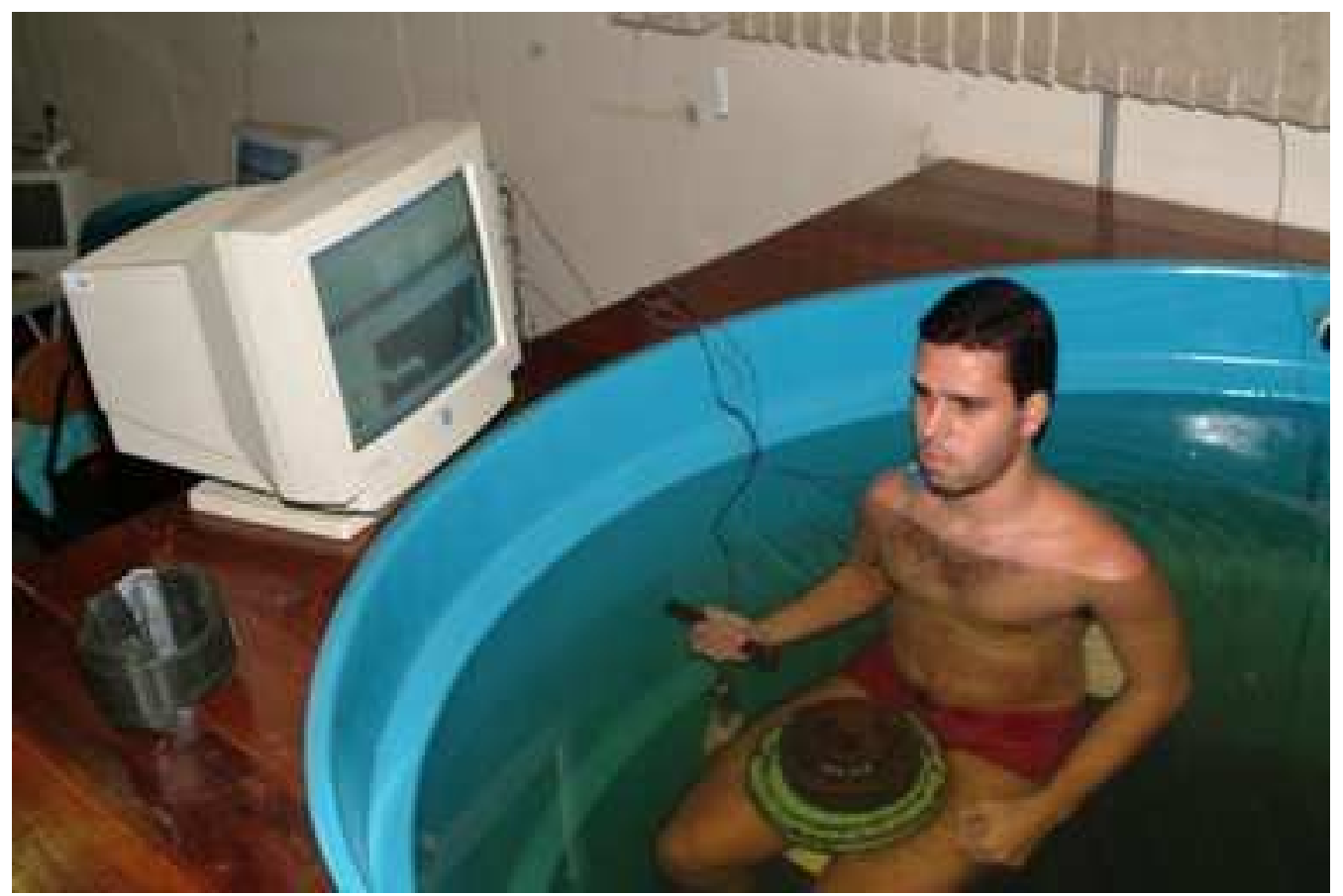

Figura 4.8 - Arranjo físico do posto de trabalho tanque grande. A cadeira é a mesma que foi utilizada para a experimentação em ambiente aéreo. No canto inferior esquerdo da fotografia, nota-se a pulseira utilizada para compensar o efeito do empuxo da água em um dos dois postos de trabalho no tanque pequeno e em um posto do tanque grande.

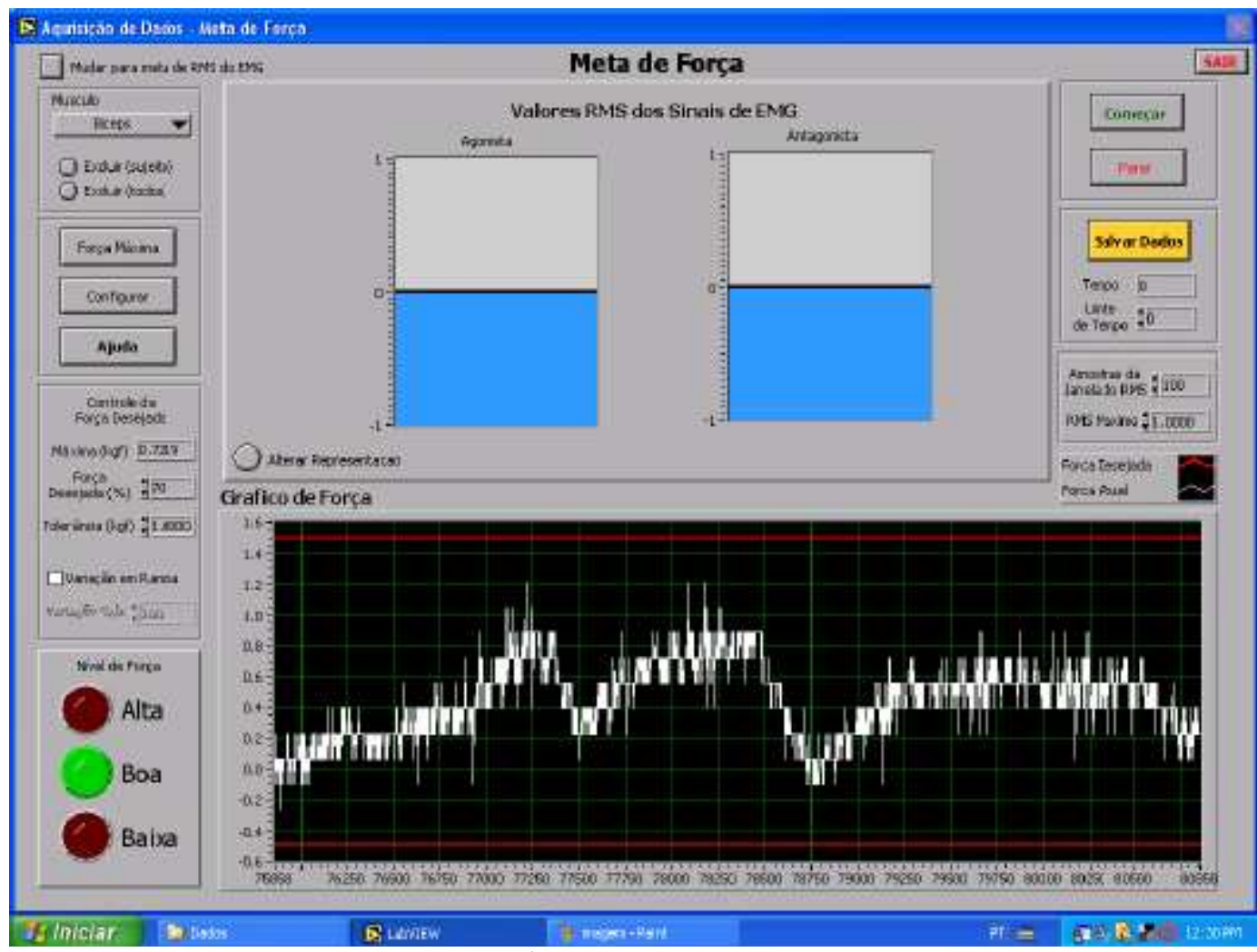

Figura 4.9 - Tela do software AquisiçãoSubaquático adquirindo sinais de EMG e de força. Percebem-se, na parte inferior, o gráfico da evolução da força no tempo, e seu valor instantâneo, utilizado para retroalimentação visual dos sujeitos. 
Os sujeitos utilizaram sempre a mesma cadeira nos cinco postos de trabalho. A temperatura do ar foi monitorada. A água, nos dois tanques, foi mantida a cerca de $33^{\circ} \mathrm{C}$, tendo sido também aterrada eletricamente para minorar interferências eletromagnéticas nos eletrodos. Nas coletas no tanque grande, o sujeito utilizou no punho esquerdo uma segunda pulseira (3kg) para manter o seu tronco alinhado com a vertical, evitando-se, assim, oscilações do tronco devido à ausência de apoio para o lado esquerdo do corpo. Também, quando no tanque grande, os sujeitos mantiveram depositadas sobre suas coxas anilhas com massa de $20 \mathrm{~kg}$, a fim de manter o sujeitos bem apoiados sobre a cadeira, evitando-se a flutuação do corpo.

Um aspecto importante na busca de sinais eletromiográficos de qualidade é a verificação da relação sinal/ruído. No caso do protocolo em questão, em todos os postos de trabalho foi realizada, antes das contrações, uma captação de sinal de EMG-S com o sujeito relaxado, o que evidencia o nível de ruído do sistema. Posteriormente, a amplitude desse sinal foi comparada com a do sinal de EMG-S (que obviamente também inclui os ruídos de sistema). No caso de má relação sinal/ruído, foi alterada a posição dos cabos elétricos, dos eletrodos de captação, verificado o aterramento elétrico da água dos tanques e pesquisadas as fontes de ruído eletromagnético. No caso de insucesso nessa etapa, os dados do sujeito foram descartados.

A seguir, será exposto o método de dimensionamento da pulseira do punho direito dos sujeitos, utilizada nos tanques, de modo que, com referência ao olécrano, o torque em ambiente aéreo fosse igual ao em ambiente subaquático. Ou seja, o objetivo foi o de compensar o efeito do empuxo em água para que o esforço efetuado pelo músculo bíceps braquial cabeça curta fosse idêntico em ambos os ambientes, caso a carga externa (força na célula de carga) também fosse idêntica. Por uma questão de praticidade, em vez de serem utilizadas pulseiras variadas para sujeitos bem distintos entre si, optou-se por dimensionar uma única pulseira, a qual atendesse a vários sujeitos com semelhantes dimensões antropométricas do membro superior direito. 


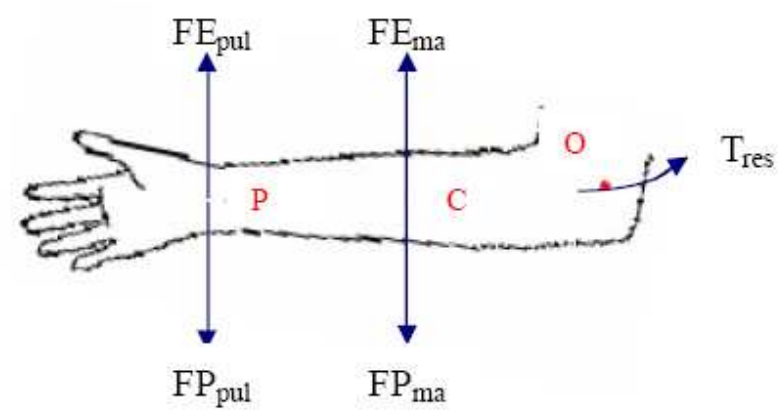

Figura 4.10 - Forças peso e empuxo aplicadas na mão e antebraço acarretando em um torque no olécrano (ponto 0 ). $P$ é o ponto médio do pulso. $C$ é o ponto do centro de massa do conjunto mão-antebraço.

Em ambiente aéreo, o torque no olécrano é oriundo da força peso no conjunto da mão com o antebraço (FPma). A força peso nesse conjunto pode ser calculada como a aceleração da gravidade ( $g=9.8 \mathrm{~m} / \mathrm{s}^{2}$ ) vezes a massa do conjunto, concentrada em seu centro de massa (C). O centro de massa do conjunto mão-antebraço encontra-se, a partir do olécrano, a $50,60 \%$ (com desvio-padrão de $\pm 12,07 \%$ ) da distância entre o olécrano e a ponta do dedo médio quando a mão está aberta. Para homens adultos, o valor médio da massa do conjunto mão-antebraço (Mma) é de 1,601kg (desvio-padrão de 0,273kg). Medições prévias com os sujeitos do experimento de Brasília mostraram que o valor médio da distância entre o olécrano e o dedo médio é de 0,46m; portanto, o centro de massa (C) situa-se a cerca de 0,23m do olécrano (distância OC).[13]

Portanto, o torque no olécrano, em ambiente aéreo (Tar) pode ser expresso por:

$$
\operatorname{Tar}=(\text { Mma.g }) \cdot \mathrm{OC}=3,61 \mathrm{kgf} . \mathrm{m}
$$

Em ambiente subaquático é adicionada uma pulseira ao pulso direito dos sujeitos para que seja compensado o empuxo do conjunto mão-antebraço e da própria pulseira. Assim, o torque resultante no olécrano é a subtração entre as forças peso da pulseira e do conjunto mão-antebraço e o empuxo da pulseira e do conjunto mão-antebraço.

Para o conjunto mão-antebraço, o centro de volume pode ser aproximado pelo centro de massa (C), considerando-se o conjunto possuir massa específica aproximadamente constante. Sendo Vma o volume do conjunto, o empuxo do conjunto mão-antebraço (Ema) concentra-se no ponto $\mathrm{C}$ e pode ser estimado por: 


$$
\text { Ema }=\text { Vma.p.g }
$$

A massa específica da água $(\rho)$ é de cerca de $1000 \mathrm{~kg} / \mathrm{m}^{3}$. Para homens adultos, o volume médio do conjunto mão-antebraço é de $1,46 \times 10^{-3} \mathrm{~m}^{3}$ (desvio-padrão de $\left.0,26 \times 10^{-3} \mathrm{~m}^{3}\right)$. Portanto, o torque devido ao empuxo do conjunto mão-antebraço é:

$$
\text { TEma }=\text { Ema.OC }=3,29 \text { kgf.m }
$$

A força peso da pulseira de massa Mpul concentra-se no ponto $\mathrm{P}$, o qual dista, em média, 0,26m do olécrano para os sujeitos avaliados neste experimento. Assim, o torque causado pela força peso da pulseira pode ser calculado como:

$$
\text { Tpeso-pul }=(\text { Mpul.g }) \cdot \mathrm{OC}=\mathrm{M} \cdot 9,8 \cdot 0,26
$$

Da mesma forma que o conjunto mão-antebraço, a pulseira também sofre efeito de empuxo (Epul):

$$
\text { Epul }=\text { Vpul.p.g }
$$

Por conseguinte, isso acarreta um torque em sentido oposto no olécrano (TEpul):

$$
\text { TEpul }=(\text { Vpul.p.g }) . \mathrm{OP}
$$

Note-se que Mpul e Vpul são as variáveis a serem dimensionadas. Buscando uma solução prática, uma pulseira comercial de academias de musculação foi modificada, de forma a atender a um compromisso entre a sua massa e o seu volume. Com o seu uso pelos sujeitos no ambiente no subaquático, obtém-se um torque no olécrano semelhante ao do meio aéreo (sem pulseira). O equacionamento geral é:

$$
\begin{aligned}
\text { Tágua } & =\text { TPeso-mao }+ \text { ant-TEmp-mao }+ \text { ant }+ \text { TPeso-pul }- \text { TEmp-pul }= \\
& =3,61-3,29+\text { M.9,8.0,26 }- \text { Vpul.1000.9,8.0,26 }
\end{aligned}
$$


Após algumas tentativas de construção, compreendendo o teste de vários materiais, conseguimos construir uma pulseira com massa de $1,6 \mathrm{~kg}$ e volume de $0,00031 \mathrm{~m}^{3}$, valores adequados para a compensação do empuxo no caso em questão.

\section{2 - ANÁLISE E PROCESSAMENTO DOS DADOS}

\subsection{1 - Software Desenvolvido para Análise em MatLab}

Dois programas foram criados, cada um para trabalharmos especificamente com o EMG de 7 canais (xarray033) e o EMG-S (filtrar06).

\section{- Xarray033}

O programa criado em ambiente MatLab (The Mathworks Inc., Natick, EUA) tem uma função bem específica: lê arquivos gerados pela placa da aquisição (PCI-6024E, National Instruments, Austin, EUA) e traduz os dados em gráficos dos sinais EMG e a FFT dos sinais nos 7 canais. Além disso, dá a opção de detalhar o processamento de dados com o cálculo da velocidade de condução da onda no músculo, usando 3 canais adjacentes.

Note que a idéia é gerar gráficos para uma visão geral do sinal no momento da aquisição, detectando se foi uma medida válida. Como foi dito anteriormente, a coleta de dados é trabalhosa e susceptível a vários erros. Portanto gerar gráficos rapidamente dos 7 sinais, mostrando inclusive certo processamento do sinal, como a FFT, facilita muito a coleta.

A opção de detalhamento do processamento não chegou a ser utilizada durante a coleta, pois não era o intuito do programa um aprofundamento da análise do sinal a cada aquisição. Depois de verificarmos a obtenção de uma medida válida, aí sim executávamos a opção de cálculo da velocidade de condução.

A idéia do algoritmo usado no xarray é possuir uma interface simples e amigável. Iniciado o programa, abre-se uma janela para a escolha do arquivo a ser processado. Selecionado o arquivo, uma caixa de diálogo requisita os dados do gráfico: 
Tensão máxima (Padrão: $0.5 \mathrm{~V}$ ): tamanho em Volts do eixo Y do gráfico do EMG. No caso, o padrão mostra um gráfico de $-0,5 \mathrm{~V}$ a $0,5 \mathrm{~V}$;

$>$ Tamanho da janela de tempo (ms) (Padrão: 200ms): é o tamanho do eixo X do gráfico do EMG. Serão abertas várias janelas de gráfico até que seja mostrado o sinal completo. No caso de um sinal de $1000 \mathrm{~ms}$, por exemplo, na opção padrão seriam abertas 5 janelas: uma com eixo X de 0 a 200ms, a segunda com o eixo de $200 \mathrm{~ms}$ a $400 \mathrm{~ms}$ e assim por diante.

> Janela da velocidade de condução (padrão: 204 amostras): é o tamanho da janela que será usada no algoritmo para o cálculo da velocidade de condução, conforme explicado mais adiante.

Feito isso, os vários gráficos de EMG são abertos, possibilitando uma boa visualização do sinal, e um gráfico com a FFT de todos os sinais também é gerado, o que nos possibilitava verificar a presença de ruídos no sinal logo após a sua coleta.

Em seguida, caso a opção do cálculo da velocidade de condução esteja ativada no código do programa, uma janela com os valores já calculados da velocidade de condução para cada janela de todos os canais adjacentes (incluindo desvio padrão de cada um) será aberta. Esta janela é somente para a seleção de quais sinais deseja-se visualizar. O resultado é disponibilizado em uma janela mais amigável.

O gráfico dos sinais EMG foram plotados diretamente com os sinais obtidos pela placa de aquisição, apenas organizados para uma boa visualização na tela. Já a velocidade de condução das fibras musculares foi calculada em três canais de EMG contíguos e distantes da zona de inervação, em janelas retangulares e deslizantes de 0,5s. Foi empregado o algoritmo de McGill[12] de correlação cruzada em canais diferenciais duplos de EMG-S, conforme recomendado pela bibliografia.

Finalizando a análise dos sinais de EMG, para cada contração foi calculada a densidade espectral de potência dos sete canais de EMG, em janelas retangulares de $0,5 \mathrm{~s}$. Isso permitiu que fossem verificados os níveis de ruído (em especial as componentes de $60 \mathrm{~Hz}$ ), além da faixa espectral, que tipicamente deve estar entre $20 \mathrm{~Hz}$ e $500 \mathrm{~Hz}$ para sinais EMG. 


\section{- Filtrar06:}

Este programa processa os sinais de EMG-S capturados a partir da placa de aquisição (PCI-6024E, National Instruments, Austin), em ambiente MatLab 7 (The MathWorks Inc., Natick, USA). Dos sinais de EMG- $\mathrm{S}$ foram computadas a freqüência mediana do espectro de potência (MDF) e a raiz quadrática média (RMS), por meio de janelas retangulares, deslizantes e sobrepostas com largura de $0,5 \mathrm{~s}$. Cada janela foi deslocada de uma amostra da anterior, levando a uma representação "alisada" do comportamento dessas variáveis. Os valores de MDF e de RMS foram obtidos calculando-se os valores médios das estimações resultantes de cada contração de 2 s.

Para cada sujeito, os valores de MDF e de RMS das vinte contrações foram plotados no tempo e foi calculada a reta de melhor ajuste. Foram determinados os valores dessa linha no instante em que a primeira contração foi efetuada (a interceptação com o eixo das ordenadas). A fim de serem compensadas tendências (vieses) devido a diferenças na espessura do tecido subcutâneo, os valores de RMS e de MDF para cada sujeito foram normalizados com respeito à interceptação de cada contração.

Posteriormente, as médias dos valores normalizados de RMS e de MDF foram calculadas para cada contração entre os dez sujeitos, gerando as curvas que representam um comportamento global médio de todos os sujeitos.

O programa possui dois modos de funcionamento: o modo gráfico e o modo tabela. No modo gráfico ele processa um sinal coletado e gera rapidamente gráficos do sinal coletado, seu RMS, da Força medida, da FFT e da frequiência mediana. Todos estes gráficos são gerados próximos e na mesma janela, para uma fácil visualização durante a coleta de dados. Novamente, o intuito destes gráficos é de verificar a presença de ruídos ou erros experimentais que poderiam invalidar um sinal no momento da coleta.

O processamento mais profundo dos gráficos é feito através do outro modo do programa; o modo tabela. Neste modo, os dados capturados são convertidos em uma tabela formato Excel (Microsoft, EUA) para a fácil manipulação destes dados. A partir daí é possível e fácil a transposição das tabelas, cálculos de média, e qualquer outra manipulação matemática que se faz necessária. 
O programa se inicia com uma janela perguntando o modo de funcionamento (Gráfico ou Tabela), como vemos na figura 4.11.

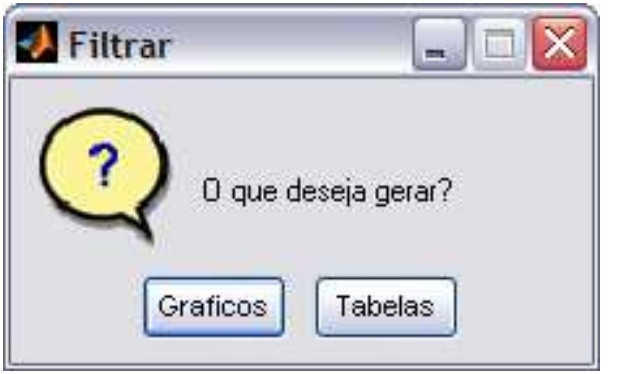

Figura 4.11 - Janela de Diálogo do modo de funcionamento do programa.

Independentemente do modo escolhido, em seguida abre-se uma janela pedindo que seja informado o arquivo a se processar (Figura 4.12).

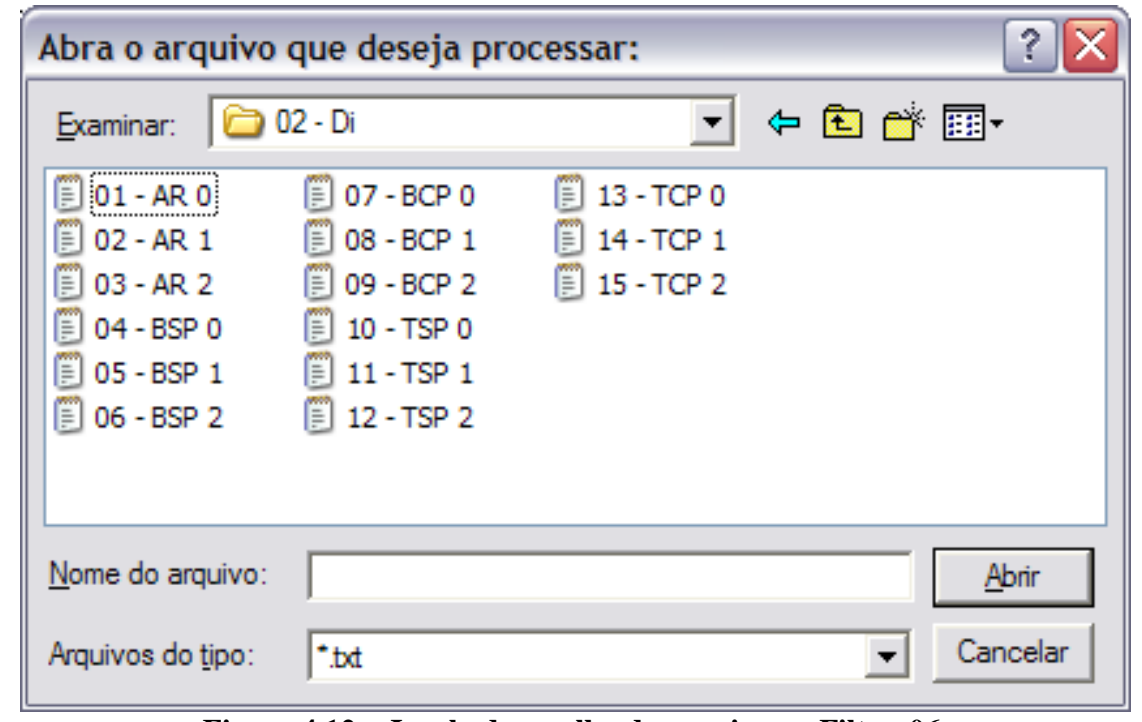

Figura 4.12 - Janela de escolha do arquivo no Filtrar06.

No modo Gráfico, então é gerado na tela uma janela com pequenos gráficos de Força, sinal EMG, RMS do sinal EMG, a FFT do sinal e a sua freqüência mediana (Figura 4.13). 


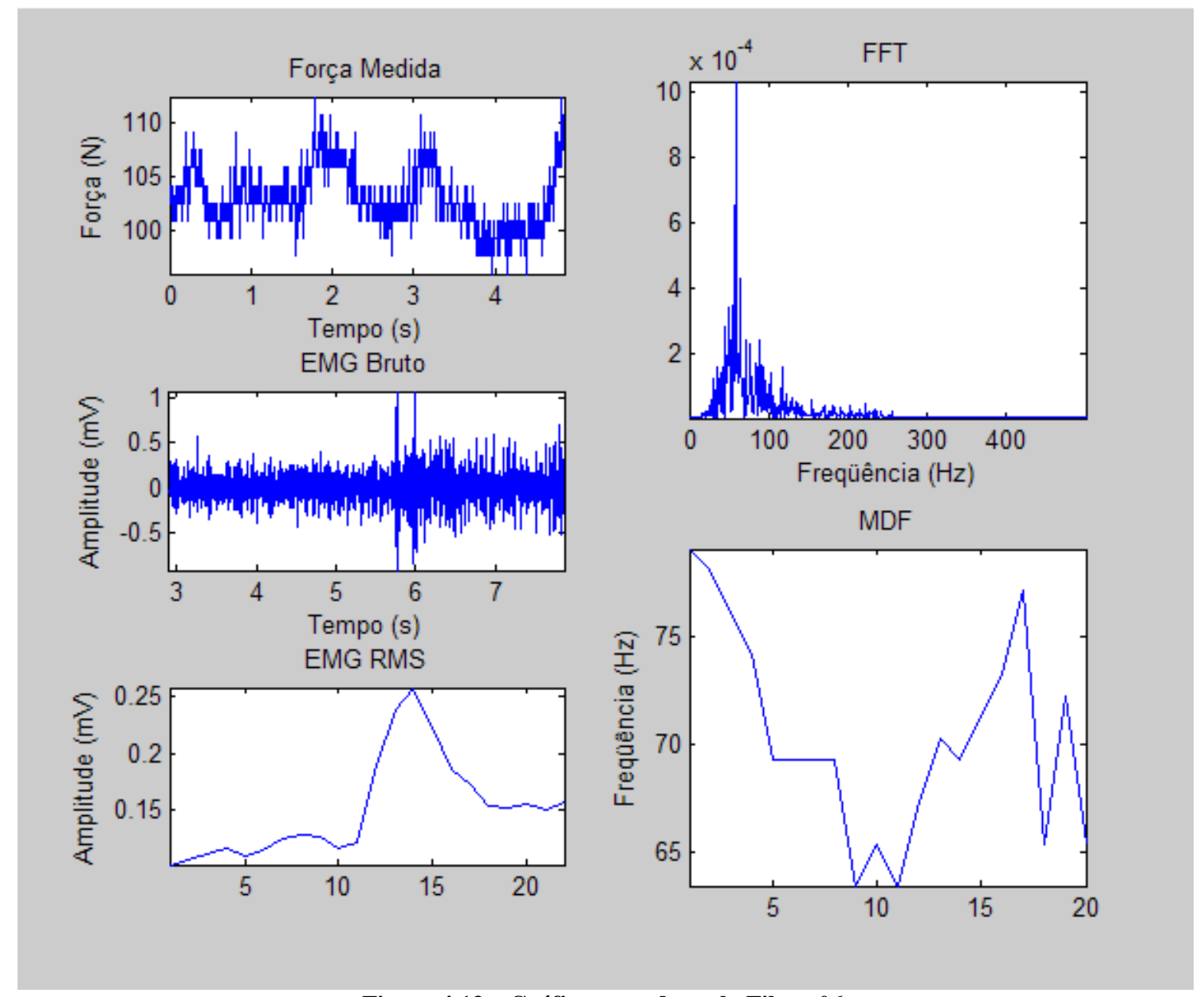

Figura 4.13 - Gráficos gerados pelo Filtrar06.

Já o modo Tabela, é possível processar vários arquivos e uni-los em uma tabela Excel apenas. Além disso, o próprio programa se encarrega de normalizar os dados em relação a alguma seqüência de dados ou não. Assim que se escolhe o modo tabela, abre uma caixa de diálogo perguntando se deseja executar a normalização (Figura 4.14). Uma seqüência de medidas, por exemplo, podem ser normalizadas em relação às primeiras feitas para aquele sujeito.

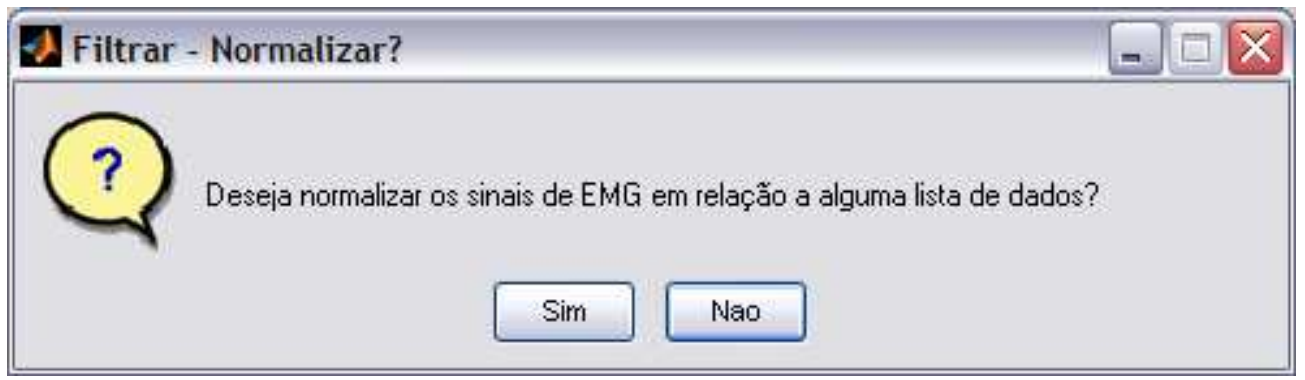

Figura 4.14 - Caixa de diálogo de normalização de dados do Filtrar06. 
Depois disso, abre-se a janela para a escolha do primeiro arquivo a ser processado, como visto acima na figura 4.12. Como há a possibilidade de se processar vários arquivos, concatenando os dados ao final de cada tabela Excel, uma nova janela se abre informando o total de arquivos processados, e perguntando se é necessário processar outro arquivo (figura 4.15).

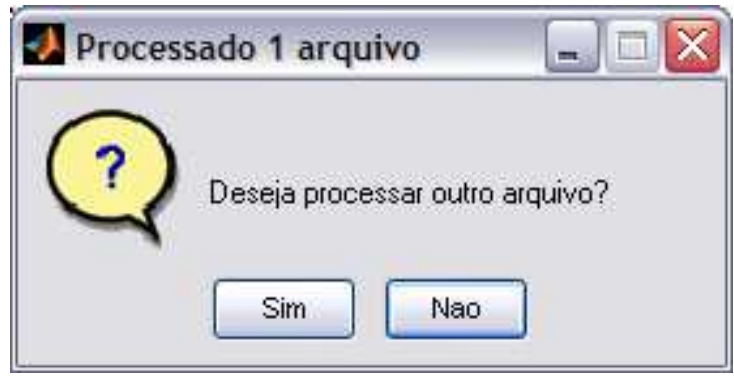

Figura 4.15 - Caixa de diálogo de processamento de outros arquivos do Filtrar06.

$\mathrm{O}$ arquivo gerado após a captura de dados possui várias medidas, que não nos interessavam durante o projeto. Assim, o Filtrar06 dá a opção de selecionar quais dados coletados do arquivo deverão ser exportados para arquivos tipo Excel (Figura 4.16). Feito isso, arquivos no formato Excel são gerados, e estão prontos para serem manipulados ou exportados (Figura 4.17).

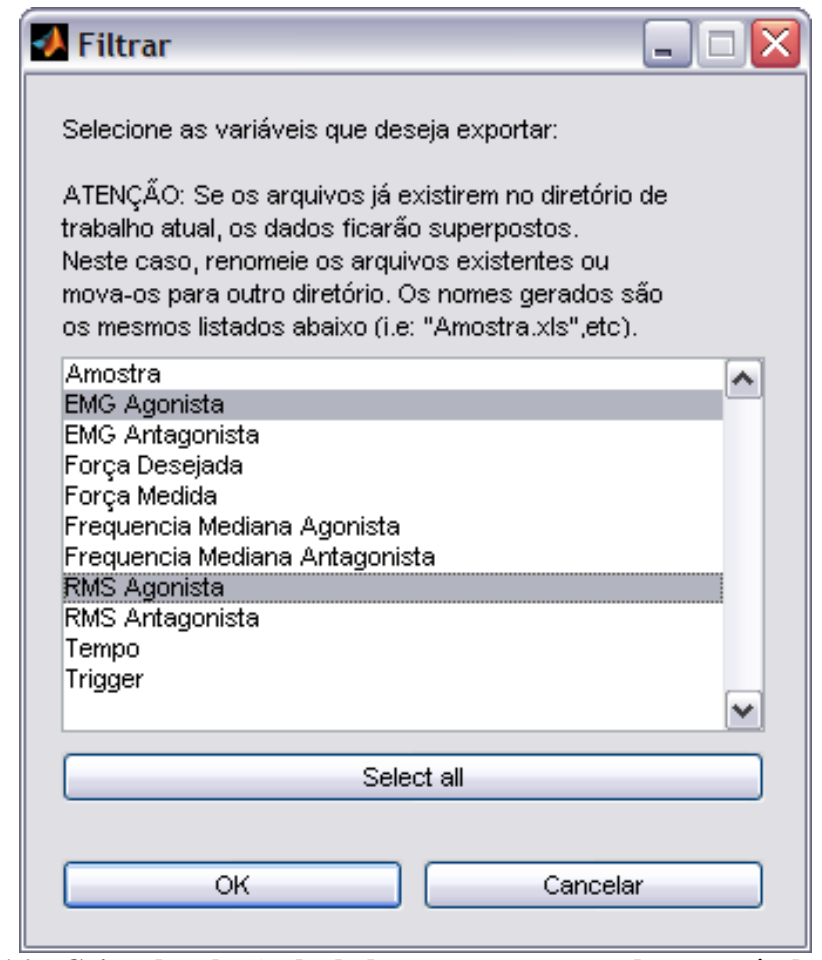

Figura 4.16 - Caixa de seleção de dados a serem exportados através do Filtrar06. 


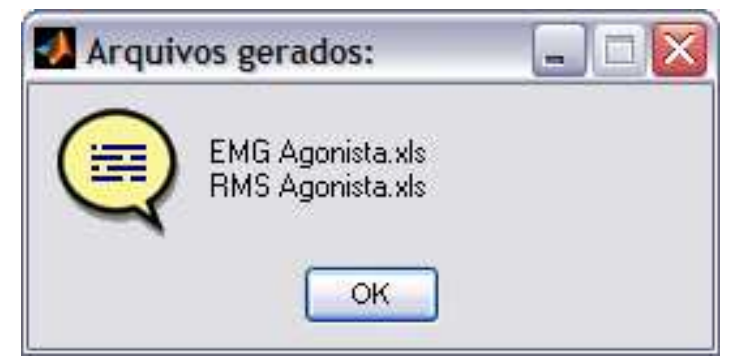

Figura 4.17 - Arquivos gerados pelo Filtrar06.

\subsection{2 - Statistica 6.0}

$\mathrm{Na}$ análise dos sinais de EMG-S de cada posto de trabalho, não foram realizados processos de filtragem, branqueamento nem integração dos sinais digitais. Para cada sinal foram estimados os valores de amplitude na forma de raiz quadrática média (RMS), por meio de janelas retangulares deslizantes de largura de $0,5 \mathrm{~s}$, com sobreposição entre elas de $0,2 \mathrm{~s}$, tendo sido gerados dezenove valores RMS.

A etapa seguinte consistiu na normalização dos dados. Respeitando-se a independência entre os sujeitos, foi calculado o valor médio dos dezenove valores RMS do posto de trabalho Ar. A partir daí, todos os valores RMS dos cinco postos de trabalho foram divididos pelo valor médio do RMS no Ar, obtendo-se, assim, uma normalização pelo posto Ar. Obviamente, o novo valor médio do posto Ar passou a ser igual a um para todos os sujeitos. Estes cálculos foram feitos no Excel (Microsoft, EUA).

Para a análise estatística dos dados do EMG-S utilizou-se o pacote Statistica 6.0 (Statsoft, Tulsa, EUA). Empregou-se então o teste ANOVA (analysis of variance - análise de variância) de medidas repetidas para uma análise multifatorial do tipo 5x19x15, correspondendo aos cinco postos de trabalho, dezenove medidas de RMS por posto e aos quinze sujeitos experimentais, como ilustrado na Figura 4.18. Isso permitiu a comparação da amplitude do sinal de EMG-S nos cinco postos de trabalho. 


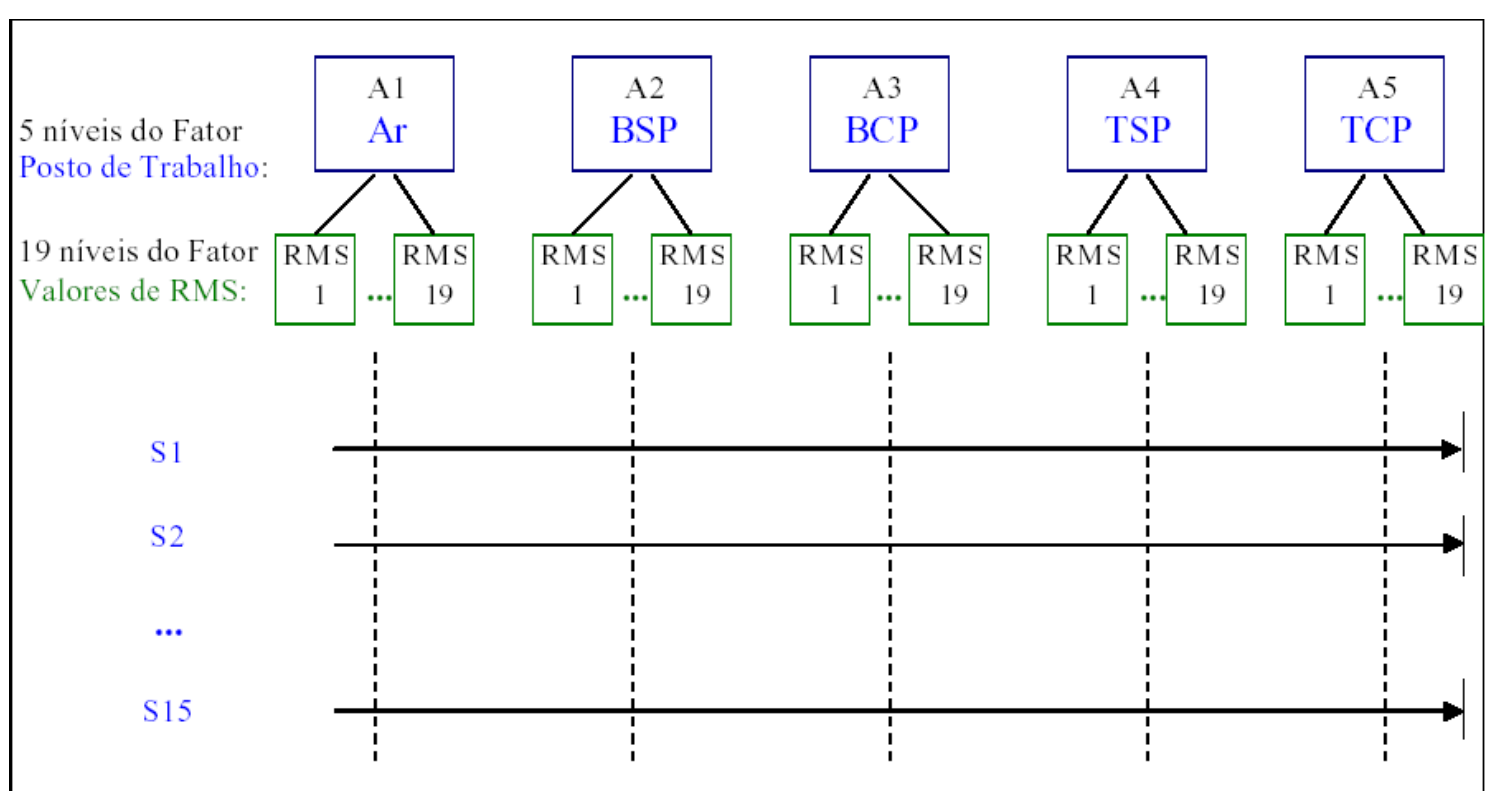

Figura 4.18 - Delineamento estatístico (5x19x15): “intra-sujeito”, com cinco níveis do fator posto de trabalho, dezenove níveis do fator valores de RMS e quinze sujeitos (representados por S1 a S15). BSP e BCP: tanque pequeno sem e com pulseira; TSP e TCP: tanque grande sem e com pulseira.

\section{3 - VALIDAÇÃO DA PARTE EXPERIMENTAL}

\subsection{1 - Tratamento Estatístico dos Dados Coletados}

Os sujeitos efetuaram contração voluntária máxima de 20,1 \pm . 5,13 kgf (média \pm . desvio padrão). A título de exemplificação da qualidade do sinal eletromiográfico captado, na Figura 4.19 está apresentado um sinal bruto, escolhido aleatoriamente entre os captados nos experimentos. Na Figura 4.20 é mostrada a densidade espectral de potência desse mesmo sinal. É interessante notar que a contaminação por ruído de $60 \mathrm{~Hz}$ não é expressiva. 


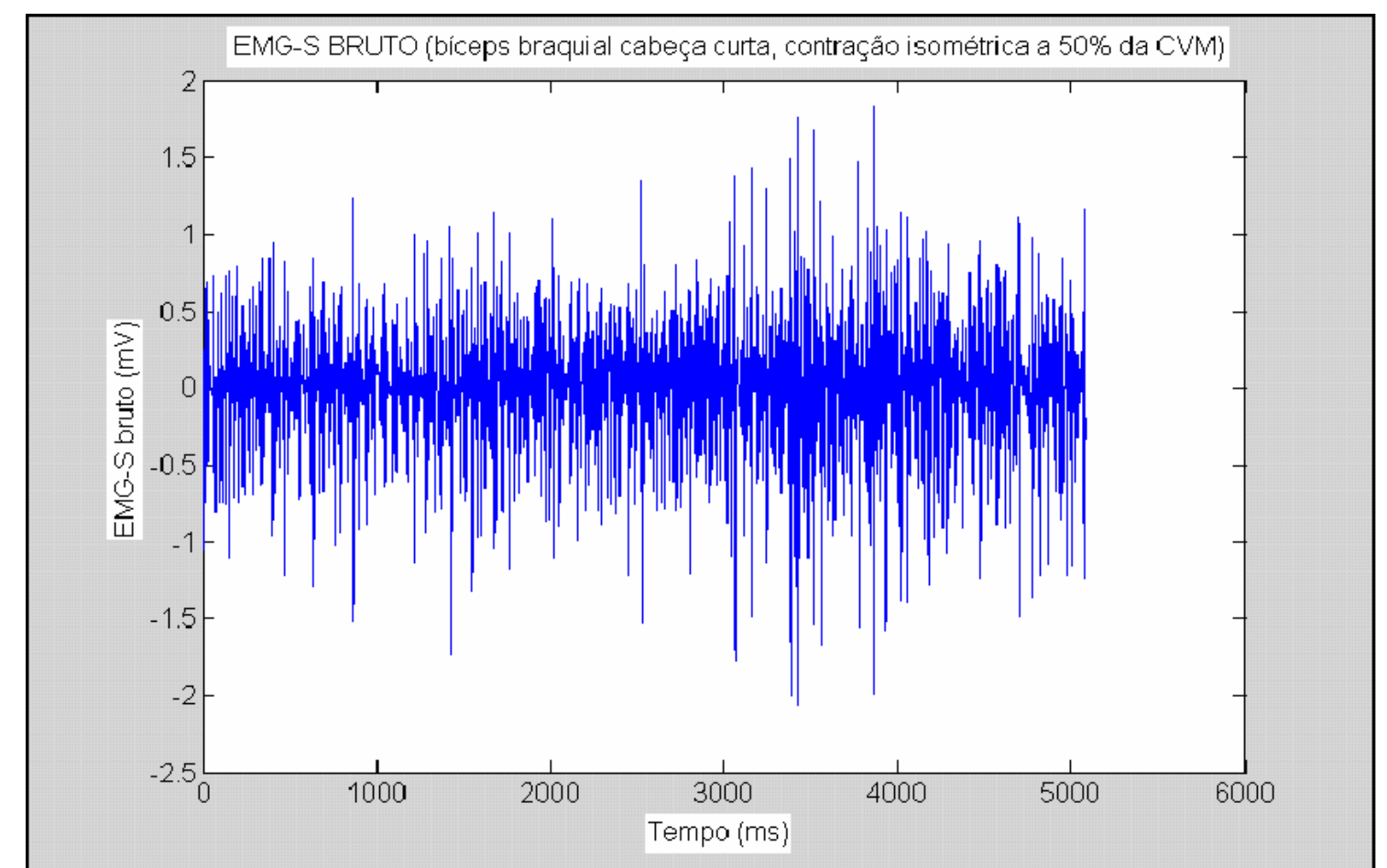

Figura 4.19 - Sinal bruto de EMG. Contração isométrica de 5 segundos do bíceps braquial cabeça curta a $50 \%$ da CVM. Taxa de aquisição de $1024 \mathrm{~Hz}$.

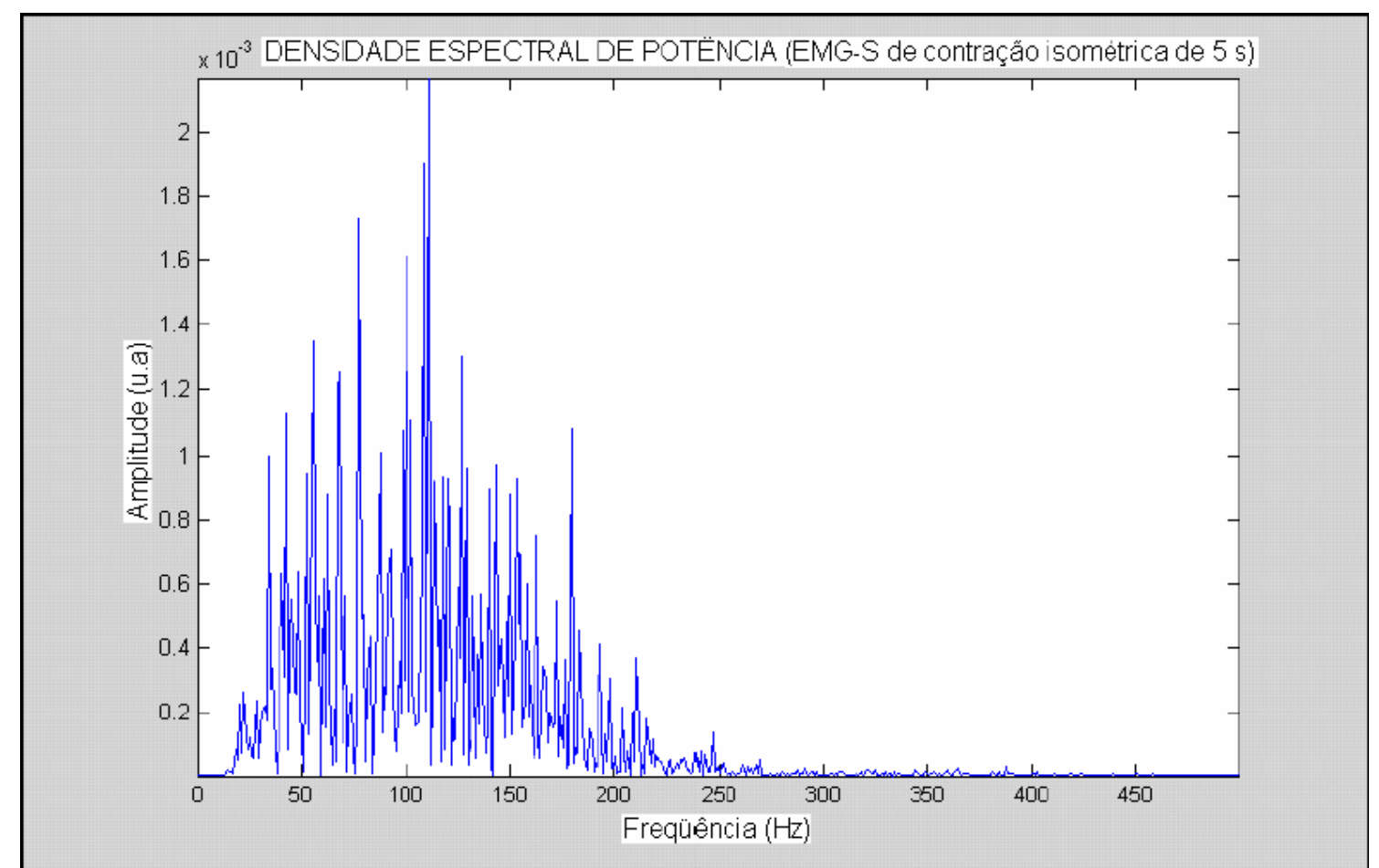

Figura 4.20 - Densidade espectral de potência do sinal de EMG apresentado na figura anterior. FFT (Fast Fourier

Transform) calculada em janelas retangulares e deslizantes de $0,5 \mathrm{~s}$, com sobreposição de $0,2 \mathrm{~s}$.

A Figura 4.21 apresenta uma visão panorâmica dos valores médios e desvios-padrão dos dezenove valores RMS de cada posto de trabalho, estratificados por sujeito. Isso também está apresentado nas Tabelas 4.1 e 4.2. Fica evidenciada a dificuldade de ser efetuada uma 
comparação entre os postos de trabalho sem que se lance mão de ferramentas estatísticas mais apuradas.

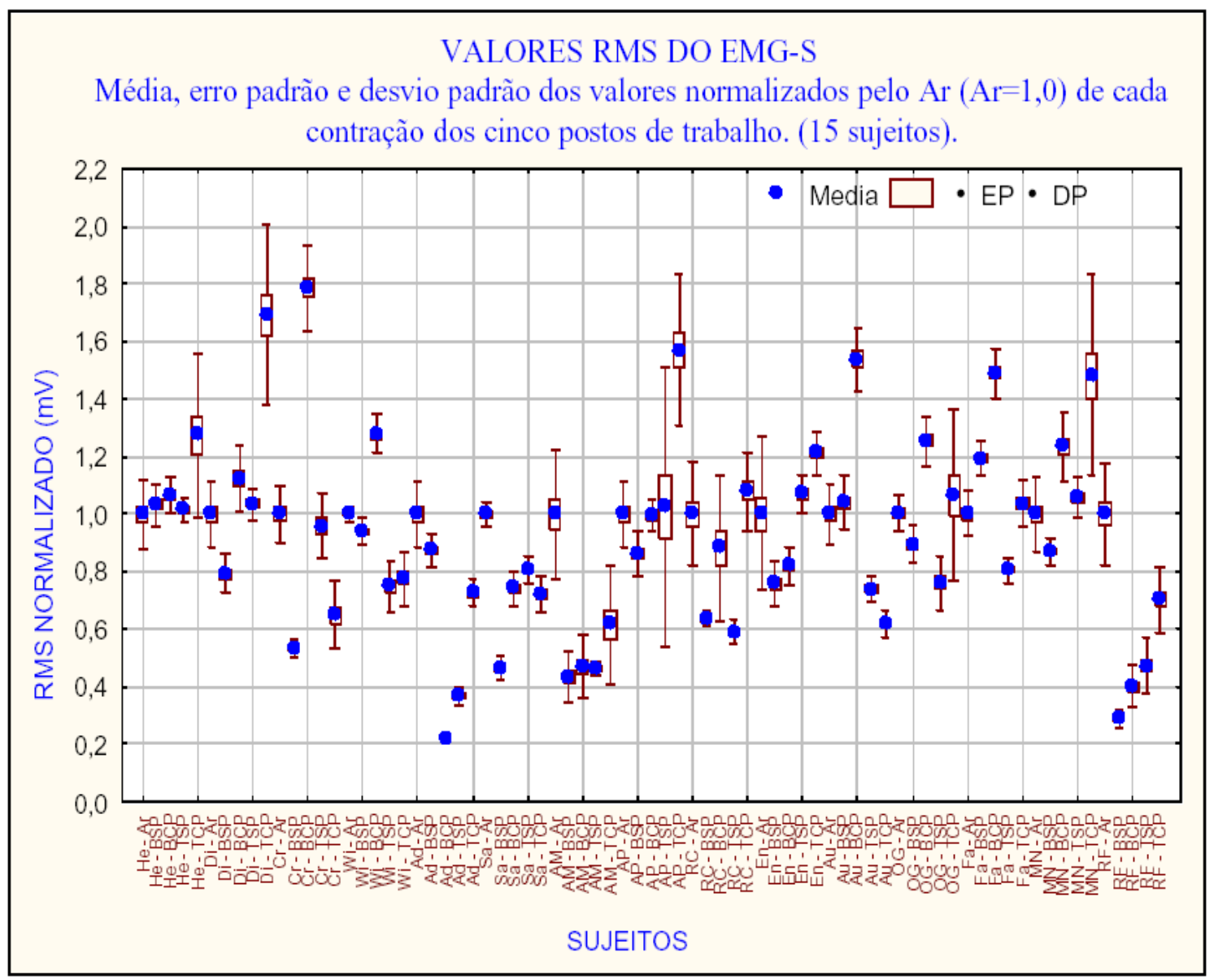

Figura 4.21 - Valores médios, erros padrão (EP) e desvios-padrão (DP) dos valores RMS (normalizado s pelo Ar) das contrações dos cinco postos de trabalho. Total de 15 sujeitos. BSP e BCP: tanque pequeno sem e com pulseira; TSP e TCP: tanque grande sem e com pulseira. As primeiras letras indicam os sujeitos. 
Tabela 4.1 - Estatística descritiva dos valores de RMS de cada contração de cada posto de trabalho, estratificada por sujeito. BSP e BCP: tanque pequeno sem e com pulseira; TSP e TCP: tanque grande sem e com pulseira.

Estatística Descritiva - RMS, em mV, normalizado pelo $\operatorname{Ar}(\mathrm{Ar}=1,0)$

\begin{tabular}{|c|c|c|c|c|c|c|c|}
\hline Sujeitos & $\begin{array}{c}\mathbf{N} \\
\text { Válido }\end{array}$ & Média & Mínimo & Máximo & Variância & $\begin{array}{l}\text { Desvio } \\
\text { Padrão }\end{array}$ & $\begin{array}{c}\text { Erro } \\
\text { Padrão }\end{array}$ \\
\hline $\mathrm{He}-\mathrm{Ar}$ & 19 & 1,0000 & 0,8304 & 1,2331 & 0,0146 & 0,1208 & 0,0277 \\
\hline $\mathrm{He}-\mathrm{BSP}$ & 19 & 1,0325 & 0,9022 & 1,1655 & 0,0057 & 0,0752 & 0,0173 \\
\hline $\mathrm{He}-\mathrm{BCP}$ & 19 & 1,0635 & 0,9734 & 1,1729 & 0,0037 & 0,0605 & 0,0139 \\
\hline $\mathrm{He}-\mathrm{TSP}$ & 19 & 1,0159 & 0,9157 & 1,0755 & 0,0018 & 0,0423 & 0,0097 \\
\hline $\mathrm{He}-\mathrm{TCP}$ & 19 & 1,2737 & 0,8486 & 1,6444 & 0,0823 & 0,2869 & 0,0658 \\
\hline $\mathrm{Di}-\mathrm{Ar}$ & 19 & 1,0000 & 0,8916 & 1,2316 & 0,0124 & 0,1115 & 0,0256 \\
\hline Di - BSP & 19 & 0,7924 & 0,6692 & 0,8816 & 0,0044 & 0,0666 & 0,0153 \\
\hline Di - BCP & 19 & 1,1217 & 0,9547 & 1,3332 & 0,0126 & 0,1124 & 0,0258 \\
\hline Di - TSP & 19 & 1,0358 & 0,9185 & 1,1220 & 0,0030 & 0,0548 & 0,0126 \\
\hline Di - TCP & 19 & 1,6906 & 1,3167 & 2,4622 & 0,0994 & 0,3153 & 0,0723 \\
\hline $\mathrm{Cr}-\mathrm{Ar}$ & 19 & 1,0000 & 0,8586 & 1,1546 & 0,0100 & 0,0998 & 0,0229 \\
\hline $\mathrm{Cr}-\mathrm{BSP}$ & 19 & 0,5351 & 0,4864 & 0,5887 & 0,0010 & 0,0315 & 0,0072 \\
\hline $\mathrm{Cr}-\mathrm{BCP}$ & 19 & 1,7867 & 1,5141 & 2,1411 & 0,0214 & 0,1464 & 0,0336 \\
\hline $\mathrm{Cr}-\mathrm{TSP}$ & 19 & 0,9592 & 0,7176 & 1,0938 & 0,0125 & 0,1119 & 0,0257 \\
\hline $\mathrm{Cr}-\mathrm{TCP}$ & 19 & 0,6486 & 0,4155 & 0,8588 & 0,0138 & 0,1176 & 0,0270 \\
\hline $\mathrm{Wi}-\mathrm{Ar}$ & 19 & 1,0000 & 0,9484 & 1,0463 & 0,0008 & 0,0281 & 0,0065 \\
\hline Wi - BSP & 19 & 0,9404 & 0,8810 & 1,0199 & 0,0023 & 0,0482 & 0,0111 \\
\hline $\mathrm{Wi}-\mathrm{BCP}$ & 19 & 1,2801 & 1,1681 & 1,3882 & 0,0046 & 0,0677 & 0,0155 \\
\hline Wi - TSP & 19 & 0,7497 & 0,6640 & 1,0003 & 0,0083 & 0,0913 & 0,0209 \\
\hline $\mathrm{Wi}$ - TCP & 19 & 0,7770 & 0,6578 & 0,9095 & 0,0085 & 0,0922 & 0,0211 \\
\hline $\mathrm{Ad}-\mathrm{Ar}$ & 19 & 1,0000 & 0,7901 & 1,1827 & 0,0131 & 0,1146 & 0,0263 \\
\hline $\mathrm{Ad}-\mathrm{BSP}$ & 19 & 0,8737 & 0,7685 & 0,9660 & 0,0037 & 0,0607 & 0,0139 \\
\hline $\mathrm{Ad}-\mathrm{BCP}$ & 19 & 0,2224 & 0,1986 & 0,2462 & 0,0002 & 0,0124 & 0,0029 \\
\hline $\mathrm{Ad}-\mathrm{TSP}$ & 19 & 0,3688 & 0,2993 & 0,4199 & 0,0010 & 0,0323 & 0,0074 \\
\hline $\mathrm{Ad}-\mathrm{TCP}$ & 19 & 0,7252 & 0,6373 & 0,8003 & 0,0022 & 0,0468 & 0,0107 \\
\hline $\mathrm{Sa}-\mathrm{Ar}$ & 19 & 1,0000 & 0,9302 & 1,0825 & 0,0020 & 0,0451 & 0,0103 \\
\hline $\mathrm{Sa}-\mathrm{BSP}$ & 19 & 0,4633 & 0,4103 & 0,5571 & 0,0018 & 0,0422 & 0,0097 \\
\hline $\mathrm{Sa}-\mathrm{BCP}$ & 19 & 0,7411 & 0,6788 & 0,8674 & 0,0037 & 0,0606 & 0,0139 \\
\hline As - TSP & 19 & 0,8081 & 0,7521 & 0,9516 & 0,0020 & 0,0446 & 0,0102 \\
\hline $\mathrm{Sa}-\mathrm{TCP}$ & 19 & 0,7226 & 0,6188 & 0,8174 & 0,0041 & 0,0639 & 0,0147 \\
\hline $\mathrm{AM}-\mathrm{Ar}$ & 19 & 1,0000 & 0,6179 & 1,2357 & 0,0496 & 0,2228 & 0,0511 \\
\hline$A M-B S P$ & 19 & 0,4335 & 0,3364 & 0,5990 & 0,0078 & 0,0883 & 0,0203 \\
\hline AM - BCP & 19 & 0,4692 & 0,3482 & 0,6489 & 0,0115 & 0,1072 & 0,0246 \\
\hline AM - TSP & 19 & 0,4607 & 0,4214 & 0,4969 & 0,0006 & 0,0253 & 0,0058 \\
\hline AM - TCP & 19 & 0,6155 & 0,4459 & 1,1786 & 0,0440 & 0,2097 & 0,0481 \\
\hline $\mathrm{AP}-\mathrm{Ar}$ & 19 & 1,0000 & 0,7812 & 1,1341 & 0,0129 & 0,1135 & 0,0260 \\
\hline AP - BSP & 19 & 0,8614 & 0,7291 & 1,0070 & 0,0057 & 0,0754 & 0,0173 \\
\hline$A P-B C P$ & 19 & 0,9916 & 0,8950 & 1,0858 & 0,0031 & 0,0556 & 0,0128 \\
\hline AP - TSP & 19 & 1,0272 & 0,7256 & 2,2212 & 0,2373 & 0,4871 & 0,1118 \\
\hline AP - TCP & 19 & 1,5677 & 1,1803 & 1,9067 & 0,0689 & 0,2625 & 0,0602 \\
\hline $\mathrm{RC}-\mathrm{Ar}$ & 19 & 1,0000 & 0,6663 & 1,2433 & 0,0322 & 0,1796 & 0,0412 \\
\hline $\mathrm{RC}-\mathrm{BSP}$ & 19 & 0,6363 & 0,5793 & 0,6715 & 0,0008 & 0,0289 & 0,0066 \\
\hline $\mathrm{RC}-\mathrm{BCP}$ & 19 & 0,8816 & 0,6206 & 1,2270 & 0,0662 & 0,2573 & 0,0590 \\
\hline RC - TSP & 19 & 0,5897 & 0,5234 & 0,7074 & 0,0019 & 0,0438 & 0,0100 \\
\hline $\mathrm{RC}-\mathrm{TCP}$ & 19 & 1,0785 & 0,8195 & 1,3329 & 0,0183 & 0,1354 & 0,0311 \\
\hline
\end{tabular}


Tabela 4.2 - Estatística descritiva dos valores de RMS de cada contração de cada posto de trabalho, estratificada por sujeito. Últimos seis dos quinze sujeitos. BSP e BCP: tanque pequeno sem e com pulseira; TSP e TCP: tanque grande sem e com pulseira. As primeiras letras indicam os sujeitos.

Estatística Descritiva - RMS, em mV, normalizado pelo $\operatorname{Ar}(\operatorname{Ar}=1,0)$

\begin{tabular}{|c|c|c|c|c|c|c|c|}
\hline Sujeitos & $\begin{array}{c}\text { N } \\
\text { Válido }\end{array}$ & Média & Mínimo & Máximo & Variância & $\begin{array}{c}\text { Desvio } \\
\text { Padrão }\end{array}$ & $\begin{array}{c}\text { Erro } \\
\text { Padrão }\end{array}$ \\
\hline En - Ar & 19 & 1,0000 & 0,7491 & 1,5550 & 0,0705 & 0,2655 & 0,0609 \\
\hline En - BSP & 19 & 0,7575 & 0,6240 & 0,9323 & 0,0063 & 0,0797 & 0,0183 \\
\hline En - BCP & 19 & 0,8184 & 0,7608 & 0,9793 & 0,0039 & 0,0627 & 0,0144 \\
\hline En - TSP & 19 & 1,0691 & 0,9035 & 1,1435 & 0,0049 & 0,0701 & 0,0161 \\
\hline En - TCP & 19 & 1,2125 & 1,1037 & 1,3443 & 0,0057 & 0,0753 & 0,0173 \\
\hline Au - Ar & 19 & 1,0000 & 0,8470 & 1,1980 & 0,0115 & 0,1073 & 0,0246 \\
\hline Au - BSP & 19 & 1,0386 & 0,9045 & 1,2143 & 0,0088 & 0,0940 & 0,0216 \\
\hline Au - BCP & 19 & 1,5372 & 1,4179 & 1,7513 & 0,0121 & 0,1102 & 0,0253 \\
\hline Au - TSP & 19 & 0,7394 & 0,6845 & 0,8517 & 0,0020 & 0,0445 & 0,0102 \\
\hline Au - TCP & 19 & 0,6185 & 0,5425 & 0,6997 & 0,0022 & 0,0467 & 0,0107 \\
\hline OG - Ar & 19 & 1,0000 & 0,8849 & 1,0872 & 0,0039 & 0,0625 & 0,0143 \\
\hline OG - BSP & 19 & 0,8957 & 0,7961 & 0,9971 & 0,0044 & 0,0667 & 0,0153 \\
\hline OG - BCP & 19 & 1,2546 & 1,1513 & 1,4280 & 0,0071 & 0,0845 & 0,0194 \\
\hline OG - TSP & 19 & 0,7635 & 0,5440 & 0,8533 & 0,0088 & 0,0940 & 0,0216 \\
\hline OG - TCP & 19 & 1,0646 & 0,7350 & 1,5230 & 0,0872 & 0,2953 & 0,0677 \\
\hline Fa - Ar & 19 & 1,0000 & 0,8568 & 1,0853 & 0,0062 & 0,0787 & 0,0180 \\
\hline Fa - BSP & 19 & 1,1940 & 1,0868 & 1,2828 & 0,0033 & 0,0577 & 0,0132 \\
\hline Fa - BCP & 19 & 1,4885 & 1,3168 & 1,6195 & 0,0074 & 0,0863 & 0,0198 \\
\hline Fa - TSP & 19 & 0,8049 & 0,7256 & 0,9027 & 0,0017 & 0,0415 & 0,0095 \\
\hline Fa - TCP & 19 & 1,0367 & 0,8692 & 1,1455 & 0,0066 & 0,0812 & 0,0186 \\
\hline MN - Ar & 19 & 1,0000 & 0,8276 & 1,1837 & 0,0163 & 0,1275 & 0,0292 \\
\hline MN - BSP & 19 & 0,8695 & 0,7772 & 0,9612 & 0,0025 & 0,0500 & 0,0115 \\
\hline MN - BCP & 19 & 1,2352 & 1,0403 & 1,4395 & 0,0143 & 0,1196 & 0,0274 \\
\hline MN - TSP & 19 & 1,0573 & 0,8657 & 1,1493 & 0,0053 & 0,0726 & 0,0167 \\
\hline MN - TCP & 19 & 1,4813 & 1,0501 & 1,9710 & 0,1213 & 0,3483 & 0,0799 \\
\hline RF - Ar & 19 & 1,0000 & 0,8281 & 1,3766 & 0,0312 & 0,1767 & 0,0405 \\
\hline RF - BSP & 19 & 0,2904 & 0,2491 & 0,3581 & 0,0011 & 0,0330 & 0,0076 \\
\hline RF - BCP & 19 & 0,4016 & 0,3184 & 0,5536 & 0,0053 & 0,0730 & 0,0167 \\
\hline RF - TSP & 19 & 0,4738 & 0,3927 & 0,7253 & 0,0099 & 0,0996 & 0,0228 \\
\hline RF - TCP & 19 & 0,7039 & 0,5109 & 0,8756 & 0,0129 & 0,1136 & 0,0261 \\
\hline
\end{tabular}


A fim de se verificar a hipótese de que, em termos de amplitude RMS do EMG-S, os postos de trabalho ar e tanques pequeno e grande com pulseira pertencem todos a um mesmo grupo, ao seja, não apresentam diferença estatística significativa, foi realizada uma análise de variância (ANOVA) para medidas repetidas desses três postos. O intervalo de confiança foi de 0,95. Os resultados estão apresentados na Figura 4.22.

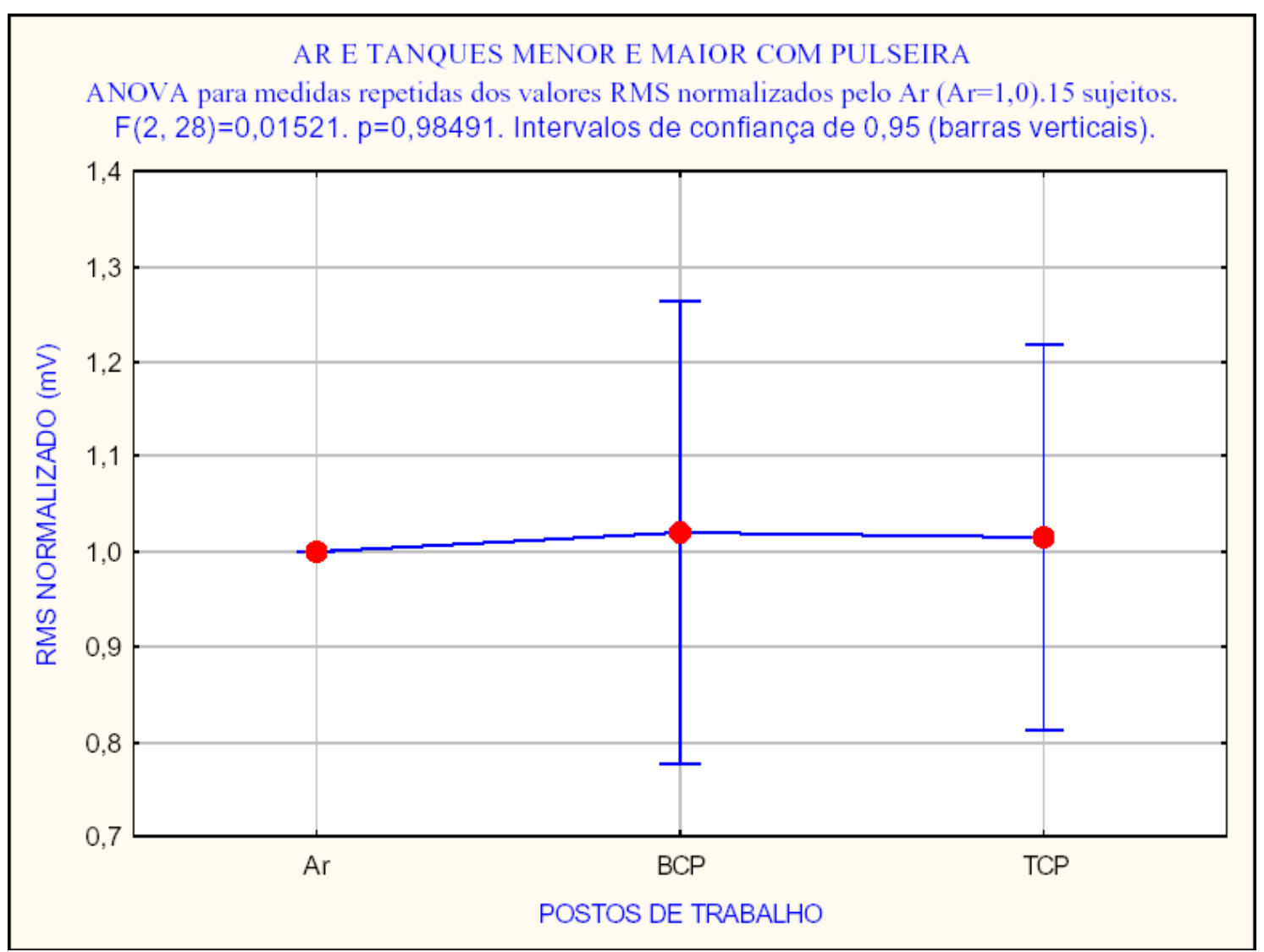

Figura 4.22 - ANOVA para medidas repetidas entre os postos de trabalho Ar e tanques pequeno (BCP) e grande com pulseira (TCP). $\mathrm{N}=15$ sujeitos.

Para se verificar a hipótese de que a compensação de empuxo altera o EMG- S, outra análise de variância para medidas repetidas foi realizada, agora entre os postos de trabalho tanque pequeno sem (BSP) e com pulseira compensadora de empuxo (BCP). O resultado pode ser verificado na Figura 4.23. Raciocínio análogo foi empregado para os dados do tanque grande sem (TSP) e com a pulseira compensadora do empuxo (TCP), conforme está apresentado na Figura 4.24. 
TANQUE MENOR SEM E COM PULSEIRA

ANOVA para medidas repetidas dos valores RMS normalizados pelo $\operatorname{Ar}(\mathrm{Ar}=1,0) .15$ sujeitos.

$F(1,14)=6,0668 . p=0,02735$. Intervalos de confiança de 0,95 (barras verticais).

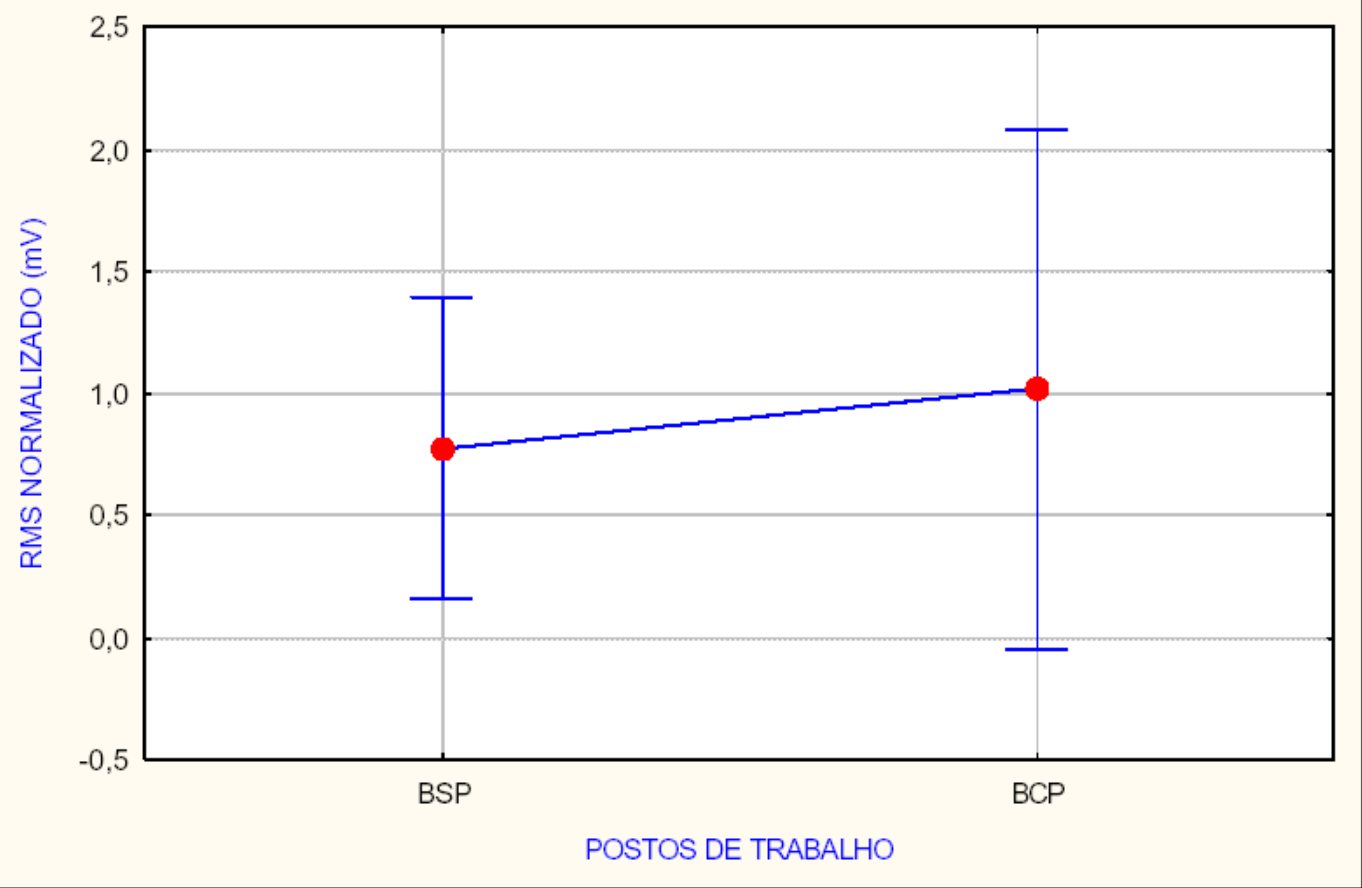

Figura 4.23 - ANOVA para medidas repetidas entre os postos de trabalho tanque pequeno sem (BSP) e com pulseira (BCP). $\mathrm{N}=15$ sujeitos.

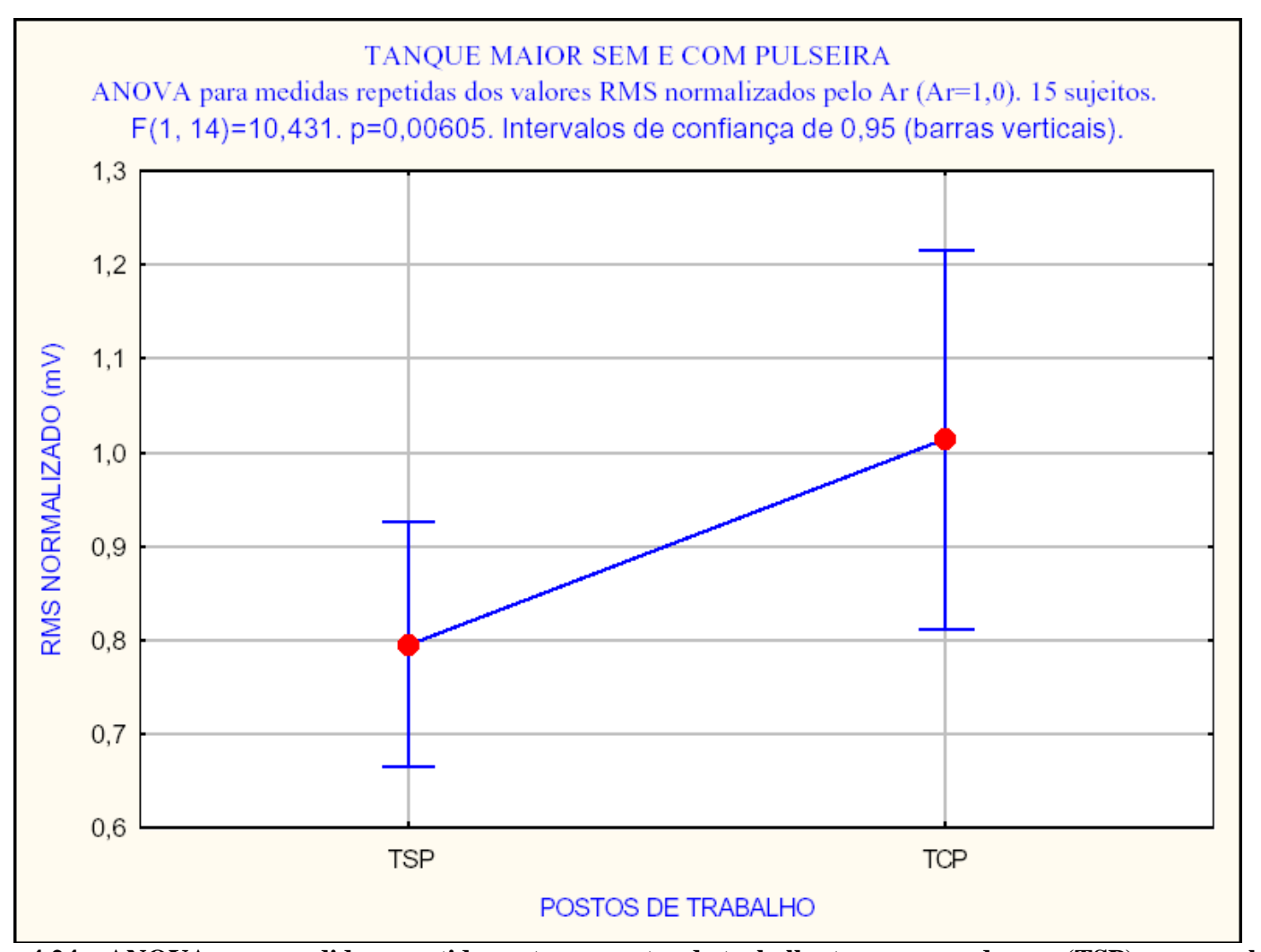

Figura 4.24 - ANOVA para medidas repetidas entre os postos de trabalho tanque grande sem (TSP) e com pulseira (TCP). $\mathrm{N}=15$ sujeitos. 
Para avaliar se ocorre diferença na amplitude RMS do sinal eletromiográfico de superfície quando se submerge somente o membro ou se submerge o sujeito até o nível do pescoço, foi realizada uma análise de variância entre os postos de trabalho tanques pequeno (BSP) e grande sem pulseira (TSP). Na Figura 4.25 está apresentado o resultado.

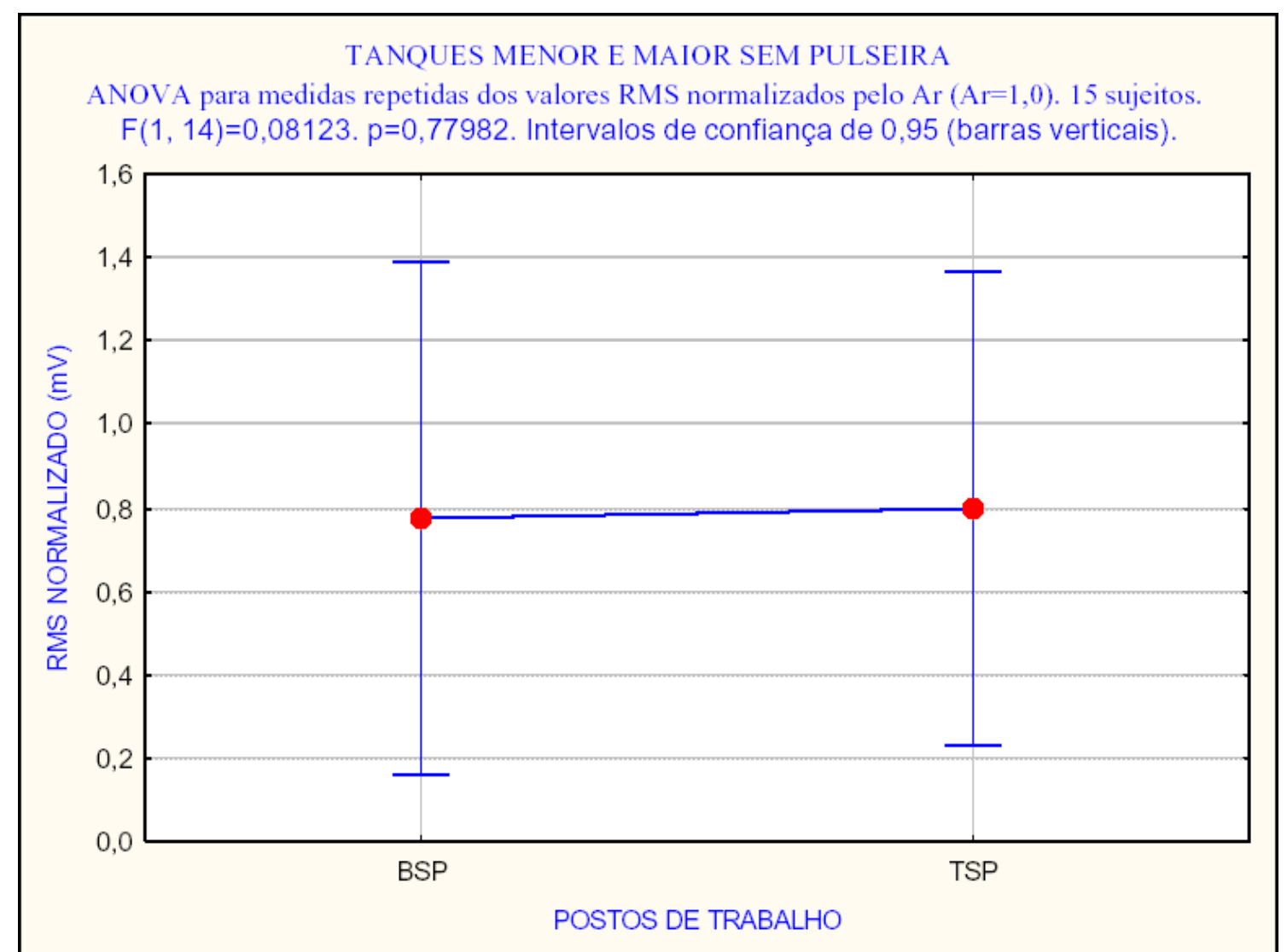

Figura 4.25 - ANOVA para medidas repetidas entre os postos de trabalho tanques pequeno (BSP) e grande sem pulseira (TSP). $\mathrm{N}=15$ sujeitos. 
A Figura 4.26 apresenta uma panorâmica da comparação dos valores RMS dos cinco postos de trabalho. A análise de variância indica que pelo menos um dos postos de trabalho se diferencia dos demais, pois o valor de pé de cerca de $1 \%$.

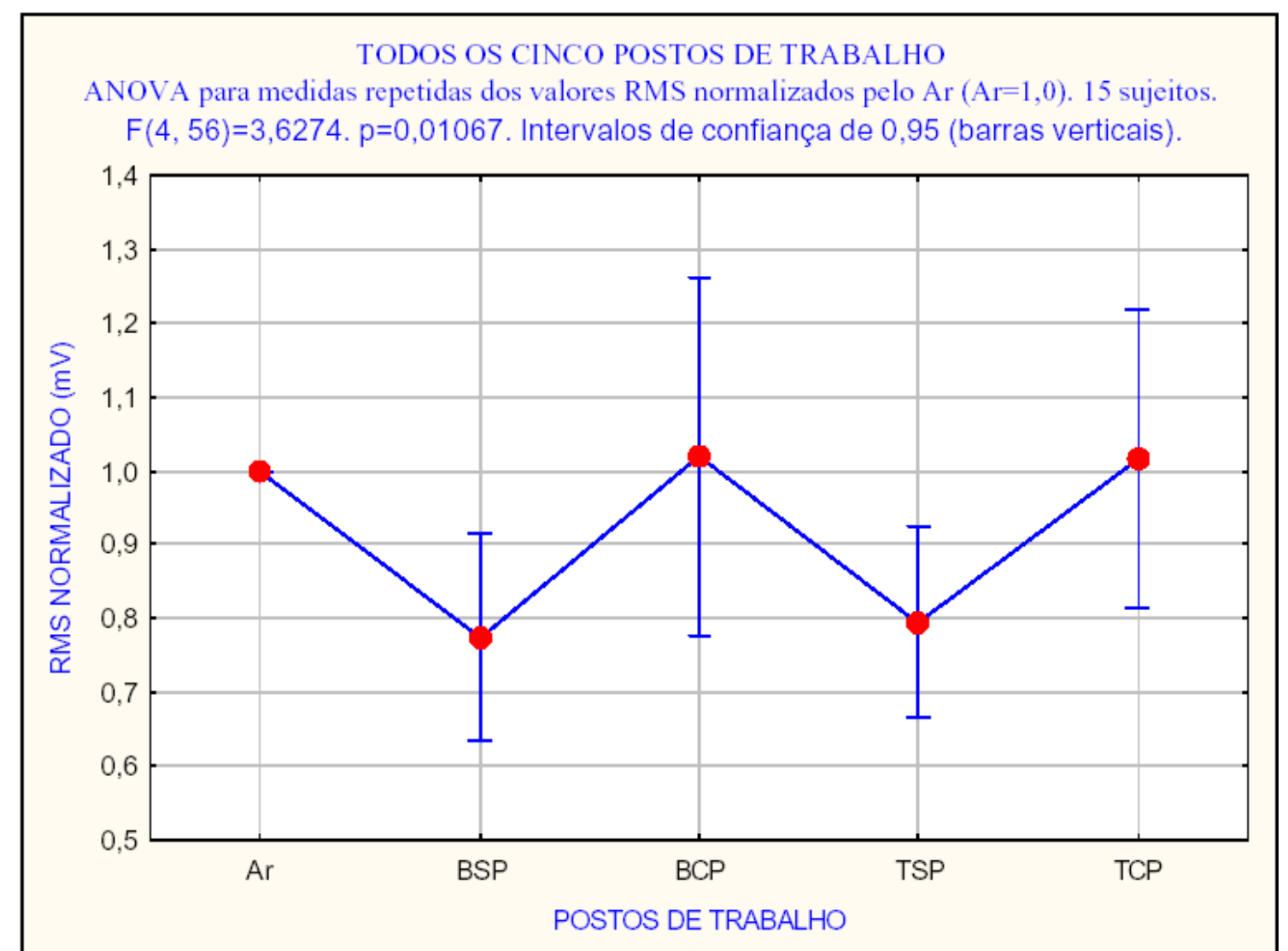

Figura 4.26 - Gráfico de ANOVA para medidas repetidas dos valores RMS (normalizados pelo Ar) nos cinco postos de trabalho. N=15 sujeitos. Legenda: BSP e BCP: tanque pequeno sem e com pulseira; TSP e TCP: tanque grande sem e com pulseira.

\subsection{2 - Avaliação dos Resultados}

Com referência à amplitude do sinal eletromiográfico (Figura 4.21), nota-se que o valor médio para o posto Ar é sempre igual a um, já que foi efetuada normalização dos dados. Também é claro que o desvio padrão é bem distinto de um sujeito para outro. Essa variabilidade nos dados era esperada, estando condizente com as características do sinal eletromiográfico de superfície.

Outro ponto a ser destacado é que varia entre os sujeitos a tendência de aumento, diminuição ou não-alteração da amplitude do EMG-S, quando um posto de trabalho é comparado com outro. Em alguns sujeitos o EMG-S é mais sensível à compensação de 
empuxo que em outros. Por exemplo, comparando-se o valor médio de RMS do posto Ar com o do posto Tanque Pequeno Sem Pulseira, em 20\% dos sujeitos houve aumento, em $80 \%$ houve decremento e em $0 \%$ não houve alteração. Essas porcentagens são diversas entre os postos de trabalho. Isto está expresso na Tabela 4.3.

Tabela 4.3 - Tendências observadas na amplitude do EMG de cada um dos cinco postos de trabalho.

\section{Número de Sujeitos}

\begin{tabular}{|l|c|c|c|c|}
\hline Situação do RMS médio & Ar x BSP & BSP x BCP & Ar x TSP & TSP x TCP \\
\hline Sem alteração & 0 & 0 & 1 & 0 \\
\hline Incremento & 3 & 14 & 4 & 12 \\
\hline Redução & 12 & 1 & 10 & 3 \\
\hline
\end{tabular}

Total de sujeitos: 15

Legenda: BSP e BCP: tanque pequeno sem e com pulseira; TSP e TCP: tanque grande sem e com pulseira

Quanto às análises de variância, a Figura 4.22 mostra que não foi encontrada diferença estatística $(\mathrm{p}=0,98491)$ entre os grupos ar e tanques pequeno (BCP) e grande com uso de pulseira (TCP). Isto valida a primeira das hipóteses aventadas na introdução deste texto. $\mathrm{Ou}$ seja, desde que não haja alteração na temperatura intramuscular, e o esforço realizado pelo músculo seja o mesmo (empuxo compensado), a água, por si só, não causa alteração na amplitude do EMG-S.

É possível verificar que a segunda hipótese, a de que a compensação de empuxo faz diferença, também é verdadeira. Isto porque, tanto no gráfico da Figura 4.23 como no da Figura 4.24, está demonstrado que a amplitude do EMG-S dos postos de trabalho sem e com o uso de pulseira não pertencem a um mesmo grupo estatístico (p » $3 \%$ e p» 1\%, respectivamente).

Analisando-se a Figura 4.26, percebe-se que a amplitude (RMS) do EMG-S diminuiu quando os sujeitos passaram do posto Ar para o Tanque Pequeno Sem Pulseira, e aumentou quando foi adicionada a pulseira neste posto, indicando, portanto, que a compensação do efeito do empuxo foi efetiva, com aumento do esforço muscular.

Fenômeno similar ocorreu na comparação entre os postos Ar e Tanque Grande Sem e Com Pulseira. Assim, quando em água, e sem compensação do efeito do empuxo, o nível de 
ativação muscular foi menor do que no ambiente aéreo, já que o efeito de flutuação auxiliou os sujeitos a realizarem o movimento de flexão de cotovelo.

Comparando-se os dados obtidos nos tanques pequeno e grande, percebe-se que a amplitude do EMG é semelhante nos dois casos, quando não houve compensação de empuxo (Figura 4.25) e no caso do empuxo compensado (Figura 4.26). Talvez, pelo fato da temperatura da água ter sido idêntica nos dois tanques, e semelhante à da pele humana, os sujeitos não tenham passado por alterações fisiológicas significativas. Possivelmente, com um tempo de imersão bem mais prolongado no tanque grande, os sujeitos tivessem sofrido alterações fisiológicas significativas a ponto de influenciar, de forma perceptível, o eletromiograma de superfície do bíceps braquial cabeça curta.

As duas hipóteses aventadas na introdução deste texto foram investigadas e comprovadas como verdadeiras. Mostrou-se que o ambiente subaquático, em relação ao aéreo, somente influencia a amplitude do EMG-S quando as forças de empuxo não são compensadas, portanto, alterando significativamente o nível de esforço muscular. Esse fenômeno foi verificado, assim como afirmado anteriormente por Veneziano[13] em experimento no qual não houve influência expressiva de empuxo. Como extensão do raciocínio, conclui-se que a hidrocinesioterapia pode, de fato, ser útil nos casos em que se deseja efetuar exercícios com menor carga, já que a redução do peso-suporte do corpo humano, pelo efeito natural do empuxo em água, também diminui o esforço muscular.

É interessante ressaltar que, diferentemente de experimentos realizados por outros pesquisadores, citados anteriormente, este experimento lidou cuidadosamente com o efeito da temperatura e do empuxo na amplitude do EMG-S, propiciando maior diligência quanto às condições de contorno e aos fatores que confundem a análise. 


\section{5 - CONCLUSÕES}

\section{1 - CONCLUSÕES DOS OBJETIVOS PROPOSTOS}

Na análise do EMG-S subaquático conseguimos comprovar que, quanto à amplitude do sinal de EMG-S, devem pertencer a um mesmo grupo estatístico as contrações isométricas (flexão de cotovelo) do bíceps braquial cabeça curta realizadas em ambiente aéreo, em um tanque com imersão somente desse membro e em um outro tanque com imersão do sujeito até a altura do pescoço, sempre mantido o mesmo nível de esforço muscular, por meio do uso de uma pulseira compensadora do empuxo na água. Também comprovamos que a compensação do empuxo na água faz diferença, ou seja, pertencem a grupos estatisticamente distintos as amplitudes do EMG-S de contrações isométricas realizadas sem a compensação de empuxo (grupo 1) e com a compensação dele (grupo 2), apesar da força externa aplicada ao membro ser de mesma amplitude.

Portanto mostrou-se que o ambiente subaquático, em relação ao aéreo, somente influencia a amplitude do EMG-S quando as forças de empuxo não são compensadas, alterando significativamente o nível de esforço muscular. Tiramos daí também a conclusão prática de que a hidrocinesioterapia pode, de fato, ser útil nos casos em que se deseja efetuar exercícios com menor carga, já que a redução do peso-suporte do corpo humano, pelo efeito natural do empuxo em água, também diminui o esforço muscular.

O sistema de arranjo de eletrodos para eletromiografia de superfície desenvolvido, composto de elementos de hardware e de software para aquisição de sinais, foi implementado e, de acordo com os três critérios adotados foi um sucesso. Foi possível visualizar a zona de inervação e dos potenciais propagantes. Visualizamos a assinatura espectral dos sinais de EMG-S captados e, por fim, as estimativas da velocidade de condução das fibras musculares. Os valores encontrados para estes testes estão condizentes com valores encontrados em bibliografias. Embora o sistema utilizado seja um protótipo, criado com um baixo orçamento e sem uma correta blindagem eletromagnética, obteve resultados excelentes, comparados aos que encontramos em bibliografias de pesquisas que utilizaram equipamentos fabricados com tecnologia de ponta. 


\section{2 - DIFICULDADES ENCONTRADAS NO PROJETO}

Dentre as dificuldades encontradas no projeto, podemos destacar a interferência de linha oriunda de fontes externas. Essa interferência de linha sempre se apresenta como um problema durante a aquisição de bio-potenciais na superfície da pele. Ela ocorre pela presença de uma corrente na freqüência de $60 \mathrm{~Hz}$ que percorre a superfície da pele, corrente esta que se apresenta devido à capacitância entre o corpo e a terra e entre o corpo e fontes de energia próximas.

As pessoas são comumente expostas a esse ruído de linha, e embora não ofereça risco algum ao corpo humano, ele pode ser catastrófico na obtenção correta de bio-potenciais na superfície da pele. Isso porque o potencial de superfície resultante desta corrente pode ter magnitude bem maior do que os potenciais de EMG que estão sendo detectados pelos eletrodos.

No entanto, se o sistema de detecção de EMG estiver funcionando corretamente, a amplitude do potencial desse ruído, pode ser desprezada quando comparada com os potencias de EMG captados. Como já foi explicado no projeto de hardware implementado, a saída de um dos canais da sonda, é a diferença entre os potenciais detectados entre dois eletrodos. $\mathrm{O}$ ruído se apresenta como um sinal de grande amplitude que pouco se altera enquanto se propaga no espaço entre dois eletrodos. Já os potenciais de EMG, apresentam variações drásticas quando se propagam dentro desse mesmo espaço. Idealmente, portanto, o resultado obtido seria um sinal de EMG diferencial do qual estaria completamente subtraído a interferência de linha. 


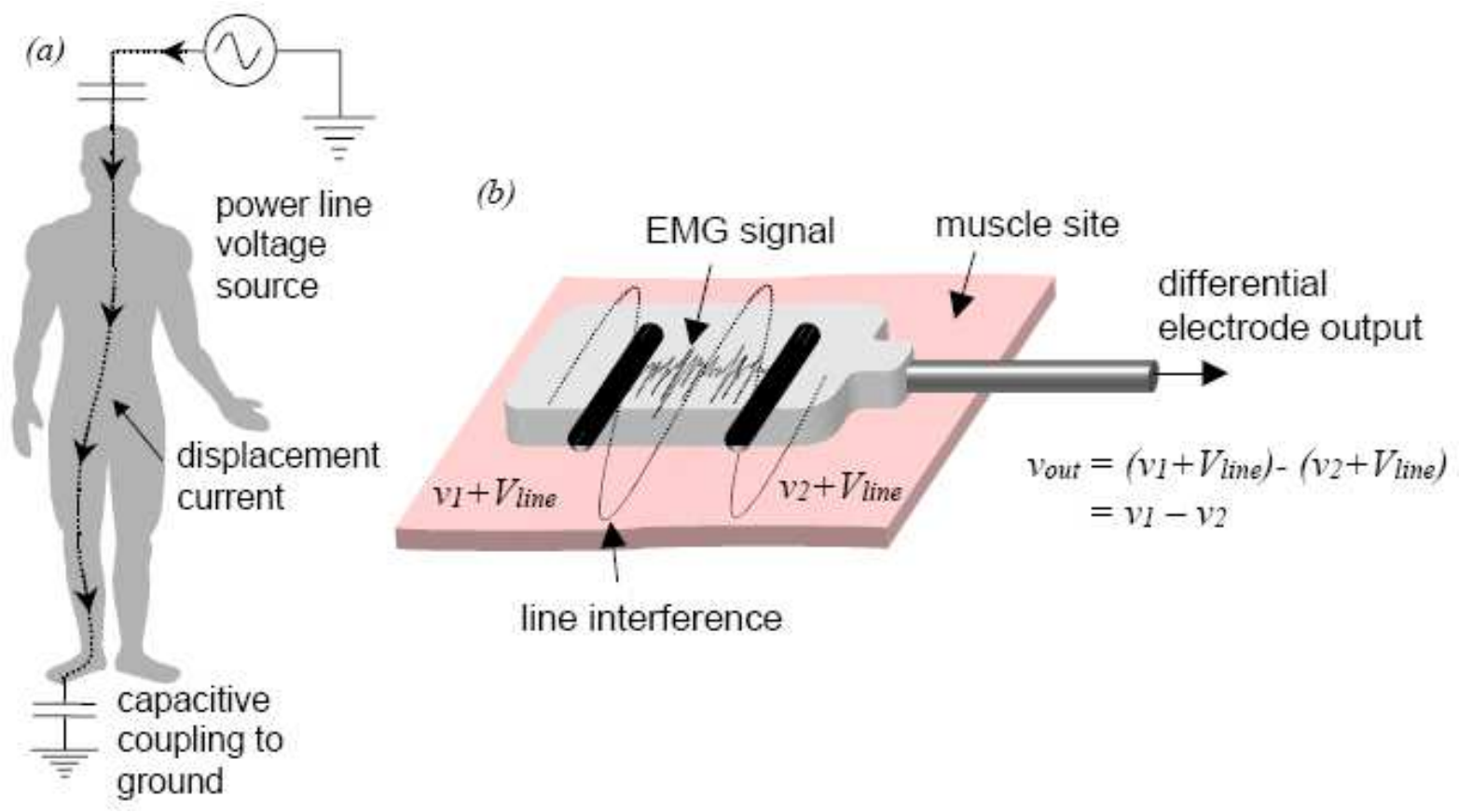

Figura 5.1 - (a) Fonte da interferência de linha captada nos sinais de EMG. (b) Subtração do sinal de ruído de linha, através do funcionamento ideal de um eletrodo diferencial.[10]

Durante a realização da parte experimental deste projeto, constatou-se a dificuldade de se eliminar completamente o ruído de linha, interferência esta que sempre se fará presente devido a um CMRR finito do eletrodo utilizado e devidos às conexões elétricas imperfeitas entre os contatos de prata dos eletrodos e a pele do sujeito. Tentou-se reduzir ao máximo a influência desta interferência através dos seguintes processos: desligamos as fontes de energia próximas aos sujeitos, tentamos melhorar o contato eletrodo-pele através de uma correta limpeza do local de aplicação dos eletrodos, garantimos a completa fixação do eletrodo de referência na pele e tomamos o cuidado de aterrar todos os postos de trabalhos no qual havia submersão dos eletrodos no meio aquático.

Vale destacar também a grande dificuldade de se trabalhar com a eletromiografia no ambiente subaquático. Segundo Rainoldi[11], a necessidade de proteção dos eletrodos quando submergidos em água se faz necessário, pois os sinais captados neste ambiente têm suas características (amplitude e freqüência) drasticamente modificadas pela condutividade e movimento da água. A utilização de proteção contra água para os eletrodos de EMG-S assegura condições constantes na captação dos sinais durante todo o período do experimento. Significa também um ganho de tempo no sentido de se evitar a utilização de técnicas de correção para remoção de artefatos de baixas freqüências, uma vez que o movimento da água introduz um aumento no espectro de potencia dentro da faixa de freqüência 0-20 Hz. 
Durante a realização de nosso experimento, as técnicas utilizadas para a isolação dos eletrodos mostraram-se eficientes, não havendo contato algum dos mesmos com a água; fato este conferido após o termino do experimento com cada um dos candidatos. Uma maior dificuldade foi encontrada para se proteger a célula de carga utilizada, uma vez que se trata de um instrumento bastante sensível e que poderia ser facilmente danificado, pois se trata de um equipamento que não é resistente à água. A necessidade de se evitar que a célula de carga entrasse em contato com a água consumiu bastante tempo no processo de elaboração do protocolo experimental, porém esta dificuldade também foi contornada com sucesso.

\section{3 - SUGESTÕES PARA APRIMORAMENTO DO PROJETO}

A primeira fase de testes de nosso eletromiógrafo de superfície foi realizada com a utilização de protoboard e circuitos integrados com encapsulamento do tipo DIP - dual in-line package. Com estes testes mostrando que os circuitos funcionavam como esperado, partiu-se para a montagem da placa de circuito impresso utilizando os mesmos circuitos integrados.

Um possível aprimoramento no projeto de hardware seria a implementação do circuito com componentes do tipo SMD - surface mounted device, componentes estes exemplificados na figura abaixo:

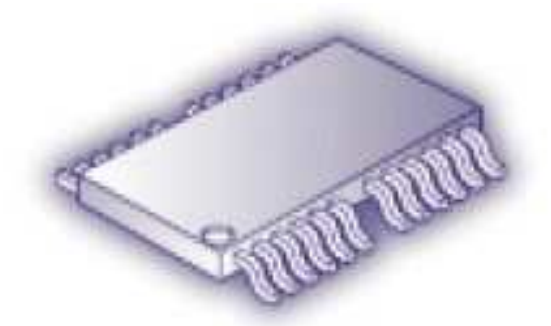

Figura 5.2 - Circuito integrado tipo SMD.

A utilização de componentes de montagem em superfície (SMD), que permitem a montagem por equipamentos de inserção automática é recomendada quando a fabricação é de muitas placas por mês e deseja-se automatizar a produção. Uma das grandes vantagens deste tipo de montagem é que há a redução drástica do tamanho físico das placas (aproximadamente $40 \%$ no tamanho do encapsulamento) uma vez que há a diminuição da espessura e comprimento das linhas condutoras. Eliminam-se capacitâncias e indutâncias parasitas em 
altas freqüências devido ao fato de uma menor indutância referente à distância entre o corpo do dispositivo e o traçado na placa de circuito impresso. Essa menor distância proporciona menores áreas de loops, potenciais geradores de corrente de RF.

Teríamos, portanto um aumento considerável na confiabilidade do sinal na saída do circuito, pois o circuito tornar-se-ia mais estável devido a uma maior imunidade à interferência eletromagnética além da eliminação de erros de montagem, pois se trata de um processo automatizado.

Devemos acrescentar também que a falha de qualquer instrumentação elétrica que possui contato direto ou contato galvânico indireto com a pele pode causar que uma corrente potencialmente prejudicial passe através da pele do sujeito. Esse problema é menos relevante em dispositivo tal como a sonda implementada, cuja alimentação é feita exclusivamente com baterias de baixa voltagem $(9 \mathrm{~V})$. Porém, existe a interface entre o eletromiógrafo e o computador utilizado para a digitalização dos dados obtidos. Para efeitos de segurança, o sujeito deveria estar eletricamente isolado de qualquer conexão elétrica (linha de energia ou terra) associada com a fonte de energia. Essa isolação poderia ser feita através de dois meios: através do uso de isoladores ópticos ou através do uso de transformadores de isolamento. Apesar de ambas as abordagens atenderem a especificação de isolamento, o uso de optoisoladores é o mais indicado, uma vez que transformadores podem acrescentar distorções ao sinal de EMG em estudo.

Além do aprimoramento do circuito em si, temos também como possíveis trabalhos futuros, a digitalização dos sinais dos eletrodos através de um microcontrolador, para conexão com um computador por portas USB ou serial e programas com interfaces simples, voltadas para médicos e outros pesquisadores da área. 


\section{REFERÊNCIAS BIBLIOGRÁFICAS}

[1] - Apostila de Confecção de Circuitos Integrados, Universidade de Brasília, Brasília, 2005.

[2] - MONTROSE, Mark I. "EMC and the Printed Circuit Board: Design, theory and Layout made simple.”, IEEE Press Series on Electronics Technology, New York, 1999.

[3] - Introduction to Surface Eletromyography, Delsys, 2002.

[4] - Merletti R.; Parker P. "Eletromyography: Physiology, Engineering and Noninvasive Applications.", IEEE Press Series on Engineering in Medicine and Biology, New Jersey, 2004.

[5] - SENIAM: Surface electromyography for the non-invasive assessment of muscles, Torino, Italy, 1996.

[6] - Masuda T.; Sadoyama T. "The propagation of single motor unit action potentials detected by a surface electrode array", Electroenc Clin Neurophysiol 63, 590-598, 1986.

[7] - Broman H.; Bolotto G; De Luca C. "Myoelectric signal conduction velocity and spectral parameters: influence of force and time”, J Appl Physiol 58, 1428-1437, 1985.

[8] - Merletti R.; De Luca C. "New techniques in surface electromyography", Computeraided electromyography and expert systems, Elsevier Science, Amsterdam, 1989.

[9] - Farina D.; Fortunato E; Merletti R. "Non-invasive estimation of motor unit conduction velocity distribution using linear electrode arrays", IEEE Trans BME 41, 380-388, 2000.

[10] - Bagnoli 2 EMG System User Manual, Delsys, 2003.

[11] - Rainoldi, A.; Cescon, C.; Bottin, A.; Casale, R.; Caruso, I. "Surface EMG alterations induced by underwater recording.", J. Electromyography and Kinesiology 14, 325-331, 2004. [12] - Merletti, R.; Farina, D.; Gazzoni, M. "The linear electrode array: a useful tool with many applications", Journal of Electromyography and Kinesiology 13, 37-47, 2003.

[13] - VENEZIANO, W. H. "Estudo do Comportamento do Sinal Eletromiográfico de Superfície em Atividades Subaquáticas", Tese de Doutorado em Engenharia Elétrica, Publicação PPGENE. DM-009/06, Departamento de Engenharia Elétrica, Universidade de Brasília, Brasília, DF, 151 p, 2006.

[14] - Poyhonen, T.; Keskinen, K.L.; Hautala, A.; Savolainen, J.; Malkia, E. “A. Human isometric force production and electromyogram activity of knee extensor muscle in water and on dry land.”, Eur. J. Applied Physiology 80, 52-56, 1999. 
[15] - Fujisawa, H.; Suenaga, A.; Minami, A. "Electromyographic study during isometric exercise of the shoulder in head-out water immersion.", Journal of Shoulder and Elbow Surgery 7, 491-494, 1998.

[16] - Poyhonen, T. "Neuromuscular function during therapeutic knee exercise under water and on dry land.”, Arch Phys Med Rehabil 82, 1446-1452, 2001.

[17] - Kelly, B. T.; Roskin, L. A.; Kirkendal., D. T.; Speer K. P. "Shoulder muscle activation during aquatic and dry land exercises in nonimpaired subjects.”, J. Orthopaedic and Sports Physical Therapy 30, 204-210, 2000.

[18] - Merletti R.; Sabbahi M. A.; deLuca C. J. "Median frequency of the myoelectric signal. Effects of muscle ischemia and cooling.”, Eur. J. Appl. Physiol. Occup. Physiol. 3, 1984. 


\section{ANEXO A - FERRAMENTAS COMPUTACIONAIS DESENVOLVIDAS}

\section{Xarray033.m:}

version $=$ '0.33';

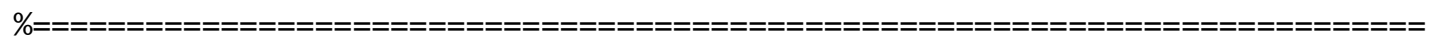

$\%=\mathrm{x}$-array - versão 0.33

$\%=$

$\%=$ sintaxe: $x$ array 033

$\%=$

$\%=$ É possível ajustar o tamanho das janelas e superposição de RMS e MDF

$\%=$ modificando os valores das variáveis 'rmssuper' , 'rmswindow' e

$\%=$ 'fmedsuper'. Possuem os seguintes valores padrão para uma taxa de

$\%=$ amostragem de $1024 \mathrm{~Hz}$ :

$\%=$ rmssuper $=205(0,2 \mathrm{~ms})$

$\%=$ rmswindow $=512(0,5 \mathrm{~ms})$

$\%=$ fmedsuper $=205(0,2 \mathrm{~ms})$

$\%=$

$\%=$ Contatenação de dados dos arquivos em uma só coluna está ativada para

$\%=$ uma quantidade par de arquivos analisados. A concatenação só está

$\%=$ disponível para ser feita 2 a 2 . Ou seja: ainda não é possível unir os

$\%=$ dados de mais de 2 arquivos em 1 só coluna. Apesar disso, ela funciona

$\%=$ muito bem para qualquer quantidade par de arquivos.

$\%=$ Para utilizá-1a, basta carregar uma quantidade par de arquivos

$\%=$

$\%=$

$\%=$ Bug detectado:

$\%=-$ Todos os arquivos processados devem possuir colunas exatamente do

$\%=$ mesmo tamanho, caso contrário ele trava e retorna o seguinte erro:

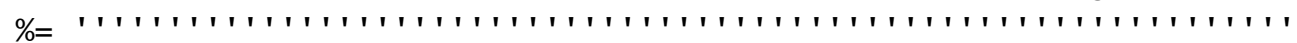

$\%=$ '??? Error using ==> \%horzcat'

$\%=$ 'A11 matrices on a row in the bracketed expression must have the'

$\%=$ 'same number of rows.

$\%=$ '

$\%=$ 'Error in $==>$ xray01 at 96

$\%=$ amostratm = [amostratm, amostra $]$;

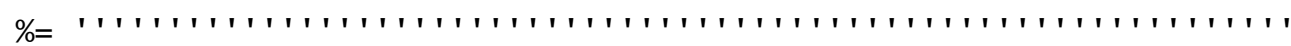

$\%=$ Caso isso ocorra, muda o valor da variável 'cut' de 0 para 1 e fixe a

$\%=$ variavel 'maxlines' como sendo igual ao número de linhas do arquivo

$\%=$ com o menor núemero de linhas.

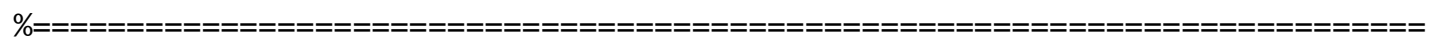

\% -> Um banner para o ínicio do programa.

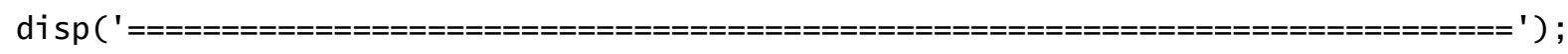

disp(['= X-Array - versão ', version,'

$='])$;

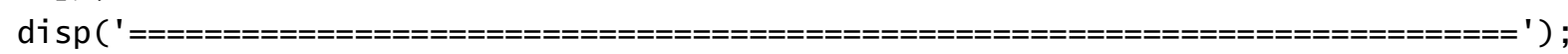

clear a11

\% Determina o ganho da sonda gain = 2200; 
\% Com esta variável ativada os gráficos da FFT ocuparão a maior área \% possível no eixo Y, e ficarão em escalas diferentes.

scretch $=1$;

\% Esta variável extrai o valor médio dos dados coletados, só para gerar os \% gráficos de EMG.

vmedio $=1$;

\% Prevenção de erro limitando a captura de um número máximo de 1inhas. Por \% padrão está desiigado.

cut $=0$;

maxlines $=1024$;

\% Esta variável faz com que as janelas das figuras apareçan todas de uma $\%$ vez ou somente uma por vez.

$\% \quad$ wwait $=1->$ Aguarda o fechamento de uma janela para abrir outra

$\% \quad$ wwait $=0 \quad->$ Abre todas janelad de uma vez (haja memória RAM)

wwait $=0$;

\% valores padrão para tensão máxima e tamaho da janela de tempo.

$\operatorname{maxV}={ }^{\prime} 0.5^{\prime}$;

twindow = '200';

\% Frequência de captura dos dados.

frequency = 1024;

\% -> Definindo tamanho de janelas RMS

rmssuper $=25$;

rmswindow $=50$;

\% -> Inicia (1) ou não (0) algoritmo de velocidade de condução $x$ vcon $=1$;

\% -> Definindo tamanho de janelas para Cálculo de velocidade de Condução crwindow = '204';

\% -> Definindo distância entre eletrodos, em metro

edist $=0.01$;

\% -> Invocando script: questiona se sedeja-se criar gráficos ou tabelas. $\%[$ graphs, tables $]=x$ generatequest () ;

graphs $=1$;

\% -> Se foi escolhido o modo de exportar dados para Tabelas Excel

$\%$ if tables $==1$

\% warndlg('Ainda não implementado', 'X-Ray')

$\%$ clear a11;

$\%$ break;

\%end

\% -> Abre uma janela para selecionar um arquivo a ser processado.

[file,path]=uigetfile('*.txt', 'Abra o arquivo que deseja processar:'); 


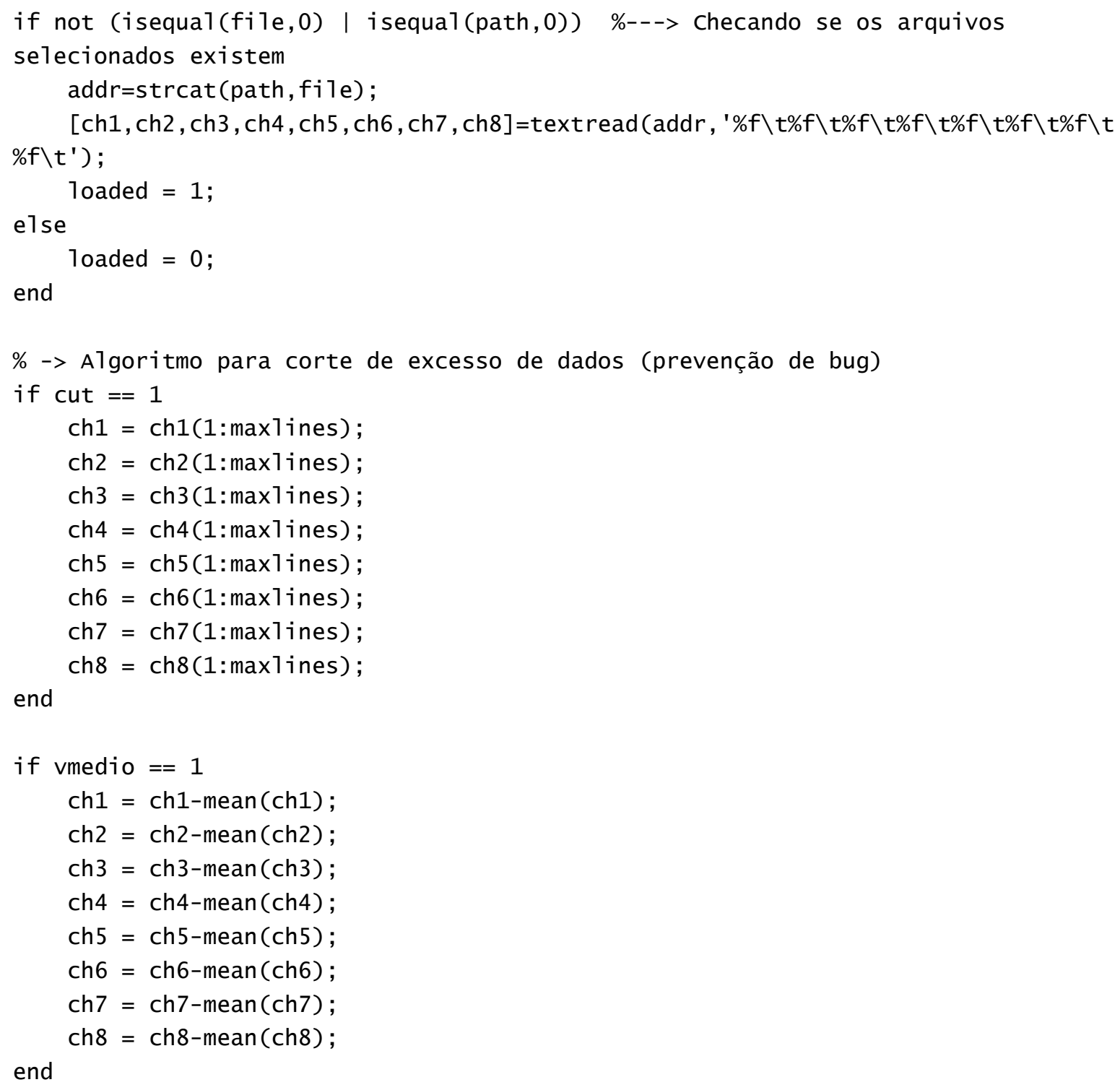




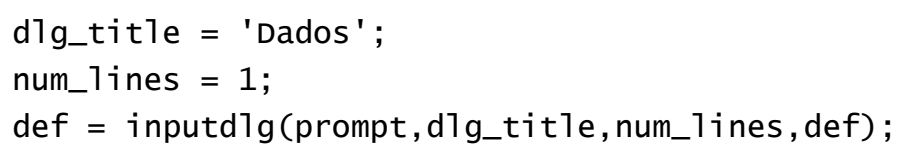


[ch1_fft, ch1_freq] $=$ xcalcfft $(\mathrm{ch} 1$, frequency $) ;$

[ch2_fft, ch2_freq] = xcalcfft $(\mathrm{ch} 2$, frequency $)$;

[ch3_fft, ch3_freq] $=$ xcalcfft $(\mathrm{ch} 3$, frequency $)$;

[ch4_fft, ch4_freq] = xcalcfft (ch4,frequency);

[ch5_fft, ch5_freq] $=$ xcalcfft (ch5, frequency);

[ch6_fft, ch6_freq] = xcalcfft (ch6, frequency);

[ch7_fft, ch7_freq] $=$ xcalcfft $(\mathrm{ch} 7$, frequency $)$;

[ch8_fft, ch8_freq] $=$ xcalcfft $(\mathrm{ch} 8$, frequency $)$;

\% Calcular a Frequencia Mediana do EMG Agonista

$\%$ fmediana_ch1 = calcfmed (ch1, fmedsuper, frequency);

$\%$ fmediana_ch2 = calcfmed (ch2, fmedsuper, frequency);

$\%$ fmediana_ch3 = calcfmed (ch3, fmedsuper, frequency);

$\% \quad$ fmediana_ch4 = calcfmed (ch4, fmedsuper, frequency);

$\%$ fmediana_ch5 = calcfmed (ch5, fmedsuper, frequency);

$\%$ fmediana_ch6 = calcfmed (ch6, fmedsuper, frequency);

$\% \quad$ fmediana_ch7 = calcfmed $(\mathrm{ch} 7$, fmedsuper, frequency $) ;$

$\%$ fmediana_ch8 = calcfmed (ch8, fmedsuper, frequency);

\% Plota todos gráficos do EMG Agonista

fu11p1otemg (1, 'X-Ray: EMG' , maxV, twindow, wwait, ch1, ch2, ch3, ch4, ch5, ch6, ch7, ch8)

$\% \quad$ ful1plot $\left(2,{ }^{\prime} X\right.$-Ray:

RMS ' , RMSch1, RMSch2, RMSch3, RMSch4, RMSch5, RMSch6, RMSch7, RMSch8)

\% fullplot (3,' 'X-Ray: Frequência

Mediana' , fmediana_ch1, fmedi ana_ch2, fmedi ana_ch3, fmediana_ch4, fmedi ana_ch5, fmedi ana_ ch6,fmediana_ch7, fmediana_ch8)

ful1fftplot (2, 'X-Ray:

FFT', scretch,ch1_fft, ch2_fft,ch3_fft,ch4_fft,ch5_fft,ch6_fft, ch7_fft,ch8_fft,ch1_fr eq, ch2_freq, ch3_freq, ch4_freq, ch5_freq, ch6_freq, ch7_freq, ch8_freq)

end

\% Inicia algoritmo para cálculo de velocidade de condução

if $x$ vcon $==1$

$\operatorname{cvmean}=\operatorname{cvp} 1$ ot $(\operatorname{ch} 1, \operatorname{ch} 2, \operatorname{ch} 3, \operatorname{ch} 4, \operatorname{ch} 5, \operatorname{ch} 6, \operatorname{ch} 7$, frequency, edist, cvwindow, 0,0$)$;

cvcal1 (cvmean);

end

clear a11;

\section{Xvc.m:}

version $=$ '0.1';

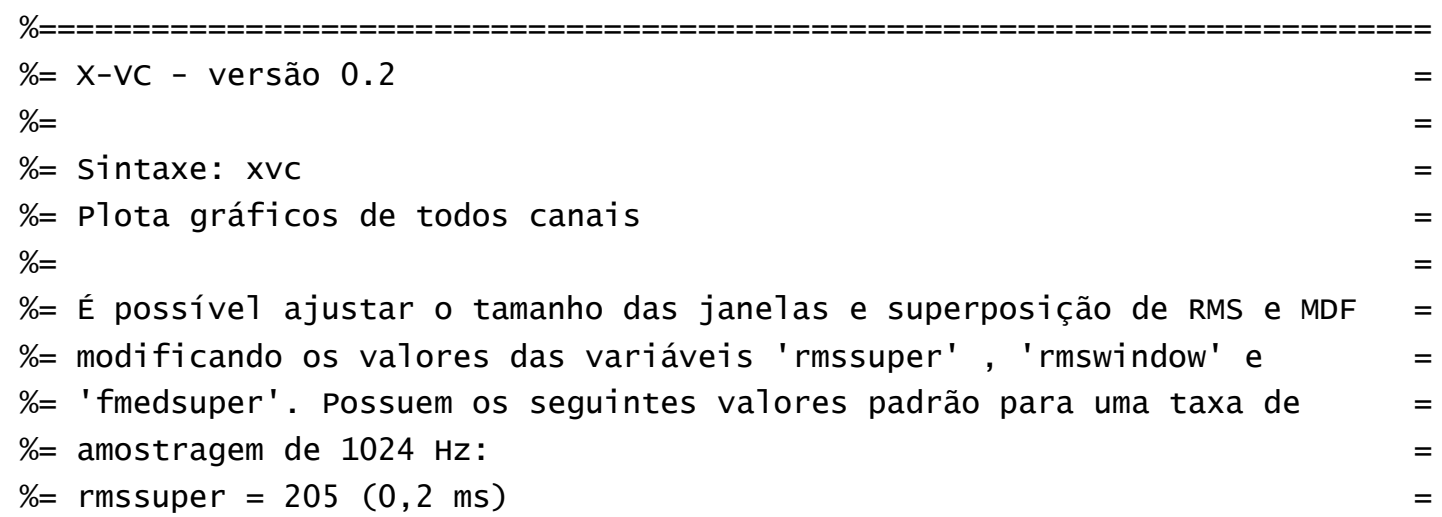




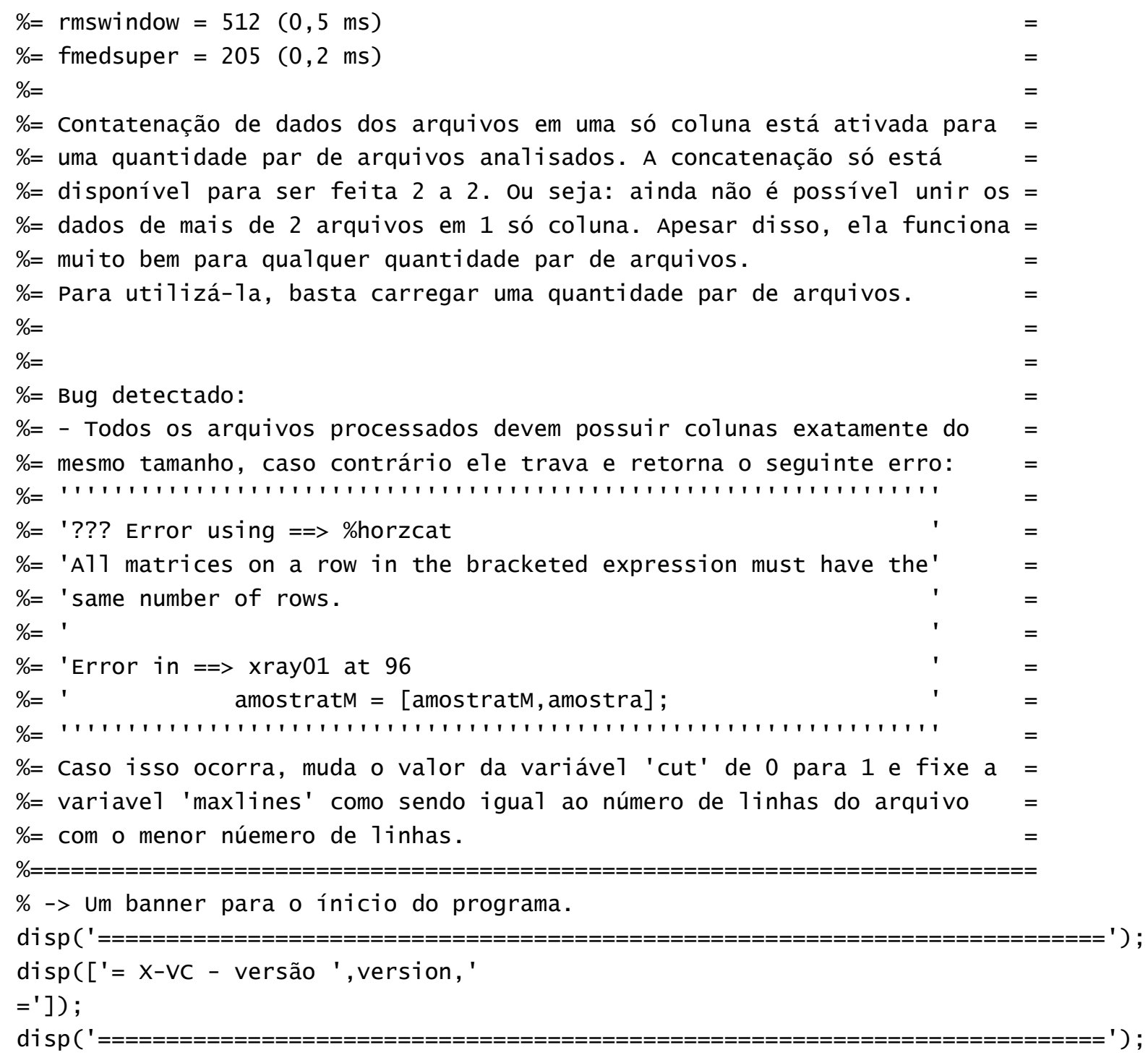


\% valores padrão para tensão máxima e tamaho da janela de tempo.

$\operatorname{maxV}={ }^{\prime} 1.0$ ';

twindow $=$ '200';

\% Frequência de captura dos dados.

frequency $=1024$;

$\%$-> Definindo tamanho de janelas RMS

rmssuper $=25$;

rmswindow $=50$;

\% -> Definindo tamanho de janelas para cálculo de velocidade de condução cvwindow = '204';

\% -> Definindo distância entre eletrodos, em metro

edist $=0.01$

\% -> Invocando script: questiona se sedeja-se criar gráficos ou tabelas.

$\%$ [graphs, tables] = xgeneratequest () ;

graphs $=0$;

\% -> Se foi escolhido o modo de exportar dados para Tabelas Excel

$\%$ if tables $==1$

\% warndlg('Ainda não implementado', 'X-Ray')

$\% \quad$ clear al1;

$\%$ break;

\%end

\% -> Abre uma janela para selecionar um arquivo a ser processado.

[file,path]=uigetfile('*.txt', 'Abra o arquivo que deseja processar:');

if not (isequal (file,0) | isequal(path,0)) \%---> Checando se os arquivos selecionados existem

addr=strcat (path, file);

$[\mathrm{ch} 1, \mathrm{ch} 2, \mathrm{ch} 3, \mathrm{ch} 4, \mathrm{ch} 5, \mathrm{ch} 6, \mathrm{ch} 7, \mathrm{ch} 8]=$ textread $\left(\operatorname{addr}, \mathrm{C}^{2} \% \mathrm{f} \backslash \mathrm{t} \% \mathrm{f} \backslash \mathrm{t} \% \mathrm{f} \backslash \mathrm{t} \% \mathrm{f} \backslash \mathrm{t} \% \mathrm{f} \backslash \mathrm{t} \% \mathrm{f} \backslash \mathrm{t} \% \mathrm{f} \backslash \mathrm{t}\right.$ $\left.\% f \backslash t^{\prime}\right)$;

loaded $=1$;

e1se

loaded $=0$;

end

\% -> Algoritmo para corte de excesso de dados (prevenção de bug)

if cut $==1$

$\operatorname{ch} 1=\operatorname{ch} 1(1: \max 1$ ines $)$;

$\operatorname{ch} 2=\operatorname{ch} 2(1: \max 1$ ines $) ;$

$\operatorname{ch} 3=\operatorname{ch} 3(1: \max 1$ ines $) ;$

ch4 = ch4(1:max7ines);

$\operatorname{ch} 5=\operatorname{ch} 5(1: \max 1$ ines $) ;$

$\operatorname{ch} 6=\operatorname{ch} 6(1: \max 7$ ines $) ;$

$\operatorname{ch} 7=\operatorname{ch} 7(1: \max 7$ ines $) ;$

$\operatorname{ch} 8=\operatorname{ch} 8(1: \max 1$ ines $) ;$ 
end

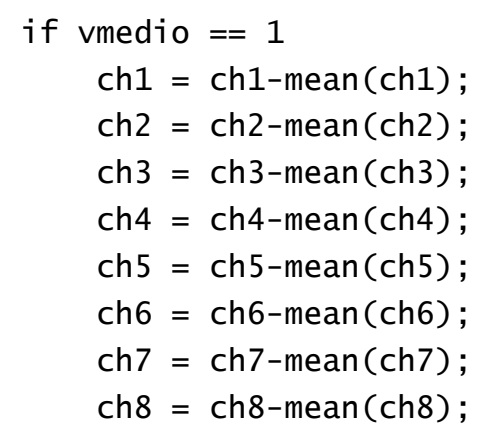


$\mathrm{h}=$ errordlg('"Janela da velocidade de Condução" deve ser um número

inteiro! Insira os dados novamente.', 'X-Array: erro!');

waitfor(h)

deferr $=1$;

end

end

\%Correção do tempo devido à frequencia de captura:

$\%$ twindow $=$ frequency $/(1 /($ twindow $/ 1000))$;

\% -> Se foi escolhido o modo de gerar gráfico:

if graphs $==1$

\% Calcular o valor do RMS do EMG Agonista

$\% \quad$ RMSch1 = calcemgrms (ch1, rmssuper, rmswindow);

$\% \quad$ RMSch2 = calcemgrms (ch2, rms super, rmswindow);

$\% \quad$ RMSch3 = calcemgrms (ch3, rmssuper, rmswindow);

$\% \quad$ RMSch4 = calcemgrms (ch4, rmssuper, rmswindow);

$\% \quad \operatorname{RMSch} 5=$ calcemgrms (ch5, rmssuper, rmswindow);

$\%$ RMSch6 = ca7cemgrms (ch6, rmssuper, rmswindow);

$\% \quad$ RMSch7 = calcemgrms (ch7, rmssuper, rmswindow);

$\% \quad$ RMSch8 = calcemgrms (ch8, rmssuper, rmswindow);

\% Calcular a FFT do EMG

[ch1_fft, ch1_freq] $=$ xcalcfft $(\mathrm{ch} 1$, frequency $)$;

[ch2_fft, ch2_freq] $=$ xcalcfft $(\mathrm{ch} 2$, frequency $)$;

[ch3_fft, ch3_freq] $=$ xcalcfft $(\mathrm{ch} 3$, frequency) ;

[ch4_fft, ch4_freq] = xcalcfft (ch4, frequency);

[ch5_fft, ch5_freq] $=$ xcalcfft $(\mathrm{ch} 5$, frequency $)$;

[ch6_fft, ch6_freq] $=$ xcalcfft $(\mathrm{ch} 6$, frequency);

[ch7_fft, ch7_freq] $=x \mathrm{ca}$ cffft $(\mathrm{ch} 7$, frequency $)$;

[ch8_fft, ch8_freq] $=x \mathrm{ca} 7 \mathrm{cfft}(\mathrm{ch} 8$, frequency);

\% Calcular a Frequencia Mediana do EMG Agonista

$\% \quad$ fmediana_ch1 = calcfmed (ch1, fmedsuper, frequency);

$\%$ fmediana_ch2 = calcfmed (ch2, fmedsuper, frequency);

$\%$ fmediana_ch3 = calcfmed (ch3, fmedsuper, frequency);

$\%$ fmediana_ch4 = calcfmed (ch4, fmedsuper, frequency);

$\% \quad$ fmediana_ch5 = calcfmed (ch5, fmedsuper, frequency);

$\% \quad$ fmediana_ch6 = calcfmed (ch6, fmedsuper, frequency);

$\% \quad$ fmediana_ch7 = calcfmed (ch7, fmedsuper, frequency $) ;$

$\% \quad$ fmediana_ch8 = calcfmed (ch8, fmedsuper, frequency);

\% Plota todos gráficos do EMG Agonista

fu17p1otemg (1, 'X-Ray: EMG' , maxV, twindow, wwait, ch1, ch2, ch3, ch4, ch5, ch6, ch7, ch8)

\% ful7plot $(2$, 'X-Ray:

RMS' , RMSch1, RMSch2, RMSCh3, RMSch4, RMSch5, RMSch6, RMSch7, RMSch8)

\% fullplot (3,'X-Ray: Frequência

Medi ana' , fmediana_ch1, fmediana_ch2,fmediana_ch3, fmediana_ch4, fmediana_ch5, fmediana_ ch6, fmediana_ch7, fmediana_ch8)

fullfftplot (2, 'X-Ray:

FFT', scretch, ch1_fft, ch2_fft, ch3_fft, ch4_fft, ch5_fft, ch6_fft, ch7_fft, ch8_fft, ch1_fr

eq,ch2_freq,ch3_freq,ch4_freq,ch5_freq,ch6_freq,ch7_freq,ch8_freq)

end

\% Inicia algoritmo para cálculo de velocidade de condução 
cvmean $=\operatorname{cvp} 1$ ot $(\operatorname{ch} 1, \operatorname{ch} 2, \operatorname{ch} 3, \operatorname{ch} 4, \operatorname{ch} 5, \operatorname{ch} 6, \operatorname{ch} 7$, frequency, edist, cvwindow, 0,0$)$;

cvcal1 (cvmean);

clear a11;

\section{Xcalcfft.m:}

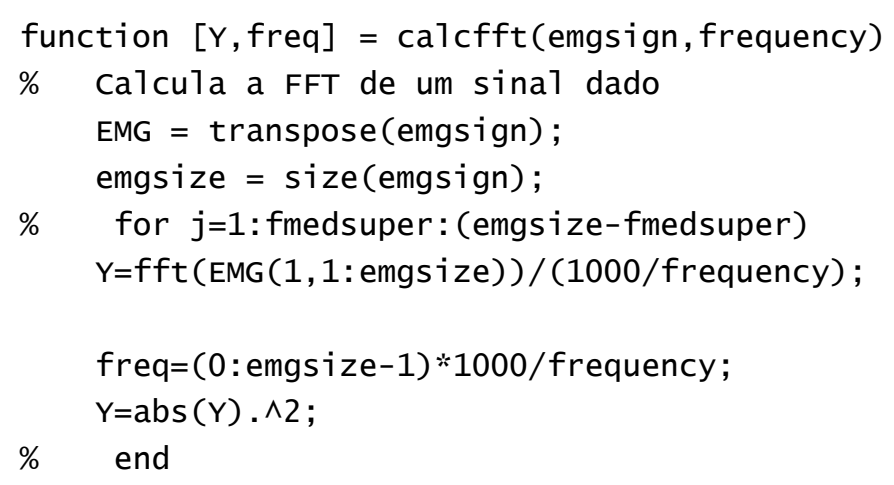

\section{Stat.m:}

\% calcula desvio padrão e média do vetor $x$

function [mean, stdev] $=\operatorname{stat}(x)$

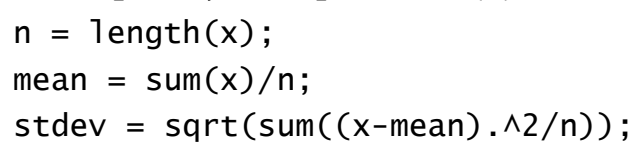

\section{Parity.m:}

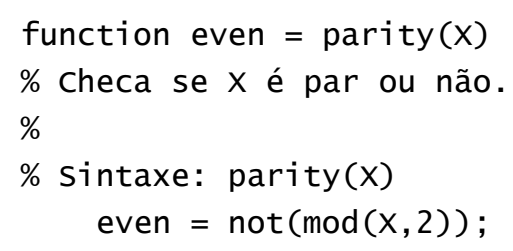

\section{Mcgill.m:}

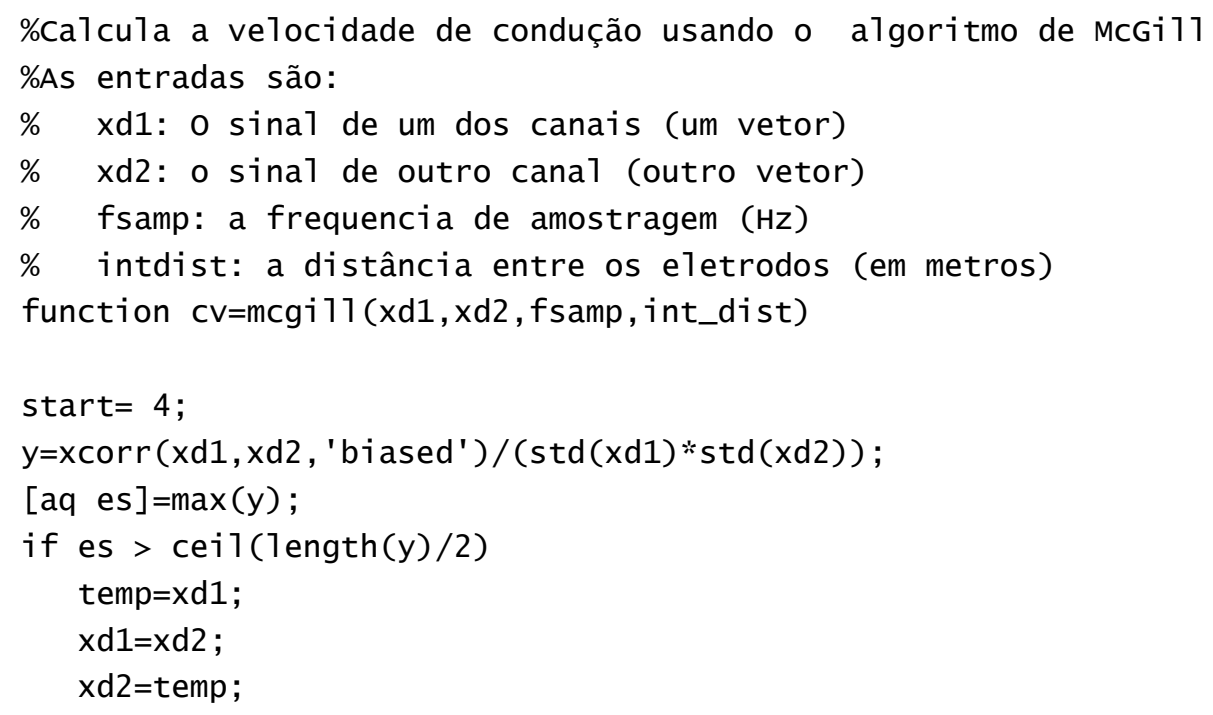


end;

$f f t 1 r=r e a 1(f f t(x d 1))$;

$f f t 1 i=i m a g(f f t(x d 1))$;

$f f t 2 r=r e a l(f f t(x d 2))$;

$f f t 2 i=i \operatorname{mag}(f f t(x d 2))$;

$\mathrm{cV}=\mathrm{de} 1$ ay $(f f t 1 r, f f t 1 i, f f t 2 r, f f t 2 i$, start $)$;

$\mathrm{cv}=$ abs (int_dist/(cv/fsamp));

$\mathrm{CC}=\mathrm{aq}$;

\section{Fullplotemg.m:}

\section{function}

fu11p1otemg (X, graphname, maxV, twindow, wwait, ch1, ch2, ch3, ch4, ch5, ch6, ch7, ch8)

$\%$ organiza os gráficos plotados em uma janela apenas, no quadrante $x$ da

\% tela, e coloca a janela com o nome 'graphname'.

scrsz $=\operatorname{get}(0$, 'screensize');

$\%$ criando a figura com o nome desejado

\%figure('Position', [0 $\operatorname{scrsz(4)} \operatorname{scrsz}(3)-50(\operatorname{scrsz}(4)-50)])$

\% Determina o tamanho máximo do eixo $Y$

$\operatorname{maxy}=\operatorname{size}(\operatorname{ch} 1) ;$

$\max Y=\max Y(1,1) ;$

lasty $=$ rem (maxy, twindow);

iterations $=\operatorname{maxy} /$ twindow $-\bmod (\max$, twindow $) /$ twindow;

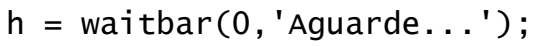

for $i=$ iterations: $-1: 0$

waitbar(1-(i/iterations))

$\mathrm{x}$ low $=i *$ twindow;

xhigh $=(i+1) *$ twindow;

figure $(i+1)$;

set ( $i+1$, 'Visible', ' off')

set (get ( 0 , 'CurrentFigure'), 'Name' , graphname)

\% Plotando o gráfico do EMG Ch1

axes('Position', [ [ $\left.\begin{array}{lllll}0.13 & 0.08 & 0.775 & 0.12\end{array}\right]$ );

plot (ch1)

\%set (gca, 'XTickLabe1', \{' ' $\}$ )

\%set (gca, 'YTickLabe1', $\{$ ' ' $\}$ )

$y \lim ([-\max v \max ])$

$x \lim ([i *$ twindow $(i+1) *$ twindow $])$

title(')

xlabel ('TEMPo (ms)')

ylabel ('Canal 1')

\% Plotando o gráfico do EMG Ch2

axes('Position', [ [ $\left.\begin{array}{lllll}0.13 & 0.20 & 0.775 & 0.12\end{array}\right]$ );

plot (ch2)

set (gca, 'XTickLabe1', \{' '\})

\%set (gca, 'YTickLabe1', \{' '\})

$y \lim ([-\max V \max ])$

$x \lim ([i *$ twindow $(i+1) *$ twindow $])$

title(')

x7abe1 (')

ylabe1 ('Canal 2') 


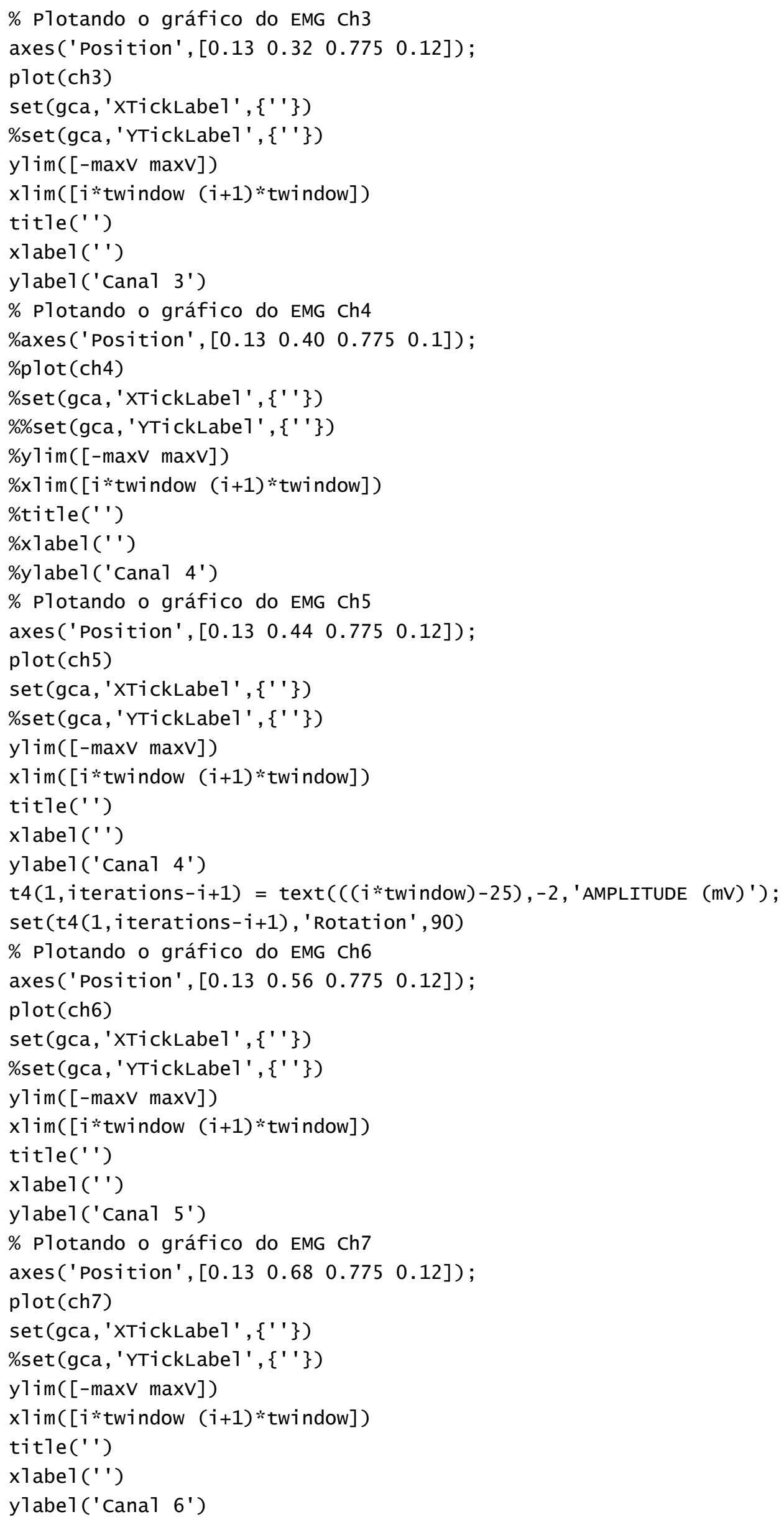




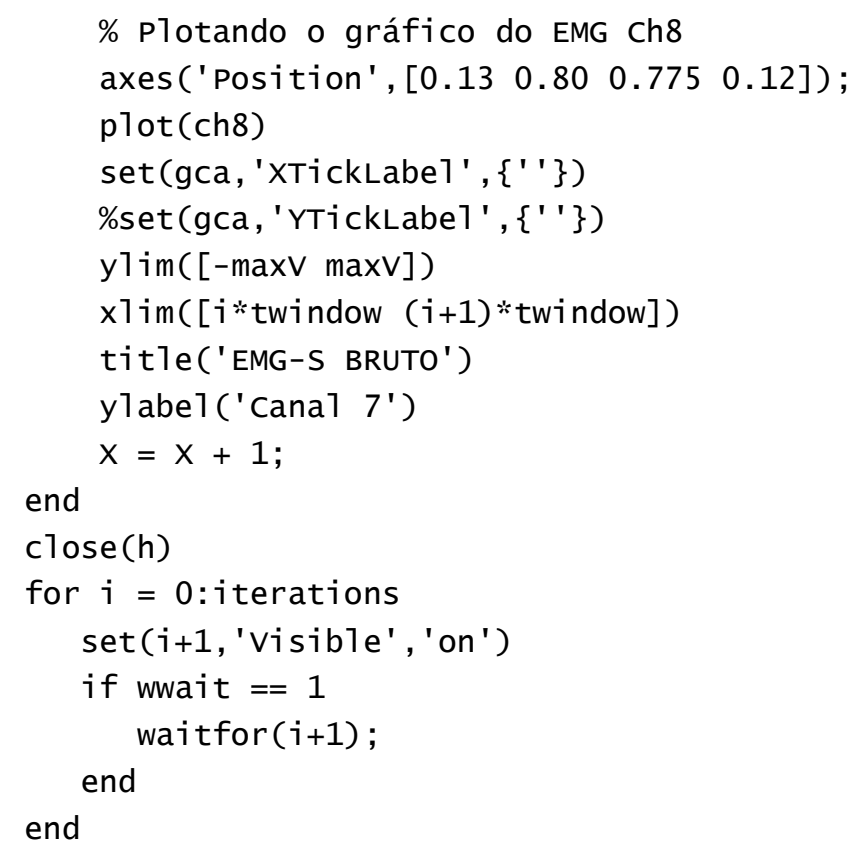

\section{Fullfftplot.m:}

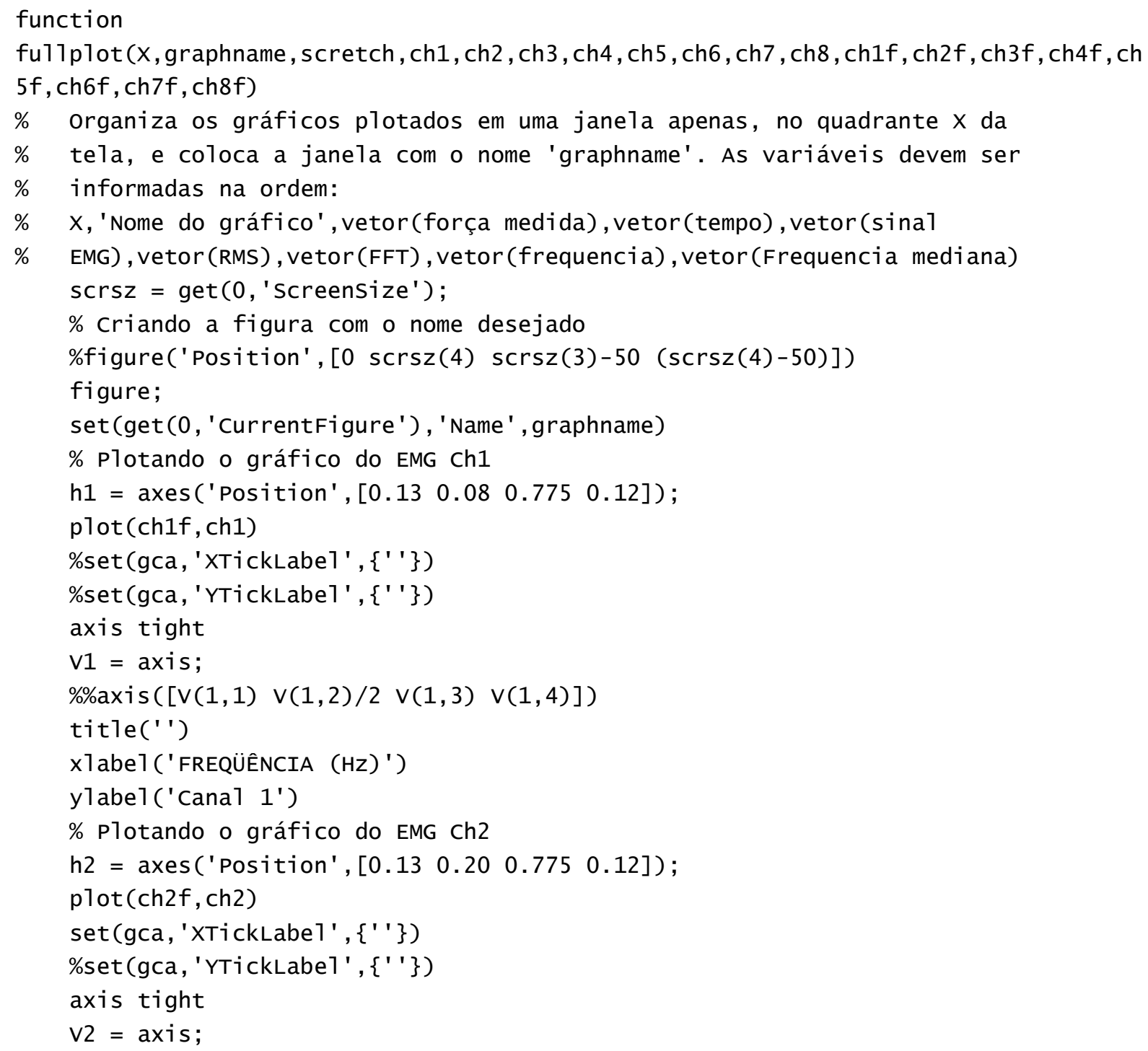




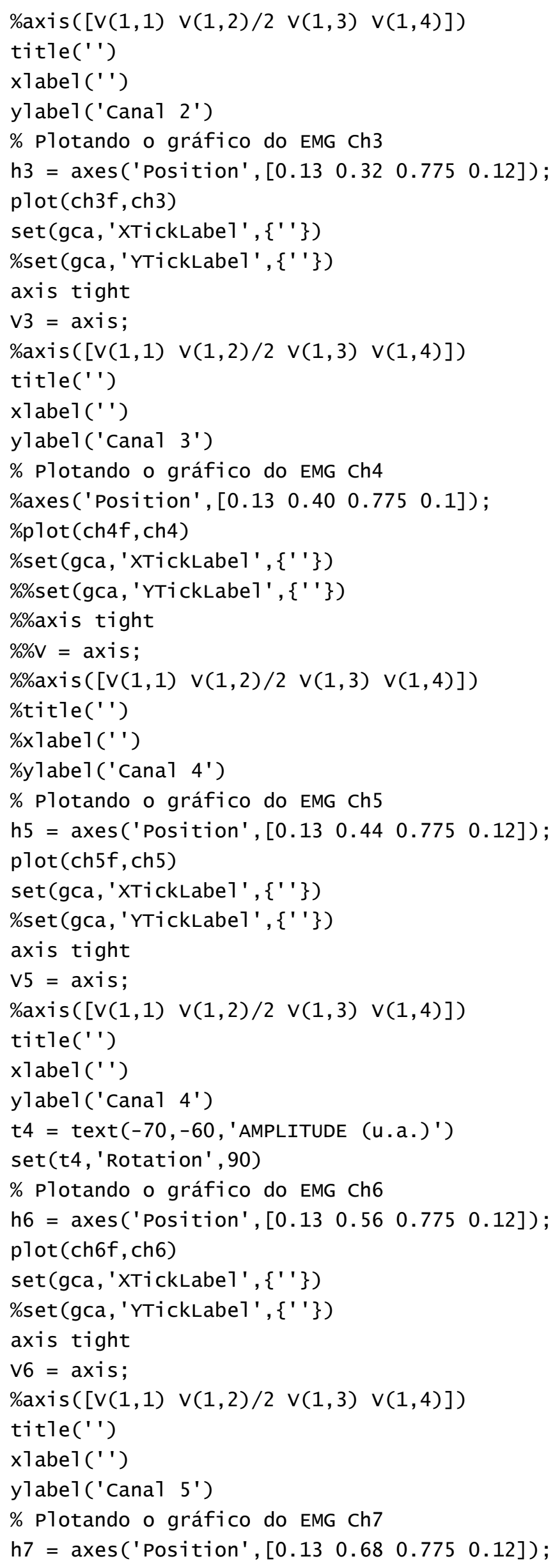




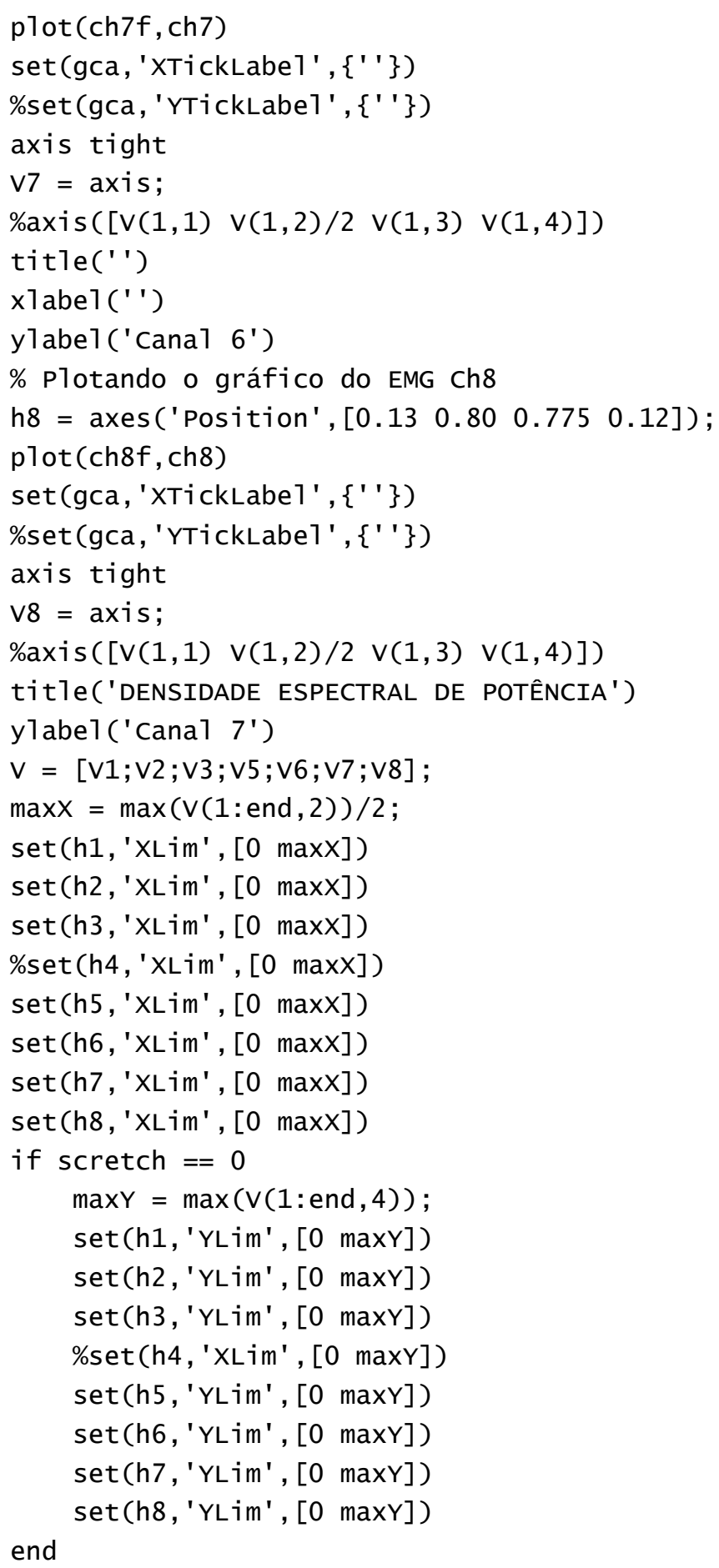

\section{Delay.m:}

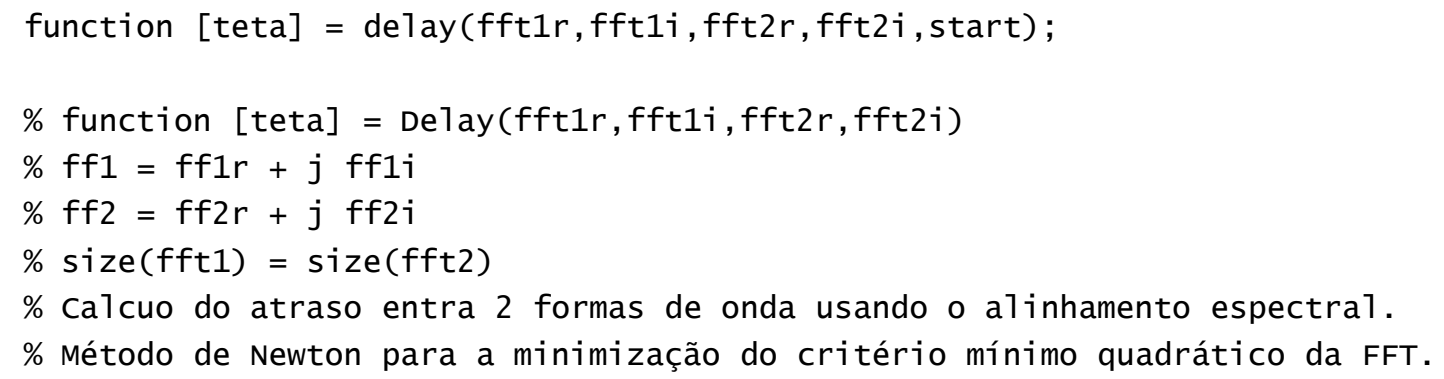




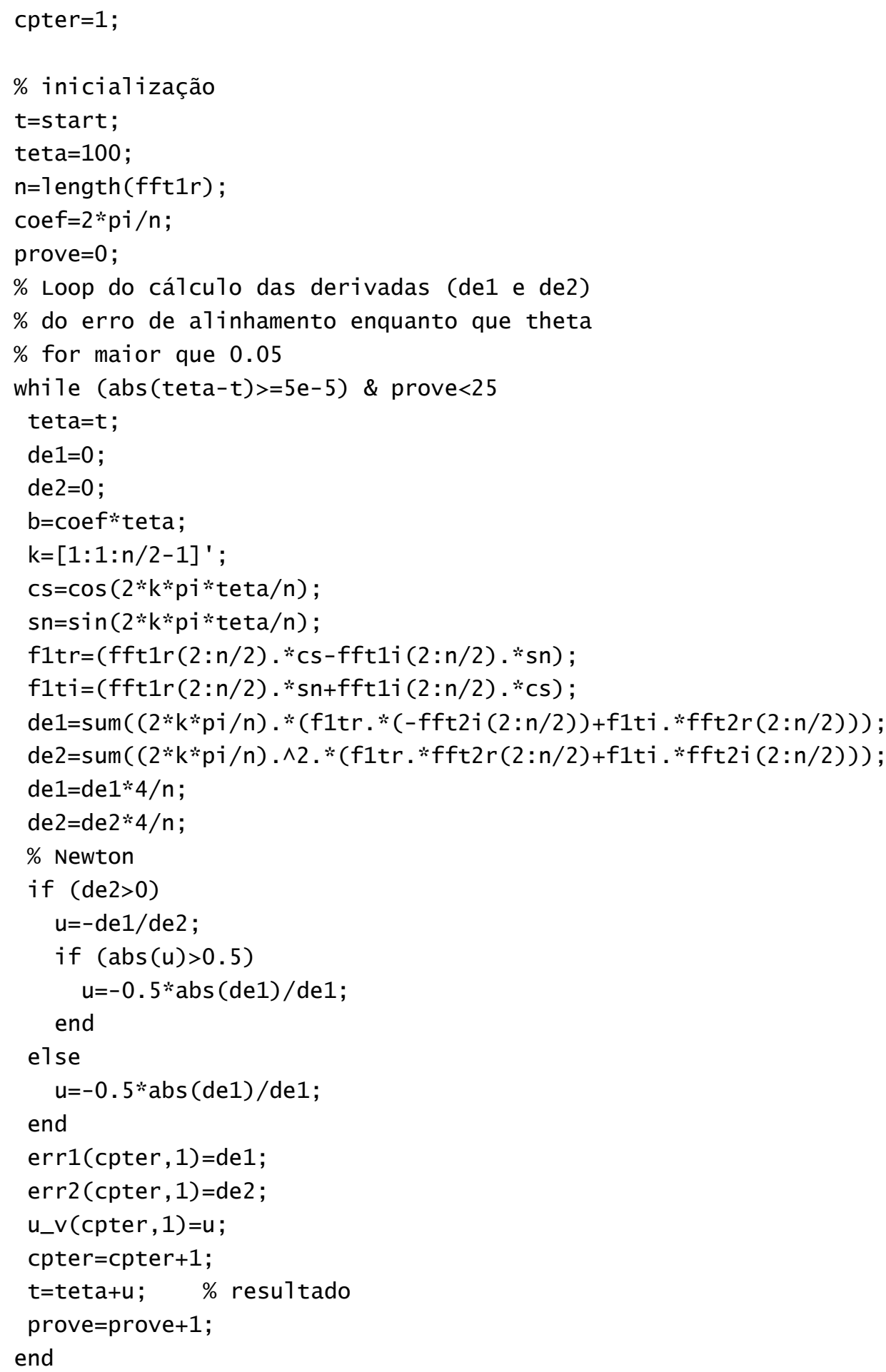

\section{Cvslide.m:}

\%calcula a velocidade de condução em vários pontos de 2 sinais usando o \%algoritmo de McGil1

\%Retorna um vetor com todos os valores obtidos

\%As entradas são:

\% ch1: o sinal de um dos canais (um vetor)

\% ch2: o sinal de outro canal (outro vetor)

\% fsamp: a frequencia de amostragem

\% intdist: a distância entre os eletrodos 


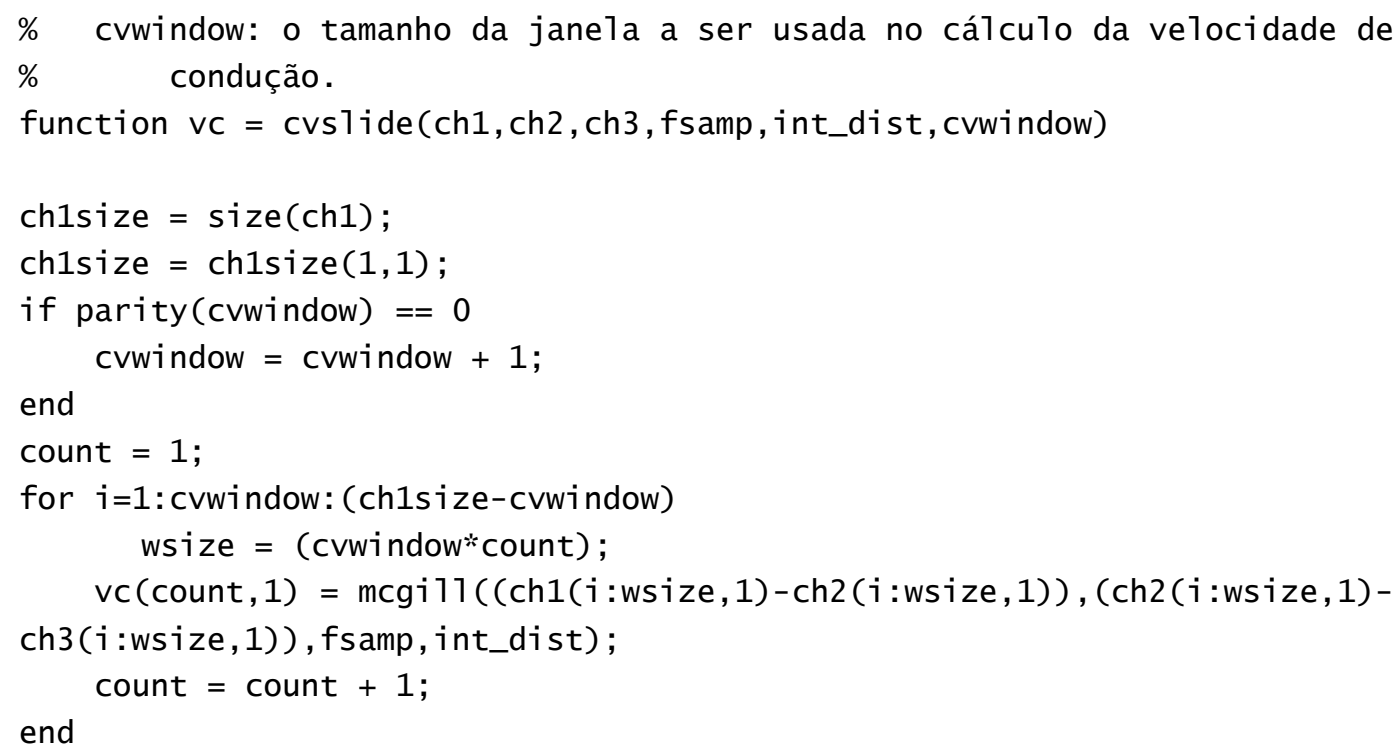

\section{Cvplot.m:}

\%Plota a velocidade de condução em uma figura, visualizando de modo \%amigáve 1 os dados.

\%As entradas são:

\% ch1: o sinal de um dos canais (um vetor)

\% ch2: o sinal de outro canal (outro vetor)

$\%$ ch3: o sinal de outro canal (outro vetor)

\% ch4: o sinal de outro canal (outro vetor)

$\%$ ch5: o sinal de outro canal (outro vetor)

\% ch6: o sinal de outro canal (outro vetor)

\% ch7: o sinal de outro canal (outro vetor)

$\%$ fsamp: a frequencia de amostragem

\% intdist: a distância entre os eletrodos

\% cvwindow: o tamanho da janela a ser usada no cálculo da velocidade de $\%$ condução.

\% cverbose: gera uma janela com os dados das médias e desvio padrão de

$\%$ todos os cálculos realizados

\% cvgrid: gera uma matriz gráfica

function vcmean $=$

cvp1ot (ch1, ch2, ch3, ch4,ch5, ch6,ch7, fsamp, int_dist, cvwindow, cvverbose, cvgrid)

$\mathrm{vc}=$ cvs1ide (ch1, ch2, ch3, fsamp,int_dist, cvwindow);

$\operatorname{vc}(1:$ end, 2$)=$ cvs7ide (ch2,ch3, ch4, fsamp, int_dist, cvwindow);

$\operatorname{vc}(1:$ end, 3$)=$ cvs7ide (ch3,ch4,ch5, fsamp, int_dist, cvwindow);

$\operatorname{vc}(1:$ end, 4$)=$ cvs7ide (ch4, ch5, ch6, fsamp, int_dist, cvwindow);

vc $(1:$ end, 5$)=$ cvs7ide(ch5, ch6,ch7,fsamp, int_dist, cvwindow);

for $i=1: 5$

end $[\operatorname{vcmean}(i, 1), \operatorname{vcmean}(i, 2)]=\operatorname{stat}(\operatorname{vc}(1:$ end,$i))$;

if cvverbose $==1$

$\mathrm{h} 1$ = figure;

$\mathrm{a} 1=\mathrm{axes} ;$ 


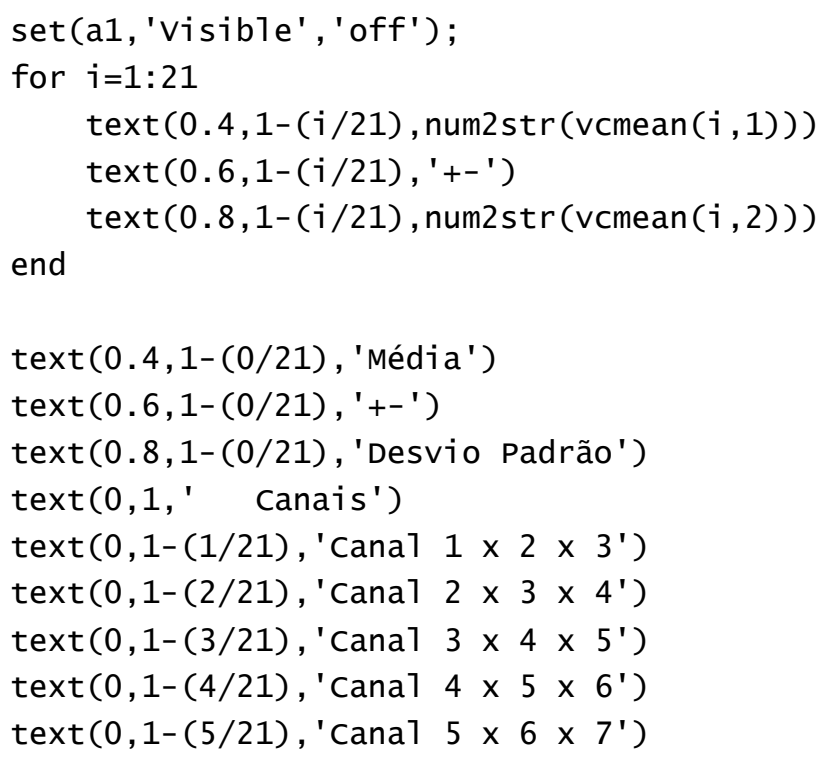

\section{Cvcall.m:}

function crcal1 (cvmean)

\% Exporta as matrizes Tistadas para arquivo XLS

$\%$

selvars $=1$ istd1g('ListSize', $[300,160]$, 'Name', 'X-

Array', 'Cancelstring', 'Cancelar', 'Promptstring', ['Selecione os canais se que deseja visualizar a média'; ...

'e desvio padrão da velocidade de condução calculados'; ...

'a partir do sinal de EMG e da janela escolhida: '],...

'ListString', [strcat ('Canal $1 \times 2 \times 3$ (Média = ', num2str(cvmean(1,1), ' \%09.4f'), '; DP $=$ ', num2str (cvmean $(1,2)$, ' \%09.4f'), ')'); $\ldots$

strcat ('Canal $2 \times 3 \times 4$ (Média $=$ ', num2str(cvmean $(2,1),{ }^{\prime} \% 09.4 f^{\prime}$ ), '; DP = ', num2str(cvmean $(2,2)$, ' \%09.4f'), ')'); ...

strcat ('Canal $3 \times 4 \times 5$ (Média $=$ ', num2str(cvmean $(3,1)$, ' \%09.4f'), '; DP = ', num2str(cvmean $(3,2)$, ' \%09.4f'), ')'); ...

strcat ('Cana1 $4 \times 5 \times 6$ (Média = ', num2str(cvmean $(4,1)$, ' \%09.4f'), '; DP = ', num2str(cvmean $(4,2)$, ' \%09.4f'), ')'); ...

strcat ('Canal $5 \times 6 \times 7$ (Média = ', num2str(cvmean $(5,1)$, ' \%09.4f'), '; DP = ', num2str(cvmean $(5,2)$, ' \%09.4f'), ')')]);

$h 1$ = figure;

set(h1, 'Name', 'Velocidade de Condução')

a1 = axes;

set(a1, 'Visible', 'off');

text $(0.4,1-(0 / 21)$, 'Média')

$\operatorname{text}(0.6,1-(0 / 21), \text { ' }+-')^{-}$

text $(0.8,1-(0 / 21)$, 'Desvio Padrão')

$\operatorname{text}\left(0,1,{ }^{\prime}\right.$ Canais')

$i=1$;

tota7mean $=\left[\begin{array}{ll}0 & 0\end{array}\right]$;

if (find(selvars $==1$ ))

text $(0,1-(i / 21)$, 'Canal $1 \times 2 \times 3$ ')

text $(0.4,1-(i / 21)$, num2str $(\operatorname{cvmean}(1,1)))$ 


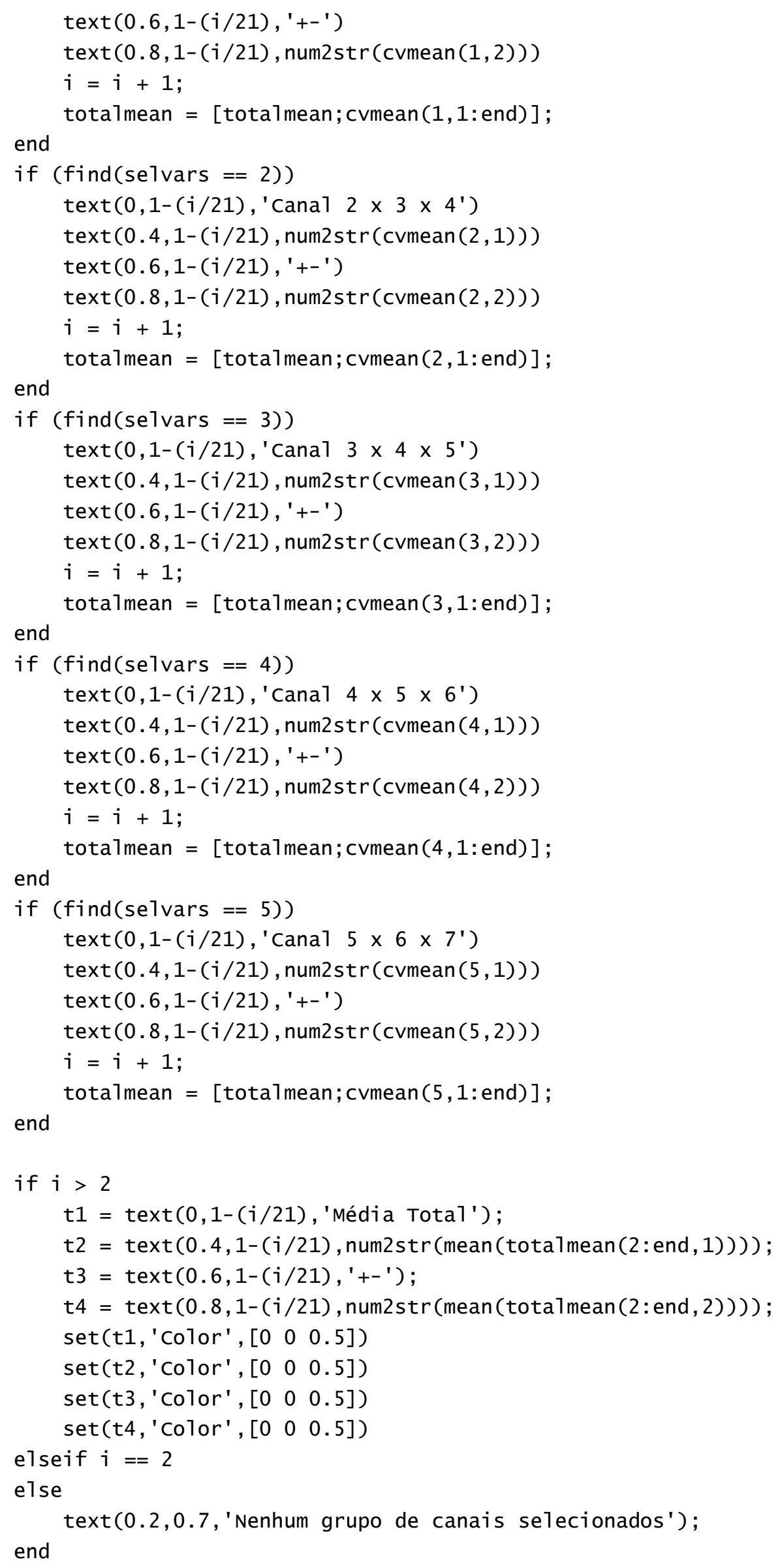


ANEXO B - ESQUEMÁTICO DOS CIRCUITOS IMPLEMENTADOS 


\section{Arranjo Linear de 8 Eletrodos Ativos}

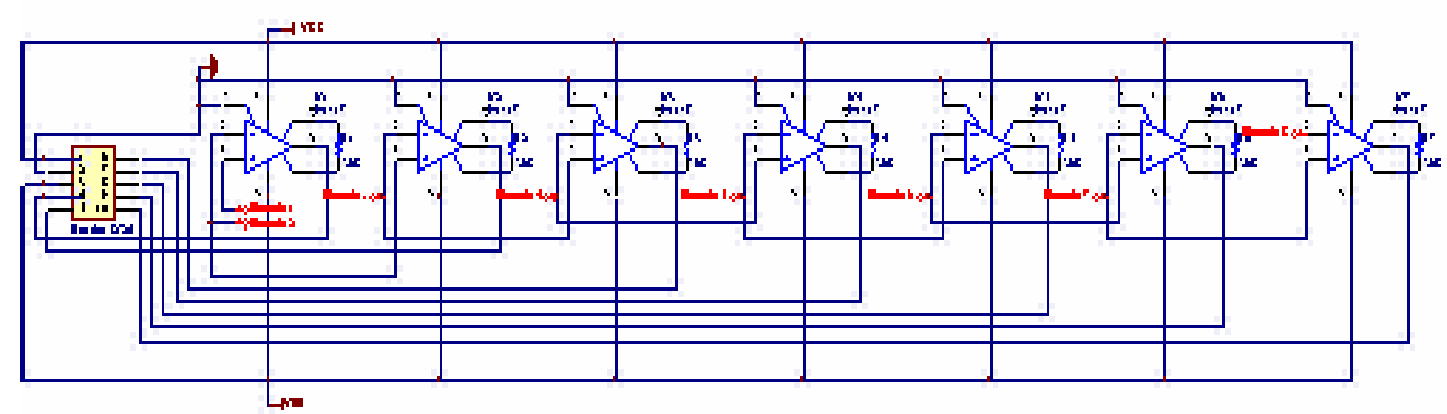

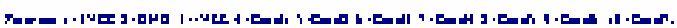

Figura B.1 - Esquemático do arranjo linear de 8 eletrodos.

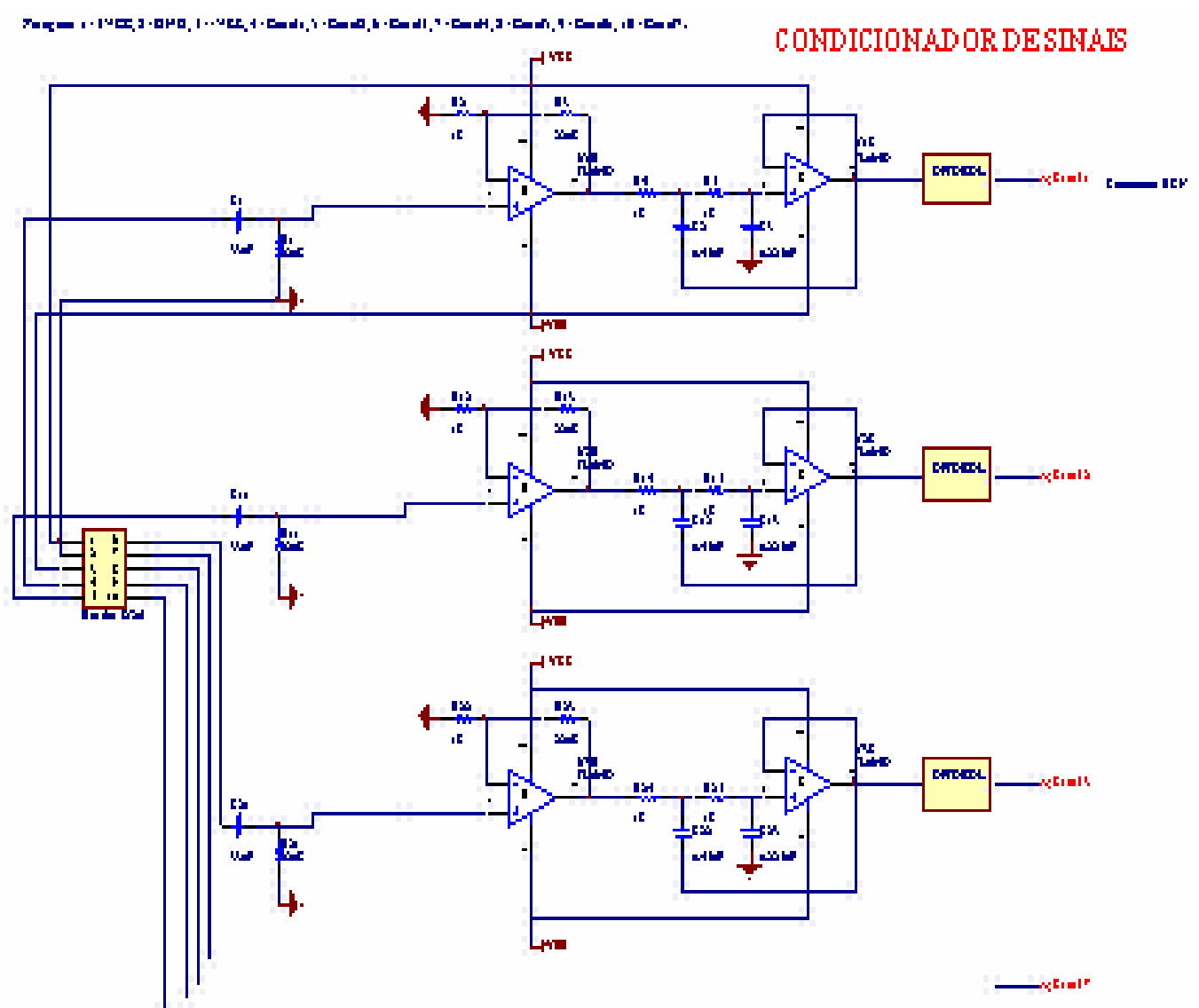

Figura B.2 - Esquemático de 3 dos 7 canais do condicionador de sinais. 


\section{ANEXO C - PROTOCOLO EXPERIMENTAL}

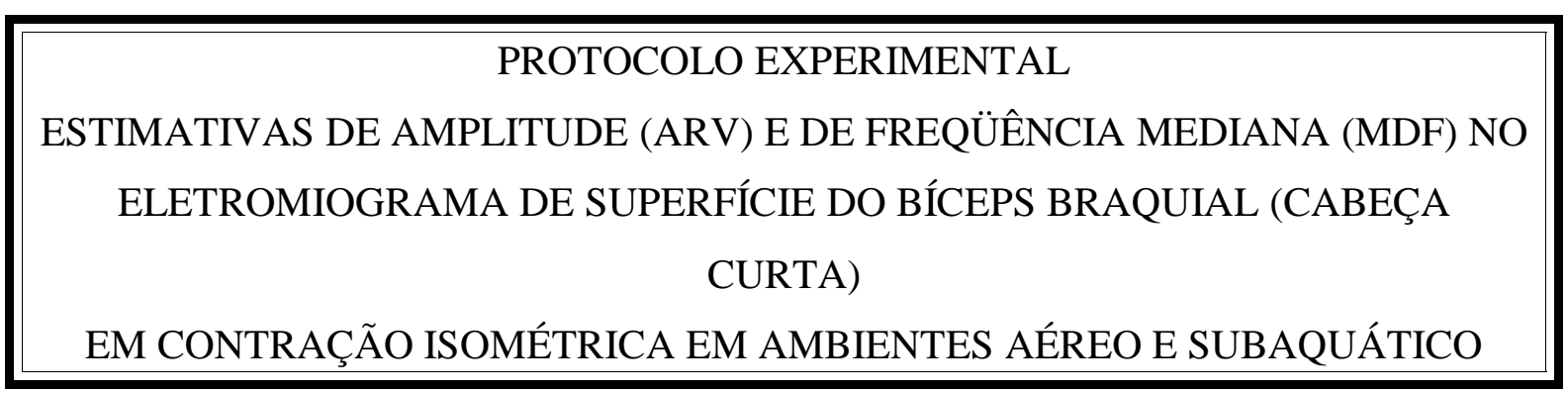

LOCAL DE REALIZAÇÃO: Laboratório de Biomecânica da Faculdade de Educação Física da Universidade de Brasília.

OBJETIVO GERAL: Verificar se há diferença entre os estimadores de amplitude (ARV) e de freqüência mediana (MDF) no EMG de superfície do músculo bíceps braquial (cabeça curta) em contrações isométricas, nos ambientes aéreo e subaquático. O movimento será de flexão do cotovelo, ou seja, o bíceps atuará como agonista.

\section{MATERIAL NECESSÁRIO:}

-tanque para água: diâmetro de $180 \mathrm{~cm}$, profundidade de $130 \mathrm{~cm}$. Água aterrada eletricamente.

-recipiente plástico de 135 litros: 0,7 m de altura por 0,5 m de diâmetro. Água aterrada eletricamente.

-cadeira com encosto, sem estofamento e sem braço: altura do assento de $44 \mathrm{~cm}$.

-microcomputador IBM-PC Pentium-4 com software Windows XP

-monitor de vídeo auxiliar de 15" para feedback

-software para aquisição de EMG e de força baseado em LabView

-eletromiógrafo de 2 canais (Bragnoli-2, Delsys, Boston). N/S 157210

-1 eletrodo ativo para EMG (DE2, Delsys, Boston).

-eletrodo adesivo e descartável para referência (Red Dot, 3M, EUA)

-célula de carga de $50 \mathrm{~kg}$ (MM, Kratos, São Paulo). Erro máx 0,03\% sobre FE

-amplificador analógico em ponte (MCS1000, Lynx, EUA).

-placa de aquisição de dados de 12 bits (PCI-6024E, National Instruments, Austin)

-termômetro de bulbo para água (Delfin, São Paulo) 
-termômetro clínico de bulbo (Gold Flsh, BD, Brasil)

-cabo de aço com suporte para mão

-massas para conexão ao pulso do voluntário para compensação do empuxo: pulseira 1,6 kg; massas para conexão ao pulso esquerdo do voluntário para equilibrá-lo no tanque maior: pulseira 3,0 kg;

-adesivo plástico hospitalar $10 \mathrm{~cm}$ x $12 \mathrm{~cm}$ (Tegaderm, 3M, EUA)

-fita adesiva (Silvertape, 3M, São Paulo)

-silicone líquido

-plataforma para suportar o recipiente plástico

SUJEITOS: 10 homens destros

\section{PROCEDIMENTO EXPERIMENTAL:}

\section{ARRANJO PARA MEDIÇÃO}

-Conecte o eletromiógrafo à placa de aquisição de dados (ajuste o software dela para "Differential, single ended"). Entrada 5: canal 1 de EMG (bíceps); Ganho=1k

-Conecte a célula de carga à entrada 8 do amplificador em ponte. (Fiação: vermelho, verde, amarelo e preto)

-Conecte o amplificador em ponte à entrada 7 da placa de aquisição de dados.

-Energize os equipamentos elétricos.

-Preencha o Formulário de Experimento com os dados do voluntário e com a temperatura ambiente.

-Abra o software AquisicaoSubaquatico e preencha-o com os dados do voluntário.

-No software, ajuste o RMS Máximo para 1. Configurações: taxa de aquisição de dados = $1024 \mathrm{~Hz}$; Força Offset $=-0.46$ e Multiplicador $=-33.6$; Canais Força $=7$, Agonista $=5$ e Trigger $=0$.

\section{CONTRAÇÃO VOLUNTÁRIA MÁXIMA (CVM)}

-Colocar o mosquetão na $3^{\text {a }}$ argola, de cima para baixo. 
-Peça ao voluntário para sentar-se na cadeira de medição, apoiar-se no encosto (coluna ereta) e manter suas pernas unidas e em um ângulo interno de $90^{\circ}$. A mão esquerda deverá repousar sobre a coxa esquerda.

-Solicitar ao voluntário para segurar com a mão direita a empunhadura do cabo de força, mantendo o cotovelo direito apoiado no encosto da cadeira. O ângulo interno entre o antebraço e o braço deve ficar fixo em $90^{\circ}$. $\mathrm{O}$ antebraço deve permanecer paralelo ao plano sagital do corpo.

-Pedir ao voluntário para puxar ligeiramente (flexionando o cotovelo) o suporte de força; explicar a ele como acompanhar a retroalimentação visual de sua força. Isso acontece por meio de um gráfico no monitor de vídeo. Previamente, o cabo que prende a célula de carga ao suporte para mão deve ser ajustado para que permaneça estendido durante a contração muscular.

-Iniciar no software AquisicaoSubaquatico a função "Força Máxima"

-Solicitar ao voluntário que realize uma contração voluntária máxima de 3 segundos.

-Após 2 minutos de repouso, solicitar ao voluntário outra contração máxima.

-Após outros 2 minutos, realizar a última contração. O maior valor de força registrado pelo software perfaz a contração voluntária máxima.

-Ajuste o software para uma meta de força de 50\% da CVM. Estabeleça uma tolerância de 4\% sobre o valor da força máxima.

\section{COLOCAÇÃO DOS ELETRODOS}

-Com o cotovelo direito a $90^{\circ}$, medir a distância da ponta do dedo médio (mão aberta) até o olecrano. Anotar no formulário.

-Colocar o cotovelo a $90^{\circ}$. Com uma trena, medir a distância entre o acrômio direito e a fossa cubital. Marcar sobre o bíceps cabeça curta um ponto a 1/3 dessa distância, a partir da fossa. -Se houver pêlos nas regiões do músculo bíceps braquial (cabeça curta), efetue depilação.

-Solicite ao voluntário para lavar vigorosamente com água e sabão seu braço direito.

-Aplique o eletrodo adesivo de referência no pescoço do voluntário. Conecte-o ao eletromiógrafo usando o cabo apropriado.

-No bíceps, coloque o eletrodo do canal de número 1. Ele deve ser posicionado perpendicularmente à direção das fibras musculares. Cabo direcionado para o acrômio. -Prenda-o sobre a pele usando fita adesiva SilverTape $(8 \mathrm{~cm})$. 
-Solicite ao voluntário que realize uma leve contração, a fim de ser verificada a qualidade do sinal; use o Matlab.

-Coloque uma gota de silicone líquido sobre o cabo elétrico do eletrodo. Ela será coberta pelo Tegaderm e impedirá a passagem de água para o eletrodo.

-Deposite fita Tegaderm sobre o eletrodo, protegendo-o contra água.

-Prender todos os cabos com fita Silvertape sobre o trapézio.

\section{PROTOCOLO:}

a) O sujeito deverá fazer abstinência de cafeína e álcool por pelo menos 24 horas antes do experimento.

b) Este protocolo compreende 5 estações de trabalho. O sujeito passará por cada uma delas em ordem aleatória, definida no começo do experimento. Em cada uma, será realizada uma contração isométrica de 5 segundos.

c) Entre o trabalho em uma estação e outra, o sujeito deverá permanecer sentado e em repouso por 20 minutos.

d) O sujeito utilizará cadeiras idênticas.

e) Em todas as estações de trabalho, o sujeito deverá manter a mesma posição do corpo: sentado na cadeira de medição (coluna ereta), apoiado no encosto e com suas pernas alinhadas e em um ângulo interno de $90^{\circ}$. O braço direito deverá estar paralelo ao plano sagital do corpo. O seu cotovelo direito deverá permanecer apoiado no encosto da cadeira, e a um ângulo interno de $90^{\circ}$. Ainda, deverá segurar com a mão direita a empunhadura do cabo de força. A mão esquerda deverá repousar sobre a coxa esquerda. O sujeito deverá apenas pressionar levemente os pés contra o solo durante as contrações, evitando, assim, alteração da postura durante as coletas de EMG.

f) Nas provas em água, prender ao pulso direito do sujeito uma pulseira com massa de 1,6 quilogramas, a fim de compensar o efeito do empuxo na mão e no antebraço.

g) Nas provas no tanque maior, prender uma pulseira de 2,9 $\mathrm{kg}$ ao pulso direito do sujeito, auxiliando-o a equilibrar-se.

h) A temperatura da água, tanto no tanque maior como no menor, deverá ser de $33^{\circ} \mathrm{C}$.

i) Procedimento padrão para todas as estações de trabalho.

-Ajuste o software AquisicaoSubaquatico para adquirir EMG por 5 segundos.

-Solicite ao sujeito que se sente e mantenha os antebraços relaxados sobre as coxas. 
-Efetue uma aquisição de EMG (sem contração muscular), a fim de ser verificado posteriormente o nível de ruído elétrico do sistema.

-Ajuste o software para adquirir EMG por 5 segundos.

-Solicite ao sujeito que se posicione corretamente e segure a empunhadura do cabo de força.

-Solicite ao sujeito que realize uma contração por 5 segundos, buscando manter o nível de força dentro da meta visual, orientando-se pelo gráfico no monitor de vídeo. Simultaneamente ao comando verbal, inicie a aquisição de EMG.

Caso 1: Ambiente aéreo. Não utilizar pulseira para compensação de empuxo. O mosquetão superior deve estar na $3^{\mathrm{a}}$ argola, de cima para baixo. O mosquetão inferior deve ser conectado ao cabo de aço da cadeira.

Caso 2: Tanque maior, com imersão do corpo até o pescoço. Sem compensação do empuxo no antebraço. $\mathrm{O}$ mosquetão superior deve estar na $3^{\mathrm{a}}$ argola, de cima para baixo. $\mathrm{O}$ mosquetão inferior deve ser conectado ao cabo de aço da cadeira.

Caso 3: Tanque maior, com imersão do corpo até o pescoço. Com compensação do empuxo no antebraço. O mosquetão superior deve estar na $3^{\text {a }}$ argola, de cima para baixo. O mosquetão inferior deve ser conectado ao cabo de aço da cadeira.

Caso 4: Tanque menor, com imersão somente da mão, do antebraço e do braço. Sem compensação do empuxo no antebraço. O mosquetão superior deve conectar-se diretamente ao cabo de aço da empunhadura. Retirar o mosquetão inferior. A célula de carga deve ser conectada diretamente ao gancho do fundo do reservatório.

Caso 5: Tanque menor, com imersão somente da mão, do antebraço e do braço. Com compensação do empuxo no antebraço. O mosquetão superior deve conectar-se diretamente ao cabo de aço da empunhadura. Retirar o mosquetão inferior. A célula de carga deve ser conectada diretamente ao gancho do fundo do reservatório. 


\title{
ANEXO D - PUBLICAÇÕES RESULTANTES DESTE PROJETO ARRANJO LINEAR DE OITO ELETRODOS ATIVOS PARA ELETROMIOGRAFIA DE SUPERFÍCIE
}

\author{
W. H. Veneziano*, G. S. S. Souza**, H. B. S. Louzada**, F. A. O. Nascimento** e A. F. da \\ Rocha** \\ *Departamento de Automação/UTFPR, Pato Branco, Brasil \\ ***Departamento de Engenharia Elétrica/Universidade de Brasília, Brasil
}

\begin{abstract}
The interest of the researchers in linear electrode arrays for surface electromyography is increasing. Besides executing the task of the traditional bipolar electrodes, they allow the study of the innervation zone location and the assessment of the muscle fiber conduction velocity. This type of equipment is manufactured commercially only in Italy, and its cost is high. So, a linear array of eight active electrodes for surface electromyography was developed in the University of Brasilia. All the tests carried through had shown that the system operates in accordance with the standards described in the literature.
\end{abstract}

\section{Introdução}

Um campo promissor de pesquisas em eletromiografia de superfície (EMG-S), iniciado há alguns anos, é o dos arranjos lineares de eletrodos. Esta tecnologia vem sendo desenvolvida principalmente por dois grupos de pesquisas: um do Laboratorio di Ingegneria del Sistema
Neuromuscolare e della Riabilitazione Motoria do Politecnico di Torino, em Turim, na Itália [1] e outro no Industrial Products Research Institute, em Tsukuba, no Japão [2] e [3]. Embora ainda não haja aplicações clínicas, têm sido muito interessantes os resultados das pesquisas com arranjo de eletrodos para a decomposição de sinais de EMG-S, estimativa de velocidade de condução das fibras musculares, localização de zonas de inervação (conjunto de pontos motores), entre outras aplicações. Como exemplo, a Figura 1 apresenta sinais diferenciais simples de EMG-S de um arranjo de oito eletrodos.

No Brasil, não há notícias da presença desse tipo de equipamento, que é produzido comercialmente apenas na Itália, a um custo de cerca de 20.000 euros. Visando suprir parte dessa deficiência, foi desenvolvido um arranjo linear de oito eletrodos ativos para EMG-S no Departamento de Engenharia Elétrica da Universidade de Brasília, tendo sido parte integrante de uma tese de doutorado [4]. Esse texto relata a topologia e a funcionalidade do sistema. 


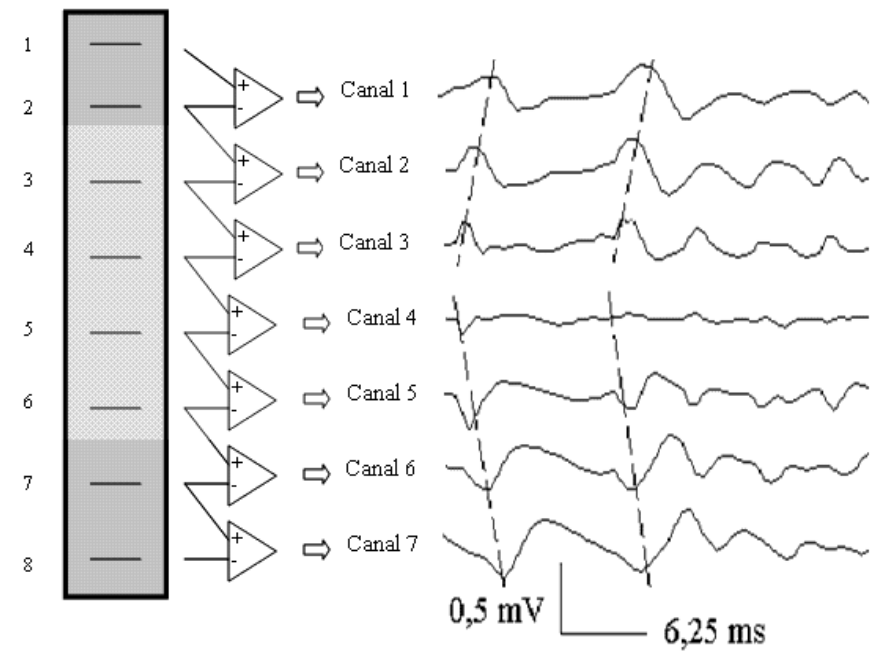

Figura 1: Potenciais propagantes no bíceps braquial cabeça curta (flexão de cotovelo a $90^{\circ}$; arranjo linear de 8 eletrodos de prata de $10 \mathrm{~mm}$ de comprimento e $1 \mathrm{~mm}$ de diâmetro, distância intereletródica de $10 \mathrm{~mm}$, em configuração bipolar). As linhas pontilhadas ilustram a propagação dos potenciais de ação das unidades motoras. A zona de inervação está na região do canal de número 4. 


\section{Materiais e Métodos}

Foi desenvolvido um sistema composto de uma sonda captadora de oito eletrodos ativos e de superfície, conectada via cabo a um condicionador de sinais, uma placa de digitalização de dados e um microcomputador para executar um software para aquisição dos sinais de EMG-S. Na Figura 2 está apresentado o diagrama de blocos do sistema. Somente a sonda captadora entra em contato com o corpo humano; o circuito condicionador permanece alojado próximo ao microcomputador.

O sistema foi avaliado em laboratório por meio da injeção de sinais senoidais diretamente sobre os eletrodos de prata, com posterior medição das saídas do condicionador com osciloscópio e analisador de espectro. Além disso, foram coletados sinais eletromiográficos de superfície, segundo o protocolo descrito a seguir:

-Sujeitos: Cinco voluntários do sexo masculino (os próprios autores do trabalho), com idades entre 22 e 42 anos (média \pm desvio-padrão: $28,2 \pm 4,3$ anos; altura: $1,75 \pm 0,62 \mathrm{~m} ;$ massa corporal: $74,1 \pm 6,9 \mathrm{~kg}$ ) participaram deste estudo. Nenhum dos sujeitos reportou patologias neuromusculares.

-Procedimentos gerais: Foram seguidas as normas da União Européia para captação de EMG-S [5]. Após a depilação da pele e higienização da mesma com água e detergente, os voluntários sentaram-se em uma cadeira, mantiveram a coluna dorsal ereta e flexionaram o cotovelo a fim de manterem-no a um ângulo articular interno de $90^{\circ}$. A palma da mão foi mantida perpendicularmente ao plano sagital do corpo. Foram realizadas contrações isométricas (flexão) do músculo bíceps braquial cabeça curta a $40 \%$ da contração voluntária máxima (medida anteriormente com o auxílio de um cabo conectado a uma célula de carga). Durante cada contração, captou-se $1 \mathrm{~s}$ de EMG-S. O passo seguinte foi a visualização simultânea dos sete canais de EMG-S em um software desenvolvido para esse fim em ambiente Matlab (Mathworks, Natick, EUA). Cada tela de visualização correspondeu a um intervalo de tempo de $200 \mathrm{~ms}$. Uma nova contração foi realizada até que fosse obtida uma seqüência de canais com correta propagação dos sinais, além da visualização da zona de inervação, de acordo com a literatura sobre arranjo de eletrodos para EMG-S [1].

Posteriormente aos experimentos, foi calculada a velocidade de condução das fibras musculares em três canais de EMG-S contíguos e distantes da zona de inervação, em janelas retangulares e deslizantes de 0,5 s. Foi empregado o algoritmo de McGill [1] de correlação cruzada em canais diferenciais duplos de EMG-S.

Finalizando a análise dos sinais de EMG-S, para cada contração foi calculada a densidade espectral de potência dos sete canais de EMG-S, em janelas retangulares de $0,5 \mathrm{~s}$. Isso permitiu que fossem verificados o nível de ruído (em especial as componentes de $60 \mathrm{~Hz}$ ), além da faixa espectral, que tipicamente deve estar entre $20 \mathrm{~Hz}$ e $500 \mathrm{~Hz}$ para EMG-S.

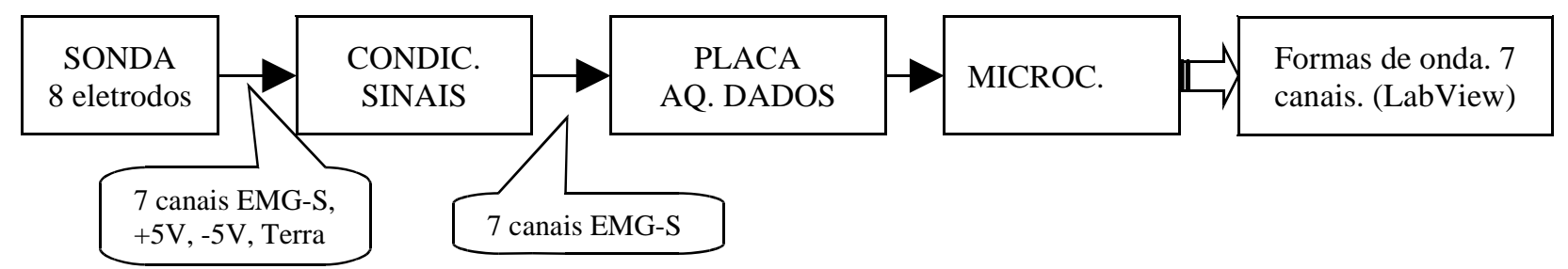

Figura 2: Diagrama de blocos do arranjo linear de eletrodos: sonda de oito eletrodos, condicionador de sinais de sete canais diferenciais, placa de aquisição de dados e microcomputador.

\section{Resultados}

A sonda captadora é composta de oito eletrodos ativos, os quais propiciaram sete canais de EMG-S em configuração diferencial simples. Cada eletrodo é constituído por uma barra de prata $(99,99 \%$ de pureza) com $1 \mathrm{~mm}$ de diâmetro e comprimento de $10 \mathrm{~mm}$, com espaçamento intereletródico de $10 \mathrm{~mm}$ (Figura 3). Houve uma pré-amplificação de dez vezes na sonda. Em seguida, os sinais foram amplificados pelo condicionador de sinais desenvolvido (ganho de tensão de $220 \mathrm{~V} / \mathrm{V}$ e filtragem passa-banda entre $20 \mathrm{~Hz}$ e 500 $\mathrm{Hz},-3 \mathrm{~dB}$ ) e convertidos para dados digitais por uma placa conversora analógico-digital de oito canais e 12 bits (PCI-6024E, National Instr., Austin, EUA) conectada a um microcomputador. A amostragem, a uma taxa de 1024 amostras/s, foi realizada por um software desenvolvido na Universidade de Brasília [6] em ambiente Labview (National Instr., Austin, EUA), e executado em sistema operacional Windows XP (Microsoft, EUA). Esse software permitiu a aquisição simultânea dos sete canais de EMG-S gerados pelo arranjo de eletrodos.

Os testes de laboratório efetuados com a injeção de sinais senoidais diretamente nos eletrodos de prata mostraram uma correta amplificação do sistema (2.200 $\mathrm{V} / \mathrm{V}$ ) e uma baixa presença de ruído de $60 \mathrm{~Hz}$ e seus harmônicos.

Nas provas com todos os sujeitos foi possível a identificação da zona de inervação muscular, como a mostrada, por exemplo, na Figura 4. É visível que a zona de inervação encontra-se entre os canais 5 e 6 , já 
que há inversão no sentido da propagação dos sinais. Essa figura também permite que seja avaliado se os potenciais são propagantes ou não, ou seja, se os eletrodos estão alinhados corretamente em relação à direção das fibras musculares.

Em todos os sinais de EMG-S coletados foi verificado se a assinatura espectral é condizente com a relatada na literatura. Como exemplo, na Figura 5 está apresentado o caso de certa contração, escolhida aleatoriamente entre as estudadas.

Quanto aos cálculos da velocidade de condução das fibras musculares, o resultado global de todos os sujeitos foi de $2,54 \pm 1,13 \mathrm{~m} / \mathrm{s}$ (média \pm desviopadrão).

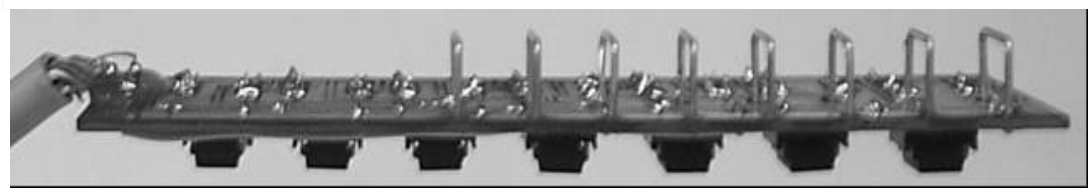

Figura 3: Superior: vista exterior do protótipo de um arranjo de 8 eletrodos para uso em arranjos lineares, sendo cada eletrodo composto de uma tira de prata pura com $1 \mathrm{~mm}$ de diâmetro e $10 \mathrm{~mm}$ de comprimento. Inferior: Protótipo de arranjo linear de 8 eletrodos desenvolvido no Departamento de Engenharia Elétrica da Universidade de Brasília.

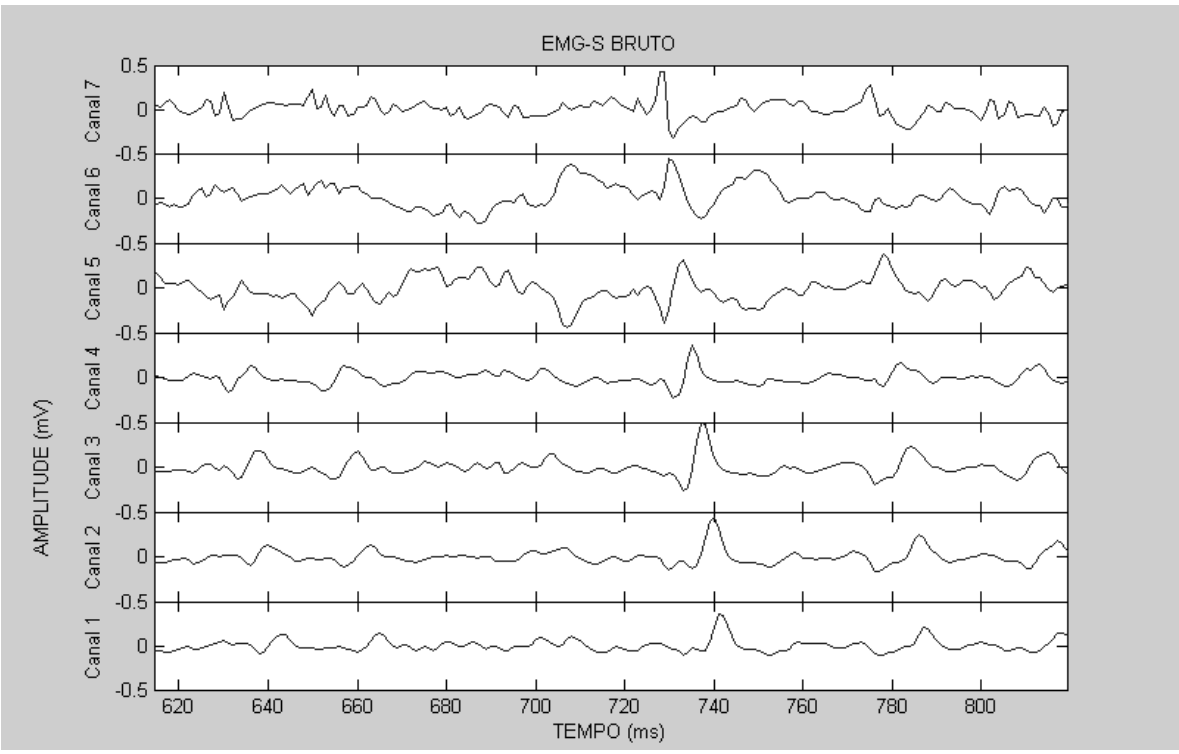

Figura 4: Trecho de EMG-S bruto de uma contração isométrica do bíceps braquial. Notam-se a propagação do sinal e a zona de inervação entre os canais 5 e 6 . 


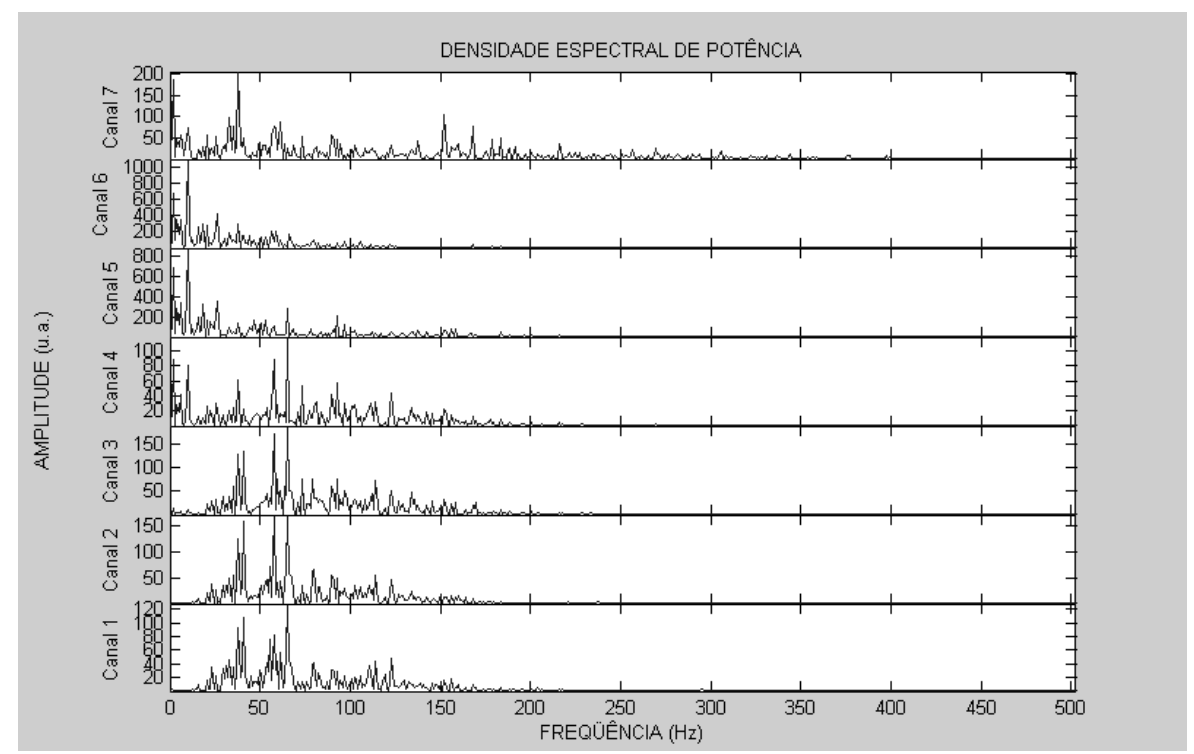

Figura 5: Gráficos da densidade espectral de potência referente a um dos sinais de EMG-S captados.

\section{Discussão}

Os três tipos de análises efetuadas no sistema desenvolvido comprovaram o correto funcionamento dele. Isto porque foi possível a identificação da zona de inervação em todos os sujeitos, a assinatura espectral está em consonância com a citada na literatura para EMG-S [7] e a velocidade de condução das fibras musculares encontra-se na faixa de valores fisiológicos $(2$ a $6 \mathrm{~m} / \mathrm{s})$.

\section{Conclusão}

O sistema de arranjo de eletrodos para eletromiografia de superfície desenvolvido, composto de elementos de hardware e de software para aquisição de sinais, foi aprovado segundo os três critérios adotados: a possibilidade de visualização da zona de inervação e dos potenciais propagantes, a assinatura espectral dos sinais de EMG-S captados e as estimativas da velocidade de condução das fibras musculares.

Embora o emprego desse tipo de tecnologia restrinja-se, ainda, a pesquisas acadêmicas, poderão ser estabelecidas aplicações clínicas futuramente. Portanto, o sistema desenvolvido será importante para a pesquisa científica com EMG-S no Brasil, já que um sistema semelhante é fabricado comercialmente apenas na Itália, a um alto custo financeiro, e, segundo o fabricante, um equipamento desse tipo ainda não está em operação no Brasil.

Passos seguintes para a melhoria do sistema congregarão a confecção de uma melhor blindagem eletromagnética para a sonda captadora e o desenvolvimento de outros protótipos, porém com distâncias intereletródicas menores, possibilitando o estudo de músculos de menor comprimento (por exemplo, o abdutor curto do polegar).

\section{Agradecimentos}

Os autores agradecem à CAPES e ao CNPq pelo apoio financeiro.

\section{Referências}

[1] Merletti, R., Farina, D., Gazzoni, M. (2003) "The linear electrode array: a useful tool with many applications" Journal of Electromyography and Kinesiology, v. 13, p. 37-47.

[2] Masuda, T., Miyano, H., Sadoyama, T. (1985) “A surface electrode array for detecting action potential trains of single motor units" Eletroenceph Clin Neurophysiol, v. 60, p. 435443.

[3] Masuda, T., Miyano, H., Sadoyama, T. (1985) "The position of innervation zones in the biceps brachii investigated by surface electromyography" IEEE Trans Biomed Eng, v. 32, p. 36-42.

[4] Veneziano, W.H. (2006), Estudo do Comportamento do Sinal Eletromiográfico de Superfície em Atividades Subaquáticas, Tese de Doutorado, Departamento de Engenharia Elétrica, Universidade de Brasília, Brasília, DF, 151 p.

[5] Hermens, H., Freriks, B., Merletti, R., Stegeman, D., Blok, J., Rau, G., Disselhorst-Klug, C., Hagg, G. (1999), European Recommendations for Surface Electromyography, The Netherlands: RRD publisher, ISBN 90-75452-15-2.

[6] Barroso, V.B.R., Oliveira, R.T.P. (2004), Projeto e Implementação de um Sistema de aquisição de sinais de força e eletromiográficos com software de monitoração e registro de biofeedback, 
Trabalho final de graduação em Engenharia Mecatrônica. Universidade de Brasília, 60 p.

[7] Merletti, R., Parker, P.A. (2004), Electromyography: physiology, engineering and noninvasive applications, EUA: IEEE Press Series in Biomedical Engineering. 